\title{
Phosphodiesterases in development : on the regulation of cGMP signal transduction in the brain
}

Citation for published version (APA):

van Staveren, W. C. G. (2003). Phosphodiesterases in development : on the regulation of cGMP signal transduction in the brain. [Doctoral Thesis, Maastricht University]. Datawyse / Universitaire Pers Maastricht. https://doi.org/10.26481/dis.20031218ws

Document status and date:

Published: 01/01/2003

DOI:

10.26481/dis.20031218ws

Document Version:

Publisher's PDF, also known as Version of record

\section{Please check the document version of this publication:}

- A submitted manuscript is the version of the article upon submission and before peer-review. There can be important differences between the submitted version and the official published version of record.

People interested in the research are advised to contact the author for the final version of the publication, or visit the DOI to the publisher's website.

- The final author version and the galley proof are versions of the publication after peer review.

- The final published version features the final layout of the paper including the volume, issue and page numbers.

Link to publication

\footnotetext{
General rights rights.

- You may freely distribute the URL identifying the publication in the public portal. please follow below link for the End User Agreement:

www.umlib.nl/taverne-license

Take down policy

If you believe that this document breaches copyright please contact us at:

repository@maastrichtuniversity.nl

providing details and we will investigate your claim.
}

Copyright and moral rights for the publications made accessible in the public portal are retained by the authors and/or other copyright owners and it is a condition of accessing publications that users recognise and abide by the legal requirements associated with these

- Users may download and print one copy of any publication from the public portal for the purpose of private study or research.

- You may not further distribute the material or use it for any profit-making activity or commercial gain

If the publication is distributed under the terms of Article $25 \mathrm{fa}$ of the Dutch Copyright Act, indicated by the "Taverne" license above, 


\title{
Phosphodiesterases in development
}

\author{
On the regulation of cGMP signal \\ transduction in the brain
}


W.C.G. van Staveren, Maastricht 2003

Phosphodiesterases in development. On the regulation of CGMP signal transduction in the brain.

Thesis with summary in English and Dutch.

ISBN: $90-5278-402-7$

Cover illustration: oGMP-immunocytochemistry in the rat brain.

Production: Datawyse | Universitaire Pers Maastricht 


\title{
Phosphodiesterases in development
}

\author{
On the regulation of cGMP signal \\ transduction in the brain
}

\section{PROEFSCHRIFT}

ter verkrijging van de graad van doctor aan de Universiteit Maastricht, op gezag van de Rector Magnificus,

Prof. Dr. A.C. Nieuwenhuijzen Kruseman, volgens het besluit van het College van Decanen, in het openbaar te verdedigen op donderdag 18 december 2003 om 14.00 uur

door

Wilma Catharina Gerarda van Staveren

Geboren op 10 januari 1974 te Venray

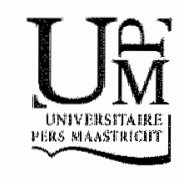




\section{Promotor}

Prof. Dr. H.W.M. Steinbusch

Co-promotor

Dr. J. de Vente

\section{Beoordelingscommissie}

Prof. dr. J.S.H. Vles (voorzitter)

Prof. dr. J.A. Beavo (University of Washington, USA)

Dr. A. Blokland

Prof. dr. J.E. Dumont (Université Libre de Bruxelles, België)

Prof. dr. J.G.R. de Mey

The publication of this thesis was financially supported by: Bayer AG, Paes Nederland bv - Olympus, Pfizer bv, Van Leersumfonds of the Royal Netherlands Academy of Arts and Sciences (KNAW).

Internationale Stichting Alzheimer Onderzoek (ISAO) 
LABOR OMNIA VINCIT IMPROBUS 



\section{Contents}

$\begin{array}{ll}\text { Abbreviations } & 8\end{array}$

Chapter 1 General introduction: Nitric oxide-cGMP 9

signaling in the brain

Chapter 2 Effects of two selective phosphodiesterase

type 5 inhibitors, sildenafil and vardenafil,

on object recognition memory and

hippocampal cGMP levels in the rat

Chapter 3 The effects of phosphodiesterase inhibition on cGMP and CAMP accumulation in the hippocampus of the rat

Chapter 4 Comparison of NO-dependent and NO-

independent stimulation of soluble guanylyl cyclase in rat forebrain slices:

a micropharmacological study

Chapter $5 \quad$ Cloning and localization of the cGMP-specific phosphodiesterase type 9 in the rat brain

Chapter 6 mRNA expression patterns of the cGMPhydrolyzing phosphodiesterases types 2,5 and 9 during development of the rat brain

Chapter $7 \quad$ Species differences in the localization of cGMPproducing and $\mathrm{NO}$-responsive elements in the mouse and rat hippocampus using cGMPimmunocytochemistry

Chapter 8 General discussion

Summary

Samenvatting

Publications

Curriculum vitae

Dankwoord 


\section{Abbreviations}

\begin{tabular}{|c|c|}
\hline $5-A M P$ & 5 -adenosine monophosphate \\
\hline $5^{3}-\mathrm{GMP}$ & 5-guanosine monophosphate \\
\hline $\mathrm{AC}$ & adenylyl cyclase \\
\hline ANOVA & analysis of variance \\
\hline ANP & atrial natriuretic peptide \\
\hline $\mathrm{AlP}$ & adenosine 5'-triphosphate \\
\hline BLAST & Basic Local Alignment Search pool \\
\hline $\mathrm{BNP}$ & brain-type natriuretic peptide \\
\hline CAMP & adenosine $3^{3}, 5^{\prime}$-cyclic monophosphate \\
\hline cGMP & guanosine $3^{3}, 5^{\prime}$-cyclic monophosphate \\
\hline cGMP-IR & CGMP-immunoreactivity \\
\hline CNG & cyclic nucleotide gated ion channel. \\
\hline $\mathrm{CNP}$ & C-type natriuretic peptide \\
\hline CNS & central nervous system \\
\hline $\mathrm{CREB}$ & $\begin{array}{l}\text { cAMP responsive element binding } \\
\text { protein }\end{array}$ \\
\hline DEANO & diethylamino NONOate \\
\hline DIG & digoxigenin \\
\hline DMPPO & $\begin{array}{l}\text { 1,3-dimethyl-6-(2-propoxy-5-methane } \\
\text { sulfonylamidophenyl) pyrazolo [3,4d]- } \\
\text { pyrimidin-4-(5H)-one }\end{array}$ \\
\hline DMSO & dimethylsulfoxide \\
\hline EAACI & rabbit anti-glutamate transporter \\
\hline EDRF & endothelial-derived relaxing factor \\
\hline EDTA & ethylenediaminetetra-acetate \\
\hline EHNA & erythro-9-(2-hydroxy-3-nonyl)adenine \\
\hline eNOS & endothelial nitric oxide synthase \\
\hline EST & expressed sequence tag \\
\hline GAI & $\begin{array}{l}\text { cGMP binding and stimulated PDEs, } \\
\text { Arabaena adenylyl cyclases and } \\
\text { Gscherichio coli transcription factor } \\
\text { FhLA domains }\end{array}$ \\
\hline $\mathrm{GC}$ & guanylyl cyclase \\
\hline $\mathrm{GlaP}$ & glin fibrillary acidic protein \\
\hline GTP & guanosine 5-triphosphate \\
\hline IBMX & 3-isobutyl-1-methylxanthine \\
\hline NOS & inducible nitric oxide synthase \\
\hline i.p. & intraperitoneal \\
\hline$L-\mathbb{N A M E}$ & $N^{6}$-nitro-L-arginine \\
\hline LSD & least significant difference \\
\hline $\mathrm{LTP}$ & long-term potentiation \\
\hline MRP & multidrug resistance protein \\
\hline NADPH & $\begin{array}{l}\text { nicotinamide adenine dinucleotide } \\
\text { phosphate }\end{array}$ \\
\hline $\mathrm{NECA}$ & 5"-Nethylcarboxamidoadenosine \\
\hline NouN & mouse anti-neuronal nuclei \\
\hline NMDA & $N$-methyl-D-aspartate \\
\hline nNOS & neuronal nitmic oxide synthase \\
\hline
\end{tabular}

NO nitric oxide

NOS nitric oxide synthase

NOSI neuronal nitric oxide synthase

NOSI inducible nitric oxide synthase

Nosm endothelial nitric oxide synthase

ODQ $\quad 1 H-[1,2,4$ loxadiazolo $[4,3-a]$. quinoxalin-1-one

PAS Drosophila periad clock protein (PER), the vertebrate aryl hydrocarbon receptor nuelear translocator (ARNT), and the Drosophila single-minded protein (SIM)

PBS phosphate buffered saline

PDE 3, 3 -cyclic nucleotide phosphodiesterase

PEST proline $(\mathrm{P})$, glutamic acid (E), serine (S), and threonine (T)

pGC particulate guanylyl cyclase

PKA cAMP-dependent protein kinase

PKG cGMP-dependent protein kinase

p.o. per os

RACE rapid amplification of CDNA ends

$\mathrm{RT}$ room temperature

$\mathrm{SGC}$ soluble guanylyl cyclase

SIN-1 3-morpholinosyd nonimine

SNOG S-nitrosoglutathione

SNP sodium nitroprusside

TBS Tris-buffered saline

TBS-T Tris-buffered saline containing $0.3 \%$ Triton X-1.00

VAchT rabbit anti-vesicular acetylcholine transporter

YC-1 3-(5'-hydroxymethyl-2'furyl)1-benzylindazole 


\section{General introduction:}

\section{Nitric oxide-cGMP signaling in the brain}

Signal transduction is one of the most fundamental processes underlying the basics of living organisms. This process includes the recognition of signals by cells and their appropriate transformation into biological responses. The central nervous system is the key connection center where at each moment millions of signals are received, translated and accurately transformed into reactions, thereby controlling a broad variety of processes in the organism.

In this thesis the nitric oxide (NO)-mediated guanosine 3',5'cyclic monophosphate (cGMP) signal transduction pathway in the brain is investigated, which is known to play a fundamental role in neuronal communication and to participate in numerous brain functions, including processes such as learning and memory.

\section{Nitric oxide is an unconventional messenger}

In the classical model of signal transduction in the brain, neurons communicate with each other by neurotransmitters released from a presynaptic axon terminal, which can act on receptors present on the membrane of a post-synaptic neuron. It has become evident during the years that neurons can also communicate with their targets without synaptic connections and that this form of non-synaptic interactions (also termed volume transmission) is of physiologicall significance (see for reviews Garthwaite, 1991, Garthwaite, 1995; Dawson et al., 1998; Baranano et al., 2001).

Nowadays, it is generally accepted that the molecule nitric oxide (NO) is involved in non-synaptic transmission. The first evidence that NO can act as a neurotransmitter in the brain was reported by Garthwaite and coworkers in the late eighties (1988). In their study it was demonstrated that a factor called endothelial-derived relaxing factor (EDR.F, nowadays known to be NO), which acts in the vascular system to relax blood vessels by increasing cGMP levels (Furchgott and Zawadzki, 1980), was also produced in the cerebellum. In Garthwaite's laboratory it was shown for the first time that through the action of glutamate on $N$-methyl-D-aspartate (NMDA) receptors, the release of $\mathrm{NO}$ was induced in a calcium-dependent manner. Since addition of haemoglobin, an NO scavenger unable to enter cells, abolished the increase in CGMP levels, it was reasoned that $\mathrm{NO}$ activated its target guanylyl cyclase (GC) by diffusion to neighboring cells and thereby could increase cGMP levels. These NO-responsive target elements are 
thought to include pre-synaptic terminals and astrocytes as depicted in Figure 1. These pioneering investigations on the role of $\mathrm{NO}$ in the mammalian cerebellum initiated a tremendous amount of research on signal. transduction pathways in which NO and cGMP are involved and how they can mediate numerous physiological processes.

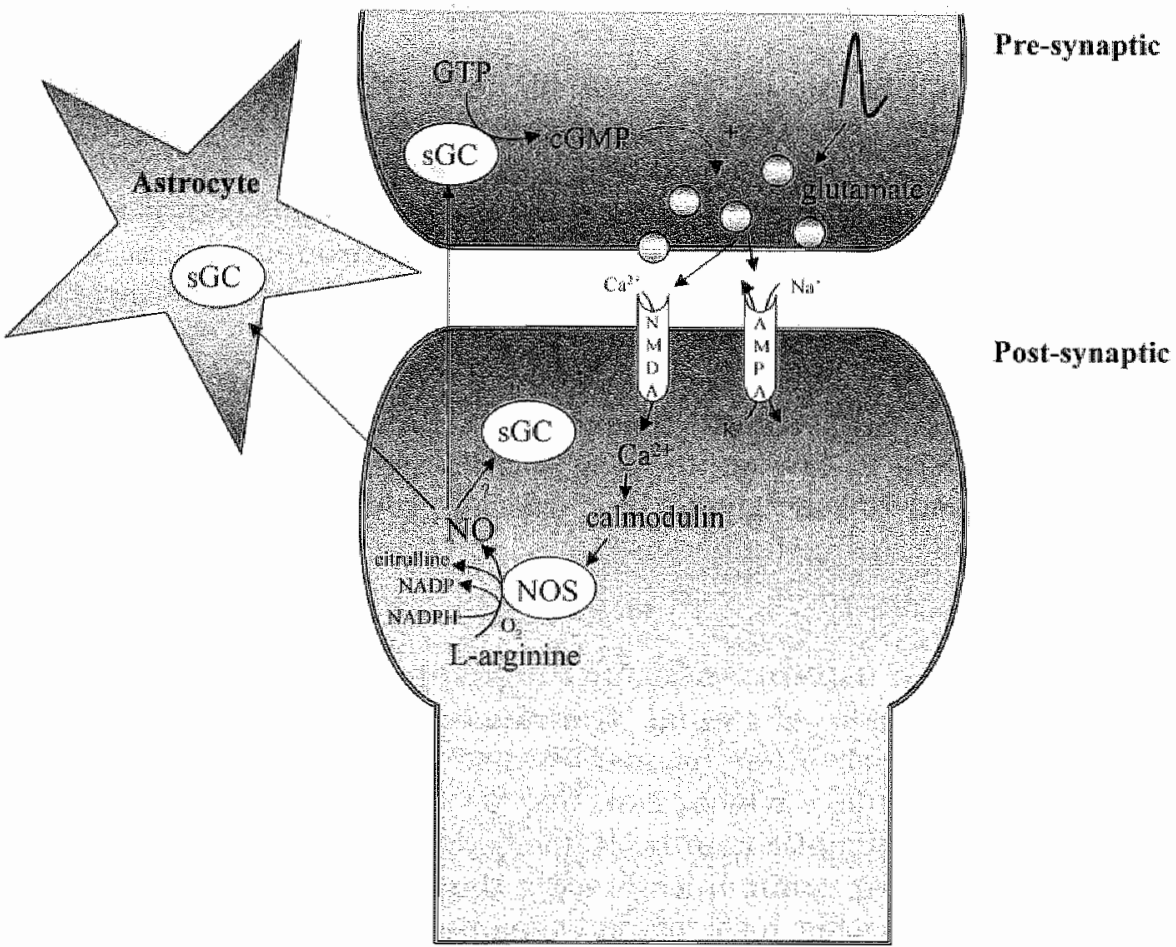

Figure 1. Schematic representation of the role of $\mathrm{NO}$ as a diffusible messenger in nemronal communication, based on Garthwaite (1991). After a depolarizing stimulus, glutamate is released from the presynaptic terminal. Glutamate binds to the AMPA receptor causing a local depolarization, which induces the release of a magnesium block from the $\operatorname{NMDA}_{\mathrm{A}}$ receptor, followed by a calcium influx. Calcium in combination with calmodulin, stimulate NOS to produce $\mathrm{NO}$. NO, in turn, diffuses to neighboring presynaptic terminal(s) and/or astrocytes where it can stimulate $8 \mathrm{GC}$ to produce cGMP. It is hypothesized that raised cGMP levels can lead to an increase in the release of glutanate. AMPA, alpha-amino-3-hydroxy-5-methyl-4isoxazolepropionic acid; CGMP, guanosine 3,5-cychic monophosphate; GTP, guanosine 5tuphosphate: NADPH, nicotimamide adenine dinucleotide phosphate; NADP, oxidized form of NADPH: NMDA, N-methyl-Daspartate; NOS, nitric oxide synthase; sGC, soluble guanylyl cyclase.

Shortly after the reported finding that NO acts as an unconventional transmitter, since it is not packed in synaptic vesicles but rather diffuses through cell membranes, the NO producing enzyme NO-synthetase, now known as NO-synthase (NOS) was purified from rat cerebellum (Bredt and 
Snyder, 1990). It was demonstrated that $\mathrm{NO}$ is produced in an activity dependent manner by calcium-calmodulin stimulation of NOS. NOS produces NO from L-arginine in the presence of oxygen giving rise to, besides NO, citrulline as a co-product, a reaction requiring nicotinamide adenine dinucleotide phosphate (NADPH) and calcium (Knowles et al., 1989; Bredt and Snyder, 1990). To date, three aistinct forms of NOproducing enzymes have been identified in tissues: neuronal NOS (nNOS or NOSI), inducible NOS (iNOS or NOSII) and endothelial NOS (eNOS or NOSIII) (Forstermann et al., 1998). All three NOS isoforms have been detected in the brain. nNOS is constitutively expressed throughout the brain with varying intensities, demonstrating highest expression in the cerebellum and olfactory bulb (Bredt et al., 1990; Eliasson et al., 1997). In addition to the expression in endothelial cells, it has been reported several years ago that eNOS is also constitutively expressed in certain neurons, for instance in pyramidal cells of the hippocampus (Dinerman et al., 1994). However, this topic is controversial, since it has been recently reported that nNOS is present in these cells but not eNOS (Burette et al., 2002). By contrast, iNOS is not constitutively expressed in the healthy brain, but expressed upon activation of cells or tissues by cytokines and/or endotoxins, and thus production of NO by iNOS is associated with tissue response against damage or inflammation (Heneka and Feinstein, 2001).

The properties of $\mathrm{NO}$ as a small molecule with a lipohilic nature, a short half-life of a few seconds and an estimated diffusion distance of $10-100 \mu \mathrm{m}$ in biological tissues, enables NO to induce local effects where the NO-target, $\mathrm{GC}$, is expressed. It has been suggested that this "sphere of influence" encompasses about two million synapses (Garthwaite, 1995). In the central. nervous system (CNS), NO is involved in a variety of processes such as longterm potentiation, long-term depression, synaptogenesis and development, drug tolerance and dependence, hyperalgesia, modulation of sensory and motor pathways, regulation of blood flow, neuroendocrine regulation, feeding, and sexual behavior (Garthwaite, 1995). In addition, the demonstration of NO production in many tissues and cell types outside the brain indicates that this molecule is involved in a large variety of signal transduction pathways. A role for $\mathrm{NO}$ in the periphery has been shown in processes such as smooth muscle relaxation (Lincoln, 1989; Carvajal et al., 2000) and inhibition of platelet aggregation (Walter, 1989; Moncada and Higgs, 1995).

\section{cGMP synthesis}

As indicated above, a major target of $\mathrm{NO}$ is the soluble isoform of $\mathrm{GC}$ ( $\mathrm{sGC}$ ), which has been initially identified as a cytoplasmic enzyme (Kimura and Murad, 1975). Stimulation of sGC by NO accurs through binding of NO to the prosthetic heme group, which can lead to an up to $100-200$ fold stimulation of the enzyme (Stone and Marletta, 1995). NO binding to the enzyme induces a conformational change in $\mathrm{sGC}$ resulting in the increased production of the second messenger cGMP from the substrate guanosine 5;- 
triphosphate (GTP) (Fig. 2). As an enzyme, $s G C$ is a heterodimeric protein consisting of two different subunits, the so-called $\alpha$ and $\beta$ subunits (Garbers, 1979; Kamisaki et al., 1986; Koesling et al., 1988; Humbert et al., 1990). Up to date, two $\alpha$-subunits $(\alpha 1$ and $\alpha 2)$ and two $\beta$-subunits $(\beta 1$ and $\beta 2$ ) have been cloned, however, activity has been only detected after coexpression of $\alpha 1$ and $\beta 1$, or $\alpha 2$ with $\beta 1$ (Nakane et al., 1988; Harteneck et al., 1990; Nakane et al., 1990; Buechler et al., 1991). Like NOS, sGC is widely distributed throughout the brain and is detected in close proximity of NOS containing cells (Schmidt et al., 1992; Furuyama et al., 1993; Southam and Garthwaite, 1993; Burgunder and Cheung, 1994; Giuili et al., 1994; De Vente et al., 1998; Gibb and Garthwaite, 2001; Burette et al., 2002).

cGMP can also be produced by membrane bound or particulate $\mathrm{GC}$ (pGC), after activation by natriuretic peptides, such as atrial natriuretic peptide (ANP), brain-type natriuretic peptide (BNP) and C-type natriuretic peptide (CNP) (see for reviews Lucas et al, 2000; Wedel and Garbers, 2001). To date, seven pGCs have been identified (GC-A to GC-G), of which GC-A to GC-C have been detected throughout the brain (Herman et al., 1996a; Herman et al., 1996b; Wedel and Garbers, 2001), whereas GC-D has been observed in the olfactory bulb (Juilfs et al., 1997).

GTP

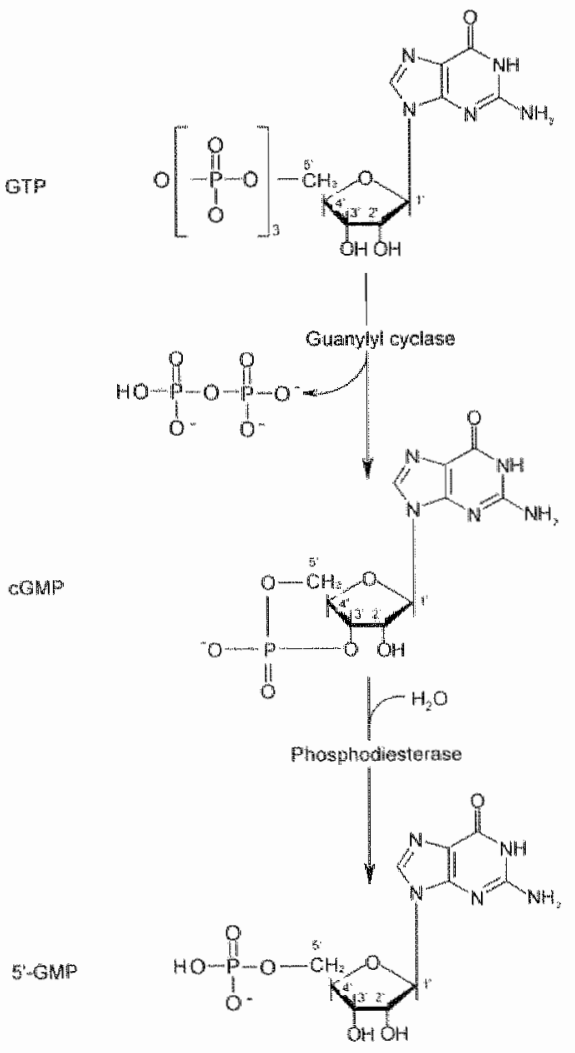

Figure 2. Schematic illustration of the metabolism of the second messenger cGMP. cGMP is produced from guanosine 5 triphosphate (GTP) by guanylyl cyclase and it is degraded into 5'uguanosine monophosphate (5-GMP) by $3^{\prime}, 5^{\prime}-\mathrm{cyclic}$ nucleotide phosphodiesterase. 


\section{Intracellular targets of cGMP}

In addition to the involvement of cGMP in neurotransmission, the second messenger adenosine $3^{\prime}, 5^{\prime}$-cyclic monophosphate (cAMP) is also known to be implicated in this process, and furthermore, both participate as well in a number of other important biological processes, such as phototransduction, olfaction (Broillet and Firestein, 1999), smooth muscle contraction and relaxation (Carvajal et al., 2000) or neural development (Truman et al., 1996; Gibbs and Truman, 1998; Schachtner et all., 1999; Van Wagenen and Rehder, 1999; Polleux et al., 2000; Gibbs et al., 2001; Simpson et al., 2002). Both cGMP and CAMP exert their action by influencing the activity of a number of intracellular targets (Fig. 3). The cGMP targets, which include cGMP-dependent protein kinases, cyclic nucleotide gated ion channels, cyclic nucleotide transporters and $3^{\prime}, 5^{\prime}$-cyclic nucleotide phosphodiesterases (PDEs), will be discussed in more detail below.

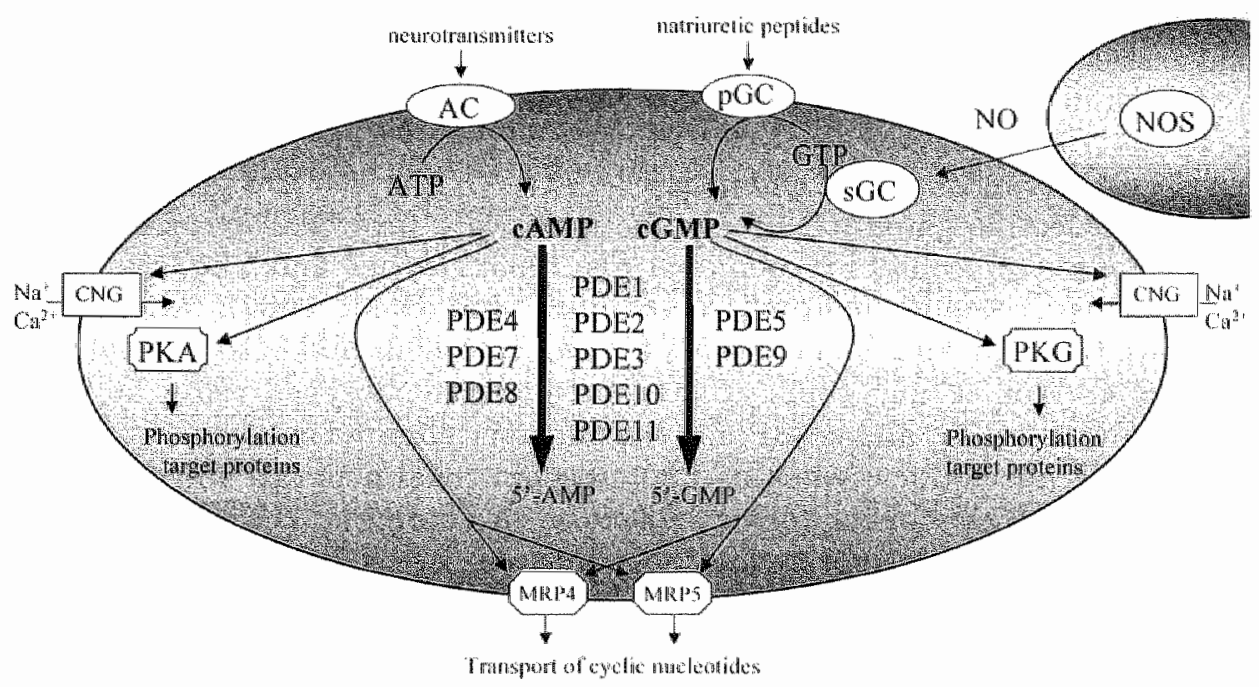

Pigure 3. Schematic overview of the cellular cGMP and CAMP metabolism. EMP. 5 '. adenosine monophosphate; 5-GMP, 5'-guanosine monoplrosplate; $A C$, andenylyl cyclase; $\mathrm{A}^{2} \mathrm{TP}$, adenosine 5'triphosphate; CNG, cyclic nucleotide gated ion channel; GTP, guanosine 5'triphosphate; MRP, multidrug resistance protein; NOS, nitric oxide synthase; $p$ GC, particulate guanylyl cyclase; PKA, cAMP-dependent protein kinase; PKG, cGMP-dependent protein kinase: $\mathrm{sGC}_{\mathrm{C}}$ soluble guanylyl cyclase.

\section{cGMP-dependent protein kinases}

One of the intracellular targets activated by cGMP are the cGMP-dependent protein kinases (PKGs) (Lohmann et al., 1997; Pfeifer et al., 1999). In mammals, three different PKGs, derived from two genes, have been identified. These two genes encode for PKGI and PKGII from which PKGI can be expressed in two alternatively $\mathrm{N}$-terminal splice variants (PKGI $\alpha$ 
and PKGIP) (Sandberg et al., 1989; Wernet et al., 1989; Uhler, 1993; Jarchau et al., 1994). PKGI is highly expressed in smooth muscles, lung and platelets. Initial studies described that PKGI in the brain was only expressed in cerebellar Purkinje cells (Lohmann et al., 1981), however, recent reports indicate expression of PKGI in some other brain areas as well (Kingston et al., 1996; El-Husseini et al., 1999). In contrast to the limited. expression of PKGI, PKGII is widely expressed throughout many brain areas (El-Husseini et al., 1995; El-Husseini et al., 1999; De Vente et al., 2001).

PKGs have been described as enzymes having high affinity for cGMP. For PKGI $\alpha$, PKGI $\beta$ and PKGII, $K_{m}$ s have been estimated at 4-38 nM, 54-750 nM and $40 \mathrm{nM}$ respectively (Smolenski et al., 1998; Kotera et al., 2003). In addition, it has been reported that autophosphorylation of PKGs can lead to an increased affinity for cGMP. Activation of PKGs by cGMP can result in phosphorylation of a number of intracellular proteins and thereby create an altered cellular status. Interestingly, it has been reported that binding of cGMP to PKG can also protect cGMP from hydrolysis. This has lead to the suggestion that protection of cGMP from degradation might be a positive feedback in the maintenance of cGMP signaling (Kotera et al., 2003).

\section{Cyclic nucleotide gated ion channels}

Cyclic nucleotide gated (CNG) ion channels were first characterized in rod and cone photoreceptors (Fesenko et al., 1985; Haynes and Yau, 1985) and in olfactory receptor neurons (Nakamura and Gold, 1987), where they mediate the transduction of sensory stimuli into neuronal activity (Zufall et al., 1994; Wei et al., 1998). CNG ion channel subtypes differ in their sensitivity to cGMP and CAMP, i.e. the olfactory channel can be activated by both cyclic nucleotides, whereas photoreceptor channels are only activated by cGMP. CNG channels open in response to binding of cGMP and CAMP. These channels are permeable for calcium or sodium. Photoreceptor channels are sodium channels, which are kept in an open state by cGMP, whereas in olfactory neurons, cyclic nucleotides regulate a calcium channel (Zufall et al., 1994; Wei et al., 1998).

For many years, it was thought that $\mathrm{PKGs}$ were the predominant, if not only, intracellular targets for cGMP in neurons. However, recent studies have shown that besides expression in olfactory and photoreceptor tissue, CNG ion channels have a widespread distribution throughout the CNS including the olfactory system, cortex, hippocampus and cerebellum (ElHusseini et al., 1995; Kingston et al., 1996; Bradley et al., 1997; Kingston et al., 1999). Compared to PKGs, CNG ion channels have a relatively low affinity for binding cGMP, requiring cGMP levels 10-100 times higher than needed for activation of PKG (Lincoln and Cornwell, 1993). Therefore, it seems unlikely that $\mathrm{CNG}$ ion channels are activated at basal or slightly elevated cGMP levels in neurons, with the exception of the photoreceptor channel in the retina. However, when cGMP levels are (locally) greatly elevated, the $\mathrm{CNG}$ ion channels might be activated, leading to an increased sodium and calcium influx followed by a membrane depolarization. Since 
these channels couple cyclic nucleotides to changes in calcium in cells, it has been proposed that these channels may play an important role as modulators of neuronal activity and synaptic plasticity (Zufall et al., 1997).

\section{Cyclic nucleotide transporters}

In cells, cGMP and cAMP can be eliminated through two different pathways: by hydrolysis due to the activity of PDEs (as described in the next paragraphs) or by transport out of the cell (Davoren and Sutherland, 1963; King and Mayer, 1974; Brunton and Mayer, 1979; Wiemer et al., 1982). In the sixties, Davoren and Sutherland already reported the possibility that intraceliular cAMP could be transported across the cell membrane, which could apparently occur against a concentration gradient (Davoren and Sutherland, 1963). It was observed that the release of cAMP into the medium was inhibited by probenecid, an inhibitor of organic anion transporters. Furthermore, it was discovered that PDE inhibitors like methylxanthines could also inhibit the egress of intracellular cAMP (Davoren and Sutherland, 1963; King and Mayer, 1974; Wiemer et al., 1982). Recently, evidence arose that cyclic nucleotides can serve as a substrate for members of the family of the multidrug resistance protein (MRP) family, which are embedded in the ATP-binding cassette (ABC) family. Proteins from the $\mathrm{ABC}$ superfamily function as transporters, which are able to transport a large variety of compounds through membranes, processes which are ATP-dependent (Borst and Elferink, 2002). Two members of the $\mathrm{ABC}$ transporter family, MRP4 and MRP5, can transport. cyclic nucleotides and nucleotide analogues (Kool et al., 1997; Jedlitschley et. al., 2000; Chen et al., 2001). It has been demonstrated that both MRP4 and MRP5 have relative high affinities for cGMP with $K_{\mathrm{n}}$ values of around 10 $\mu \mathrm{M}$ and $2 \mu \mathrm{M}$ respectively, whereas their affinity for cAMP is much lower $\left(\mathrm{K}_{\mathrm{m}} 45 \mu \mathrm{M}\right.$ for MRP4 and $400 \mu \mathrm{M}$ for MRP5) (Jedlitschky et al., 2000; Chen et al., 2001).

The physiological functions of MRP4 and MRP5 still remain to be defined. Recently, both MRP4 and MRP5 have been detected in the brain as well as in different neuronal and glial cell cultures (McAleer et al., 1999; Ballerini et al., 2002; Hirrlinger et al., 2002). Furthermore, MRP4 and MRP5 are expressed in capillary endothelial cells forming the blood brain barrier (Zhang et al., 2000). The discovery that these pumps can transport cyclic nucleotides, particularly cGMP, raises the interesting question whether MRP4 and MRP5 affect cGMP signal transduction by removing cyclic nucleotides from cells, which would be additional to the degradation of second messengers by PDEs. It was demonstrated using inside-out vesicles that MRP5 can be inhibited by a variety of PDE inhibitors, among them sildenafil, zaprinast, dipyridamole and requinsin (Jedlitschky et al., 2000; Sundkvist et al., 2002). Thus, it is of interest that cyclic nucleotide levels can be increased in two ways by the same class of compounds: by inhibition of hydrolysis or inhibition of export. 


\section{3', 3 -cyclic nucleotide phosphodiesterases}

Although cyclic nucleotides can be removed from cells by transporters, the effect of this process to lower intracellular cyclic nucleotide levels is minor, compared to the hydrolytic activity of PDEs. Tissue cGMP levels are mainly determined by the tight balance between the activities of the cGMP. producing GCs (Lucas et al., 2000) and the cGMP-hydrolyzing PDEs (Beavo, 1995; Conti and Jin, 1999; Dousa, 1999; Francis et al., 2001; Beavo and Brunton, 2002). Sutherland and coworkers discovered PDE activity shortly after the identification of CAMP (Sutherland and Rall, 1958; Butcher and Sutherland, 1962). In the 1970s, diversity among PDEs was recognized when partial purification of PDE activity from various tissues resulted in the observation that proteins showing PDE activity, existed with different affinities for CAMP and cGMP and had different physiochemical properties (Thompson and Appleman, 1971). Since this time, results from isolation, purification, sequencing and other molecular biological techniques clearly show that mammalian PDEs exist as a large group of structurally related isozymes, which belong to associated gene families. In particular, the screening of data bases of expressed sequence tags (ESTs) obtained from information of the elucidation of the genome of several species, has allowed for the extension of the original seven PDE families discovered until 1993 (see reviews Beavo and Reifsnyder, 1990; Thompson, 1991; Bolger, 1994; Beavo, 1995; Manganiello et al., 1995; Pyne et al., 1996; Rybalkin and Beavo, 1996; Degerman et al., 1997; Houslay, 1998; Conti and Jin, 1999) from PDE8 (1998) to PDE11 (2000) in only a few years (see reviews Dousa, 1999; Juilfs et al., 1999; Soderling and Beavo, 2000; Francis et al., 2001; Conti et al., 2003; Houslay and Adams, 2003).

To date, the eleven different PDE families (PDE1-PDE11) have been classified based on their primary amino acid sequences, biochemical properties, sensitivities to inhibitors, regulatory mechanisms and affinities for CGMP and cAMP (Table 1). Both cGMP and cAMP can be inactivated by PDEs through conversion of these second messengers into 5'-guanosine monophosphate (5'-GMP) and 5'-adenosine monophosphate (5'-AMP), respectively (Fig. 2). Three of the eleven PDE families, specifically use cGMP as a substrate, which are: PDE5 (Thomas et al., 1990; Kotera et al., 1997; Loughney et al., 1998), the photoreceptor specific PDE6 (Gillespie and Beavo, 1988; Florio et al., 1996) and PDE9 (Fisher et al., 1998a; Guipponi et al., 1998; Soderling et al., 1998a; Andreeva et al., 2001; Rentero et al., 2003). Furthermore, cGMP can be degraded by dual-substrate PDEs, which can hydrolyze both CAMP and cGMP. These are PDE1 (Bentley et al., 1992; Furuyama et al., 1994; Yan et al., 1994), PDE2 (Murashima et al., 1990; Sonnenburg et al., 1991; Repaske et al., 1993; Yang et al., 1994; Rosman et al., 1997; Martinez et al., 2002), PDE3 (Meacci et al., 1992; Taira et al., 1993), PDE10 (Fujishige et al., 1999a; Fujishige et al., 1999b; Kotera et al., 1999a; Loughney et al., 1999; Soderling et al, 1999; Fujishige et al., 2000) and PDE11 (Fawcett et al., 2000; Hetman et al., 2000b; Yuasa et al., 2000; Yuasa et al., 2001). Moreover, cAMP can be degraded by cAMP-specific PDEs, which are PDE4 (Colicelli et al., 1989; Bolger et al., 1997), PDE7 
(Michaeli et al., 1993; Bloom and Beavo, 1996; Han et al., 1997; Gardner et al., 2000; Hetman et al., 2000a; Sasaki et al., 2000) and PDE8 (Fisher et al., 1998b; Soderling et al., 1998b; Wang et al., 2001).

Within a number of PDE families, multiple genes have been cloned, and it has been reported that many of these genes are expressed in several alternately spliced forms (Table 1). This indicates that cyclic nucleotides can be degraded by a large number of different PDE isoforms. So far, twentythree PDE genes have been identified and the total number of enzymes is now estimated at around ninety-five. It should be noted that the total number of PDE isoforms described to date are derived from bovine, human, canine, rat and mouse tissues, giving the possibility that some variants can be expressed in one species and not in the other, as was for instance shown for PDE11 (Yuasa et al., 2000; Yuasa et al., 2001). Furthermore, the expression of all of these splice variants has not been investigated so far on the protein level and therefore the physiological significance of a number of splice variants still remains to be elucidated.

Most of the reported splice variants differ at their 5 '-end, although also 3 ' splice variants have been detected, for example for PDE1 and PDE10. Formation of splice variants within a PDE family can create the possibility to produce distinctive forms, having interaction with different cellular target molecules. Furthermore, splice variants within a PDE family can differ in biochemical properties, such as differences in maximum rate of hydrolysis $\left(\mathrm{V}_{\max }\right)$ or demonstrate variable regulation or phosphorylation properties. Moreover, the fact that alternative splicing is highly tissue specific creates the possibility that certain isoforms within a PDE family are selectively expressed (Yan et al., 1996; Kotera et al., 1999a; Michibata et al., 2001; Miro et al., 2001; Yuasa et al., 2001; Sasaki et al., 2002; Rentero et al., 2003).

From the eleven described PDE families, all have been localized with various distribution patterns in the CNS, with the exception of the photoreceptor PDE6 (Kincaid et al., 1987; Billingsley et al., 1990; Repaske et al., 1993; Furuyama et al., 1994; Polli and Kincaid, 1994; Yan et al., 1994; Iwahashi et al., 1996; Reinhardt and Bondy, 1996; Kotera et al., 1997; Cherry and Davis, 1999; Fujishige et al., 1999a; Fawcett et al., 2000; Andreeva et al., 2001; Miro et al., 2001). The localization studies demonstrate that many cells contain members of several PDE families, which can be expressed in different amounts and proportions and furthermore with different subcellular localization. For instance, it has been demonstrated that olfactory neurons express both PDE1C and PDE4 in different compartments in the same cell (Juilfs et al., 1997; Beavo and Brunton, 2002). 


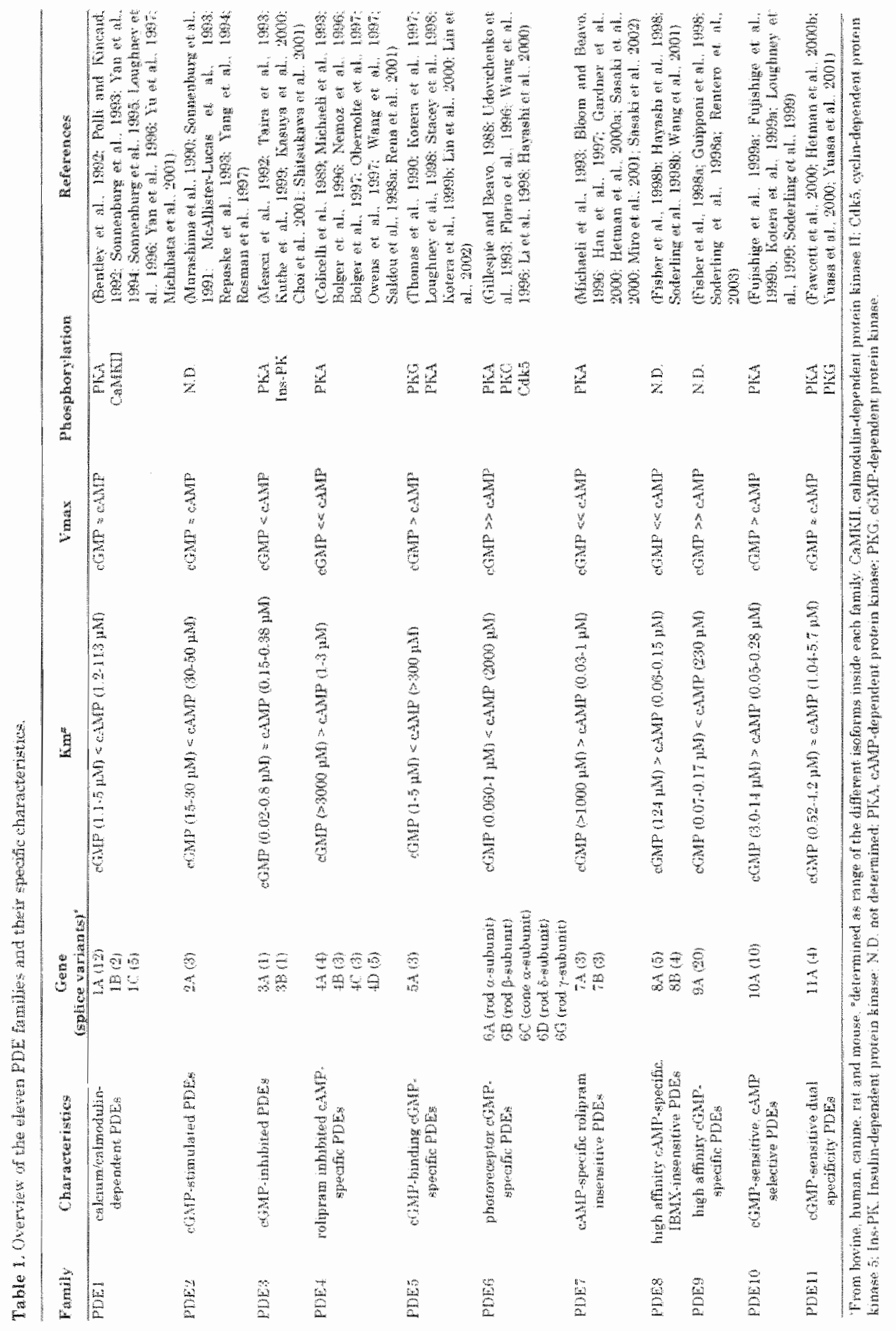




\section{PDE structure}

For the degradation of cyclic nucleotides, each PDE family contains a highly conserved catalytic domain of about 270 amino acids, which is located close to the carboxy-terminus (Fig. 4). The catalytic core is thought to contain common structural components important for hydrolysis of the phosphodiester bond of cGMP and/or cAMP. Furthermore, this domain encompasses family-specific elements, causing differences in substrate affinities and sensitivity towards PDE inhibitors among the various PDE families. PDEs are dimeric proteins composed of multiple functional domains, with the exception of the photoreceptor PDE6 which is a tetrameric protein. In general, PDEs within one family are $65 \%$ or more homologous with each other at the amino acid level, whereas sequence homology falls to $40 \%$ or less between the different families, mostly occurring in the catalytic domains (Beavo, 1995). Interestingly, it is observed that across different species the homology between the same gene family is very high (more than 90\%), indicating high conservation of PDE families between species.

Besides the catalytic domain, PDE monomers contain regulatory domains located at their amino-terminus (Fig. 4). These regulatory domains diverge in structure and size between PDE families. These domains include calcium-calmodulin binding domains (PDE1), two non-catalytic cGMPbinding domains (PDE2, PDE5, PDE6, PDE10 and PDE11), membrane association domains (PDE3), upstream conserved regions (PDE4) and phosphorylation sites for a number of kinases such as PKG or CAMP. dependent protein kinase (PKA) (Fig. 4, Table 1). Moreover, PDE8 is the only PDE family containing a PAS domain (Soderling et al., 1998b; Soderling and Beavo, 2000). PAS is the shortened version of the names from the proteins in which they were first recognized: the Drosophila period clock protein (PER), the vertebrate aryl hydrocarbon receptor nuclear translocator (ARNT), and the Drosophila single-minded protein (SIM) (for review see Taylor and Zhulin, 1999). Analysis of PAS domains indicates that this domain mediates specific homomeric and heteromeric protein-protein interactions that often regulate subcellular distribution. At this moment the precise function of the PAS domain in PDE8 still remains to be elucidated.

Within the PDE superfamily, the cGMP-hydrolyzing PDEs, PDE2, PDE5, PDE6, PDE10 and PDE11, contain two non-catalytic cGMP-binding domains or the so-called GAF domains (Fig. 4). These conserved repeats are present in a variety of signaling proteins from eubacterial, archaeal and eukaryotic organisms and have therefore named GAF (cGMP-binding and stimulated PDEs, Anabaena adenylyl cyclases and Escherichia coli transcription factor FhlA domains). The two GAF domains are arranged in tandem and are located at the amino-terminus of the PDE monomer. However, some isoforms also exist which contain only one or parts of the GAF domains as for instance reported for PDE11 (Fawcett et al., 2000; Hetman et al., 2000b; Yuasa et al., 2000). Binding of cGMP to the GAF domains can induce variable effects in different PDE families. For instance, in PDE2 binding of cGMP to these sites stimulates both CAMP and cGMP 
hydrolysis at the catalytic site MacFarland et al., 1991; Rosman et al., 1997), whereas in PDE5, cGMP binding to GAF domains leads to increased phosphorylation of PDE5 and thereby stimulates PDE5 activity (Gopal et al., 2001; Rybalkin et al., 2002). Besides PDE5, phosphorylation of a number of PDE families by PKG or PKA or other protein kinases has been described, including PDE1, PDE3, PDE4, PDE7, PDE10 and PDE11 (Beltman et al., 1993; Florio et al., 1994; Degerman et al., 1997; Saldou et al., 1998b; Kotera et al., 1999a; Yuasa et al., 2000; Sasaki et al., 2002; Table 1). Furthermore, analysis of the PDE structures reveals that they can contain a number of various potential phosphorylation sites from which the exact function is still not known.

Cell specificity is the result of the unique expression of proteins and their isoforms at all the levels of signal transduction pathways (Dumont et al., 2002). Altogether, the above described characteristics of the PDE superfamily gives the possibility to create unique PDE expression profiles in cells. Differential expression of PDE isoforms is a critically important determining factor that can cause fundamental diversity between cell types. By influencing the degradation rate of cGMP and CAMP, PDEs determine the amplitude and the duration of these second messenger signals. Therefore, tight modulation of PDE functioning is necessary for the maintenance of cellular cyclic nucleotide levels. Variation in PDE profiles can be created by the largenumber of PDE genes, represented in multiple splice variants having specific biochemical properties and regulated by events such as phosphorylation. Moreover, different PDE expression in different cellular compartments enables cells to create local differences in cyclic nucleotide metabolism.

\section{PDE inhibitors}

The eleven PDE families have been classified into these families based on the above described features, among them their affinity towards a large number of PDE inhibitors (Table 2). Some of these compounds were already used as drugs in medical practice long before they were identified as PDE inhibitors. The medicinal use of PDE inhibitors can be traced to Henry Hyde Salter's work on asthma in 1860 , in which the administration of two breakfast cups of strong coffee given on an empty stomach was recommended as a remedy that in many cases is more efficacious than any other (Persson, 1985). However, therapeutic use of PDE inhibition might already be traced back to ancient Egypt where Nymphaea caerulea (the blue lotus or blue water lily) was used for good health, used to release pain, increase memory, increase circulation, promote sexual desire and create a feeling of euphoria and ecstasy. Interestingly, recent analysis revealed that besides phytosterols and bioflavonoids, this flower contains a couple of compounds that are PDE inhibitors. 1

It was not until the beginning of the 1960 s, that more insight was obtained into the mechanism of action of PDE inhibitors. Butcher and

Thtrp//ww healthherbs com/products/singheherbtinctures/bluelatus.pdf 


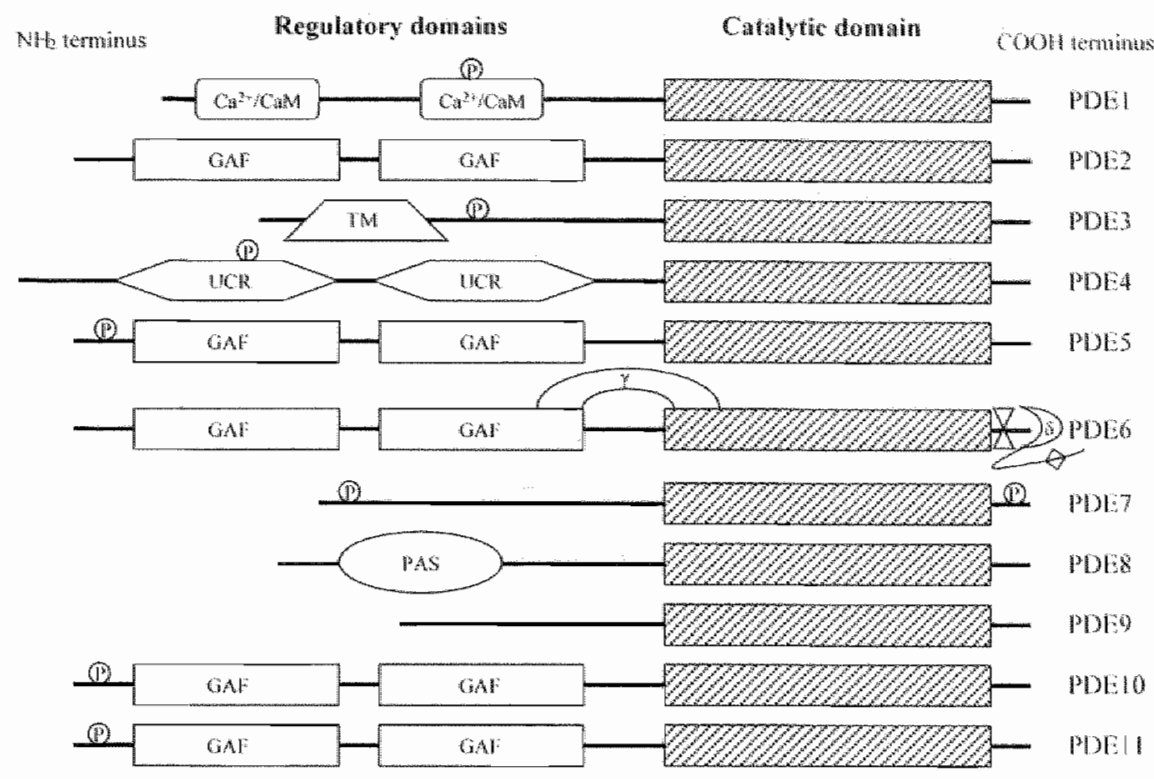

Figure 4. Schematic depiction of characteristic domains present in the monomeric structure of the elleven PDE families based on Soderling and Beavo (2000), Yuasa et al. (2000). Francis et al. (2001) and Sasaki et al. (2002). Ca2\%/CaM, calcium-calmodulin binding domain; GAF domain, cGMP-binding site (see text); $P$, phosphorylation site; PAS, see text, TM, possible transmembrane domain; UCR, upstream conserved region; $\delta$, delta subunit; $Y_{*}$ gamma subunit; $\mathbb{Z}$. Prenyl groups; $\diamond$, putative PDZ domain.

Sutherland (1962) demonstrated that methylxanthines, such as caffeine and theophylline, inhibit cyclic nucleotide degradation. Since this time, many studies have been performed to identify drugs that inhibit PDE activity. Intriguingly, the fact that different PDE families have unique primary sequences in their catalytic or regulatory domains and that they demonstrate sellective expression patterns, offers the opportunity to modulate individual isozymes using specific drugs (Beavo and Reifsnyder, 1990).

PDE inhibitors are known as targets for many drugs, used to treat a variety of diseases such as cardiovascular diseases, asthma, depression or male impotence (Essayan, 2001; Corbin et al., 2002; Sturton and Fitzgerald, 2002). Methylxanthines like caffeine, theophylline or 3-isobutyl-1.methylxanthine (IBMX), together with the isoquinoline derivative papaverine, are all members of the group of the so-called non-selective PDE inhibitors. These compounds inhibit both cGMP- and cAMP-hydrolyzing PDEs with low affinity ( $\mathrm{Ki}$ around $1 \mathrm{mM}$ ) and are indicated as the "first generation PDE inhibitors". Furthermore, these inhibitors have the disadvantage that often side effects occur, such as interference of adenosine metabolism (Dousa, 1999). 
The involvement of $\mathrm{NO}$ and $\mathrm{CGMP}$ in the regulation of blood pressure has raised interest in the development of compounds interacting in this signaling pathway. Nitrovasodilators, or compounds releasing NO (NO donors), are used clinically in the treatment of cardiovascular disorders. However, development of tolerance following chronic treatment with these compounds is a major draw back of such agents. In recent years, NOindependent sGC activators have been developed such as YC-1 (Ko et al., 1.994) and BAY 41-2272 (Stasch et al., 2001) as promising tools for the treatment of hypertension. The PDE5 inhibitor sildenafil citrate developed by Pfizer and marketed as Viagra was originally investigated as a potential antianginal agent. Nowadays, this drug is prescribed as an effective treatment for erectile dysfunction. Since the release of this compound, interest in the development of new and more selective PDE inhibitors has strongly increased. Over the past few years, a rapid growth can be observed in the number of publications on the physiological functions of second messengers and their regulation by PDEs. Expanding research on PDEs has resulted in the identification of a large number of compounds, which have higher affinity ( $\mathrm{Ki}$ in low $\mu \mathrm{M}$ to $\mathrm{nM}$ range) for PDEs than the non-selective PDE inhibitors. More importantly, these "second generation PDE inhibitors" demonstrate high affinity for selective PDE families.

Other PDE5 inhibitors, such as vardenafil, also known as Levitraß (BAYER AG/GlaxoSmithKline) or tadalafil, marketed as Cialisß) (Lilly ICOS LLC), are both expected to be released this year for treatment of erectile dysfunction $^{2}$. In addition to the application of PDE5 inhibitors as therapeutic agents, also selective PDE4 inhibitors used clinically are becoming available. These compounds, like cilomilast (Ariflo®, GlaxoSmithKline) and roflumilast (Altana Pharma)', are already in advanced stages of development for the treatment of respiratory diseases such as chronic obstructive pulmonary disease and asthma (Sturton and Fitzgerald, 2002). Furthermore, exisulind (sulindac sulfone), commercial named Aptosyn@ (Cell Pathways Inc), is a combined inhibitor of PDE5 and PDE2 (Liu et al., 2001). This drug induces apoptosis in a broad range of cancer cell lines including breast, lung, prostate, and colon, and inhibits the formation and growth of cancer in several animal models (see review Haanen, 2001). Presently this compound is being tested in clinic for breast, lung, prostate and colon tumors. ${ }^{3}$

Although so far only limited studies have been reported on the effect of these new highly selective PDE inhibitors in numerous in vitro and in vivo models, recent research indicates expanded potential for influencing PDE activity in other disorders. Experiments have shown that PDE5 inhibitors such as zaprinast and T-1032 protect motor and non-motor neurons against neurotoxicity, suggesting a possibility for a potential treatment in amyotrophic lateral sclerosis (Nakamizo et al., 2003). Furthermore,

2http://w w escriber.com/Assets/EscriberDownlonds/Lmages/Autumndrugstable.pdf http:/www.cellpathways.com/6_APTOSYN/aptosyn.html 
application of sildenafil promoted functional recovery after stroke (Zhang et al., 2002).

Application of PDE inhibitors to tissues leads to prevention of cGMP and/or cAMP degradation. Lilkewise, compounds are available which influence the activity of enzymes, that produce $\mathrm{NO}$ or cGMP, such as NOS or $\mathrm{SGC}$ inhibitors. Effects of these compounds influencing NO-CGMP PDE signaling in relation to learning and memory models will be described in the following section.

Table 2. Selectivity of a number of PDE inhibitors towards the eleven PDE families.

\begin{tabular}{|c|c|}
\hline Family & Inhibitors \\
\hline PDEN & vinpocetine, calmidazolium, SCH51866, zaprinast, 8MMX IBMX \\
\hline PDE2 & EHNA, IBMX \\
\hline PDEs & milrimone, cilostamide, amrinone, enoximone, SK\& $95654,1 B M X$ \\
\hline PDE4 & rolipram, RO 20-1724, cilomilast, roflumilast, BAY 19-8004, IBMX \\
\hline PDES & $\begin{array}{l}\text { sildenafil, vardenafi, taldenafil, zaprinast, dipyridamole, SCH 51866. SK\&F } \\
96231 \text {, WIN 65579, DMPPO, E4021, KF31327, T-1032, T-0156. IBMX }\end{array}$ \\
\hline PDE6 & sildenafil, vardenafi], zaprinast, dipyridamole, DMPPO, 1 ,4021, IBMX \\
\hline PDE7 & dipyridamole, SCH51866, papaverine, IBMX \\
\hline PDE8 & dipyridamole \\
\hline PDE9 & Zaprinast, SCH51866 \\
\hline PDE10 & dipyridamole, zaprinast, E4021, SCH51866, IBMX \\
\hline PDE11 & dipyridamole, zaprinast, E021, SCH51866, IBMX \\
\hline
\end{tabular}

8-MMX, 8-methoxymethyl-3-isobutyl-1-methylxanthine; FHNA, erythro-9-(2-hydroxy-3-nonyl) adenine; IBMX, 3-isobutyl-1-methylxanthine.

\section{Pharmacological intervention of the NO-cGMP PDE signaling pathway in learning and memory models}

The fact that the memory of even a small event can last a lifetime, implies that storage of information in the brain is likely to involve rapid and persistent changes to brain circuits. The ability to remember is a crucial feature for an organism. Impairment in learning and memory processes can lead to disorders varying from moderate forgetfulness during normal ageing, to the disabling severe memory loss, associated with disease like Alzheimer's disease. Therefore, more insight into the underlying cellular communication pathways, which participate in the translation of signals into a neuronal representation of memory, might be beneficial in the development of therapeutics used to treat memory impairments (Alberini, 1999; Mayford and Kandel, 1999; Lynch, 2002; Rose, 2002).

In the $1950 \mathrm{~s}$, it became evident that the brain structure named hippocampus, plays an important role in memory formation (Scoville and Milner, 1957). Removal of the medial temporal lobes, including the hippocampus, of a patient as a treatment for epileptical seizures, resulted in ceased seizures. However, the patient had permanently lost the ability to 
learn new things. Old memories from before the operation were still intact, but anything novel such as new faces or new facts, could no longer be stored in the long-term memory of this patient (Scoville and Milner, 1957). More recent studies of this patient and other patients with amnesic syndromes, as well as animal model studies indicate that the hippocampus plays a fundamentall role during memory formation.

\section{In vitro pharmacological intervention}

Although there are some controversial views on the mechanisms underlying learning and memory, the generally accepted concept of how memory is stored in the brain is by activity-dependent strengthening of synaptic connections between neurons. A candidate cellular mechanism thought to play a role in memory formation is long-term potentiation (LTP) (Bliss and Lomo, 1973). LTP can be defined as a long-lasting increase in synaptic efficacy in response to high-frequency stimulation. It is thought that in this process two facts are essential: a triggering step from the post-synaptic neuron and a maintenance signal derived from the pre-synaptic neuron. This phenomenon implies that, if the post-synaptic neuron can trigger the pre-synaptic neuron, a messenger is required from the post-synaptic neuron, which can "inform" the pre-synaptic cell. NO is thought to act as such a retrograde messenger. The blocking of NO production by NOS inhibitors or the application of an NO scavenger such as hemoglobin, abolished (Bohme et al., 1991; O'Dell et al., 1991; Schuman and Madison, 1991; Bon et al., 1992) or partially blocked (Gribkoff and Lum-Ragan, 1992) the induction of LTP in hippocampal slices. In addition, administration of $\mathrm{SGC}$ or PKG inhibitors also impaired LTP (Zhuo et al., 1994; Monfort et al., 2002; Bon and Garthwaite, 2003). In contrast, application of NO donors or a CGMP analogue facilitated LTP (Zhuo et al., 1994; Arancio et al., 1995). It has been reported that induction of LTP involves activation of $\mathrm{SGC}, \mathrm{PKG}$ and $\mathrm{CGMP}$ hydrolyzing PDEs (Monfort et al., 2002). Although these studies indicate a role for NO-cGMP signaling in LTP, it must be noted that the role for NO in LTP is still under debate, since some reports have also been published which do not confirm a role of NO in LTP. It has been suggested that differences in the experimental protocols used (Son et al., 1998) or animal strain tested are responsible for the observed discrepancies (Holscher, 2002).

\section{In vivo pharmacological intervention}

Strong evidence that NO-cGMP signaling is important during memory formation, originates from behavioral tasks in which compounds that interact with the components of this signaling pathway are tested. First evidence demonstrating a critical role for NO during memory formation was derived from a passive avoidance task in the young chick. It was shown that the blocking of NO production via application of a NOS inhibitor, results in amnesia for this task, which interestingly could be reversed by administration of the NOS substrate L-arginine (Holscher and Rose, 1992). Since this report, many others have been published showing that the 
blocking of NOS resulted in an impaired performance in various learning and memory tasks studied in a large number of species. Studies in invertebrates demonstrated an impaired performance after application of a NOS inhibitor in food-attraction conditioning in snails (Teyke, 1996; Katzoff et al., 2002), visual and touch learning in octopus (Robertson et al., 1994; Robertson et al., 1995), olfactory memory in honey bees (Muller, 1996; Hosler et al., 2000) or maze learning in crickets (Jaffe and Blanco, 1994). In mammals, an impaired performance as a result of blocking NO production has been demonstrated in olfactory memory in sheep (Kendrick et al., 1997), in object recognition memory in rats (Prickaerts et. al., 1997; Blokland et al., 1998; Pitsikas et al, 2002a), inhibitory learning or olfactory associative learning in newborn rats (Myslivecek et al., 1996; Samama and Boehm, 1999), radial arm maze test in rats (Bohme et al., 1993; Yamada et al., 1995; Zou et al., 1998), social recognition test in rats (Bohme et al., 1993), passive avoidance in rats (Bernabeu et al., 1995; Fin et al., 1995; Huang and Lee, 1995), inhibitory avoidance in mice (Baratti and Kopf, 1996), or delayed recall in monkeys (Prendergast et al., 1997; for review see Prast and Philippu, 2001). These findings in learning and memory behavioral tasks, provide strong evidence for a critical role of NO in memory formation. Furthermore, they strongly suggests that the role of $\mathrm{NO}$ in memory formation is conserved in various species.

In two rat learning and memory behavioral tasks, the object recognition task and a passive avoidance paradigm, pharmacological intervention of NO-cGMP signaling has been most extensively investigated (Bernabeu et al., 1995; Fin et al., 1995; Huang and Lee, 1995; Bernabeu et al., 1996; Bernabeu et al., 1997; Prickaerts et al., 1997; Telegdy and Kokavszky, 1997; Blokland et al., 1998; Izquierdo et al., 2000; Pitsikas et al., 2002a; Pitsikas et al., 2002b; Prickaerts et al., 2002). The object recognition task measures in a first test trial whether or not rats remember an object, which is subsequently presented following a delayed time interval, in a second learning trial. Similar to the object recognition task, the passive avoidance task is also a one-trial learning paradigm. However, an aversive stimulus, i.e. an electrical shock, has to be remembered. In these tasks it has been demonstrated that the time point of infusion of the NOS inhibitor is a significant factor. Application of the NOS inhibitor only shortly before or immediately after the first test trial induced an impaired memory performance in the learning trial, whereas administration of the compound at other stages did not effect the performance (Bernabeu et al., 1995; Fin et al., 1995; Blokland et al., 1998). The fact that the impairment after treatment with NOS inhibitors can be reversed by application of compounds which release NO (NO donors) or by the NOS substrate L-arginine, indicates that NO levels need to be critically regulated during memory formation (Fin et al., 1995; Huang and Lee, 1995; Pitsikas et al., 2002a). In agreement with the observed findings after NOS inhibition, inhibition of the NO target, sGC, also leads to memory impairment (Bernabeu et al., 1997; Izquierdo et al., 2000). Similar to application of NOS inhibitors, the time point of application of the $\mathrm{sGC}$ inhibitor is also significant, having effect 
only on immediate application after the first test trial (Bernabeu et al., 1997). Interestingly, it has been demonstrated biochemically that NOS and ${ }_{8 G C}$ activity and also cGMP levels were increased in the hippocampus immediately after the test trial (Bernabeu et al., 1995; Bernabeu et al., 1996; Bernabeu et al., 1997). In addition, the cGMP target PKG showed an increased activity at this similar time point (Bernabeu et al., 1997). These findings would indicate that NO levels are critically involved in memory formation and furthermore that this is probably mediated by stimulation of sGC.

The initial evidence, which indicated that PDEs play a critical role in learning and memory processes, was derived from studies using the fruit fly Drosophila melanogaster. In 1976, a gene named dunce was identified from flies that showed an impaired performance in a memory task (Dudai et al., 1976). Later studies demonstrated that this gene encodes a cAMP-specific PDE (Byers et al., 1981), which is a homologue of the mammalian PDE4 (Swinnen et al., 1989; Monaco et al., 1994). Interestingly, another Drosophila mutant impaired in learning, named rutabaga, showed impaired activity in the cAMP-producing enzyme, adenylyl cyclase (Feany, 1990). Furthermore, a mutant called amnesiac has been identified to be involved in learning and memory in Drosophila (Feany and Quinn, 1995). The predicted amnesiac gene product is an apparent preproneuropeptide from which it is suggested that it stimulates cAMP synthesis.

The first studies indicating a criticical role for PDEs in memory formation in mammals was demonstrated in rats. In contrast to the reported impaired performance after administration of NOS or sGC inhibitors, application of the non-selective PDE inhibitor caffeine enhanced the memory performance in maze learning (Roussinov and Yonkov, 1976). In mice, administration of the non-selective PDE inhibitors IBMX (Villiger and Dunn, 1981) or papaverine (Chutae et al., 1981), or the PDE4 inhibitor RO-20-1724 (Villiger and Dunn, 1981), resulted in an enhanced retention in a passive avoidance task. A study from our department was the first to demonstrate that administration of zaprinast, initially described as an inhibitor of the cGMP-hydrolyzing PDE5, facilitated memory in an object recognition task (Prickaerts et al., 1997). Interestingly, it was demonstrated that the memory deficit induced by administration of an NOS inhibitor, was reversed by application of zaprinast (Prickaerts et al., 1997). Similarly, it has been shown that intrahippocampal administration of a cGMP analogue after the first test trial, also leads to an enhanced retention in the object recognition task (Prickaerts et al., 2002) and in a passive avoidance task (Bernabeu et al., 1996) in rats. From these observations it was hypothesized that, memory improving effects might be caused by increased cGMP levels in the hippocampus after administration of PDE inhibitors. 


\section{Aim and outline of the thesis}

Taken altogether, the studies described above strongly indicate that the performance in behavioral learning and memory tasks can be influenced with compounds, which interact with the components of the NO-cGMP PDE signaling pathway. In contrast to the impaired performance after blocking of NO or cGMP synthesis, it is of special interest that application of PDE inhibitors can lead to an enhanced memory retention in healthy animals. Based on the previous observation that application of zaprinast, a PDE5 inhibitor, improved retention for object recognition memory, our interest was heightened to investigate the role of PDE5 in relation to learning and memory in greater detail. The main question underlying the experiments in this thesis was: how does administration of a PDE5 inhibitor lead to an enhanced memory performance in the object recognition task?

As mentioned before, cGMP signaling in tissues is comprised of a complex concert of numerous proteins. Considering the complexity of NOcGMP signaling, it was decided to investigate this signaling pathway in more detail by using a behavioral, pharmacological, morphological, and molecular biological approach. At the behavioral level, the effect of more selective PDE5 inhibitors than zaprinast, such as sildenafil and vardenafil, was investigated in the rat object recognition task (Chapter 2). To investigate the mechanism of action of PDE5 inhibitors, the method of in vitro incubation of hippocampal slices was used. In vitro incubation of brain slices or spinal cord slices has been published previously (De Vente et al., 1987; De Vente et al., 1989; De Vente and Steinbusch, 1992; De Vente et al., 1996; Vles et al., 2000; de Louw et al., 2002). The use of this model provides an efficient means of determining whether or not a compound can influence cyclic nucleotide levels. These cyclic nucleotide levels can be assessed using two independent methods. First, at the morphological level by using cGMP. immunocytochemistry, which can be combined with a number of cellular markers. Second, biochemically by measurement of cGMP and cAMP levels using a radioimmunoassay. Using these methods, the effects of selective PDE5 inhibitors, like zaprinast, sildenafil and vardenafil were investigated and compared to other PDE inhibitors, which have different affinity profiles towards a number of PDE families (Chapter 2 and Chapter 3). Furthermore, the effect of a number of $\mathrm{sGC}$ activators was studied in the in vitro slice model (Chapter 4).

It was hypothesized that increased hippocampal cGMP levels can enhance memory retention. Therefore, the cellular localization of the mRNAs of PDE5 and two other cGMP-hydrolyzing PDE families (PDE2 and PDE9) was investigated in the hippocampus and other brain areas, since these enzymes critically determine cGMP levels. For this reason, the rat PDE9 was cloned and the cellular expression of this enzyme was investigated, because literature reported that this enzyme has the highest affinity for cGMP (Soderling et al., 1998a) and therefore is thought be a key enzyme in regulating cellular cGMP levels (Chapter 5). Furthermore, a comparison was made between the mRNA localization of PDE2, PDE5 and PDE9 in the adult rat brain, in combination with a study of the expression 
of these enzymes during brain development (Chapter 6). Moreover, a comparison was made between the cellular localization of the NO-cGMP signaling pathways in rat and mouse hippocampus by a combination of the above described methods (Chapter 7 ).

\section{References}

ALBERINII CM. (1999) Genes to remember. I Exp Biol 202: 2887-2891.

ANDRELVA SG, DKKKES P. EPSTEIN PM, ROSENBERG PA. (2001) Expression of CGMPspecific phosphodiesterase 9A mENA in the rat brain. I Neurosci 21: 9068-9076.

ARANC1O O, KANDEL ER, HAWKINS RD. (1995) Activity-dependent long-term enhancement of transmitter release by presynaptic $3^{2}, 5^{\prime}$-cyclic GMP in cultured hippocampal neurons. Noture 376 : 7 - H- -80 .

BALLIERINI P, DI IORIO P, CICCARELI $\mathbb{R}$, NARGI E, DALIMONTE I, TRAVERSA U, RATHBONF MP, CACLAGLI F. (2002) Glial cells express multiple ATP binding cassette proteins which are inwallved in ATP release. Neuroreport 13: $1789-1792$.

BARANANO DE, FERRIS CD, SNYDER SH. (2001) Atypical neural messengers. Trends Neurosei 24: 99-106.

BARATTI CM, KOPF SR. (1996) A nitric oxide synthase inhibitor impairs memory storage in mice. Neurobiol Learn Mem 65: 197-201.

BEAVO JA, REIFSNYDER DH. (1990) Primary sequence of cyclic nucleotide phosphodiesterase isozymes and the design of selective inhibitors. Trends Phamacol Sci 11: $150-155$.

BEAVO JA. (1995) Cyclic nucleotide phosphodiesterases: functional implications of multiple isoforms. Physion Rev 75: 725-748.

BEAVO JA, BRUNTON LL. (2002) Cyclic nucleotide research - still expanding after half a century, Nal Reu Mol Cell Biol 3: 710-718.

BELLTMAN d, SONNENBURG WK, BEAVO JA. (1993) The role of protein phosphorylation in, the regulation of cyclic nucleotide phosphodiesterases. Mol Cell Biochem 127-128: 239-253.

BENTLEY JK KADLECEK A, SHERBERT CH, SEGER D, SONNENBURG WK, CHARBONNEAU H, NOVACK JP, BEAVO JA (1992) Molecular cloning of cDNA encoding a "63" $\mathrm{kDa}$ calmodulin-stimulated phosphodiesterase from bovine brain. I Blol Chem 267 . $1.8676-18682$

BERNABEU $R$, DE STEIN ML, FIN C, IZQUIERDO I, MEDINA JH (1995) Role of hippocampal $\mathrm{NO}$ in the acquisition and consolidation of inhibitory avoidance learning. Nearoment 6: 1498.1500.

BERNABEU R, SCHMITZ P, FAILLACE MP, IZQUIERDO I, MEDINA JH. (1996) Hippocampal CGMP and CAMP are differentially involved in memory processing of inhibitory avoidance learning. Neuroreport $7: 585-588$.

BERNABEU R. SCHRODER N. QUEVEDO J, CAMMAROTA M, IZQUTERDO I, MEDNA JH (1997) Further evidence for the involvement of a hippocampal cGMP/cGMP dependent protein kinase cascade in memory consolidation. Neuroreport $8: 2221.2224$.

BILLINGSLEY ML POLLI JW. BALABAN CD, KINCAID RL. (1990) Developmental expression of calmodulin-dependent ayclic nucleotide phosphodiesterase in rat brain. Dev Broin. Res 58: 253-263

BLISS TV, LOMO TH. (1973) Long-lasting potentiation of synaptic transmission in the dentate area wi the manesthetized rabbit following stimulation of the perforant path. of Physiol 232 . 331.356.

BLOKLAND A, PRICKAERTS J, HONIG W, DE WENTE J. (1998) State-dependent impairment in object recognition after hippocampal NOS inhibition. Neuroreport 9: 42054208.

BLOOM "J, BEAVO JA (1996) Identification and tissue-specific expression of PDE7 phosphodiesterase splice variants. Proc Nall Acad Sci U S A 93: 14188-14192.

BOHME GA. BON C. STUTZMANN JM, DOBLE A. BLANCHARD JC. (1991) Possible involvement of nitric oxide in long-term potentiation. Eur ef Phannacol 199; 379-381. 
BOHME GA, BON C. LEMAIRE M, REIBAUD M, PIOT O, STUTZMANN JM, DOBLE A, BLANCHARD JC. (1993) Altered synaptic plasticity and memory formation in nitric oxide synthase inhibitor-treated rats. Proc Nat Acad Sci U S A 90: $9191-9194$.

BOLGER GB. (1994) Molecular biology of the cyclic AMP-specific eyclic nucleotide phosphodiesterases: a diverse family of regulatory enzymes. Cell Signal 6: 851.859.

BOLGER GB, MCPHEE I, HOUSLAY MD. (1996) Alternative splicing of CAMP-specific phosphodiesterase mRNA transcripts. Characterization of a navel tissue-specific isoform, RNPDE4A8. J Biol Chem 271: 1065-1071.

BOLGER GB, ERDOGAN S, JONES RE, LOUGHNEY $\mathbb{K}$, SOOTLAND G. HOFFMANN $R$, WILKINSON I, FARRELL C, HOUSLAY MD. (1997) Characterization of five different proteins produced by alternatively spliced mRNAs from the human CAMP-specific phosphodiesterase PDE4D gene. Biochem of 328: 539-548.

BON C, BOHME GA, DOBLE A, STUTZMANN JM, BLANCHARD JC. (1992) A Role for Nitric Oxide in Long term Potentiation. Eur \& Neurosci 4: 420-424.

BON CL, GARTHWAITE J. (2003) On the role of nitric oxide in hippocampal long-term potentiation. INeurosci 23:1941-1948.

BORST P, ELFERINK RO. (2002) Mammalian ABC transporters in heath and disease. Amm Rev Biochem 71: 537-592.

BRADLEY J, ZHANG Y, BAKIN R, LESTER HA, RONNETY GV, ZINN K. (1997) Functional expression of the heteromeric "olfactory" cyclic nucleotide-gated chamnel in the hippocampus: a potential effector of symaptic plasticity in brain neurons. \& Nenrosci 17: 1993-2005.

BREDT DS, HWANG PM, SNYDER SH. (1990) Localization of nitric oxide synthase indicating a neural role for nitric axide. Nature 347 : $768-770$.

BREDT DS, SNYDER SH. (1990) Isolation of nitric oxide synthetase, a calmodulin-requiring enzyme. Proc Natl Acad Sei U S A 87: 682-685.

BROILIET MC, FIRESTEIN S. (1999) Cyclic nucleotide-gated channels. Molecular mechanisms of activation. Ann $N$ Y Acad Sci 868: 730-740.

BRUNTON LL, MAYER SE. (1979) Extrusion of cyclic AMP from pigeon erythrocytes. of Biol Chem 254: 9714-9720.

BUECHLER WA, NAKANE M, MURAD F. (1991) Expression of soluble guanylate cyclase activity requires both enzyme subunits. Biochem Biophys Res Commun 1.74: $351-357$.

BURETTE A, ZABEL U, WEINBERG RU, SCHMIDT HHFW, VALTSCHANOFF J. (2002) Synaptic localization of nitric oxide synthase and soluble guanylyl cyclase in the hippocampus. J Neurosci 22:8961-8970.

BURGUNDER JM, CHEUNG PT. (1994) Expression of soluble guanylyl cyclase grene in adult rat brain. Eur of Neurosci 6: 211-217.

BUTCHER RW, SUTHERLAND EW. (1962) Adenosine 3',5-phosphate in biological materials. $y$ Biol Chem 237 : 1244-1250

BYERS D, DAVIS RL, KIGER. JA, JR. (1981) Defect in cyclic AMP phosphodiesterase due to the dunce mutation of learning in Drosophila melanogaster. Nature 289: 79-81.

CARVAJAL JA, GERMAIN AM, HUIDOBRO-TORO JP, WEINER CP, (2000) Molecular mechanism of cGMP-mediated smooth muscle relaxation. of Cell Physiol 184: 109-120.

CHEN ZS, LEE K, KRRUH GD. (2001) Transpont of cyclic nucleotides and estradiol 17.betanD. glucuronide by multidrug resistance protein 4. Resistance to 6-mercaptopurine and 6 thioguanine. of Biol Chem 276:33747.33754.

CHERRY JA. DAVIS RL. (1999) Cyclic AMP phosphodiesterases are localized in regions of the mouse brain associated with reinforcement, movement, and affect. $\int$ Comp Nerurol 407: 287301.

CHOI YH, EKHOLM D, KRALL J, AHMAD FE, DEGERMAN E, MANGANIELLO VC, MOVSPSIAN MA. (2001) Identification of a novel jisoform of the cyclic-nucleotide phosphodiesterase PDEsA expressed in vascular smooth-muscle myocy tes. Biochem $J 353$ : $41-50$.

CHUTAE DL, VLLIGER JW, KIRTON NF. (1981) Testing cyclic AMP mediation of memory: reversal of alpha-methyl p-tyrosine-induced amnesia, Psychopharmacology (Berl) 74: 129131. 
COLICALI \&, BIRCHMEIER C, MCHAELI T, ONEILI, K, RIGGS M, WIGLER M. (1989) lisolation and characterization of a mammalian gene encoding a high-affinity CAMP phosplodiesterase. Proc Natl Acad Sci U S A 86: $3599-3603$.

CONTI M. INN SL. (1999) The molecular biology of cyclic nucleotide phosphodiesterases. Prog Nucleic Acid Res Mol Biol 63 : 1.38.

CONTI M, RICHTER W, MEHATS C, LIVERA G, PARK JY, INN C. (2003) Cyclic AMP specific PDEA Phosphodiesterases as Critical Components of Cyclic AMP Signaling. I Biol Chem 278: $5499-5496$.

CORBIN JD. FRANCIS SH, WEBB D. (2002) Phosphodiesterase type 5 as a pharmacologic target in erectile dysifunction. Urology 60: 4-11.

DAVOREN PR, SUTHERLAND EW. (1963) The effect of L-epinephrine and other agents on the symthesis and release of adenosine $3^{\prime}, 5^{\prime \prime}$-phosphate by whole pigeon erythrocytes. I Biol Chen 238: $3009-3015$.

DAWSON TM, GONZALEZZUULUTA M, KUSEL J, DAWSON VL. (1998) Nitric oxide: diverse actions in the central and peripheral nervous systems. Neuroscientist 4: 96-112.

DE LOUW Ad, DE VENTE J, STEINBUSCH HP, STEINBUSCH HW, TROOST J, VLES IS. (2002) Baclofen inhibits ANP-mediated cyclic GMP synthesis in the rat cervical spinal cord. Neurosci Let 321: 120-122.

DE VENTTE J, STEINBUSCH HW, SCHIPPER J. (1987) A new approach to immunocy tochemistry of $3^{\prime}, 5^{\prime}$-cyclic guanosine monophosphate: preparation, specificity, and initial application of a new antiserum against formaldehyde-fixed $3^{\circ}, 5^{\prime}$-cyclic guanosine monophosphate. Neuroscience 22: $361-373$.

DE VENTE J, BOL JG, STEINBUSCH HW, (1989) Localization of CGMP in the cerebellum of the adullt rat: an immunohistochemical study. Brain Res 504: 332-337.

DE VENTE, STEINBUSCH HW. (1992) On the stimulation of soluble and particulate guanylate cyclase in the rat brain and the involvement of nitric oxide as studied by cGMP immunocytochemistry. Acta Histochem 92: 13-38.

DE VENTE J, HOPKINS DA, MARKERINK-VAN ITTERSUM M, STEINBUSCH HW. (1996) Effects of the $3,5^{\circ}$-phosphodiesterase inhibitors isobutylmethylxanthine and zaprinast on NO-mediated GGMP accumulation in the hippocampus slice preparation: an immunocytochemical study. J Chem Neuroanat 10: 241-248.

DE VENTE J, HOPKINS DA, MARKERINK-VAN ITTERSUM M, EMSON PC, SCHMIDT HHHW, STEINBUSCH HWM. (1998) Distribution of nitric oxide synthase and nitric oxidereceptive, cyclic GMP-producing structures in the rat brain. Neuroscience 87: 207-241.

DE VENTE J, ASAN E, GAMBARYAN S, MARKERINT-VAN ITTERSUM M, AXER H, GALLATZ, K, LOHMANN SM, PALKOVITS M. (2001) Localization of cGMP-dependent protein kinase type II in rat brain. Neuroscience 108: 27-49.

DEGERMAN E, BRLFRAGE P, MANGANIELLO VC. (1997) Structure, localization, and regulation of CCMP-inhibited phosphodiesterase (PDE3). I Biol Chem 272: 6823.6826.

DINERMAN „L, DAWSON TM, SCHELL MJ SNOWMAN A, SNYDER SH. (1994) Endothelial nitric oxide synthase localized to hippocampal pyramidal cells: implications for synaptic plasticity. Proc Noll Acad Sci U S A 91: 42144218.

DOUSA TP. (1999) Cyclic-3',5'-nucleotide phosphodiesterase isozymes in cell biology and pathophysiology of the kidney. Kidney In. 55: 29.62 .

DUDAI Y JAN YN, BYERS D, QUINN WG, BENZER S. (1976) Dunce, a mutant of Drosophila deficient in learning. Proc Nall Acad Sci U S A 73: 1684-1688.

DUMON'T JE, DREMIER S. PIRSON 1, MAENHAUT C. (2002) Cross signaling, cell specificity, and physiology. Am of Physiol Cell Physiol 283: C2-28.

EL-HUSSEINT AE, BLADEN C, VINCENT SR. (1995) Molecular characterization of a type II cyclic GMPdependent protein kinase expressed in the rat brain. of Neurochem 64: 2814 2817 .

BL-HUSSEINT AR, WLLLIAMS J, REINER PB, PELECH S, VINCENT SR. (1999) Localization of the cGMP-dependent protein kinases in relation to nitric oxide synthase in the brain. $f$ Chem Nenroanal 17: 45-55.

ELIASSON MJ, BLACKSHAW S, SCHELL MJ, SNYDER SH. (1997) Neuronal nitric oxide synthase altematively spliced forms: prominent functional localizations in the brain. Proc Nati Acod Sci U SA 94: 3396-3401. 
ESSAYAN DM. (2001) Cyclic nucleotide phosphodiesterases. I Allergy Clin Immunol 108: 671 . 680.

FAWCETT L, BAXENDALE R, STACEY P. MCGROUTHER C, HARROW II, SODERLING S, HETMAN J, BEAVO JA, PHILIPS SC. (2000) Molecular cloning and characterization of a distinct human phosphodiesterase gene family: PDE11A Proc Natl Acad Se: U S A 97: $3702-3707$.

FEANY MB. (1990) Rescue of the learning defect in dunce, a Drosophila leaming mutant, by an allele of rutabaga, a second learning mutant. Proc Noll Acod Sci U S A $87: 279542799$.

FEANY MB, QUINN WG. (1995) A newropeptide gene defined by the Drosophila memory mutant ammesiac. Science 268: 869-873.

FESENKO EE, KOLESNTKOV SS, LYUBARSKY AL. (1985) Induction by cyclic GMP of cationic conductance in plasma membrane of retinal rod outer segment. Nature 313 : 310 313.

FIN C, DA CUNHA C, BROMBERG E, SCHMITZ PK, BIANCHIN M, MEDINA UH, IZQUIERDO I. (1995) Experiments suggesting a role for nitric oxide in the hippocampus in memory processes. Neurobiol Learn. Mem 63: 113-115.

FISHER DA, SMITH JF, PLLAR JS, ST DENIS SH, CHENG JB. (1998a) Isolation and characterization of PDE9A, a novel human cGMP-specific phosphodiesterase. of Biol Chem 273: $15559-15564$.

FISHER DA, SMITH JF, PILLAR JS, ST DENIS SH, CHENG JB. (1998b) Isolation and characterization of PDE8A, a novel human AMP-specific phosphodiesterase. Biochem Biophys Res Commun 246: 570-577.

FLORTO VA, SONNENBURG WK, JOHNSON R, KWAK KS, JENSEN GS, WAL,SH KA, BEAVO JA. (1994) Phosphorylation of the 61-kDa calmodulin-stimulated cyclic nucleotide phosphodiesterase at serine 120 reduces its affinity for calmodulin. Biochenistry 33 : 8948 8954.

FLORIO SK, PRUSTI RK, BEAVO IA. (1996) Solubilization of membranebound rod phosphodiesterase by the rod phosphodiesterase recombinant delta subunit. of Biol Chem 271: 24036-24047.

FORSTERMANN U, BOISSEL JP, KLEINERT H. (1998) Expressional control of the 'constitutive' isoforms of nitwic oxide synthase (NOS I and NOS III). FASEB J 12: 773-790.

FRANCIS SH, TURKO IV, CORBIN JD. (2001) Cyclic nucleotide phosphodiesterases: relating structure and function. Prog Nucleic Acid Res Mol Biol 65: 1-52

FUJISHIGE K, KOTERA J, OMORI K. (1999a) Striatum- and testis-specific phosphodiesterase PDE10A isolation and characterization of a rat PDE10A Eur J Biochem 266: 1118-1127.

FUJISHIGE $K$, KOTERA J, MICHIBATA $H$, YUASA $\mathbb{K}$, TAKEBAYASHI S, OKUMURA $K$, OMORI K. (1999b) Cloning and characterization of a novel human phosphodiesterase that hydrolyzes both CAMP and CGMP (PDE10A). S Biol Chem 274: 18438-18445.

FUJISHIGE $K$, KOTERA J, YUASA $K$, OMORI K. (2000) The human phosphodiesterase PDE10A gene genomic organization and evolutionary relatedness with other PDEs containing GAl* domains. Fur ol Brochem 267: 5943-5951.

FURCHGOTT RF, ZAWADZKI JV. (1980) The obligatory role of endothelial cells in the relaxation of arterial smooth muscle by acetylcholine. Nature $288: 373-376$.

FURUYAMA T, INAGAKI S, TAKAGI H. (1993) Localizations of alpha 1 and beta 1 subunits of soluble guanylate cyclase in the rat brain. Mol Brain Res $20: 335-344$.

FURUYAMA T, IWAHASHI Y, TANO $Y$, TAKAGI H, INAGAKI S. (1994) Localization of 63 . KKa calmodulin-stimulated phosphodiesterase mRNA in the rat brain by in situ hybridization histochemistry. Mol Brain Res 26: 331-336.

GARBERS DL. (1979) Purification of soluble guanylate cyclase from rat lung. I Biol Chem 254: 240.243.

GAPDNER C, ROBAS N, CAWKILL D, FLOCK M. (2000) Cloning and characterization of the human and mouse PDE7B, a novel CAMP-specific cyclic nucleotide phosphodiesterase. Biochem Biophys Res Commun 272: 186-192.

GARTHWAITE J. (1991) Glutamate, nitric oxide and cell-cell signalling in the mervous system. Trends Neurosci 14: 60-67.

GARTHWAITE of. (1995) Neural nitric oxide signalling. Trends Newrosci 18: 51.62.

GIBB BrJ, GARTHWAITE J. (2001) Subunits of the nitric oxide receptor, soluble guanyly! cyclase, expressed in rat brain. Eur of Neurosci 13: 539-544. 


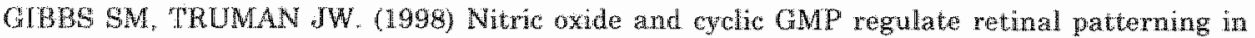
the optuc lobe of Drosoplilat. Neuton 20:83-93.

GIBBS SM, PECRER A. HARDY RW, TRUNAN JW (2001) Saluble guanylate cyclase is required during development for visual system function in Drosophila. ef Neurasci 21:77057714 .

GLLESPIE: BG, BEAVO JA. (1988) Chatacterization of a bovine cone photorecepton phosphodiesterase purified by cyclic GMP-sepharose chromatography. I Biol Chen 263: 8139.8141.

GLILI G, LUZI A, POYARD M, GULLLAEN G. (1994) Expression of mouse brain soluble guanylyl cyclase and NO synthase during ontogeny. Dev Brain Res 81:269.283.

GOPAL VK, FRANCIS SH, CORBN JD. (2001) Allosteric sites of phosphodiestersa-5 (PDE5). A potential rolie in negative fedback regulation of $\mathrm{CMP}$ signaling in corpus anvenosum. Eur Biochem 268:3304-3312.

GRIBKOFF" VR, LUM.RAGAN JT. (1992) Evidence for nitric oxide synthase inhibitor-sensitive and ingensitive hippocampal symaptic potentiation. f Newrophystol 68: 639-642.

GUIPPONI M. SOTT HS, KUDOH J, KAWASAKI K, SHIBUYAK, SHINTANI A. ASAKAWA S, CHEN H, ILALTI MD, LOSSTER C, MINOSHIMA S, SHIMTZU N, ANTONARAKIS SE. (1998) Identification and characterization of a novel cyclic nucleotide phosphodiesterase gene (PDE9A) that maps to 21 q22.3: altemative splicing of mRNA transcripts, genomic structure and sequence. Hum Cenet 103: $386-392$.

HAANEN C. (2001) Sulindac and its dervatives: a novel class of anticancer agents. Curr Opin lmuestig Drugs $2: 677.683$.

HAN P, ZHU X, MICHAELI T. (1997) Alternative splicing of the high affinity CAMP-specific phosphodiesterase (PDE7A) mINA in human skeletal muscle and heart. I Biol Chem 272: $16152-16157$

HARTENECK C, KOESLING D, SOLING A, SCHULTZ G, BOHME E. (1990) Expression of soluble guanylyl cyclase. Catalytic activity requires two enzyme subunits. FEBS Lett 272: 221.223

HAYASHI M, MATSUSHIMA $K$, OHASHI H, TSUNODA H, MURASE S, KAWARADA Y, TANAKA T. (1998) Molecular cloning and characterization of human PDE8B, a novel thyroid-sperific isozyme of $3^{0}, 5^{\prime}$-cyclic nucleotide phosphodiesterase. Brochem Biophys Res Commun 250:751-756.

FAYASHI F, MATSUURA I, KACHI S, MAEDA T, YAMAMOTO M, FU.HI Y, LIU H, YAMAZAKI M, USUKURA J, YAMAZAKI A. (2000) Phosphorylation by cyclin-dependent protein kimase 5 of the regulatory subunit of retinal cGMP phosphodiesterase. Il. It.ts role in the turnoff of phosphodiesterase in vivo. A Bol Chem 275: $32958-32965$.

HAYNES L, YAU KW. (1985) Cyclic GMP-sensitive conductance in outex segment membrane of catfish cones. Nature $517: 61464$.

HENICA M" "FEINSTELN ]DL: (200L) Expression and function of inducible nitric oxide synthase in nenrons. Newrommunal $114: 8.18$.

HERMAN, IP, DOLGAS CM, RUCKER D, LANGUB MCE, (1996a) Localization of natruretic peptide-atevaled guanylate cyclase mRNAs in the rat brain. J Comp Neurol 369: 165-187.

HERMAN IP, DOLGAS CM, MARCINEK R, LANGUB MC, JR, (1996b) Expression and glucocorticoid regulation of netriuretic peptide clearance receptor (NPR-C) $m R N A$ in rat bran and chonold plexus, I Chem Nerrodmat 1: $1: 257-265$.

HETMAN IM, SODERLING SH, GLAVAS NA, BEAVO JA (2000a) Cloning and characterization of PDE7B, a cAMP-apecific phosphodiesterase. Proc Nat Acod Sc U S A 97: $4172 \sim 476$.

HWMAN WM, ROBAS N, BAXENDALE R, FLOCK M, PHILLIPS SC, SODERLING SH. BEAVO JA. (2000b) Cloning and characterization of two splice variants of human phosphodicsterase 11A. Proc Nall Acad Sci O S A 97: 12891-12895.

HIRRLINGER J, KONIG J, DRINGEN R. (2002) Expression of mRNAs of multidrug resistance proteins (Mrps) in cultud rat astrocytes, olyodendrocytes, microglial cells and neurones. Newochem 82:716.719.

HOLSCHER C ROSE SP. (1992) An inhubitor of nitric oxide synthesis prevents memory formation in the chick. Neurosci Lett 145: 165-16\%.

HOLSCHER C. (2002) Different strains of rats show different sensitivity to block of long-term potentiation by nitric oxide synchase inhibitors. Eur of Phamacol 457: 99-106. 
HOSLER JS, BUXTON KL, SMTTH BH. (2000) Impaiment of alfactory discrimination by blockade of GABA and nitric oxide activity in the honey bee antennal lobes. Behov Neurosen 114: $514-525$.

HOUSLAY MD. (1998) Adlaptation in cyclic AMP signalling processes: a central role for cyclic AMP phosphodiesterases. Semin Cell Dev Biol 9: 161-167.

HOUSLAY MD, ADAMS DR. (2003) PDE4 CAMP phosphodiesterases: modular encymes that orchestrate signalling cross-talk, desensitization and compartmentalization. Biochen $d$ 370: 1.18 .

HUANG AM, LEE EH. (1995) Role of hippocampal nitric oxidle in memory retention in rats. Pharmacol Biochem Behav 50:327.332.

HUMBERT P, NIROOMAND F, FISCHER G, MAYER B, KOESLING D, HINSCH KD, GAUSEPOHL H, FRANK R, SCHULT' $G$, BOHME E. (1990) Purification of soluble guanylyl cyclase from bovine lung by a new immunoaffinity chromatographic method. $E u$ J Biachem 190: 273-278.

IWAHASHI $Y$, FURUYAMA 'T, TANO Y, ISHTMOTO I, SHMMOMURA Y, INAGAKI S. (1996) Differential distribution of mRNA encoding CAMP-specific phosphodiesterase isoforms in the rat brain. Mol Brain Res 38: 14-24.

IZQUIERDO LA, VIANNA M, BARROS DM, MELLO IS SOUZA T', ARDENGHI P. SANT" ANNA MK, RODRIGUES C, MEDINAM JH, IZQUIERDO I. (2000) Short: and longterm memory are differentially affected by metabolic inhibitors given into hippocampus and entorhinall cortex. Neurobiol Learn Mem 73: 141-1449.

JAFFE KK, BLANCO ME. (1994) Involvement of amino acids, opioids, nitric oxide, and NMDA receptors in learning and memory consolidation in crickets. Pharmacol Biochem Behav 47. $493-496$.

JARCHAU T, HAUSLER C, MARKERT T, POHLER D, VANDERKERCKHOVE U, DE JONGE HR, LOHMANN SM, WALTER U. (1994) Cloning, expression, and in situ localization of rat intestinal cGMP dependent protein kinase II. Proc Natl Acod Sci U S A 91: 9426-9430.

JEDLITSCHKY G, BURCHELLL B, KEPPLER D. (2000) The multidrug resistance protein 5 functions as an ATP-dependent export pump for cyclic nucleotides, J Biol Chem 275: 30069 30074 .

JULFS DM, FULLE HJ, ZHAO AZ, HOUSLAY MD, GARBERS DL, BEAVO JA. (1997) A subset of olfactory neurons that selectively express cGMP-stimulated phosphodiesterase (PDE2) and guanylyl cyclase-D define a unique olfactory signal transduction pathway, Proc Natl Acad Sci U S A 94: 3388-3395.

JUILFS DM, SODERLING S, BURNS F, BEAVO JA (1.999) Cyclic GMP as substrate and regulator of cyclic nucleotide phosphodiesterases (PDEs). Rev Physiol Biochem Pharmacol 135: 67.104.

KAMISAKI $Y$, SAHEKI S, NAKANE M, PALMIERI JA, KUNO 'T. CHANG BY, WALDMAN SA, MURAD F. (1986) Soluble guanylate cyclase from rat long exista as a heterodimer. d Biol Chem 261: 7236-7241.

KASUYA J, LIANG SI, GOKO H, PARK SH, KATO K, XU ZD, HOCKMAN S, MANGANTELLO VC, FU』ITA.YAMAGUCHI Y. (2000) Cardiac type cGMP-inhibited phosphodiesterase (PDE3A) gene atructure: similarity and difference to adipocyte type PDE3B gene. Biochem Biophys Res Commun 268: 827-834.

KATZOFF A, BEN-GEDALYA T, SUSSWEIN AJ. (2002) Nitnic oxide is necessary for multiple memory processes after leaming that a food is inedible in aplysia. of Neurosci 22: 9581 . 9594.

KENDRICK KM, GUEVARA-GUZMAN R, ZORRLLJA J, HINTON MR, BROAD KD, MTMMACK M, OHKURA S. (1997) Formation of olfactory memories medated by nitric oxide. Nature 388: 670-674.

KIMURA H, MURAD F. (1975) Two forms of guanylate cyclase in mammalian tissues and possible mechanisms for their regulation. Metobolism. 24: $439-445$.

KINCAID RL, BALABAN CD, BILLINGSLEY ML. (1987) Diferential localization of calmodulin-dependent enzymes in lat brain: evidence for selective expression of cyclic nucleotide phosphodiesterase in specific neurons. Proc Nall Acad Sici U S A B4: $1118-1122$.

KING CD, MAYER SE. (1974) Inhibition of egress of adenosine 3',5'-monophosphate from pigeon erythrocytes. Mol Phamacol 10: 941-958. 


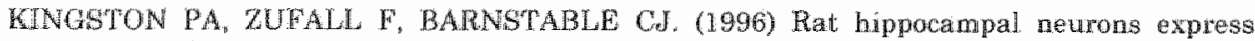
geres for both rod retand and olfactory owclic mucleotide gated chnnels novel targets for CAMP/cGMP function. Proc Noll Acad Ser U S A 93: 10440-10445.

KINCSTON PA, ZUFALI F, BARNSTABLF CU. (1999) Widespread expression of olfactory cyclic rucleotide-gated channel genes in rat bam: implications for neuronal signaling. Syndipse 32: $1 \cdot 12$.

KWOWLES RG, PALACIOS M, PALMER RM, MONCADA S. (1989) Formation of nitric oxide from L-arginine in the central nervous system: a tranduction mechamism for stimulation of the soluble guanyllate cyclase. Proc Nat Acad Sct U S A 86: 5159-5162.

KO WN, WU CG, KUO SC, LEE FY, TENG CM. (1994) $\mathrm{YC}$ - , a novel activator of platelet guanylate aydase. Blood $84: 4226-4233$.

KOESLNG D, HERZ J, GASGPOHL H, MIROOMAND F, HINSCH KD, MULSCH A, BOHME E, SCHULIZ G, FRANKR. (1988) The prinary structure of the $70 \mathrm{kDa}$ subunit ot bovine soltuble guanylate cycllase. FEBS Lett 239: 29.34 .

KOOL M, DE HAAS N, SCHEFFER GI, SCHEPFR RJ, VAN FI, MK JUJJN JA, BAAS T", BORGT P. (1997) Analysis of expression of CMOAT (MRP2), MRPS, MRP4, and MRP5, homologues of the multidrug resistance-associated protein gene (MRPI), in human cance: cell lines. Cancer Res 57: $3537-3547$.

KOTERA, YANAKA W, WUSHIGE IK, IMAI Y, AKATSUKA H, ISHIZUEA T, KAWASHIMA K, OMOR』 K (1997) Expression of wat cQMP binding CGMP-specific phosphodiesterase mRNA in Purlkinje cell layers during postatal newronal development. Eur Bochem 249 : 434442.

KOTWRA \%, FUJSHTGE KK, YUASA K, OMORI K. (1999a) Chanacterization and phosphorylation of PDE10A2, a novel alternative splice variant of human phosphodiesterase that hydrolyzes cAMP and CGMP. Biochem Biophys Res Commun 261: 551-657.

KOTERA \#U, FUHIGE K, IMAI $\mathrm{X}$, KAWA E, MICHIBATA H, AKATSUKA H, YANAKA N, OMORI K. (1999b) Genomic origin and transcriptional regulation of two variants of cGMP. binding cCMP-specific phosphodiesterases Eur of Brochem 262: 866-873.

KOTFRA I, GRIMES K, CORBIN JD, FRANCIS SH (2003) Cyclic GMP-dependent protein kinase protects cGMP from thydrolysis by phosphodiesterase-5. Biochen of $372: 419-426$.

KUPHE, A, ECKEL H, STIE CG, UCKERT S, FORSSMANN WG, JONAS U, MAGERT HJ. (1999) Molecular biological characterization of phosphodiesterase 3A from human corpus cavernosum. Chem Brol Interact 119.120: $593-598$.

LI N, FLORIO SK, PEHTENTL MU, RAO PN, BEAVO JA, BAEHR W. (1998) Characterization of human and mouse rod cCMP phosphodiesterase delta subunit (PDE6D) and chromosomal localization of the human gene. Genonks $49: 76.82$.

LIN CS, LAU A, TU R, LUE TF. (2000) Fxpression of three isoforms of cGMP-binding cGMP. specific phosphodiesterase (PDEs) in human perile cavennosum. Biochen Biophys Res Commun 268: 628-655.

HWN GS, CHOW S, IJAU A. "UU R. LUE TR. (2002) Human PDESA gene encodes thee PDE5 isoforms from two alternate promoters. Int of Impot Res 14: 15-24.

LINCOLN TM. (1989) Gyclo GMP and mechanimm of vasodilation. Pharmacol Ther 41: 479. 502 .

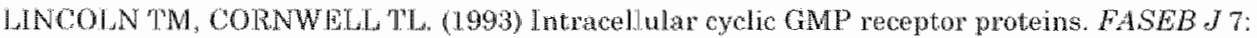
$328 \cdot 338$

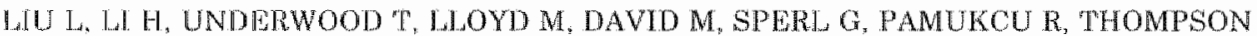
W. $(200 L$ ) Golic GMI-fependent protein kinase actuation and induction by axisulind and CP36l in colon tumor colls. J Pharmacol Enp Ther 299:583w592.

LOHMANN SM, WALTHR U, MLLLER PE, GREENGARD P, DE CAMLLL P. (1981) Immunohistochamical localization of cyclic GMPdependent protein kinase in mammalian buain. Prot Noll Acad ScI U 5 A 78:65:657.

LOHMANM SM, VAAMITRGER AB, SMOLENSKI A, WALIER U, DE JONGE HR. (1997) Distinct and specinc functions of oGNLP-cependent protein kinases. Thends Biochem Sci 22 . $307-312$

LOUGHNEY K, MARTINS TJ, HARRIS FA, SAJHU K, HCKS JB, SONNENBURG WK, BEAVO oA, FERCLSON K (1996) Isolation and characterization of cDNAs cowresponding 
to two human calcium, calmodulin-regulated, $3^{4}, 5^{8}$-cyclic nucleotide phosphodiesterases. $f$ Biol Chem 271: 796-806.

LOUGHNEY $\mathbb{K}$, HILL TR, FLORIO VA, UHER L, ROSMAN GI, WOLDA SL, JONES BA, HOWARD ML, MCALLISTER-LUCAS LM, SONNENBURG WK, FRANCIS SH, CORBIN JD, BEAVO JA, FERGUSON K. (1998) Isolation and characterization of cDNAs encoding PDE5A, a human cGMP-binding, cGMP-specific $3^{\prime}, 5^{\circ}$ cyclic nucleotide phosphodiesterase. Gene 216: 139-147.

LOUGHNEX K, SNYDER PB, UHER L, ROSMAN Gd, FERGUSON K. FLORIO VA. (1999) Isolation and characterization of PDE10A, a novel human $3^{\circ}$, $5^{\circ}$-cyche nucleotide phosphodiesterase. Gene 234: 109-117.

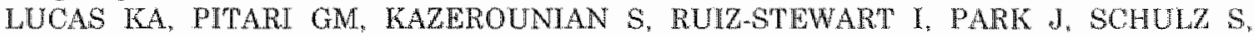
CHEPENTK IRP. WALDMAN SA. (2000) Guanylyl cyclases and signaling by cyclic GMP. Pharmacol Rev 52: $375-414$

LYNCH G. (2002) Memory enhancement: the search for mechanism-based drugs. Nat Neurosci 5 Suppl: $7035-1038$.

MACFARLAND RT, ZELUS BD, BEAVO JA. (1991) High concentrations of a CCMP-stimulated phosphodiesterase mediate ANP-induced decreases in cAMP and steroidogenesis in adrenal glomerulosa cells. J Biol Chem 266: 136-142.

MANGANTELLO VC, MURATA 'T, TAIRA M, BELFRAGE P, DEGERMAN E (1995) Diversity in cyclic nucleotide phosphodiesterase isoenzyme families, Arch Biochem Biophys 322: 1-13.

MARTINEZ SE, WU AY, GLAVAS NA, TANG XB, TURLEY S, HOL WG, BEAVO JA. (2002) The wo GAF domains in phosphodiesterase $2 \mathrm{~A}$ have distinct roles in dimerization and in cGMP binding. Proc Natl Acad Sci US A 99: 13260-18265.

MAYFORD M, KANDEL ER. (1999) Genetic approaches to memory storage. Tiends Gene: 15: $463-470$.

MCALEER MA, BREEN MA, WHTTE NL, MATTHEWS N. (1999) pABC11. (also known as MOAT-C and MRP5), a member of the ABC family of proteins, has anion transporter activity but does not confer multidrug resistance when overexpressed in human embryonic kidney 293 cells. I Biol Chem 274: 23541-23548.

MCALLISTER-LUCAS LM, SONNENBURG WK, KADLECEK A, SEGER D, TRONG HL, COLBRAN JL, THOMAS MK, WALSH KA, FRANCIS SH, CORBIN JD, ET AL. (1993) The structure of a bovine lung cGMP-binding, cGMP-specific phosphodiesterase deduced from a cDNA clone. J Biol Chem 268: 22863-22873.

MEACCI $\mathbb{E}$, TAIRA M, MOOS $M$, JR, SMITH CJ, MOVSESIAN MA, DEGERMAN $E$, BEIFRAGE P, MANGANIELLO V. (1992) Molecullar cloning and expression of human myocardial cGMP-inhibited cAMP phosphodiesterase. Proc Nall Acad Sci U S A 89: 3721 . 3725.

MICHAELI T, BLOOM TU, MARTINS T, LOUGHNEY K, FERGUSON $K$, RIGGS $M$, RODGERS L, BEAVO JA. WIGLER M. (1993) Isolation and characterization of a previously undetected human CAMP phosphodiesterase by complementation of CAMP phasphodiesterase deficient. Saccharomyces cerevisine. I Biol Chem 268: 12925-12982.

MICHIBATA H, YANAKA N. KANOH Y, OKUMURA K, OMORI K. (2001) Human Ca2+/cal modulin-dependent phosphodiesterase PDELA: novel splice variants, their specific expression, genomic organization, and chromosomal localixation. Biochm Biophys Acta $1517: 278-287$.

MIRO X, PEREZ-TORRES S, PALAGIOS JM, PUIGDOMENECH P, MENGOD G. (2001) Differential distribution of CAMP-specific phosphodjesterase $7 \mathrm{~A}$ mRA in rat brain and peripheral organs. Synapse 40: 201-214.

MONACO L, VICINI E, CONTI M. (1994) Structure of two rat genes coding for aloselly related rolipram-sensitive cAMP phosphodiesterases. Multiple mRNA variants originate from alternative splicing and multiple start sites. of Biol Chen 269:347-357.

MONCADA S, HGGS EA. (1995) Molecular mechanisms and therapentic stratiegies related to nitric oxide. FASEB J 9: 1319-1330.

MONFORT P. MUNOZ MD, KOSENKO E, FELIPO V. (2002) Long-Lerm potentiation in hippocampus inwolves sequential activation of soluble guanylate cyclase, coMP dependent. protein kinase, and cGMP-degrading phosphodiesterase. J Neurosci 22: $10116-10122$.

MULLER U. (1996) Inhibition of nitric oxide synthase impairs a distinct form of long-term memory in the honeybee, Apis mellifera. Neuron 16: 541.549. 
MURASTIMA S, TANAKA T, HOCKMAN S, MANGANELLO V. (1990) Characterization of partidulate cyclic nucleotide phosphodiesterases from bovine brain: purification of a distinct cOMP-glimulated isomzyme. Biochem istry $29 \% 5285-5292$.

MYSLIVECEK J. HASSMANNOVA J, BARCAL I, SAFANDA J, ZALUD V. (1996) Inhibitory leaning and memory in newbor ats influenced by nitric oxide. Neuroscience $71: 299 \times 312$.

NAKAMZOT, KAWAMATA J, YOSHIDA K, KAWAI Y KANKI R, SAWADA H KIHARA T, YAMASHTTA H, SHIBASAKI H, AFAIKE A. SHIMOHAMA S. (2003) Phosphodiesterase inthibitors are neuroprotective to cultured spinal motor newrons. Fe Newosct Res 71 : 485 . 495.

NAKAMURA T, GOLD GH. (1987) A cyclic nucleotide-gated conductance in olfactory receptor cilia. Nalury $325: 442-444$.

NAKANE M, SAHEKI S, KUNO T, ISHU K, MURAD F. (1988) Mollecular cloning of a cDNA coding lot 70 kilodalton subumit of soluble guanylate cyclase from rat lung. Biochem. Blophys Res Commun 157: 1139.1147.

NAKANE M, ARAI K, SAHEKI S, KUWO T, BUECHLER W. MURAD F. (1990) Molecular cloning and expression of cDNAs coding for soluble guanylate cyclase from rat lung. I Biol Chen 265: 1.6841-16845.

NEMOZ G, ZHANG $\mathbb{R}_{*}$ SETTE $\mathbb{C}$, CONTT M. (1996) Identilication of cyclic AMPphosphodtosterase variants from the PDEAD gene expressed in human peripheral mononumlear cells. FEBS Let 384: 97. 102.

OBRRNOJTE R, RATZLIFF J, BAECKER PA, DANIELS DV, ZUPPAN P, IARNAGN K, SHELTON ER (1997) Multiple iplice variants of phosphodiesterase PDEAC cloned from human lung and testis. Biochin. Biophys Acta 1353: $287-297$.

OMELL TJ, HAWKINS RD, KANDRL ER, ARANCIO O. (1991) Tests of the roles of two diffusible substances in long-term potentiation: evidence for nitric axide as a possible early retrograde messengev. Proc Nat Acad Sci US A 88: 11285-11289.

OWTMS RA, CATTERALL, C, BATTY D, JAPPY J, RUSSELL A, SMITH B, OCONNELJ J, PERRY MU. (1997) Human phosphodiestenase 4A: characterization of full-length and truncated enzymes expressed in COS cells. Biochem $\int 326: 53-60$.

PERSSON CG. (1985) On the medical history of xanthines and other remedies for asthma: a tribute to HH Salter. Thorax 40:881-886.

PFEIFER A, RUTH P. DOSTMANN W, SAUSBIER M, KLATT P, HOFMANN F. (1999) Structure and function of cGMPdependent protein kinases. Rev Physiol Bhowem Pharmacol 135: 105-1.49.

PITSTKAS N, RIGAMONTI AE, CELLA SG, MULLER EE (2002a) Molsidomine attenuates N(omega)-nitro-L-argininemethylesterinduced deficits in a memory task in the wat. Eur $J$ Pharmacol 452: $83-86$

PTTSIKAS N, RIGAMONTI AE, CELIA SG, MULLER EE. (2002b) Effects of the nitric oxide donor molsidomine on different memory components as assessed in the object-recognition task in the rat. Psychophamacology (Berl) 162: 239-245.

POLLEUX F, MORROW " ${ }^{2}$, GHOSH A. (2000) Semaphorin 3 A is a chemoatiractant for contical apion dendrites. Nafure $104: 567.573$.

POLLI JW, KINCAID RL. (1992) Molecular cloning of DNA encoding a calmodulim-dependent phosphodiesterase enriched in striatum. Proc Natl Acad Sow U S 89: 11079 11083.

POLLL .JW. KINCAID Rl. (1994) Expression of a calmodulin-dependent phosphodiesterase isofom (PDELB1) correlates with brain regions having extensive dopaminergic

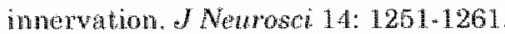

PRAST H, PHIIPPU A. (2001) Nitric oxide as modulator of neuronal function. Prog Neurobiol 64: 1.68 .

PRENDFRGAST MA, TERRY AV, JR., JACKSON WE, BUCCAFUSCO JJ. (1997) Nitric oxide symthase inbibition impains delayed recall in mature monkeys. Phannacol Biochem Behav $56: 81-8:$

PRICKAERTS J, STEINBUSCH HWM, SMITS IIM, DE VENTE I. (1997) Passible role of nitrin oxide-cyclic GMP pathwy in object recognition memory: effects of 7 -nitroindazole and zaprimast. Eur J Phormacol $337: 125-136$.

PRICKAERTS J, DE VENTE J, HONGG W, STEINBUSCH HWM, BLOKLAND A. (2002) cGMP, but not CAMP, in rat hippocampus is involved in early stages of object memory

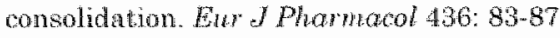


PYNE NJ, ARSHAVSKY V, LOCHHEAD A. (1996) CGMP signal temmation. Biochom Soc Trans 24: 1019-1022.

REINHARDT RR, BONDY CA. (1996) Differential cellular pattem of gene expression for two distinct cGMP.inhibited cyclic nucleotide phosphodiesterases in developing and mature rat brain. Neuroscience 72 . $567-578$

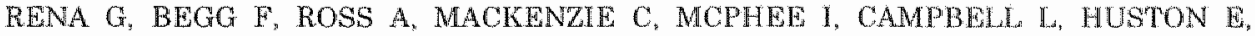
SULLIVAN M. HOUSLAY MD. (2001) Molecular cloning, genomic pusitioning, promoter identification, and characterization of the novel cyclic amp-specific plosplaodiesterase PDEAA10. Mol Pharmacol 59: 996-1011.

RENTERO C, MONFORT A, PUIGDOMENECH P. (2003) Identification and distribution of different $m \mathbb{R} N A$ variants produced by differential splicing in the human phosphodiesterase 9A gene. Biochem Biophys Res Commun 301: 686-692.

REPASKE DR, CORBIN JG, CONTI M, GOY MF. (1993) A cyclic GMP-stimulated cyclic nucleotide phosphodiesterase gene is highly expressed in the limbic system of the rat brain. Neuroscience 56: $673-686$.

ROBERTSON JD, BONAVENTURA J, KOHM AP. (1994) Nitric oxide is required for tactile learning in Octopus vulgaris. Proc $R$ Soc Lond B Biol Sci 256: 269-273.

ROBERTSON JD, BONAVENTURA J, KOHM A. (1995) Nitric oxide synthase inhibition blocks octopus touch learning without producing sensory or motor dysfunction. Proc $R$ Soc Lond $B$ Biol Sci 261: 167-172.

ROSE SP. (2002) Science And Society: 'Smart Drugs': do they work? Are they ethical? Will they be legal? Nat Rev Neurosci $3: 975-979$.

ROSMAN GJ, MARTINS TJ, SONNENBURG WK, BEAVO JA, FERGUSON K, LOUGHNEY K. (1997) Isolation and characterization of human cDNAs encoding a cGMP-stimulated 3",5'-cyclic nucleotide phosphodiesterase. Gene 191: 89-95.

ROUSSINOV KS, YONKOV DI. (1976) Cholinergic mechanisms in the learning and memory facilitating effect of caffeine. Acta Physiol Pharmacol Bulg 2: 61-68.

RYBALKIN SD, BEAVO JA. (1996) Multiplicity within cyclic nucleotide phosphodiesterases. Biochem Sac Trans 24: 1005-1009.

RYBALKIN SD, RYBALKINA IG, FETL, R, HOFMANN [F, BEAVO JA. (2002) Regulation of cGMP-specific phosphodiesterase (PDE5) phosphorylation in smooth muscle cells. I Biol Chem 277: 3310-3317.

SALDOU $\mathbb{N}$, BAECKER PA, JI B, YUAN $Z$, OBERNOLTE R, RATZILIFF d, OSTSN $\mathbb{E}$, JARNAGIN K, SHELTON ER. (1998a) P'urification and physical characterization of cloned human cAMP phosphodiesterases PDE-4D and -4C. Cell Biochem Biophys 28: 187-217.

SALDOU N, OBERNOLTE R, HUBER A. BAECKER PA, WILHELM R, ALVAREZ R, LI B, XIA L, CALLAN O, SU C, JARNAGIN TK, SHIBLTON ER. (1998b) Comparison of recombinant human PDE4 isoforms: interaction with substrate and inhibitors. Cell signal 10: $427-440$.

SAMAMA B, BOEHM N. (1999) Inhibition of nitric oxide synthase impairs early olfactory associative learning in newborn rats. Newrobiol Locarn Men: 71: 219-231.

SANDBERG M, NATARAJAN V, RONANDER I, KAJDERON D, WAJTER U, LOHMANN SM, JAHNSEN $T$. (1989) Molecular cloning and predicted full-length a mino acid sequence of the type I beta isozyme of CGMP dependent protein kinase from human placenta. Tissue distribution and developmental changes in rat. FEBS Le11 255: 321-329.

SASAKI T, KOTERA I, YUASA K, OMORI $K$. (2000) Identification of human PDE7B, a CAMP. specific phosphodiesterase. Blochem Biophys Res Commun 271: $575-583$.

SASAKI T. KOTERA J, OMORI KK (2002) Novel alternative splice variants of rat phosphodiesterase $7 \mathrm{~B}$ showing unique tissue-specific expression and phospluorylation. Biochem of 361: 211.220.

SCHACHTNER J, HOMBERG U, TRUMAN JW. (1998) Regulation of cyclic GMP elevation in the developing antennal lobe of the Sphinx moth, Manduca sexta. of Neurobiol 41 : 359975 .

SCHMIDT HH, GAGNE GD, NAKANE M, POLLOCK JS, MLLERR MP, MURAD F. (1992) Mapping of neural nitric oxide synthase in the rat suggests frequent co-localization with NADPH diaphorase but not with soluble guanylyl cyclase, and novel paraneural functions for nitrinergic signal transduction. OH Histochem Cytochen 40: 1439-1456.

SCHUMAN EM, MADISON DV. (1991) A requirement for the intercellular messenger nitric: oxide in long-term potentiation. Science 254: 1503-1506. 
SCOVILLE WA, MULER B. (1957) Lose of recent memory after bilaterall hippocampal lesions. ff Nurol Newrosurg Pychatry 20 : $11-21$

SHITSUIFAW K, AWDEFSEN CB, RCHARD F, HORNER AK, WIERSMA A, VAN DUTN M. CONTI M. (2001) Cloning and characterization of the cyclic guanosine monophosphate. inhibited phosphodiesterase PDESA expressed in monse oocyte. Biol Reprad 65: 188-196.

STMPSON PJ, MLLER I, MOON C, HALON AL, LIEBL DJ, RONNETT GV, (2002) Atrial natruretic peptide ype $C$ induces a cell-cycle switch from prolliferation to differentiation in brain-derived neurotrophic factor or nerve growth factor-primed olfactory receptor neunons. I Neuroget 22: $5536.555 \mathrm{~L}$

SMOLENSKI A, BURKHARDT AM, WIGENTHALER M, BUTI E, GAMBARYAN S, LOHMANN SM, WALTER U (1998) Functional analysis of cGMP-dependent protein kingess I and II as mediators of WO/GMP effects. Nawny Schmiedebergs Arch Pharmacol $358: 134.139$

SODERLING SH, BAYUCA SJ, BEAVO JA. (1998a Identification and charaterization of a nowel family of cyclic nucleotide phosphodiestarases. I Biol Chem 273:15553-15558.

SODERUING SH, BAYUGA St, BEAVO JA. (1998b) Cloning and characterization of a cAMP. sperifur eyclic nucleotide phosphodiesterase. Proc Nat Acad Sa U S A 95: 8991-8996.

SODERUING SH, BAYUGA SJ, BEAVO JA. (1999) Isolation and characterization of a dual.

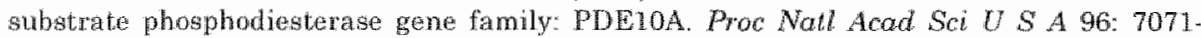
7076.

SODERLING SH, BEAVO JA. (2000) Regulation of cAMP and cGMP signaling: new phosphodiesterases and new functions. Curr Opin Cell Biol 12: 174:-179.

SON H, LU YF, ZHUO M, ARANCIO O, KANDEL ER, FAWKTNS RD. (1998) The specific role of cGMP in hippocampal LTP. Leam Mem 5: 231.245.

SONNENBURG WK, MULLANEY PJ, BRAVO JA. (1991) Molecular cloning of a cyclic GMP. stimulated cyclic nucleotide phosphodiesterase cDNA. Identification and distribution of isoryme variants. of Bul Chem 266:17655-17661.

SONNENBURG WK, SECER D. BEAVO JA. (1993) Molecular cloning of a cDNA encoding the "61-kDa" calmodulin-stimulated cyclic nucleotide phosphodiesterase. Tissue-speciffo expression of structurally related isoforms. of Biol Chem $268: 645-652$.

SONNENBURG WK, SEGER D, KWAK KS, HUANG J, CHARBONNEAU H, BEAVO JA. (1995) Identifintion of inhibitory and calmodulin-binding domains of the PDE 1 Al and PDELA2 calmodulin-stimulated cyclic nucleotide phosphodiesterases. I Biol Chem 270: 30989.31000

SOUTHAM E, GARTHWAITE J. (1993) The nitwic oxide-cyclic GMP signaling pathway in rat brain. Neuropharmacology $32: 1267-1277$.

STACEX P. RULTEN S, DAPLING A. PHILLIPS SC (1998) Molecular cloning and expression of human oCMPabing cGMPMpecitic phosphodiesterase (PDE5). Biochem Biophys Res Commonst $247: 249.254$.

STASCH JP, BECKRR EM, ALONSO-ALIAA APELER H, DEMBOWSRY K, FEURER A GERZER R, MINUTH T, PERZBORN E, PLEISS U, SCHRODTR H, SCHROEDFR W, S'AHL E, STEINKE W, STRAUB A, SCHRAMM M. (2001) NO-independent regulatory site on soluble gurnylate cyclese. Noture 410:212-215.

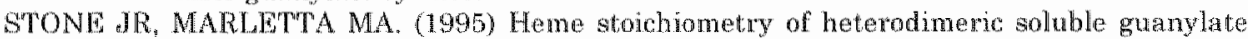
cyclase Biochemistry $34: 14668-14674$.

STURTON G, FTTZGERALD M. (2002) Phosphodiesterase 4 inhibitors for the treatment of COPD. Chost 121: 192S.1965.

SUNDKVIST HA EGER R, SAGER G. (2002) Pharmacological characterization of the ATPdependent low $\mathrm{K}(\mathrm{m})$ gunosine 3,5 -cyclic monophosphate (cGMP) transporter in human erythocytes. Biochem Phomacol 63: $945-949$

SUTHERLAND EW, RALL "TW. (1958) Fractionation and characterization of ayclic adenine ribonucleotide formed by tissue particles. J Biol Chem 232: 1077-1091.

SWTNNEN JV, JOSEPH DR, CONTY M. (1989) Molecular cloning of rat homologues of the Drosophila melanogaster dunce cANP phosphodiesterase: evidence for a family of genes. Proc Not Acad Sei U S A 86:5325-5329.

TAIRA M. HOCKMAN SC, CALVO JC, BELFRAGE P, MANGANIELLO VC (1993) Molecular coning of the at adpocyte hom mone-sensitive cyclic GMP inhibited cyclic nucleotide phosphodiestense of Biol Chom 268 : $18573-18579$ 
TAYLOR BL, ZHULIN IB. (1999) PAS domains: internal senswrs of oxygeri, redox potential, and light. Microbiol Mol Biol Rev 63:479-506.

TELEGDY G, KOKAVSZKY R. (1997) The role of nitric oxide in passive avoidance learning. Neuropharmacology 36: 1583-1587.

TEYKE T. (1996) Nitric oxide, but not serotonin, is involved in acquisition of food-attraction condlitioning in the snail Helix pomatia. Nerrasel Let 206: 2932 .

THOMAS MK, FRANCIS SH, CORBIN JD. (1990) Characterization of a purified bovine lung cGMP-binding cGMP phosphodiesterase. I Biol Chem 265: $14964-14970$.

THOMPSON WJ, APPLEMAN MM. (1971) Characterimation of cyclic nucleotide phosphodiesterases of rat tissues. of Biol Chem 246: $3145 \cdot 3150$.

THOMPSON WJ. (1991) Cyclic nucleotide phosphodiesterases: pharmacology, biochemistry and function. Pharmacol Ther 51: 13-33.

TRUMAN JW, DE VENTE J, BALL EE. (1996) Nitric oxide-sensitive guanylate cyclase activity is associated with the maturational phase of neturonal development in insects. Development 122: $3949-3958$.

UDOVICHENKO IP, CUNNICK J, GONZALES K, TAKEMOTO DJ. (1993) Phosphorylation of bovine rod photoreceptor cyclic GMP phosphodiesterase. Biochen of 295: 49-55.

UHLER MD. (1993) Cloning and expression of a novel cyclic GMP-dependent protein kinase from mouse brain. J Biol Chem 268: 13586. 13591.

VAN WAGENEN S, REHDER V. (1999) Regulation of neuronal growth cone filopodia by nitaic oxide el Neurobiol 39: 168-185.

VILLIGER JW, DUNN A.. (1981) Phosphodiesterase inhibitors facilitate memory for passive awoidance conditioning. Behaw Neural Biol 31: 354-359.

VLES JS, DE LOUW AJ, STEINBUSCH H, MARKERINTV.VAN ITTERSUM M, STEINBUSCH HW, BLANCO CE, AXER H, TROOST J, DE VENTE J. (2000) Localization and age-related changes of nitric oxicle- and ANP-mediated cychic-GMP synthesis in rat cervical spinal cord: an immunocytochemical study. Brais Res 857: 219.234.

WALTER U. (1989) Physiological role of cGMP and GMP dependent protein kinase in the cardiovascular system. Rev Physiol Biachem Pharmacol 113: 41-88.

WANG W, ACLAND GM AGUIRRE GD, RAY K. (1996) Cloning and characterization of the CDNA and gene encoding the gamma-subunt of CGMP-phosphodiesterase in canine retinal rod photoreceptor cells. Gene 181: 1-5.

WANG P. MYERS JG, WU P, CHEEWATRAKOOLPONG B, EGAN RW, BMLAH MM. (1997) Expression, purification, and characterization of humar cAMP-specific phosphodiesterase (PDE4) subtypes A, B, C, and D. Biochem Biophys Res Commun 234: 320-324.

WANG P, WU P, EGAN RW, BILLAH MM. (2001) Human phosphodiesterase 8A splice variants: cloning, gene organization, and tissue distribution. Gene 280: 183-194.

WEDEL BJ, GARBERS DL. (2001) The guanylyl cychase family at Y2K. Amnu Rev Physiol 63: $215 \cdot 233$

WEI JY, ROY DS, LECONTE L, BARNSTABLE C. (1998) Molecular and pharmacological analysis of cyclic nucleotidexgated chamnel function in the central nerwous system. Prog Neurobiol 56: 37-64.

WERNET W, FLOCKERZI V, HOFMANN F. (1989) The CDNA of the two isoform of bovine cGMP - dependent protein kinase. FEBS Lett 251: 191-196.

WIEMER G, HELLWICH U, WELLSTEIN A, DIFTZ J, HELLWICH M, PALM D. (1982) Energy-dependent extrusion of cyclic $3,5^{\prime \prime}$-adenosine-monophosphate. A drug-sensitive regulatory mechanism for the intracellular" nucleotide concentration in rat erythrocytes. Naunyn Schmiedebergs Arch Pharmacol 321: 239-246.

YAMADA K, NODA Y, NAKAYAMA S, KOMORT $Y$, SUGIHARA H, HASEGAWA ' $\mathrm{K}$, NABESHIMA T. (1995) Role of nitric oxide in leaming and memory and in monomine metabolism in the rat brain. Br J Pharmacol 115: 852.858 .

YAN C, BENTLEY JK, SONNENBURG WK, BEAVO JA (1994) Differential expression of the $61 \mathrm{kDa}$ and $63 \mathrm{kDa}$ calmodulin dependent phosphodiesterases in the mouse brain. $f$ Neurosci 14: $973-984$.

YAN C, ZHAO AZ, BENTLEY JK, BEAVO NA (1996) The calmodulindependent phosphodiesterase gene $\mathrm{PDE}] \mathrm{C}$ encodes several functionally different splice variants in at tissue-specific manner, of Biol Chem 271: 25699.25706. 
YANG Q, PASKIND M, BOLGER O, THOMPSON WJ, REPASKE DR, CUTIER LS, EPSTEIN PM. (1994) A nowel cyelic GMP stimulated phosphodiesterase from rat brain. Biochem Biophys Res Commun 205: 1850-1858.

YU J. WOLDA SL, FRAZIER AL, FLORIO VA, MARTINS TJ, SNYDER PB, HARRIS EA, MCCAW KN, FARRELL CA, STELNER B, BENTLEY JK, BEAVO JA, FERGUSON $K$, GELINAS R. (1997) ldentification and characterisation of a human calmodulin-stimulated phosphodiegtertse PDE1B1. Cell Signal 9: 519-529.

YUASA K, KOTERA J, FUISHIGE KF, MCHIBATA H, SASAKI T, OMORI K. (2000) Isolation and characterization of two novel phosphodiesterase PDEL1A variants showing unique structure and tissue-specific expression. IJ Biol Chem 275: 31469 31479.

YUASA $K$, OHGARU T. ASAHINA M, OMORI $K$. (2001) Identification of rat cyclic nucleotide phosphodiesterase $11 \mathrm{~A}$ (PDE11A): comparison of rat and human PDE1IA splicing variants. Eu" Biocheri 268: 4440.4448.

ZHANG Y, HAN H, ELMQUIST WF, MILLER DW. (2000) Expresion of various multidrug resistance-associated protein (MRP) homologues in brain microvessel endothelial cells. Brain Res 876: 1.48-153.

ZHANG R, WANG Y, ZHANG L, ZHANG Z, TSANG W, LU M, CHOPP M. (2002) Sildenafil (Viagra) induces neurogenesis and promotes functional recovery after stroke in rats. Stroke 33: $2675-2680$.

ZHUO M, HU Y, SCHULTZ C, KANDEL ER, HAWKINS RD. (1994) Role of guanylyl cyclase and cGMP-dependent protein kinase in long-term potentiation. Nature 368: 635-639.

ZOU LB, YAMADA $K$, TANAKA T, KAMEYAMA T, NABESHIMA T. (1998) Nitric oxide synthase inhibitors impair reference memory formation in a radial arm maze task in rats. Neurophamacology 37: $323-330$.

ZUFALL F, FIRESTEIN S, SHEPHERD GM. (1994) Cychic nucleotide-gated ion channels and sensory transduction in olfactory receptor neurons. Annu Rev Biophys Biomol Struct 23: 577.607 .

ZUFALL F, SHEPHERD GM, BARNSTABLE CJ. (1997) Cyclic nucleotide gated channels as regulators of CNS development and plasticity. Curr Opin Neurobiol 7: 404-412. 


\section{Effects of two selective phosphodiesterase}

type 5 inhibitors, sildenafil and vardenafil, on object recognition memory and hippocampal cGMP levels in the rat

Jos Prickaerts, ${ }^{1}$ Wilma C.G. van Staveren, ${ }^{1}$ Ayhan \$ik, ${ }^{\prime}$ Marjanne Markerink-van Ittersum, ${ }^{1}$ Ulrich Niewöhner, ${ }^{2}$ Franz-Josef van der Staay, Arjan Blokland ${ }^{3}$ and Jan de Vente'

"Dept. of Psychiatry and Neuropsychology, Diwision Cellular Nenrosicience, Maastricht University, European Graduate School of Neuroscience (EURON), P.O. Box 616, 6200 MD Maastricht, The Netherlands; 2 Phama Research, BAYER AG, Aprather weg 18A D-42096 Wuppertal, Germany; Dept. of Psychology, Maastricht University, P.O. Box 616, 6200 MD Maastricht, The Netherlands

Neuroscience $113(2): 351-361$ (2002)

\section{Abstract}

The present study investigated the effects of two cyclic GMP-specific phosphodiesterase enzyme type 5 inhibitors, sildenafil and vardenafil, on the memory performance in the object recognition task. Both compounds were given orally (p.o., 1,3 and $10 \mathrm{mg} / \mathrm{kg}$ silldenafil; $0.1,0.3,1$ and $3 \mathrm{mg} / \mathrm{kg}$ vardenafil) immediately after the exposure to two identical objects. The memory for the objects was tested $24 \mathrm{~h}$ later. Vehicle treated rats spent equal times exploring a new and the familiar object demonstrating that they did not remember the familiar one. However, sildenafil improved the object discrimination performance of the rats with a high discrimination performance at a dose of $3 \mathrm{mg} / \mathrm{kg}$. Rats treated with vardenalil also showed an improved object discrimination performance. Compared with sildenafil, vardenafil appeared to be even more potent in this respect since it produced already a high discrimination performance at a dose of $0.3 \mathrm{mg} / \mathrm{kg}$. The effects of both compounds on CGMP and cAMP accumulation were studied in rat hippocampus slices incubated in vitro. cGMP levels were increased after incubation with the highest concentration of $100 \mu \mathrm{M}$ vardenafil (togethex with $0.1 \mathrm{mM}$ sodium nitroprusside), although no changes in cGMP levels were detected after incubation with different concentrations of sildenafil. Both compounds had no effect on cAMP levels. Additional cGMP. immunocytochemistry showed that incubation with vardenafil (in the presence of sodium nitroprusside) resulted in a concentration-dependent staining of cGMP. Staining was predominantly found in neuronal fibers in the hippocampal CA2/CA3 region. It was already detected at a concentration of $0.1 \mu \mathrm{M}$ vardenafil. Also positive fibers were detected after incubation with sildenafil but yet at a higher concentration of $10 \mu \mathrm{M}$. 
Taken together, these results suggest that inhibition of phosphodiesterase enzyme type 5 improves object recognition memory. This effect might be explained with increased levels of central cGMP.

\section{Introduction}

Previously, we have shown that zaprinast, an inhibitor of the phosphodiesterase enzyme type 5 (PDE5) that selectively breaks down cyclic GMP (cGMP), improved the memory performance of rats in the object recognition task (Prickaerts et al., 1997). This finding indicates that the cGMP signal transduction pathway is likely to be involved in this type of memory task. The object recognition task measures in a test trial whether rats remembered an object that has been presented in one learning trial. Since zaprinast was given immediately after the learning trial we concluded that it improved the early consolidation of object information into memory (Prickaerts et al., 1997).

Recently, it has been found that the PDE5 inhibitor sildenafil improved the memory performance of mice in the passive avoidance task (Baratti and Boccia, 1999). This task has a one-trial learning paradigm similar to the object recognition task. However, an aversive stimullus, i.e. an electrical shock, has to be remembered. In the same passive avoidance task it has been found that injections of the cGMP-analogue 8-bromo-cGMP into the hippocampus of rats improved their memory performance (Bernabeu et al., 1996). Recently, we have found that intrahippocampal injections of 8-bromocGMP also improved the memory performance of rats in the object recognition task when injected immediately after the learning trial (Prickaerts et al., 2002). Similarly, in the passive avoidance task 8-bromocGMP and sildenafil were only effective when given immediately after the shock trial. Thus, there are strong arguments to advocate a role of cGMP in the early consolidation of both electrical shock and object information into memory of rodents.

It has been demonstrated using cGMP-immunocytochemistry that incubation of hippocampal slices with zaprinast increased the nitric oxidemediated cGMP response throughout the hippocampus (De Vente et al., 1996; Van Staveren et al., 2001). This finding supports the notion that the memory-improving effect of PDEs inhibition may be mediated via cGMP in the hippocampus. The aim of the present study was to further investigate the cognition-enhancing properties of PDE5 inhibition using the object recognition task. Rats were treated with two selective PDE5 inhibitors immediately after the first trial. The compounds used were sildenafil and the novel PDE5 inhibitor vardenafil (Kim et al., 2001). To study the possibility of increasing cyclic nucleotide levels in the brain after treatment with these compounds, a radioimmunoassay was used to measure the effects on cGMP and cyclic AMP (cAMP) accumulation in hippocampal slices after in vitro incubation with sildenafil or vardenafil. In addition, the localization 
of the effect of these PDE inhibitors on the accumulation of CGMP in hippocampal slices was studied using cGMP-immunocytochemistry.

\section{Materials and Methods}

\section{Animals}

All experimental procedures were approved by the local ethical committee of the Maastricht University for animal experiments according to governmental guidelines. Four-month-old male Wistar rats (Charles River, The Netherlands) were used. Thirty-six animals were tested in the object recognition task and eleven animals were used for radioimmunoassay and immunocytochemistry. The animals were housed individually in standard type 3 Makrolon cages on sawdust bedding in an air-conditioned room (about $20^{\circ} \mathrm{C}$ ). They were kept under a reversed $12 / 12$-hour light/dark cycle (lights on from 18.00 to $6.00 \mathrm{~h}$ ) and had free access to food and water.

\section{Treatments}

Each compound was freshly suspended in $1 \%$ tylose (methyl-cellulose) on every experimental day. Doses of 1,3 and $10 \mathrm{mg} / \mathrm{kg}$ were used for sildenafil, as citrate. For vardenafil doses of $0.1,0.3,1$ and 3 were used. Administrations were always p.o. (injection volume $2 \mathrm{ml} / \mathrm{kg}$ ) immediately after the first trial. Sildenafil and vardenafil were provided by BAYER AG (Germany). The molecular weight of sildenafil and vardenafil are 666.7 and 488.6 , respectively.

Rats were not housed in the same room as where the animals were tested. A radio, which was playing softly, provided background noise in all rooms. All testing was done between 9.00 and 17.00 h. Rats were randomly assigned to two experimental groups: sildenafil, $n=12$ (tested twice); vardenafill, $\mathrm{n}=24$ (tested once).

\section{Object recognition task}

The object recognition test was performed as described elsewhere (Ennaceur and Delacour, 1988). The apparatus consisted of a circular arena, $83 \mathrm{~cm}$ in diameter. Half of the $40 \mathrm{~cm}$ high wall was made of grey polyvinyl chloride, the other half of transparent polyvinyl chloride. The light intensity (20 Ix) was equal in the different parts of the apparatus. "Two objects were placed in a symmetrical position about $10 \mathrm{~cm}$ away from the grey wall. We used four different sets of objects. The different objects were: 1) a cone consisting of a grey polyvinyl chloride base (maximal diameter $18 \mathrm{~cm}$ ) with a collar on top made of brass (total height $16 \mathrm{~cm}$ ), 2) a standard 11 transparent glass bottle (diameter $10 \mathrm{~cm}$, height $22 \mathrm{~cm}$ ) filled with sand, 3) a massive metal cube $(10.0 \times 5.0 \times 7.5 \mathrm{~cm})$ with two holes (diameter $1.9 \mathrm{~cm}$ ), and 4$)$ a massive aluminium cube with a tapering top $(13.0 \times 8.0 \times 8.0 \mathrm{~cm})$. The objects could not be displaced by a rat.

In the first week, the animals were handled daily and were adapted to the procedure in two days, i.e., they were allowed to explore the apparatus 
(without any objects) twice for 3 min each day. In the two following weeks the rats were adapted to the testing and p.o. administration procedure by a saline injection $(0.4 \mathrm{ml})$ immediately after the first trial until they showed a stable discrimination performance, i.e., a good object discrimination at a 1 -h interval. Subsequently, testing of the drugs began.

A testing session comprised two trials. The duration of each trial was 3 min. During the first trial (T1) the apparatus contained two identical objects (samples). A rat was always placed in the apparatus facing the wall in the center of the transparent front segment. After the first exploration period the rat was put back in its home cage. Subsequently, after a delay interval, the rat was put back in the apparatus for the second trial (T2), but now with two dissimilar objects, a familiar one (the sample) and a new one. The times spent exploring each object during T1 and T2 were recorded manually with a personal computer.

Exploration was defined as follows: directing the nose to the object at a distance of no more than $2 \mathrm{~cm}$ and/or touching the object with the nose. Sitting on the object was not considered as exploratory behavior. In order to avoid the presence of olfactory trails the objects were always thoroughly cleaned. Moreover, each object was available in triplicate so none of the two objects from the first trial had to be used as the familiar object in the second trial. In addition, all combinations and locations of objects were used in a balanced manner to reduce potential biases due to preferences for particular locations or objects.

Since we expected the drug treatments to improve memory performance we needed a delay interval at which no more discrimination between the objects occurs. Therefore, we selected a delay interval of $24 \mathrm{~h}$, since there is virtually no discrimination between the two objects after this interval. Each week two testing sessions were given, one session comprised Monday and Tuesday and the other one comprised Thursday and Friday. The doses of each drug were tested in random order. Each dose of sildenafil was tested twice in 12 rats and each dose of vardenafil was tested once in 24 rats.

\section{Tissue preparation}

Rats were decapitated and their brains were immediately removed. Brains were transferred to ice-cold Krebs-Ringer bicarbonate buffer (Krebs incubation buffer) of the following composition: $121.1 \mathrm{mM} \mathrm{NaCl}, 1.87 \mathrm{mM}$ $\mathrm{KCl}_{3} 1.17 \mathrm{mM} \mathrm{KH} \mathrm{PO}_{4}, 1.15 \mathrm{mM} \mathrm{MgSO}_{4} .7 \mathrm{H}_{2} \mathrm{O}_{2} 24.9 \mathrm{mM} \mathrm{NaHCO}, 2.0 \mathrm{mM}$ $\mathrm{CaCl}_{2} 2 \mathrm{H}_{2} \mathrm{O}$ and $11.0 \mathrm{mM}$ glucose, aerated with $95 \% \mathrm{O}_{2}$ and $5 \% \mathrm{CO}_{2}$.

For radioimmunoassay measurements the hippocampal area was removed and placed on a filter paper on a precooled stainless steel table. Slices (400 $\mu \mathrm{m}$ thick) were cut using a McIlwain tissue chopper in ice-cold Krebs incubation buffer. For immunocytochemistry, coronal sections (400 $\mu \mathrm{m}$ ) with the hippocampal area were cut with a Vibroslicer (Campden Instruments). Slices were equilibrated at room temperature for $15 \mathrm{~min}$ in Krebs incubation buffer. Next, the slices were incubated in multi-well tissue culture plates containing $2 \mathrm{mll}$ Krebs incubation buffer. Slices were incubated in Krebs incubation buffer at $35.5^{\circ} \mathrm{C}$, under an atmosphere of 
95\% Os and 5\% CO2 at $\mathrm{pH} 7.4$. The incubations lasted 40 min; when appropriate, the last $10 \mathrm{~min}$ in the presence of the nitric oxide donor sodium nitroprusside (SNP) (Fluka) in a concentration of $0.1 \mathrm{mM}$. Sildenafil or vardenafil were present from the start of the incubation and were added in different concentrations (final concentrations of $0.01 \mu \mathrm{M}$ to $1.00 \mu \mathrm{M}$ ) to the slices. Both compounds had to be dissolved in dimethylsulfoxide (DMSO), therefore a fimal concentration of $1 \%$ DMSO was present in all experiments. In an earlier study we had found that $1 \%$ DMSO had no effect on cGMP levels in hippocampal slices (unpublished observations).

\section{Radioimmunoassay}

Three rats were used for sildenafil and four rats for vardenafil. cGMP and CAMP levels were determined in individual hippocampal slices, incubated as described above, using a radioimmunoassay as published previously (De Vente et al., 1988). Briefly, the incubations were terminated by placing the slices into Eppendorf tubes containing 300 ul of $5 \%$ trichloroacetic acid. Subsequently, the samples were sonicated and centrifuged. The supernatant was used for the determination of the cGMP and CAMP content, measured by a radioimmunoassay according to Steiner et al. (1972). The pellet was used for the analysis of the protein content according to Lowry et al. (1951).

The effect of each concentration of both PDE inhibitors was measured in two slices per animal. In each slice, both cGMP and cAMP levels were measured in triplicate and the median was taken for each sample. In the radioimmunoassay, a level of 0.6 fmol cGMP and 5 fmol cAMP could be detected. cGMP and CAMP levels were corrected for the protein content of each slice.

\section{Immunocytochemistry}

Hippocampal slices of four rats (two per PDE inhibitor) were processed for immunocytochemistry after the incubation. Slices were fixed with ice-cold fixative solution of $4 \%$ freshly prepared depolymerised paraformaldehyde in $0.1 \mathrm{M}$ phosphate buffer $\left(\mathrm{pH} 7.4\right.$ ) for $30 \mathrm{~min}$ at $4{ }^{\circ} \mathrm{C}$. The slices were then fixed for another $90 \mathrm{~min}$ with $4 \%$ paraformaldehyde containing $10 \%$ sucrose. After washing ovemight at $4^{\circ} \mathrm{C}$ in $0.1 \mathrm{M}$ phosphate buffer (pH 7.4) containing $10 \%$ sucrose, the slices were frozen in $\mathrm{CO}_{2}$. Cryostat sections (10 um) were cut, thawed onto chrome-alumn/gelatin coated slides and processed for immunocytochemistry. Frozen sections were dried for $20 \mathrm{~min}$ at room temperature, followed by three $5 \mathrm{~min}$ washes with Tris-buffered saline (TBS). Sections were incubated overnight at $4{ }^{\circ} \mathrm{C}$ with sheep anti. formaldehyde fixed cGMP, diluted 1.4000 in TBS containing 0.3\% Triton $\mathrm{X}$ 100 (TBS-T). The specificity of this antibody has been detailed elsewhere (De Vente et all, 1998). Washing consisted of $10 \mathrm{~min}$ of TBS, followed by TBS-T and another $10 \mathrm{~min}$ of washing with TBS at room temperature. The primary antibody was visualised by the incubation of sections for $1 \mathrm{~h}$ at room temperature with the Alexa 488 donkey anti-sheep $\operatorname{TgG}(\mathbb{H}+\mathrm{L})$ conjugate (Molecular Probes), diluted 1:100 in TBS-T. After having been washed, sections were mounted and examined with an Olympus AX-70 
microscope. Pictures of the hippocampus were taken with a magnification of $20 \times$ using a CCD video camera (Paes, Zoeterwoude, The Netherlands) and visualized with the computer program analySIS 3.0 (Soft Imaging System GmbH, Germany). All pictures were taken under standardized conditions.

\section{Statistical analysis}

The basic measures in the object recognition task were the times spent by rats in exploring an object during $\mathrm{T} 1$ and $\mathrm{T} 2$ (see Table 1 ). $e 1$ and $e 2$ are measures of the total exploration time of both objects during T1 and T2 respectively. $h 1$ was considered as an index measure of global habituation of exploratory behavior from $\mathrm{T} 1$ to $\mathrm{T} 2 . d 1$ and $d 2$ were considered as index measures of discrimination between the new and the familiar objects. In fact, $d 2$ is a relative measure of discrimination which corrects $d 1$ for exploration activity ( $(2)$ ). Thus, there should be no differences in $d 2$ indices between experiments with similar treatments at similar intervals. However, this needs not to be the case for $d l$ because of possible differences in exploration activity.

Testing of each dose of sildenafil and of the vehicle alone in 12 rats comprised two sessions and the results of sessions testing the same treatment (dose/vehicle) condition were averaged. Each treatment condition of vardenafil was tested once in 24 rats. All vehicle sessions (of both drug experiments) were averaged to attain a control condition. One-sample $t$ statistics were performed in order to assess per treatment condition whether $h 1$ and the discrimination indices $d 1$ and $d 2$ differed from zero. Effects between the different doses of each drug were assessed by an analysis of variance (ANOVA). In case of a statistically reliable dose effect, comparisons between means of the different doses were analysed in more detaill using post hoc least significant difference (LSD) tests $(P<0.05)$. Location preferences were tested by comparing $a 1$ and $a 2$ for each object (paired $t$ test). One rat of the sildenafil group was excluded from the experiment because it did not show exploratory behavior in T1 (i.e. less then $10 \%$ of mean e1). Therefore, the final number of rats per group used for analysis were: sildenafil, $n=12$; vardenafil, $n=24$.

The effect on cGMP and CAMP of each concentration of a drug was measured in two hippocampal slices of an animal. These results of both slices were averaged. To test whether the different concentrations of a drug (both in the absence and presence of SNP) had an effect on cGMP and CAMP levels in the radioimmunoassay, an ANOVA was used. Concentration effects were evaluated in more detail using post hoc LSD tests $(P<0.05)$. In addition, at each concentration a $t$-test was performed to analyze whether the presence or absence of SNP had a different effect on the cGMP and cAMP levels. 
Table 1. Measures inwolved in the object recognition teat.

\begin{tabular}{ccc}
\hline Exploration & Habituation & Discrimination \\
\hline$e l=a 1+a 2$ & $h 1=e 1-e^{2}$ & $d 1=b-a$ \\
$e 2=a+b$ & $d 2=d 1 / e^{2}$ \\
\hline
\end{tabular}

el is the measure of the time spent in exploring both identical objects (al and $a 2$ ) in the first trial, and $e 2$ is the measure of the time spent in exploring both the familiar (a) and new object (b) in the second trial; $h I$ is the measure of global habituation from trial 1 to trial $2 ; d I$ and $d 2$ are the measures of discrimination between the new and familiar objects.

\section{Results}

\section{Object recognition task}

At the start of the present study, the mean body weights ( $g$ ) of the sildenafil and the vardenafil group were, respectively, $340 \pm 4$ and $345 \pm 5$ (mean \pm S.E.M.). After the last object recognition test of the vardenafil group, the rats of the two experimental groups were weighing on average $409 \pm 5$ and $414 \pm 6 \mathrm{~g}$, respectively. At none of these two time points there were any differences in body weight between the experimental groups (both $t \mathrm{~s}<0.71$, n.s.). The sildenafil group finished object recognition testing three weeks later and were weighing $449 \pm 5 \mathrm{~g}$.

Table 2. Results of treatment with sildenafil on the measures of the object recognition test.

\begin{tabular}{|c|c|c|c|c|}
\hline & Vehicle & $1 \mathrm{mg} / \mathrm{kg}$ & $3 \mathrm{mg} / \mathrm{kg}$ & $10 \mathrm{mg} / \mathrm{kg}$ \\
\hline \multicolumn{5}{|c|}{ A. Mean values ( $(\mathrm{S}$. E.M.) of total exploration time $(\mathrm{s})$ during the first (el) and second trial $(e 2$} \\
\hline el & $25.88(1.18)$ & $23.35(1.94)$ & $24.88(2.13)$ & $23.98(1.97)$ \\
\hline$e 2$ & $23.84(1.25)$ & $26.40(2.411)$ & $29.68(1.63)$ & $25.58(2.02)$ \\
\hline
\end{tabular}

B. Mean walues ( $\#$ S. E.M. ) of the global index of habituation ( $h$ ) from the first to the second trial
hl
$2.05(1.66)$
$-3.04(2.34)$
$-4.80(1.23)^{* \text { * }}$
$-1.60(1.48)$

C. Mean values ( \pm S.E.M) of the index of discrimination (dl) between the new and familiar objects

$\begin{array}{lllll}d 1 & -0.36(1.07) & 3.53(1.43)^{*} & 9.62(1.49)^{\text {*.* }} & 6.16(1.15)^{* * k} \\ d^{*} & -0.03(0.06) & 0.14(0.05)^{*} & 0.33(0.05)^{* *} & 0.22(0.03)^{* * *}\end{array}$

Rats $(n=11)$ received a p.o. injection of sildenafil at a dose of 1.3 or $10 \mathrm{mg} / \mathrm{kg}$ after the first. trial. For each treatment the averaged data of two sessions are presented. In addition, the vehicle ( $1 \%$ tylose) session is the averaged data of all vehicles sessions, i,e. the vardenafil experiment included. The delay interval between the first and second trial was $24 \mathrm{~h}$, $h$ and $d$ measures different from zero are depicted with asterisks (one-sample $t$-test, * $P<0.05$; ** $P<$ 0.01 ). 
Table 2 summarizes the results of the sildenafil treatments. When comparing the exploration time according to the location of the objects in the apparatus, no location preference was found in any of the treatment sessions (data not shown). No differences were found between the different doses in the total level of exploration in T1 $(e 1 ; F(3,67)=0.49$, n.s. $)$. Neither were there differences between the doses in the total exploration time in $\mathrm{T} 2$ $(e 2 ; F(3,67)=1.96$, n.s. $)$. At the medium dose $(3 \mathrm{mg} / \mathrm{kg})$ the index measure of habituation of exploratory behavior $h I$ differed from zero (one-sample $t$-test; see Table 2B). This indicates that the exploration time was increased from T1 to $\mathbb{T} 2$. However, the $h 1$ indices at all treatment conditions (vehicle/doses) were not different from each other $(F(3,67)=2.56$, n.s. $)$.

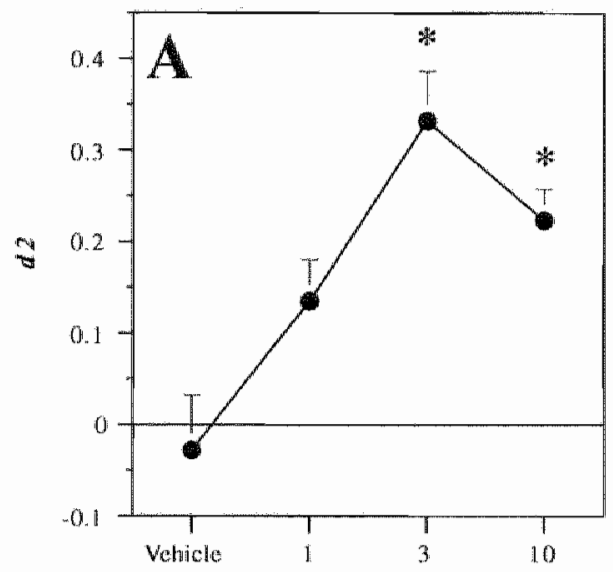

Dose of sildenafil [mg/kg]

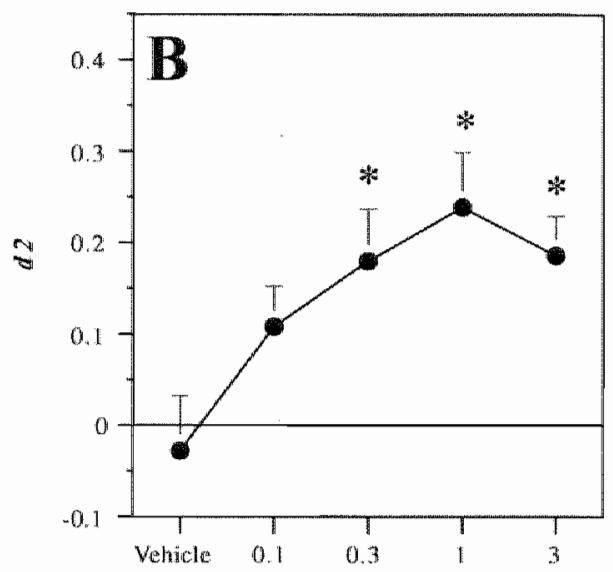

Dose of vardenafill [mg/kg]

Figure 1. Effects of different doses of sildenafil $(A)$ and vardenafil $(B)$ on the index of discrimingtion $d 2$ in the object recognition task (mean values $+S . E . M$ ). In the velaicle sessions, rats were treated with $1 \%$ tylose (p.o). *Different from vehicle (LSD test, $\mathrm{P}<0.05$ ).

The vehicle sessions of both drug experiments were pooled. The index of discrimination $d 1$ showed that $24 \mathrm{~h}$ after $\mathrm{T} 1$, the rats did not discriminate between the objects ( $d 1$ was not different from zero after vehicle treatment; see Table $2 \mathrm{C}$ and $3 \mathrm{C})$. After treatment with each dose $(1,3$ and $10 \mathrm{mg} / \mathrm{kg})$ of sildenafil the rats discriminated between the objects (Table $2 \mathrm{C}$ ). The $d 1$ indices were different between the treatment conditions $(F(3,67)=10.65, P$ $<0.01$ ). Post hoc analysis showed that the $d I$ index at each dose of sildenafil was higher then after vehicle treatment. Further, the $d 1$ index after treatment with the medium dose was higher than that of the low dose treatment. The effects of the sildenafil treatments on the relative discrimination index $d 2$ are presented in Fig. 1A. One-sample $t$-tests showed that $d 2$ was higher than zero at each sildenafil dose (Table 2C). Comparing 
between treatment conditions it was found that the 12 indices differed from each other $(F(3,67)=5.79, P<0.01)$. Post hoc analysis showed that the $d 2$ value after treatment with the medium and high dose was higher than that of the vehicle treatment, while there was no difference in $d 2$ between these two dose conditions (Fig. 1A).

The results of the treatments with vardenafil are summarized in Table 3 . No location preference was found in any of the treatment sessions (data not shown). In $\mathrm{T} 1$ there was no difference between the treatment conditions on the total level of exploration $(e 1 ; F(4,130)=0.16$, n.s.). However, the total level of exploration $24 \mathrm{~h}$ after $\mathrm{T} 1$ was different between the treatment conditions $(e 2 ; F(4,120)=5.03, P<0.01)$. This is also reflected by an increase in exploration activity from $\mathrm{T} 1$ to $\mathrm{T} 2$ after treatment with $0.1,0.3$ and $1 \mathrm{mg} / \mathrm{kg}$ vardenafil ( $\mathrm{l} 1$ indices were different from zero; see Table $3 \mathrm{~B}$ ). The $h 1$ indices were different between the treatment conditions $(F(4,130)=$ 4.63, $P<0.01$ ). Post hoc analysis showed that after treatment with all doses of vardenafil except the highest dose $(3 \mathrm{mg} / \mathrm{kg})$, the $h I$ index was different from that of the vehicle treatment.

Table 3 . Results of treatment with vardenafil on the measures of the object recognition test.

\begin{tabular}{|c|c|c|c|c|c|}
\hline & Vehicle & $0.1 \mathrm{mg} / \mathrm{kg}$ & $0.3 \mathrm{mg} / \mathrm{kg}$ & $1 \mathrm{mg} / \mathrm{kg}$ & $3 \mathrm{mg} / \mathrm{kg}$ \\
\hline \multicolumn{6}{|c|}{ A. Mean values ( + S. E.M.) of total exploration time (s) during the first (eI) and second trial ( $e 2)$} \\
\hline el & $25.88(1.18)$ & $25.98(1.86)$ & $25.72(1.88)$ & $24.41(1.4 .7)$ & $25.33(1.66)$ \\
\hline$e 2$ & $23.84(1.25)$ & $34.10(1.80)$ & $30.23(1.71)$ & $30.02(1.92)$ & $28.24(2.29)$ \\
\hline
\end{tabular}

B. Mean values ( \pm S.E.M.) of the global index of habituation $(h t)$ from the first to the second trial

$\begin{array}{llllll}h 1 & 2.05(1.66) & -8.13(2.08)^{* *} & -4.50(1.70)^{*} & -5.61(1.81)^{* *} & -2.91(2.21)\end{array}$

C. Mean values ( $($ S. E.M. ) of the index of discrimination $(d I)$ between the new snd familar objects

d.1 $\quad-0.36(1.07) \quad 3.81(1.40)^{*} \quad 4.89(1.61)^{* *} \quad 6.21(1.50)^{* *} \quad 6.10(1.57)^{* *}$

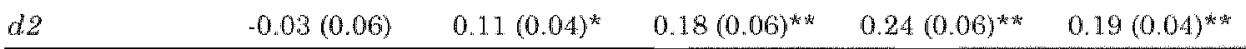

Rats $(\mathrm{n}=24)$ received a p.o. injection of vardenafil at a dose of $0.1,0.3 .1$ or $8 \mathrm{mg} / \mathrm{kg}$ after the first trial. The vehicle ( $1 \%$ tylose) session is the averaged data of all wehicles sessions, i.e. the sildenafil experiment included. The delay interval between the first and second trial was $24 \mathrm{~h}$. $h$ and $d$ measures different from ze ro are depicted with asterisks (one-sample $t$-test. * $P<0.05$ " * $P<0.011$.

As already mentioned before, the index of discrimination $d 1$ showed that $24 \mathrm{~h}$ after $\mathrm{T}$ 1, the rats did not discriminate between the objects. After treatment with each dose $(0.1,0.3,1$ and $3 \mathrm{mg} / \mathrm{kg})$ of vardenafil the rats discriminated between the objects (Table 3C). Comparisons between treatment conditions showed a difference in $d 1$ values $(F(4,130)=4.38, P<$ 0.01). Post hoc analysis showed that the $d I$ indices after treatment with 
each dose were different from that after vehicle treatment, while the $d I$ indices at all dose conditions were not different from each other. The effects of the treatments with vardenafil on the $d 2$ index are presented in Fig. 1B. $d 2$ was higher than zero after treatment with each dose of vardenafil (Table $3 \mathrm{C})$. The $d 2$ values were different between the treatment conditions $(F(4,130)=4.02, P<0.01)$. Post hoc analysis revealed that $d 2$ after treatment with all doses except the lowest, that is $0.3,1$ and $3 \mathrm{mg} / \mathrm{kg}$, was higher than that after vehicle treatment, while there was no difference in $d 2$ between these three dose conditions (Fig. 1B).

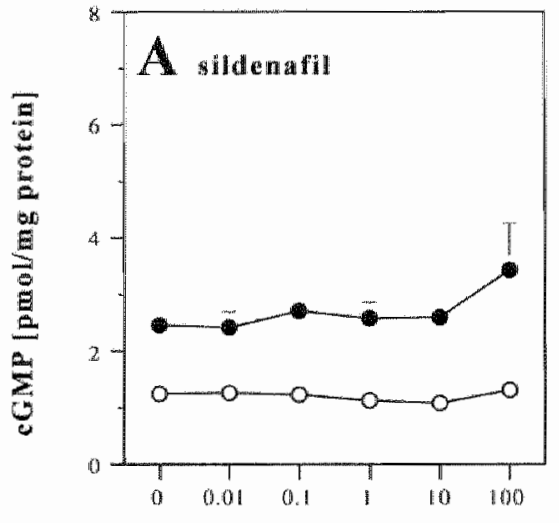

Concentration $\|\mu \mathrm{M}\|$

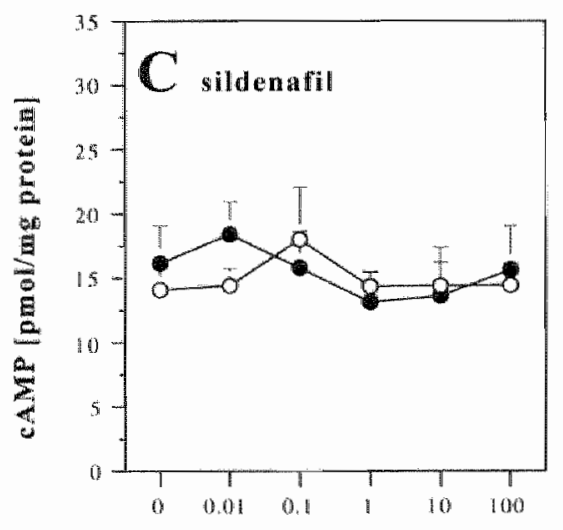

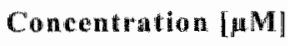

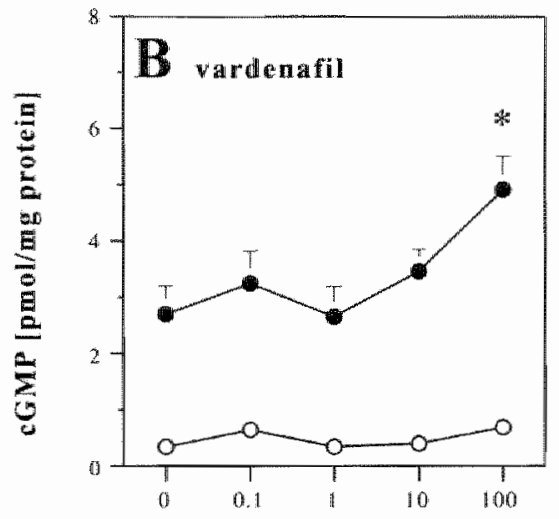

Concentration $[\mu \mathrm{M}]$

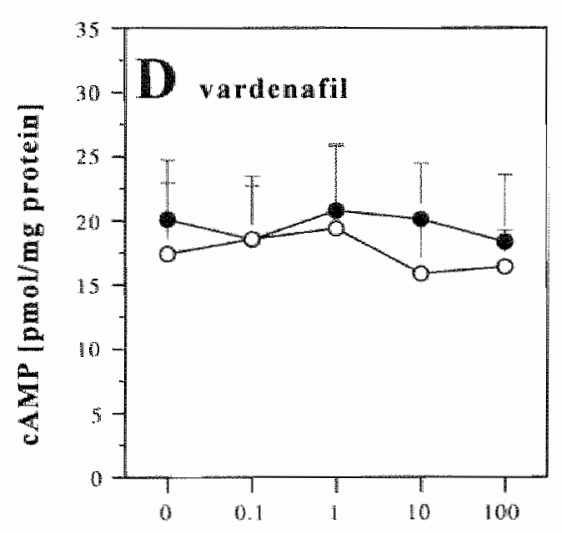

Concentration $[\mu \mathrm{M}]$

Figure 2. Etects of sidenafil and vardenafil on cGMP levels $(A, B)$ and cAMP (C, D) in hippocampal slices of rats in the absence (o) or presence (-) of $0.1 \mathrm{mM}$ SNP, as measured by a nadiommunonssay. Each value is the mean $(+$ S.E.M.) of three (sildenafil) or four (vardenafil) animals. Wach concentration was performed in duplicate per animal. Values of a concentration curve different from its comeponding control value (at. 0 M) were marked with an asterisk (1.sD test. $\left.\mathrm{P}^{\mathrm{S}}<0,00\right)$. 
cGMP and cAMP levels in hippocampal slices

The effects of sildenafil and vardenafil on cGMP levels in hippocampal slices measured by a radioimmunoassay are shown in Fig. $2 \mathrm{~A}$ and $\mathrm{B}$, respectively. In the absence of a PDE inhibitor the mean cGMP content rose by adding SNP (final concentration $0.1 \mathrm{mM}$ ) ( $t \mathrm{~s}>4.52, P<0.01$ ). The nitric oxidle donor SNP was used as a stimulator of the soluble isoform of the enzyme guanylyl cyclase that synthesizes cGMP. Thus, with SNP a larger increase of cGMP accumulation can be observed after incubation with a PDE inhibitor than after incubation with the PDE inhibitor alone. This effect has already been described previously (De Vente et al., 1996; Van Staveren et al., 2001). In the absence of SNP the cGMP content in the hippocampal slices did not change when incubated with different concentrations of sildenafil or vardenafil ( $F_{S}<0.91, n . s$.). In the presence of SNP there was also no change in cGMP accumulation by the different sildenafil concentrations $(F(5,17)=0.92$, n.s.). Incubation of slices with vardenafil in the presence of SNP increased the cGMP content $(F(4,19)=3.14, P<0.05)$. Post hoc analysis showed that the cGMP content was only raised at the highest concentration $(100 \mu \mathrm{M})$ of vardenafil (see Fig. $2 \mathrm{~B}$ ).

The effects of sildenafil and vardenafil on cAMP levels in hippocampal slices are shown in Fig. $2 \mathrm{C}$ and $\mathrm{D}$, respectively. In the absence of PDE inhibitors, adding SNP had no effect on the basal cAMP content $(t s<0.57$, n.s.). Incubation of hippocampal slices with sildenafil, in the absence as well as in the presence of SNP, had no effect on the cAMP content $(F \mathrm{~s}<0.46$, n.s.; see Fig. 2C). Likewise, incubation with vardenafil in both the absence and presence of SNP had no effect on the CAMP content of slices $\left(F_{\mathrm{S}}<0.10\right.$, n.s.; see Fig. 2D).

\section{cGMP-immunocytochemistry in hippocampal slices}

Fig. 3 shows the effects of sildenafil and vardenafil on cGMPimmunocytochemistry in hippocampal slices. When slices were incubated without PDE inhibitors and in the absence of 0.1. $\mathrm{mM}$ SNP, CGMP. immunostaining was nearly absent (data not shown). No effect on cGMP. immunoreactivity was observed when slices were treated with PDE inhibitors alone (data not shown). Some positive fibers were observed throughout the slices after incubation with SNP alone (see Fig. 3E). The combination of SNP and sildenafil or the vardenafil increased cGMP. immunostaining in a large number of varicose neuronal fibers in the CA2/CA3 region (see Fig. 3A and B). Furthermore, some cGMP-positive fibers were found in hippocampal regions outside this area, e.g. CA1 and dentate gyrus. When different concentrations of sildenafil (in combination with SNP) were tested, cGMP-immunostaining was still clearly visible at a concentration of $10 \mu \mathrm{M}$ (compare Fig. 3A with 3C). In contrast, the minimum concentration of vardenafil at which cGMP-immunostaining was still seen was $0.1 \mu \mathrm{M}$ (Fig. $3 \mathrm{~F}$ ). 

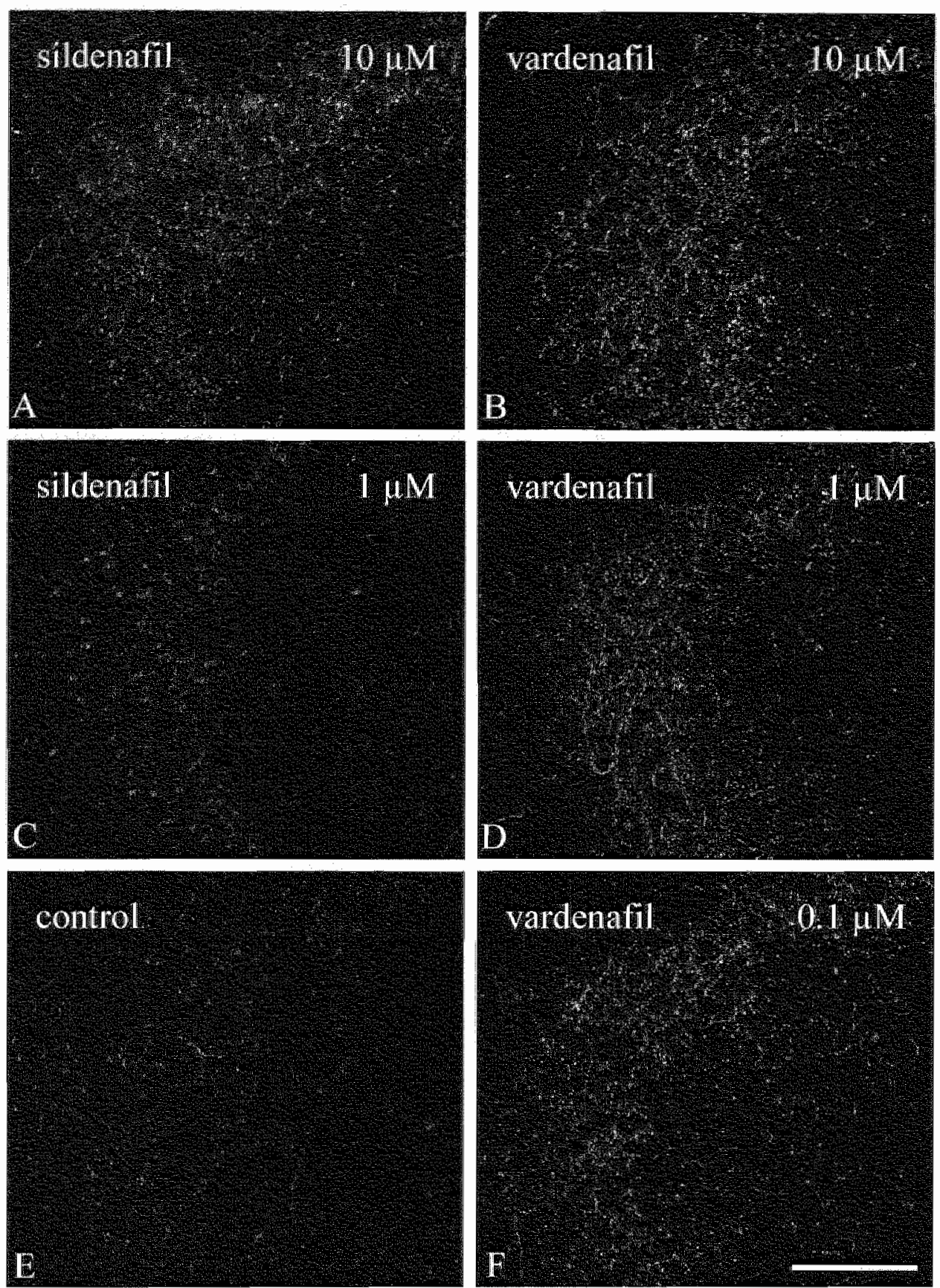

Figure 3. Effects of different concentrations of sildenafil $(A, C)$, vardenafil $(B, D, E)$ or no $P D E$ inhibitor $(E)$ on eCMP-immunoreactivity in the $\mathrm{CA} 2 / \mathrm{CA} 3$ region of hippocampal slices incubated in the presence of $0.1 \mathrm{mM}$ SNP. Scale bar $=100 \mu \mathrm{m}$ for all pictures. 


\section{Discussion}

\section{Behavior}

When treated (p.o.) with vehicle only, the wats showed no memory of the familiar object after a 24 -h interval. However, after treatment with sildenafil or vardenafil rats remembered the famillar object. Thus, these PDE5 inhibitors improved memory performance in the object recognition task. However, there was an incidental increase in exploration activity found $24 \mathrm{~h}$ after treatment with the medium dose $(3 \mathrm{mg} / \mathrm{kg})$ of sildenafil. Close examination of the changes in activity revealed that this could not be attributed to sildenafil, since the change in activity after the medium dose of sildenafil was still within the range of the non-significant changes after the other treatments, vehicle included. For vardenafil an increase in exploration activity was found $24 \mathrm{~h}$ after administration of all the doses except; however, for the highest dose $(3 \mathrm{mg} / \mathrm{kg}$ ) which had no effect on exploration activity. We have no explanation for these increases in overall exploration activity although it is unlikely that it affected the (improved) discrimination performances of the rats. Furthermore, the absolute discrimination index $d I$ showed in general the same results as the relative discrimination index $d 2$. $d 2$ is a more representative measure of discrimination since it corrects $d 1$ for overall explloratory activity. Therefore, the dose-ffect curves of this index provide the best information about the memory-improving properties of a drug. The $d 2$ indices revealed that all doses of both drugs improved memory performance. However, the doses tested of sildenafil were about ten times higher than those of vardenafil. For sildenafil, the first high discrimination (d2) was found after treatment with the medium dose of 3 $\mathrm{mg} / \mathrm{kg}$ (see Fig. 1A). Rats treated with vardenafil allready had a high discrimination performance (d2) at the low dose of $0.3 \mathrm{mg} / \mathrm{kg}$ (see $\mathrm{Fig} . \mathrm{lB}$ ). Thus, it may be argued that vardenafil is more effective than sildenafil, probably about 7 times when correcting the doses for molecular weights. Both sildenafil and vardenafil are more effective than the PDES inhibitor zaprinast, since this drug was previously found to be only effective at the high dose of $10 \mathrm{mg} / \mathrm{kg}$ (administered intraperitoneal. (i.p.). Prickaerts et al, $1997)$.

Recently, sildenafil has been reported to improve the memory performance in another one-trial learning paradigm, the passive avoidance task using mice as subjects (Baratti and Boccia, 1999). However, in this task subjects are shocked and have to remember an aversive stimulus. The mice were treated $(1,3,10$ and $30 \mathrm{mg} / \mathrm{kg}$, i.p.) immediately after the first trial and only the dose of $3 \mathrm{mg} / \mathrm{kg}$ of sildenafil was found to be effective. In the present study sildenafil was administered p.o. instead of i.p. which would suggest a reduced efficacy due to the passage through the gastrointestinal tract. Despite this route of application, in the present study all doses of sildenafil $(1,3$ and $10 \mathrm{mg} / \mathrm{kg}$ ) improved the discrimination performance of rats in the object recognition task. 
Biochemistry and anatomy

cGMP-immunocytochemistry revealed that sildenafil (in combination with SNP) increased cGMP-immunostaining in neuronal fibers which were mainly localized in the CA2/CA3 region of the hippocampus. However, clear effects of sildenafil were only found at a relatively high concentration (10 $\mu \mathrm{M}$ ). Both the regional localization of the cGMP-immunostaining and the lowest effective concentration of sildenafil are the same as those found in our previous immunocytochemical studies with zaprinast (De Vente et al., 1996; Van Staveren et al., 2001). In our radioimmunoassay it was found that incubation of sildenafil (in combination with SNP) had no effect on cGMP levels. 'This suggest that the effects of sildenafil are small and variable, just as was the case for zaprinast in our previous study (Van Staveren et al., 2001). Taken together, the effect of sildenafil on cGMP levels (in both radioimmunoassay and immunostaining) are similar to the effects of zaprinast. However, one might expect sildenafil to be more potent since ${ }^{1 C_{50}}$ values of sildenafil against human cavernosal smooth muscle PDE5 have been found to be up to 240-fold lower than that of zaprinast (Ballard et al., 1998; Turko et al., 1999; for a review see Gibson, 2001).

Vardenafil (in combination with SNP) increased cGMP accumulation in both the radioimmunoassay and the cGMP-immunocytochemistry. Since this PDE5 inhibitor, compared with sildenafil, did show an effect in the radioimmunoassay and was effective at a lower concentration $(0.1 \mu \mathrm{M})$ in the immunocytochemistry, it is clear that this compound is more potent than sildenafil. This also applied to our behavioral data. These findings are in agreement with $\mathrm{IC}_{50}$ measurements, which revealed that vardenafil is more potent than sildenafil as an inhibitor of PDE5 of human cavernosal smooth muscle $\left(\mathrm{IC}_{5}\right.$ values for vardenafill were approximately 5 -fold lower than for sildenafil) (Kim et al., 2001). Thus, these findings provide evidence to state that the behavioral and biochemical effects of vardenafil and sildenafil in our study are indeed due to PDE5 inhibition. Nevertheless, a contribution of other PDEs (e.g. PDE9: Soderling et al., 1998) cannot be ruled out.

Despite the consistency in the biochemical and behavioral data of vardenafil it has to be noted that the effective concentration of vardenafil in the radioimmunoassay is rather high $(100 \mu \mathrm{M})$. This implicates that nonspecific effects on other PDEs might be involved. Furthermore, it has to be noted that one has to be cautious comparing the biochemical and behavioral data. First, the in vilro biochemical data were obtained after incubation in combination with the compound SNP. Second, the brain levels reached by vardenafil, sildenafil and zaprinast after peripheral administration in the behavioral experiments are not known. Nevertheless, we do know that an injection of $10 \mathrm{~kg}$ of 8 -bromo-cGMP into the dorsal hippocampus is sufficient to improve the memory performance of rats in the object recognition (Prickaerts et al., 2002). In addition, our in vitro radioimmunoassay demonstrated that hippocampal cGMP levels do increase after treatment with a PDE5 inhibitor. Finally, the immunocytochemistry showed that mainly neuronal fibers in the $\mathrm{CA} 2 / \mathrm{CA} 3$ region of the dorsal hippocampus are 
hereby involved. However, whether these fibers are responsible for the improved performance in the object memory task after treatment with PDE5 inhibitors such as zaprinast, sildenafil or vardenafil, remains to be established.

\section{Possible mechanism of action of PDE5 inhibition}

Administration of PDE5 inhibitors such as sildenafil or zaprinast immediately after the first trial improved the memory performance of rodents in one-trial learning task like the object recognition task (this study and Prickaerts et al., 1997) and passive avoidance learning task (Baratti and Boccia, 1999). Furthermore, it has been found that injections of 8 bromo-cGMP into the hippocampus immediately after the first trial also improved the memory performance in tasks of object recognition (Prickaerts et al., 2002) and passive avoidance (Bernabeu et al., 1996). Considering the lipophilic structure of the PDE5 inhibitors used, they can be regarded to penetrate the brain as had been demonstrated for sildenafil (FDA, 1998). Taken together, these findings support the notion that increased hippocampal cGMP levells may be responsible for the improved memory performance in one-trial learning after treatment with PDE5 inhibitors. Such improvement of memory is thought to be related to an enhancement of processes of early-consolidation of information into memory (Bernabeu et al., 1996; Bernabeu et al., 1997a; Prickaerts et al., 2002). Several mechanisms of action of cGMP have been suggested to explain how cGMP exerts its action in processes of memory formation. For example, cGMP is thought to act through regulation of cGMP-gated ion channels, regulation of cAMP-selective PDEs or activation of cGMP-dependent protein kinases (PKGs) (Schmidt et al., 1993; Wei et al., 1998). The latter was confirmed by the finding that cGMP levels and PKG activity were increased in the hippocampus immediately after passive avoidance training (Bernabeu et al., 1997a). It is interesting to note that compared with cGMP, the cyclic nucleotide CAMP is involved in later stages of consolidation processes since administration of CAMP into the hippocampus was only effective when given $3 \mathrm{~h}$ after the first trial in passive avoidance learning (Bernabeu et al., 1996). cAMP is thought to act through cAMP-gated ion channels and cAMPdependent protein kinases (PKAs) (Schmidt et al., 1993; Wei et al., 1998). Especially the latter is interesting since passive avoidance learning resulted in a peak of hippocampal PKA activity at the same time when cAMP administration was effective, i.e. $3 \mathrm{~h}$ after training (Bernabeu et al., 1997b; Vianna et al., 2000). Furthermore, an increase in immunoreactivity of the phosphorylated form of the cAMP responsive element binding protein (CREB) was also found $3 \mathrm{~h}$ after training (Bernabeu et al.., 1.997b). Thus, both cyclic nucleotides cGMP and cAMP are involved in consolidation processes of memory, although the nucleotides are involved in different subsequent stages of consolidation, that is early (cGMP) and late (cAMP) consolidation processes respectively.

Despite these findings regarding the possible mechanisms of cGMP and cAMP action it remains unclear how cGMP, or in a later stage CAMP, could 
result in a changed signal transduction thereby improving memory performance. In addition, it has to be noted that it is unclear where the changes in the signal transduction take place, i.e. in pre- and/or postsynaptic terminals. For instance, the cGMP/PKG pathway is thought to be mainly related to presynaptic changes and is probably involved in early phases (up to one h) of hippocampal signal transduction (e.g. Zhuo et al., 1994). In contrast, the mechanisms of the CAMP/PKA/CREB pathway are assumed to be localized in postsynaptic terminals and this pathway is usually related to late phases (more than $3 \mathrm{~h}$ ) of signal transduction (e.g. Impey et al., 1996). Recently, it has been suggested that the cGMP/PKG pathway also contributes to the phosphorylation of CREB, which acts in parallel (at least in part via another pathway) with PKA to phosphorylate CREB during changes in hippocampal signal transduction (Lu et al., 1999). Such cGMP/PKG/CREB pathway is likely to occur in postsynaptic dendrites or cell bodies and may be responsible for late phases (more than $3 \mathrm{~h}$ ) of signal transduction, just like the CAMP/PKA/CREB pathway is assumed to be. This is in apparent contrast to the part of the same pathway which is presynaptically localized and related to early phases of signal transduction. Furthermore, this presynaptic cGMP/PKG pathway is involved in signal transduction that probably does not require protein synthesis, whereas the postsynaptic cGMP/PKG/CREB pathway results in protein synthesis (Lu et al., 1999). This suggests that the cGMP/PKG/CREB pathway induces synthesis of proteins essential for consolidation of information into memory, just as has already been suggested for the cAMP/PKAVCREB pathway (see Abel et al., 1997).

Although both the postsynaptic cGMP and CAMP pathway are involved in late phase signal transduction, the behavioral findings indicate that the pathways are involved in different stages of consolidation of information into memory (see above). The finding that a part of the same cGMP pathway is localized in different cellular locations and is involved in two different phases of signal transduction also suggests that the situation is far more complex. That is, a simplistic view in terms of a pre-and postsynaps or an early and late phase in regards to the signal transduction pathways of CGMP and $\mathrm{CAMP}$ may not be valid. One suggestion to be made is that signal tansduction may also occur at the level of fibers (axons and dendrites) as becomes evident from the present observation that the nitric oxide-mediated cGMP response to PDE5 inhibitors was mainly found in neuronal fibers of the hippocampal CA2/CA3 region. This is also corroborated by similar findings with other types of PDE inhibitors in the rat hippocampus (De Vente et al., 1996; Van Staveren et al., 2001).

Questions about the site of the mechanism of action of PDE5 inhibition and thus cGMP can be answered by establishing the (cellular) localization of PDE5 inhibition. However, our in vitro method of an immunocytochemical staining of cGMP is merely an indirect way of detecting PDE5 activity. Thus, our results indicated a decreased PDE5 activity in hippocampal fibers after administration of PDE5 inhibitors. However, whether other PDEs are inhibited as well cannot be ruled out. Therefore, localization studies of the 
PDE5 enzyme itself are more useful to reveal a direct relationship between PDE5 inhibition, cGMP and memory. Recently the presence/localization of PDE5 in the brain is being investigated. Using the Northern blot technique expression of PDE5 has been found in the human hippocampus. However, expression was low, especially when compared to the high levels of expression found in the cerebellum (Loughney et al... 1998). In rats using Northern blots or immunocytochemistry also lower levels of PDE5 signals were found in the hippocampus when compared to the cerebellum, or a PDE5 signal was even not detected (Kotera et al., 1997; Kotera et al., 2000). These findings suggest that the PDE5 enzyme is present in the hippocampus, although its expression is low or at the limit of detection. It is not known in which neurons in the hippocampus PDE5 is localized and the subcellular localization of PDE5 (e.g. pre- or postsynaps) needs further investigation. In addition, it is possible that other structures besides the hippocampus are involved in memory processes and are influenced by PDE5 inhibition. For instance, we abserved in our brain slices cGMP. immunostaining in incidental varicose fibers in the cortex and neuronal cells in the thalamus after incubation with sildenafil or vardenafil (both in combination with SNP). Especially the rhinal cortex may be of interest since there are indications that object information is integrated in both rhinal cortex and hippocampus in order to memorize/recognize an object (Bussey et al., 2000). However, the rhinal cortex was not investigated in the present study.

The memory improving effects of PDE5 inhibition may also, or alternatively, be related to an increased blood flow and, consequently, an increased glucose metabolism as PDE5 inhibitors are known to result in vasodilatation, probably via cGMP (e.g. Dundore et al., 1993). In a previous study we have found that i.p. administration of $10 \mathrm{mg} / \mathrm{kg}$ zaprinast had an effect on the mean arterial blood pressure in conscious rats (Prickaerts et al., 1997). Surprisingly, a slight increase in mean arterial blood pressure was found instead of an expected decrease. The same dose of zaprinast improved memory performance in the object recognition task. Therefore, we concluded that it is unlikely that effects on blood pressure after zaprinast treatment contributed to the memory improvement of zaprinast. Recently, it has been demonstrated that p.o. administration of $10 \mathrm{mg} / \mathrm{kg}$ sildenafil. decreased the systolic arterial blood pressure in conscious rats (Rehse et al., 1999). This effect lasted for at least $6 \mathrm{~h}$. Administration of $5 \mathrm{mg} / \mathrm{kg}$ sildenafil had no effect on blood pressure. In the present study the most effective dose of sildenafil was already $3 \mathrm{mg} / \mathrm{kg}$ p.o.. This suggests that it is not likely that the improved object recognition memory after treatment with this dose of sildenafil can be simply explained through changes in blood flow. However, it could be argued that peripheral administration of sildenafil or vardenafil increased the blood flow in brain structures like for instance the hippocampus or rhinal cortex. 


\section{Conclusions}

The present study showed that p.o. administration of the PDE5 inhibitor sildenafil or vardenafil improved the menory performance of rats in the object recognition task. Vardenafil appeared to be more potent than sildenafil. Likewise, compared with sildenafil, vardenafil resulted in a larger increase in the CGMP accumulation in the dorsal hippocampus as assessed in vitro with radioimmunoassay and immunocytochemisty. Recently, we have demonstrated that injection of the cGMP-analogue 8-bromo-cGMP into the dorsal hippocampus of rats improved object recognition memory (Prickaerts et al., 2002). Thus, it may be argued that inhibition of PDE5 in the dorsal hippocampus improves object recognition memory which might be explained by increased levels of cGMP. Since all compounds were always administered immediately after training it is concluded that processes of early consolidation of object information into memory are influenced (cf. Bernabeu et al., 1996; Prickaerts et al., 1997; Baratti and Boccia, 1999). However, the precise memory-improving mechanism of action of PDE5 inhibition, and thus cGMP, needs to be investigated in future research.

\section{Acknowledgements}

The authors thank Karlygash Abildayeva for her technical assistance in the radioimmunoassay and immunocytochemistry.

\section{References}

ABEL T, NGUYEN PV, BARAD M, DEUEL TA, KANDEL ER, BOURTCHOULADZE R. (1997) Genetic demonstration of a role for PKA in the late phase of LTP and in hippocampusbased long-term memory. Cell 88: 6I -626.

BAILARD SA, GINGELL CJ, TANG K, TURNER LA, PRICE ME, NAYLOR AM. (1998) Ifffects of aildenafil on the relaxation of human corpus cavernosum tissue in vitro and on the activities of cyclic nucleotide phosphodiesterase isozymes. J Unol 159: 2164-2171.

BARATIY CM, BOCCIA MM. (1999) Effects of sildenafil on long-term retention of an inhibitory aroidance response in mice. Behav Pharmacol 10: 731-737.

BERNABEU R, SCHMTIZ P, FAILLACE MP, IZQUIERDO I, MEDINA JH. (1996) Hippocampal CGMP and CAMP are differentially involved in memory processing of inhibitory avoidance learning. Neuronepor: 7: $585-588$.

BERNABEU R, SCHRODRR N, QUEVEDO J, CAMMAROTA M, IZQUIERDO I, MEDINA WH. (1997a) Further evidence for the involvement of a hippocampal cGMP/cGMP-dependent protein kinase cascade in memory consolidation. Neuroreport 8: 2221.2224.

BERNABEU R, BEVLAQUA L, ARDENGHI P, BROMBERG E, SCHMITZ P, BIANCHIN M, IZQUIERDO 1. MEDINA JH. (1997b) Involvement of hippocampal cAMP/cAMP dependent protein kinase signaling pathways in a late memory consolidation phase of aversively motivated lequing in rats. Proc Noul Acad Sci US A 94: 7041.7046.

BUSSEY TJ, DUCK J MUR JL, AGGLETON JP. (2000) Distinct patterns of behavioural impaiments resulting from fornix transection or neurotosic lesions of the perirhinal and posthinal cortices in the rat. Behow Broin Res 111:187-202.

DE VENTE \&, BOL, JG, HUDSON L, SCHIPPER I, STEINBUSCH HWM. (1988) Atrial natriuretic factor-responding and cyclic guanosine monophosphate (cGMP)-producing cells 
in the rat hippocampus: a combined micropharmacological and immunocytochemical approach. Broin Res 4.46: $387-39 \%$.

DE VENTE \%, HOPKINS DA, MARKERINE-VAN ITTERSUM M, STEINBUSCH HWM. (1996) Effects of the $3^{\prime}, 5^{\circ}$-phosphodiesterase inhibitors isobutylmethylxanthine and zaprinast on $\mathrm{NO}$-mediated cGMP accumulation in the hippocampus slice preparation: an immunocytochemical study. I Chem Neuroonat 10: 241-248.

DE VENTE J, HOPKINS DA, MARKERINK-VAN ITTERSUM M, EMSON PC, SCHMTDT HH. STEINBUSCH HWM (1998) Distribution of nitric oxide synthase and nitric oxidereceptiwe, cyclic GMP producing structures in the rat brain. Netroscience 87: 207-241.

DUNDORE RL, CLAS DM, WHEELER LT', HABEEB PG, BODE DC, BUCHHOLZ RA, SILVER PJ, PAGANI ED. (1993) Zaprinast increases cyclic GMP levels in plasma and in aortic tissue of rats. Eur J Pharmacol 249:293-297.

ENNACEUR A, DELACOUR J. (1988) A new one-trial test for neurobiological studies of memory in rats. 1: Behavioral data. Behov Brain Res 31: 47-59.

FDA (1998) Viagra tablets (sildenafil citrate). Review and evaluation of pharmacology and toxicology data. Report from the Division of Cardio-renal Drug Products (HFD-10), Center: for Drug Evaluation and Research. Food and Drug Administration, Washington, DC: 121122.

GIBSON A. (2001) Phosphodiesterase 5 inhibitors and nitrergic transmission from zaprinast to sildenafil. Eur J Phammacol 411: 1-10.

IMPEY S, MARK M, VLLACRES EC, POSER S, CHAVKIN C, STORM DR. (1996) Induction of CRE-mediated gene expression by stimuli that generate long-lasting LTP in area CAI of the hippocampus. Neuron 16:973.982.

FIM NN, HUANG YH, GOLDSTEIN I, BISCHOFF E, TRAIS AM. (2001) Inhibition of cyclic GMP hydrolysis in human corpus cavernosum smooth muscle cells by vardenafil, a novel. selective phosphodiesterase type 5 inhibitor. Life Sci 69: 2249.2256 .

KOTERA J, YANAKA N, FUJISHIGE K, IMAI Y, AKATSUKA H, ISHIZUKA T, KAWASHIMA $K$, OMORI $K$. (1997) Expression of rat cGMP-binding cGMP-specific phosphodiesterase mRNA in Purkinje cell layers during postnatal neuronal development. Eur J Biochem 249:434-442.

KOTERA J, FUJSHIGE K, OMORI K. (2000) Immunohistochemical localization of cGMP. binding cGMP-specific phosphodiesterase (PDE5) in rat tissues. I Histochem Cytochem 48: $685-693$.

LOUGHNEY K, HILL TR, FLORIO VA, UHER L, ROSMAN GJ, WOLDA SL, JONES BA, HOWARD ML, MCALLISTER LUCAS IM, SONNENBURG WIK, FRANCIS SH, CORBIN JD, BEAVO JA, FERGUSON K. (1998) Isolation and characterization of cDNAs encoding PDE5A, a human cGMP-binding, cGMP-specific $33^{\prime}, 5$-cyclic nucleotide phosphodiesterase. Gene 216: 1394147.

LOWRY OH, ROSEBROUGH NJ, FARR AL, RANDALL, Fu. (1951) Protein measurement, with the Folin reagent. If Biol Chem 193: 265-275.

LU YF, KANDEL ER, HAWKINS RD. (1999) Nitric oxide signaling contributes to late-phase LTP and CREB phosphorylation in the hippocampus. of Neurosich 19: 10250-10261.

PRICKAERTS J, STEINBUSCH HWM, SMITS JF, DE VENTE J (1997) Passible role of nitric oxide-cyclic GMP pathway in object recognition memory: effects of 7 -nitroindazole and zaprinast. Eur J Phormacol $337: 125-136$.

PRICKAERTS J, DE VENTE J, HONIG W, STEINBUSCH HWM, BLOKLAND A (2002) CGMP, but not CAMP, in rat hippocampus is involved in early stages of object memory consolidation. Eur of Pharmacol 436:83-87.

REHSE K, SCHEFFLER H, REITNER N. (1999) Interaction of Viagra with the NO donors molsidomine and RE 2047 with regard to antithrombotic and blood pressure lowering activities. Arch Prarm. (Womheim) 332: 182-184.

SCHMID'T HHHW, LOHMANN SM. WALTER U. (1993) The nitric oxide and CGMP signal transduction system: regulation and mechanism of action. Brochim Biophys Acta 1178: 153175 .

SODERLING SH, BAYUGA SJ, BEAVO JA. (1998) Identification and characterization of a novel family of cyclic nucleotide phosphadiesterases. I Biol Chem 273: 15553-15558.

STEINER AL, PARKER CW, KIPNIS DM. (1972) Radioimmunoassay for cyclic nucleotides. 1 . Preparation of antibodies and iadinated cyclic nucleotides. I Biol Chem 247: 1106-1113. 
TURKO IV, BALLARD SA, FRANCKS SH, CORBIN JD. (1999) Inhibition of cyclic GMP. binding cyche GMP-specific phosphodiesterase (Type 5) by sildenafil and related compounds. Mol Pharmacol 56: 124-130.

WAN STAVEREN WCG, MARKERINK.WAN ITTERSUM M, STEINBUSCH HWM, DE VENTE J. (2001) The effects of phosphodiestarase inhibition on cyclic GMP and cyclic AMP accumulation in the hippocampus of the rat. Brain Res 888 : 275-286.

VLANNA MR, IZQUTERDO LA, BARROS DM, ARDENGHI P, PEREIRA P, RODRIGUES C, MOLETA B, MEDINA JH, IZQUIERDO I. (2000) Differential role of hippocampal cAMP. dependent protein kinase in short-and long-term memory. Neurochem Res 25: 621-626.

WBI JY, ROY DS, LECONTE J, BARNS ${ }_{4}$ ABLE CI. (1998) Molecular and pharmacological analysis of cyclic nucleotide-gated channel function in the central nerwous system. Prog Neurobiol 56: 37.64 .

ZHUO M, HU Y, SCHULTZ C, KANDEL ER, HAWKDNS RD. (1994) Role of guanylyl cyclase and cGMP-dependent protein kinase in long-term potentiation. Nature 368: 635-639. 


\section{The effects of phosphodiesterase inhibition on cGMP and cAMP accumulation in the hippocampus of the rat}

Wilma C.G. van Staveren, Marjanne Markerink-van Ittersum, Harry W.M. Steinbusch and Jan de Vente

Dept. of Psychiatry and Neuropsychology, Division Cellular Neuroscience, Maastricht University, European Graduate School of Neuroscience (EURON), P.O. Box 616, 6200 MD Maastricht, The Netherlands

Brain Research 888 (2): $275-286$ (2001)

\section{Abstract}

The effects of selective and non-selective $3^{\prime}, 5^{\prime}$-cyclic nucleotide phosphodiesterase (PDE) inhibitors on cGMP and CAMP accumulation were studied in rat hippocampal slices incubated in vitro. The following PDE inhibitors were used: vinpocetine and calmidazolium (PDE1 selective), erythro-9-(2-hydroxy-3-nonyl)adenine (EHNA, PDE2 selective), SK\&F 95654 (PDE3 selective), rolipram (PDE4 selective), SK\&F 96231. (PDE5 selective), the mixed type inhibitors zaprinast and dipyridamole, and the non-selective inhibitors 3-isobutyl-1-methylxanthine (IBMX) and caffeine. cGMP levels were increased in the presence of different concentrations of IBMX, EHNA, dipyridamole, vinpocetine and rolipram. cGMPimmunocytochemistry showed that incubation with different inhibitors in the presence and/or absence of sodium nitroprusside resulted in pronounced differences in the extent and regional localization of the cGMP response and indicate that PDE activity in the hippocampus is high and diverse in nature. The results suggest an interaction between cGMP and cAMP signaling pathways in astrocytes of the rat hippocampus. 


\section{Introduction}

Nitric oxide synthase (NOS) has a widespread distribution in the central nervous system (CNS) (Bredt et al., 1990; Vincent and Kimura, 1992). In the hippocampus, two constitutive isoforms of NOS have been described, i.e. the neuronal NOS (nNOS) and the endothelial NOS (eNOS), also referred as NOS-I and NOS-III respectively (Dinerman et al., 1994). In this brain area, both isoforms are activated through calcium/calmodulin dependent pathways, which are triggered by the $N$-methyl-D-aspartate (NMDA)-type glutamate receptors (Garthwaite and Boulton, 1995). NO diffuses from the site of synthesis to the target structures which are neurons and astrocytes close to the site of the NO production (Garthwaite, 1991; O'Dell et al., 1991; Garthwaite and Boulton, 1995; Lev-Ram et al., 1997; De Vente et al., 1998). The soluble isoform of guanylyl cyclase ( $\mathrm{sGC}$ ) presents an important target molecule for NO (Bredt and Snyder, 1989; Knowles et al., 1989). NO activates $\mathrm{sGC}$ by binding to the heme group of this enzyme which leads to an increased cGMP synthesis.

cGMP and the other second messenger cAMP are inactivated by hydrolytic cleavage of their ' 3 -phosphoester bonds to form 5'GMP and 5'AMP by the superfamily of enzymes known as the 3',5-cyclic nucleotide phosphodiesterases (PDEs). At present, the PDEs have been classified into 11. different families i.e. PDE1 to PDE11, based on their substrate and inhibitor profiles together with their structural characteristics (Beavo, 1995; Conti and Jin, 1999; Fawcett et al., 2000; Soderling and Beavo, 2000). Within families multiple splice variants of those isozymes exist which makes the number of PDE isozymes more than 30 (Beavo, 1995; Houslay, 1996). A number of these enzymes were shown to be localized regionally (Kincaid et al., 1987; Billingsley et al., 1990; Ludvig et al., 1991; Repaske et al., 1993; Furuyama et al., 1994; Polli and Kincaid, 1994; Yan et al., 1994; Sakagami et al., 1995; Iwahashi et al., 1996; Reinhardt and Bondy, 1996; Juilfs et al., 1997) and may be expressed to different degrees even within one cell type (Beavo, 1995; Juilfs et al., 1997).

From previous studies it is known that the PDE activity in the hippocampus is high (e.g. De Vente and Steinbusch, 1992). We also found evidence for the presence of oGMP-hydrolyzing PDE activity in the hippocampus which is not or only partly inhibited by JBMX (De Vente and Steinbusch, 1992). In addition, it was shown in brain slices that zaprinast, an inhibitor of cGMP-specific PDE activity (PDE5 and PDE9), increased NO-mediated cGMP accumulation especially in the CA2/CA3 region and the stratum lacunosum moleculare of the hippocampus. In contrast, IBMX, a non-selective PDE inhibitor, increased cGMP levels in varicose fibers and astrocytes throughout the hippocampus (De Vente et al., 1996). Thus, the choice of the PDE inhibitor is a very important factor when cyclic nucleotide levels are studied in complex tissues. In this respect it is striking that in the canine proximal colon only a combination of zaprinast and IBMX was effective in inhibiting NO-mediated cGMP in smooth muscle cells (Shuttleworth et al., 1993). 
In order to study the possibilities of locally increasing cyclic nucleotide levels using selective inhibitors of PDE activity (De Vente et al., 1996), we measured the effects on cGMP and cAMP accumulation in hippocampal slices, after the incubation with a number of PDE inhibitors with different selectivity profiles. In addition, we visualized the effect of these inhibitors on the accumulation of NO-mediated cGMP synthesis using cGMP. immunocytochemistry. A comparison was made between the determination of cGMP levels by the use of a radioimmunoassay and by the evaluation of cGMP-immunofluorescence intensity using an image analysis system.

\section{Materials and Methods}

\section{Animals}

Experiments were performed on hippocampal slices obtained from adult male Lewis rats $(200-240 \mathrm{~g}$ ). The effect of zaprinast on two different rat strains was studied in female Lewis and Wistar rats (obtained from Charles River). The animals were housed under standard conditions at the local animal facility. All experiments were approved by the committee on animal welfare according to Dutch governmental rules.

\section{Tissue preparation}

Animals were decapitated and their brains were immediately removed. Brains were transferred to ice-cold Krebs-Ringer bicarbonate buffer (Krebs incubation buffer) of the following composition: $121.1 \mathrm{mM} \mathrm{NaCl}, 1.87 \mathrm{mM}$ $\mathrm{KCl}, 1.17 \mathrm{mM} \mathrm{KH}_{2} \mathrm{PO}_{4}, 1.15 \mathrm{mM} \mathrm{MgSO}_{4} .7 \mathrm{H}_{2} \mathrm{O}, 24.9 \mathrm{mM} \mathrm{NaHCO}, 2.0 \mathrm{mM}$ $\mathrm{CaCl}_{2} .2 \mathrm{H}_{2} \mathrm{O}$ and $11.0 \mathrm{~m} \mathrm{M}$ glucose.

Hippocampal slices $(400 \mu \mathrm{m})$ were prepared as described previously (De Vente et al., 1998). Slices were incubated in Krebs incubation buffer at 35.5 ${ }^{\circ} \mathrm{C}$, under an atmosphere of $95 \% \mathrm{O}_{2}$ and $5 \% \mathrm{CO}_{2}$ at $\mathrm{pH}$ 7.4. The incubations lasted 40 minutes; when appropriate, the last 10 minutes in the presence of the NO donor sodium nitroprusside (SNP) in a concentration of $0.1 \mathrm{mM}$. The PDE inhibitors were present from the start of the incubation and were added in different concentrations to the slices. Vinpocetine, calmidazolium, EHNA, SK\&F 96231, SK\&F 95654, rolipram, dipyridamole and zaprinast had to be dissolved in dimethylsulfoxide (DMSO), therefore a final concentration of $1 \%$ DMSO was present in all experiments. In an earlier study it was found that 1\% DMSO had no effect on cGMP levels in hippocampal slices (unpublishedl results).

\section{Radioimmunoassay}

cGMP and CAMP levels were determined in individual hippocampal slices, incubated as described above, using a radioimmunoassay as published previously (De Vente et al., 1988). Briefly, the incubations were terminated by placing the slices into a solution of $5 \%$ trichloroacetic acid. Subsequently, the samples were sonicated and centrifuged. The supernatant was used for the determination of the CGMP and cAMP content, measured by a 
radioimmunoassay according to Steiner et al. (1972). The pellet was used for the analysis of the protein content according to Lowry et al. (1951).

Each condition was measured in two different slices per animal and for each $\mathrm{PDE}$ inhibitor three different rats were tested. In each slice, both CGMP and $C A M P$ levels were measured in triplicate and the median was taken for each sample. In the radioimmunoassay, a level of 0.6 fmol cGMP and 5 fmol cAMP could be detected. CCMP and CAMP levels were corrected for the protein content of each slice.

\section{Immunocytochemistry}

After the incubation, slices were fixed with ice-cold fixative solution of $4 \%$ freshly prepared depolymerised paraformaldehyde in $0.1 \mathrm{M}$ phosphate buffer $(\mathrm{pH} 7.4)$ for 30 minutes at $4{ }^{\circ} \mathrm{C}$. The slices were then fixed for another 90 minutes with $4 \%$ paraformaldehyde containing $10 \%$ sucrose. After washing overnight at $4{ }^{\circ} \mathrm{C}$ in $0.1 \mathrm{M}$ phosphate buffer $(\mathrm{pH} 7.4$ ) containing $10 \%$ sucrose, the slices were frozen in $\mathrm{CO}_{2}$. Cryostat sections $(10 \mu \mathrm{m})$ were cut, thawed onto chrome-alumn/gelatin coated shides and processed for immunocy ochemistry.

Frozen sections were dried for 20 minutes at room temperature, followed by three 5 minute washes with Tris-buffered saline (TBS). Sections were incubated overnight at $4{ }^{\circ} \mathrm{C}$ with sheep anti-formaldehyde fixed cGMP, diluted 1:4000 in TBS containing 0.3\% Triton X-100 (TBS-T). The specificity of this antibody has been detailed elsewhere (De Vente et al., 1.998). Washing consisted of 10 minutes of TBS, followed by TBS-T and another 10 minutes of washing with TBS at room temperature. The primary antibody was visualized by the incubation of sections for 1 hour at room temperature with Fluorescein (FITC)-conjugated rabbit anti-sheep immunoglobulins (Jackson), diluted 1:30 in TBS-T. After having been washed, sections were mounted and studied with an Olympus AX-70 microscope, equipped with a narrow band MNIBA-type FITC filter, or a MNG filter for Cy3 fluorescence (Chroma Technology Corporation). These filters made it possible to photograph FTTC or Cy3 fluorescence without any bleeding of the other fluorescent marker through the filter (De Vente et al., 1998).

Glial fibrillary acidic protein (GFAP) was stained with mouse anti-GFAP serum (Innogenetics), dilluted 1:10 in TBS-T and visualised with donkey anti-mouse Cy3 (Jackson), diluted 1:800 in TBS-T.

\section{Image analysis}

For the semi-quantitative measurement of cGMP, sections were stained for cGMP as described above and the primary antibody was visualised by the incubation of sections for 1 hour at room temperature with the Alexa 488 donkey anti-sheep $\operatorname{IgG}(\mathrm{H}+\mathrm{L})$ conjugate (Molecular Probes), diluted 1:100 in TBS-T. Each condition was tested in hippocampal slices obtained from three different animals and from each slice, three different sections of the hippocampal area were studied per animal. All sections were stained and analysed at the same time under standard conditions. Pictures of the stratum lacunosum moleculare and the CAl area were made at a 
magnification of $20 x$ using a Sony Power HAD 3 CCD Color Video Camera (Paes, Zoeterwoude, The Netherlands). All pictures were analysed with the computer program analysis Vers.3.0. For each image, a color separation of the green image was done and the mean grayralue of each area was estimated as a measure for the cGMP content of the hippocampal area. All measurements were corrected for control sections which were incubated without the primary antibody.

\section{Statistical analysis}

To determine whether different concentrations of the PDE inhibitor tested, differed from its control, a Student Newman Keuls test and a Student t-test were used.

\section{Chemicals}

IBMX was from Janssen Chimica; zaprinast, dipyridamole and EHNA from Sigma; rolipram and calmidazolium from RBI; vinpocetine from Tocris; SK\&F 96231 and SK\&F 95654 were kindly donated by SmithKline Beecham. L-NAME and SNP were obtained from Fluka.

\section{Results}

cGMP levels in hippocampal slices after incubation with different PDE inhibitors

The effect of different PDE inhibitors on cGMP levels in hippocampal slices measured by a radioimmunoassay is shown in Fig. 1. In the absence of a PDE inhibitor, the cGMP content of the hippocampal slice was $0.42 \pm 0.08$ $\mathrm{pmol} / \mathrm{mg}$ protein and rose till $1.77 \pm 0.17 \mathrm{pmol} / \mathrm{mg}$ protein in the presence of $0.1 \mathrm{mM}$ SNP (mean \pm S.E.M.; significantly different from control (O M) without SNP, Student t-test, $p<0.01$ ). As shown in Fig. 1, in the absence of SNP the cGMP content in hippocampal slices was increased by IBMX (1) mM), EHNA (100 $\mu \mathrm{M})$, dipyridamole $(100 \mu \mathrm{M})$ and vinpocetine (1 $\mu \mathrm{M}$ and higher) compared to its controls. No changes in cGMP levels were found when slices were incubated with rolipram or zaprinast.

Incubation of slices with $0.1 \mathrm{mM}$ SNP in the presence of different concentrations of IBMX, EHNA or dipyridamole, resulted in a concentration dependent increase of cGMP levels. Rolipram increased cGMP levels significantly at $1 \mu \mathrm{M}$ and $1.00 \mu \mathrm{M}$ and the cGMP content was only raised in the presence of the highest dose of zaprinast (100 HM). On a molar basis EHNA and dipyridamole appeared to be the most potent inhibitors. In the presence of SNP we did not find a significant increase in cGMP accumulation by vinpocetine (Fig. 1) or calmidazolium (not shown). 

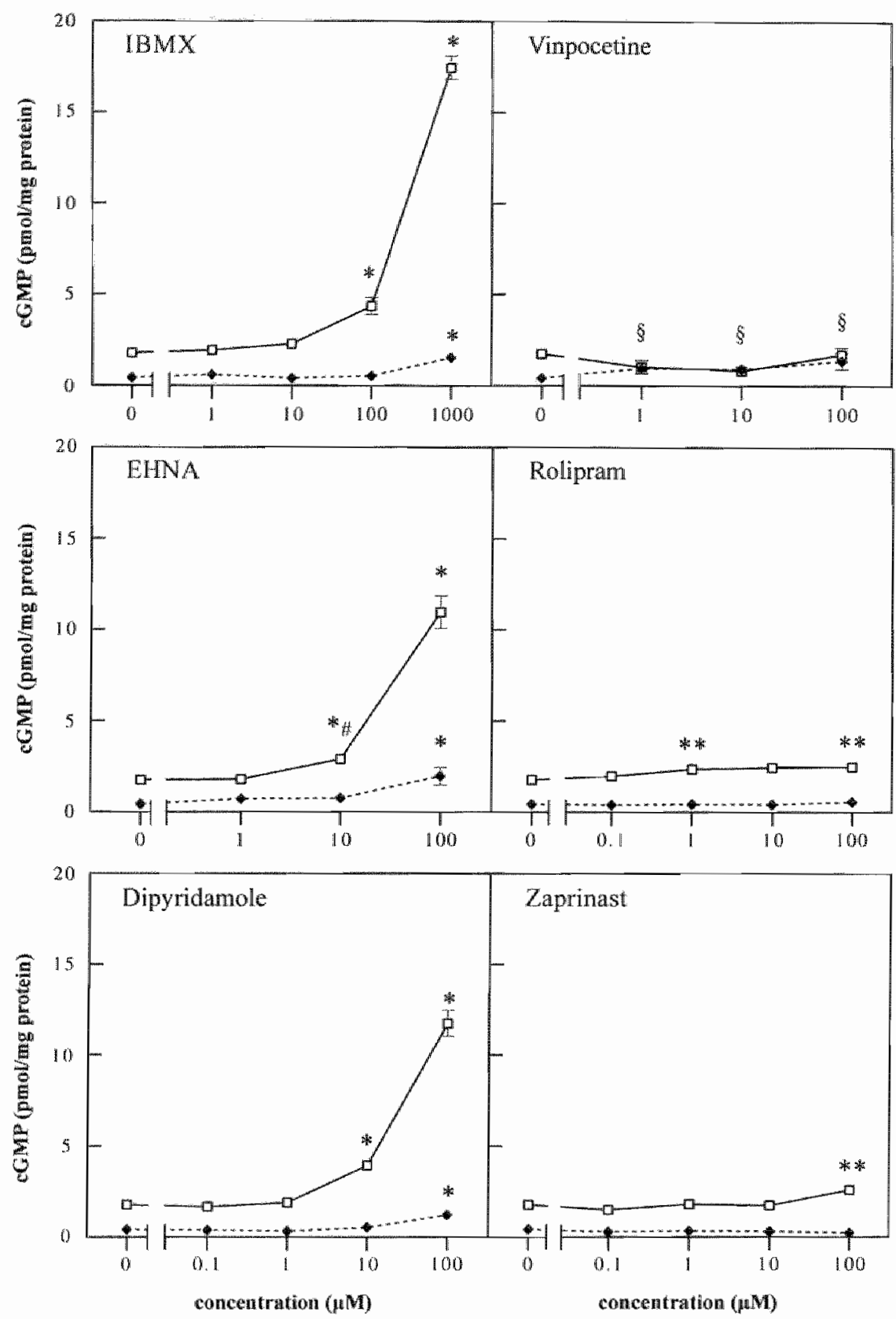

Figure 1. Effect of PDE inhibitors on oGMP levels in hippocampal slices of the rat, in the absence () or presence (a) of $0.1 \mathrm{mM} \mathrm{SNP}$, measured by a radioimmunoassay. Each value is the mean (+ S.E.M.) of three animals. Each concentration was performed in duplicate per animal and assayed in triplicate in a radioimmunonssay. Values which were different from control $(0 \mathrm{M})$ (Student Newman Keuls test; $p<0.01$ ) were marked with an asterisk ${ }^{*}$ ). Values which were different from control tested with a Student tntest were marked as ** $(p<0.05)$ and t $(p<0.01)$. \$, different from control without SNP $(p<0.05)$. 
AMP levels in hippocampal slices after incubation with differen PDE inhibitors

As shown in Fig. 2, in the absence of PDE inhibitors the basal CAMP content of hippocampal slices was $37.94 \pm 4.94 \mathrm{pmol} / \mathrm{mg}$ protein (determined in six animals). This is in the range of reported hippocampal levels (Fowler and O'Donnell, 1988). Rolipram strongly increased cAMP levels while no effect on the cAMP content was found in the presence of zaprinast, dipyridamole or IBMX. There was no effect of SNP on CAMP levels regardless of the PDE inhibitors being present. Incubation of hippocampal slices with $10 \mu \mathrm{M}$ forskolin (an activator of adenylyl cyclase) or $10 \mathrm{\mu M}$ noradrenalin, both in the presence of IBMX, resulted in large increases of cAMP levels.

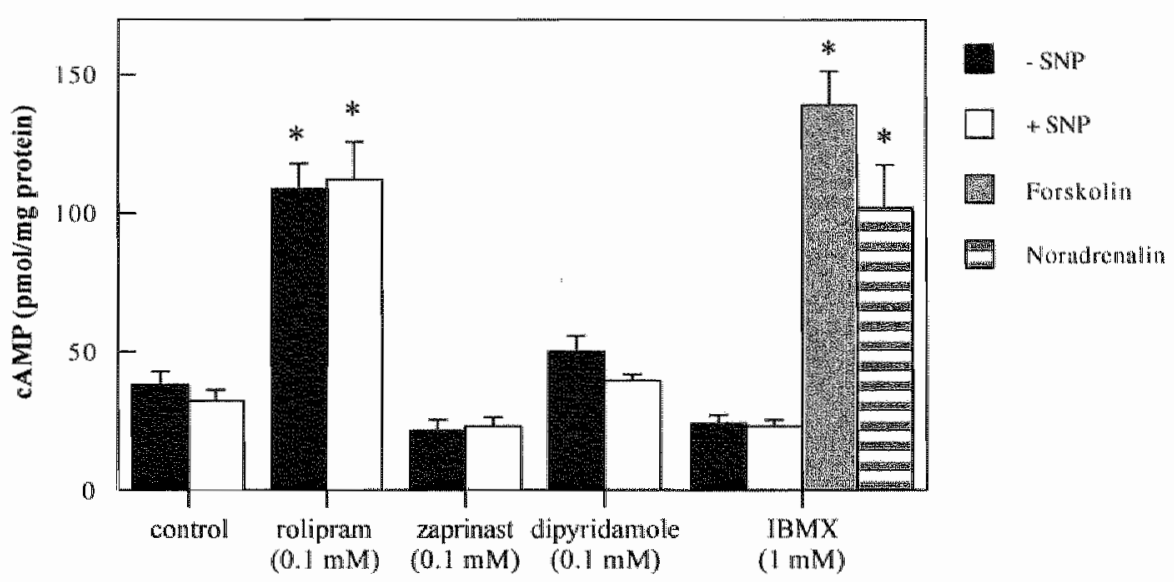

Figure 2. Effect of PDE inhibitors on cAMP levels in hippocampal slices of the rat, in the presence or absence of $0.1 \mathrm{mM}$ SNP, measured by a radioimmunoassay. Forskolin and noradrenalin were both used in a concentration of $10 \mu \mathrm{M}$. Each value is the mean ( + S.E.M.) of three animals. Each concentration was performed in duplicate per animal and assayed in triplicate in a radioimmunoassay. Values which were different from control (Student t-test; $\mathrm{p}<$ 0.01 ) were marked with an asterisk.

cGMP-immunostaining after incubation with different PDE inhibitors

When hippocampal s]ices were incubated in vitro without PDE inhibitors, cGMP-immunostaining was nearly absent (Fig. 3A). No effect on cGMP. immunocytochemistry was observed when slices were treated with vinpocetine, calmidazolium, SK\&F 95654, SK\&F 96231 or zaprinast (data not shown). In the presence of $1 \mathrm{mM}$ IBMX isolated fibers were observed distributed at random throughout the hippocampal slice, with a cluster of thin, punctate fibers in the stratum lacunosum moleculare (data not shown). The NOS inhibitor $\mathrm{N}^{\mathrm{s}}$-nitro-L-arginine (L-NAME) abolished the effect of IBMX (not shown). When slices were incubated with 0.1 mM EHNA (Fig. $3 \mathrm{C}$ ) a similar staining pattern was seen as with IBMX incubation. 
Rolipram $(0.1 \mathrm{mM}$ ) increased cGMP in astrocytes weakly (Fig. 3E and 3F); this effect might be observed in any region of the hippocampus. Incubation of the slices in the presence of L-NAME did not have an effect on rolipram induced cGMP-immunostaining (data not shown). Dipyridamole (0.1 $\mathrm{mM}$ ) strongly increased cGMP in the smooth muscle layer of what appeared to be the larger blood vessels of the hippocampus (Fig. 3D).
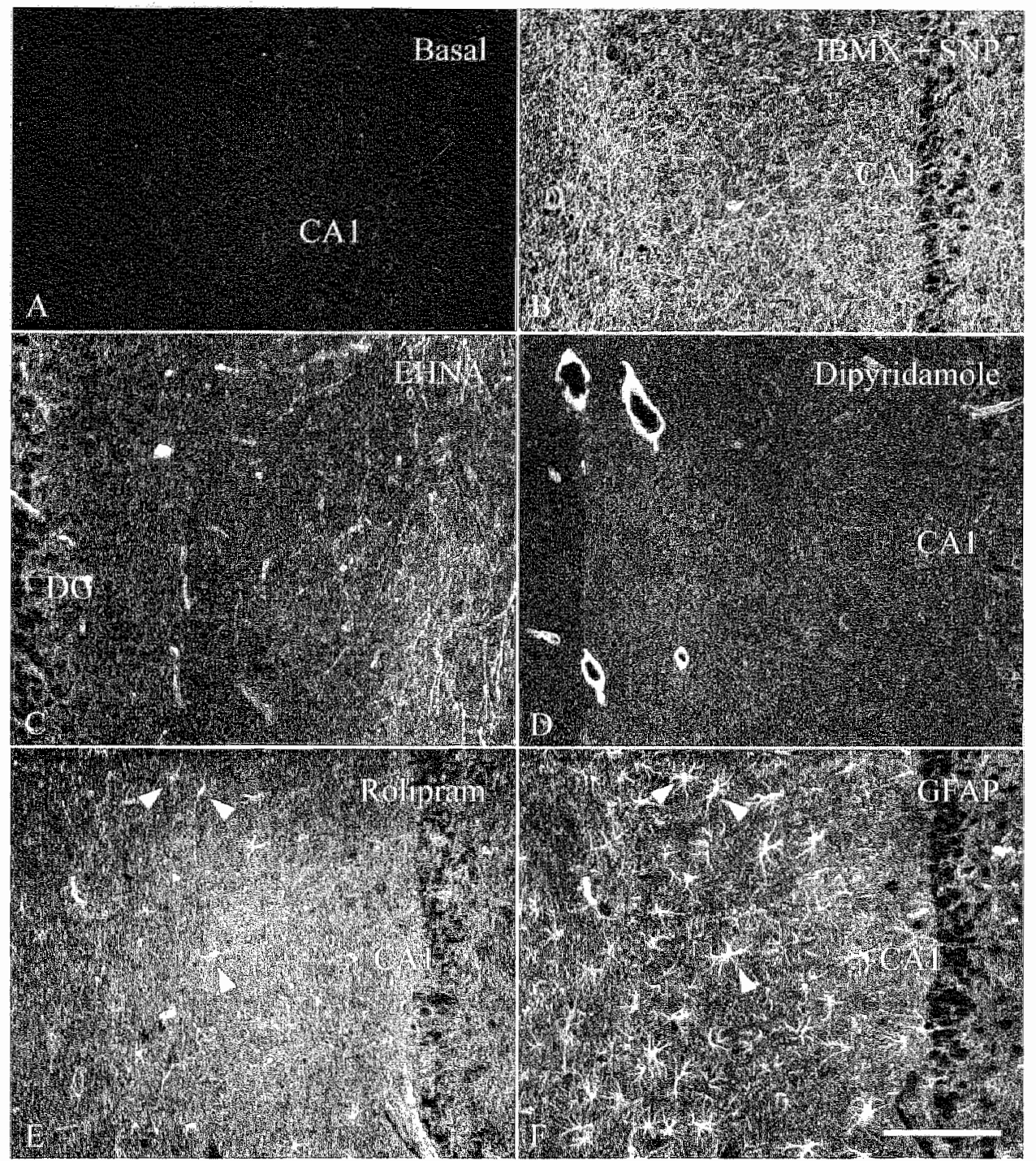

Figure 3 . Localization of oGMP-immunoreactivity in hippocampal slices incubated in vitro: $\mathrm{A}$. in the presence of $1 \mathrm{mM} T B M X ; B$, combination of $1 \mathrm{mM} \mathrm{IBMX}$ and $0.1 \mathrm{mM} S \mathrm{NP} ; \mathrm{C}, 0.1 \mathrm{mM}$ EHNA: D, $0.1 \mathrm{mM}$ dipyridamole; $\mathbb{E}, 0.1 \mathrm{mM}$ rolipram. The immunostaiming in $F$, with GFAP show the same field as depicted in E, indicating that rolipram increases cGMP in astrocytes (arrowheads). DG, dentate gyrus. Bar represents $100 \mu \mathrm{m}$ for all pictures. 


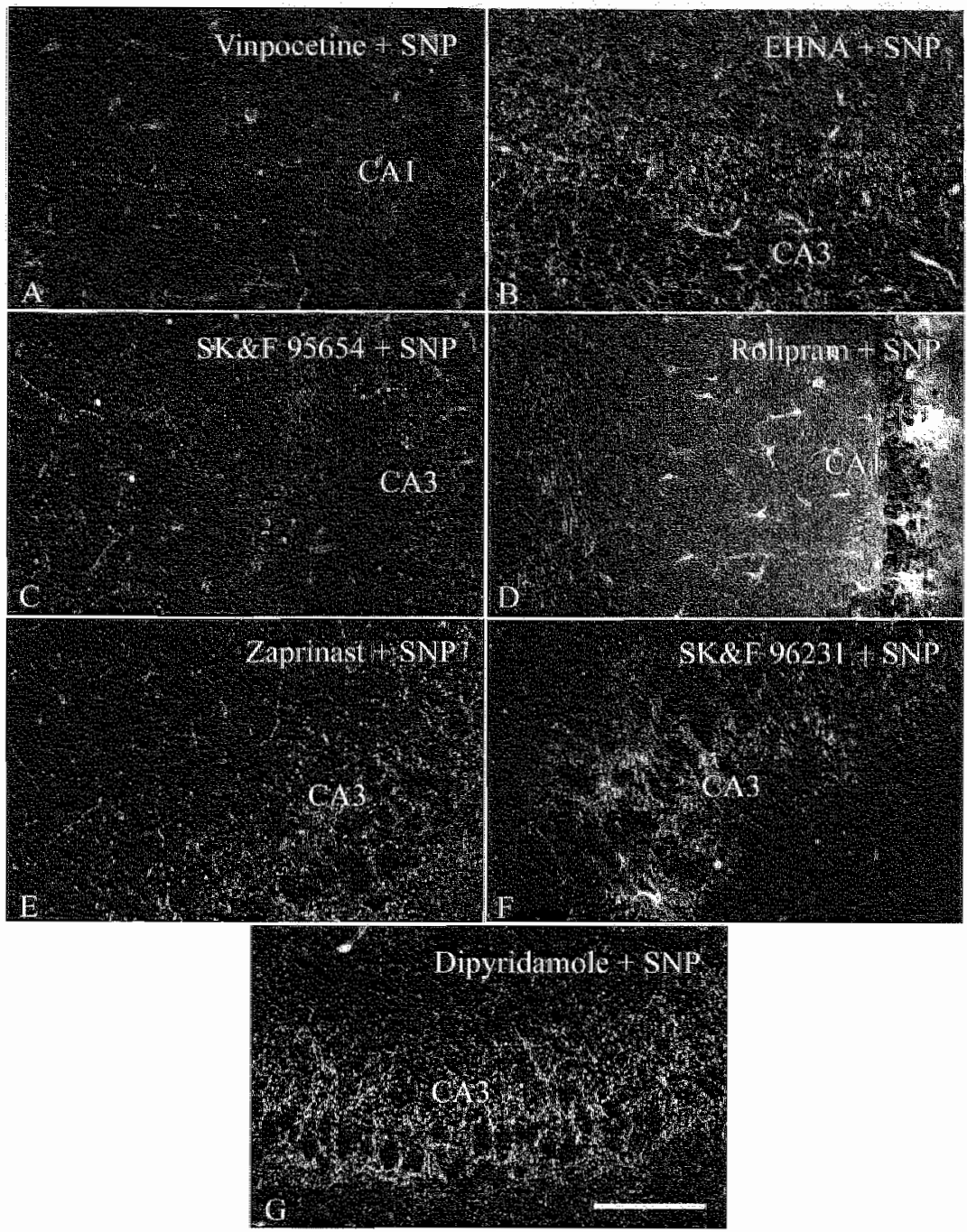

Figure 4. Localization of cGMP-immunoreactivity in hippocampal slices incubated in the presence of $0.1 \mathrm{mM}$ SNE and: $\mathrm{A}, 0.1 \mathrm{mM}$ vinpocetine; $\mathrm{B}, 0.1 \mathrm{mM}$ EHNA; C, 0.1 mM SKF 95654; D. 0.1 mM rolipram; $\mathrm{E}, 0.1 \mathrm{mM}$ zaprinast; $\mathrm{F}, 0.1 \mathrm{mM} \mathrm{STF} 96231 ; \mathrm{G}, 0.1 \mathrm{mM}$ dipyridamolo. Bar represents $100 \mu \mathrm{m}$ for all pictures.

cGMP accumulation after stimulation of SGC by SNP in the presence of PDE inhibitors

Incubation of hippocampal slices with $0.1 \mathrm{mM}$ SNP in the absence of PDE inhibitors, showed a few intensely stained fibers, which, taking into account all experiments $(>10)$, might be observed in any region of the hippocampus (not shown). cGMP-immunocytochemistry after in vitro incubation of the slices in the presence of IBMX and SNP has been described previously (e.g. De Vente et al., 1996). This combination of drugs resulted in cGMP 
accumulation in a multitude of varicose fibers throughout the hippocampus (Fig. 3B). Similar staining patterns were observed when EHNA or dipyridamole were used (Fig. $4 \mathrm{~B}$ and $4 \mathrm{G}$ ). In contrast, the combination of SNP with the inhibitors zaprinast (Fig. 4E) or SK\&F 96231 (Fig. 4F) increased cGMP-immunostaining in neuronal fibers, especially in the CA2/CA3 region and the stratum lacunosum moleculare. Astrocytes and a few neuronal cells were found to be cGMP-immunopositive after incubation of the slices with IBMX, EHNA or dipyridamole in the presence of SNP. The effects of combinations of calmidazolium (data not shown), vinpocetine (Fig. 4A), SK\&F 95654 (Fig. 4C) with SNP were not different from the effect of SNP alone.

When different concentrations of EHNA or dipyridamole in combination with SNP were tested, cGMP-immunostaining was still visible at low concentrations (Fig. 5). In contrast, in the radioimmunoassay the effect of 1 $\mu \mathrm{M}$ of these inhibitors on the cGMP content was not significantly different from controls (Fig. 1).

Incubation of slices with rolipram and SNP resulted in cGMPimmunostaining in astrocyte-like cells and a few isolated varicose fibers scattered throughout the hippocampus (Fig. 4D). Using double immunostaining of cGMP in combination with GFAP, these cells could indeed be identified as astrocytes (see also Fig. $3 \mathrm{E}$ and $3 \mathrm{~F}$ ). When slices were incubated with rolipram combined with IBMX and SNP, cGMPstaining was observed similar as in the case of IBMX and SNP, although the cGMP-immunostaining in the astrocytes was more pronounced (Fig. 6A). Strikingly, only a subpopulation of astrocytes showed cGMP. immunoreactivity (Fig. 6B).

\section{Image analysis of cGMP-immunostaining after treatment with IBMX or zaprinast}

Hippocampal slices were incubated with different concentrations of IBMX or zaprinast ( $1 \mathrm{mM}$ to $0.1 \mu \mathrm{M}$ ) and the effect on cGMP-immunostaining in the stratum lacunosum moleculare and the CA1 area was measured by a semiquantitative image analysis (Fig. 7). In the absence of SNP, the cGMP content in the stratum lacunosum moleculare was increased at the highest concentration of IBMX ( $1 \mathrm{mM}$ ) compared to control (0 M) (Student Newman Keuls test, $p<0.01$ ), while no effect was measured of this dose in the CA1 area. Incubation of slices with different concentrations IBMX in the presence of SNP, resulted in a concentration dependent increase in cGMPimmunostaining in the stratum lacunosum moleculare. In the CA1 area, a raised cGMP level was only found at the highest dose of IBMX used ( $1 \mathrm{mM}$ ).

In the absence of SNP, no effect of zaprinast could be detected in the stratum lacunosum moleculare or the CA1 area. When slices were treated with SNP and different concentrations of zaprinast, a significant increase in the intensity of the cGMP-immunostaining was detected in both areas at the highest dose tested (1 mM). 

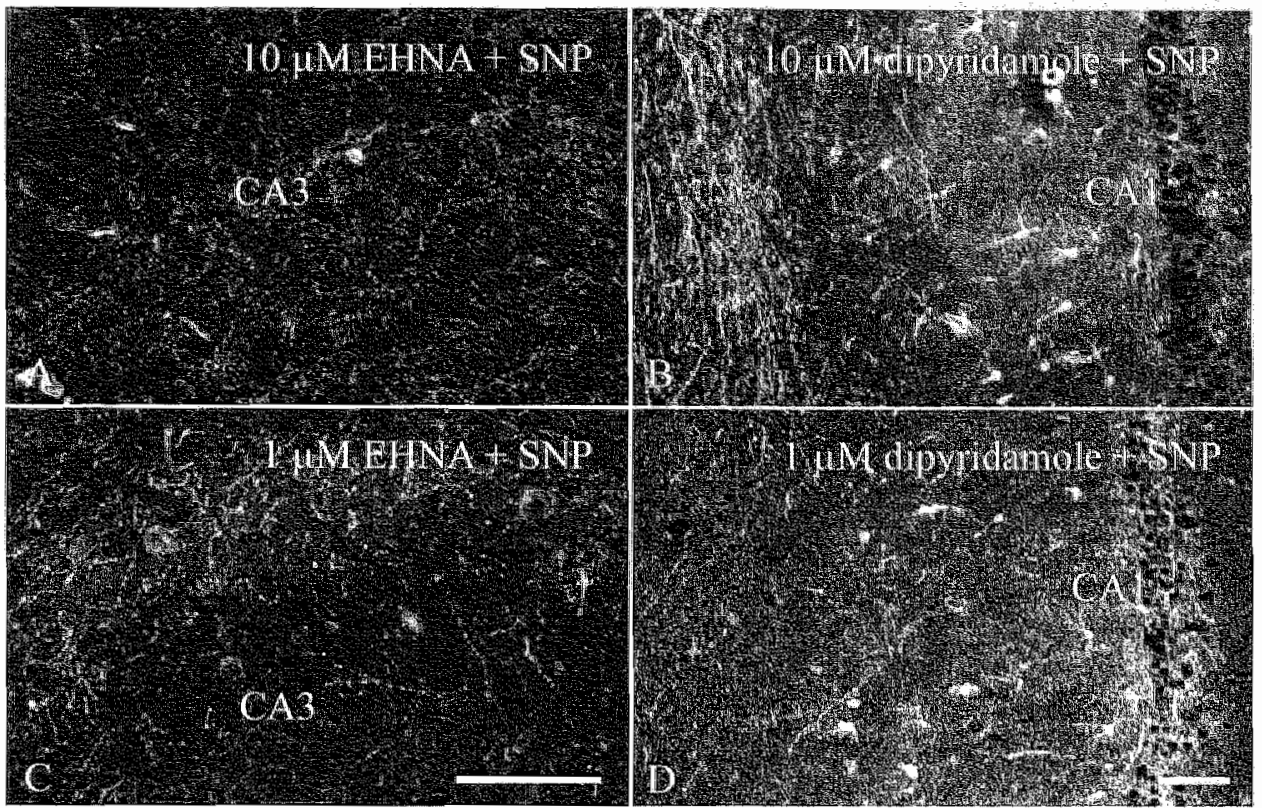

Figure 5. Localization of cGMP-immunoreactivity in the hippocampal slice incubated in the presence of $0.1 \mathrm{mM}$ SNP and 1 or $10 \mu \mathrm{M}$ of EHNA or dipyridamole. Bar represents $100 \mu \mathrm{m}$ for all pictures.

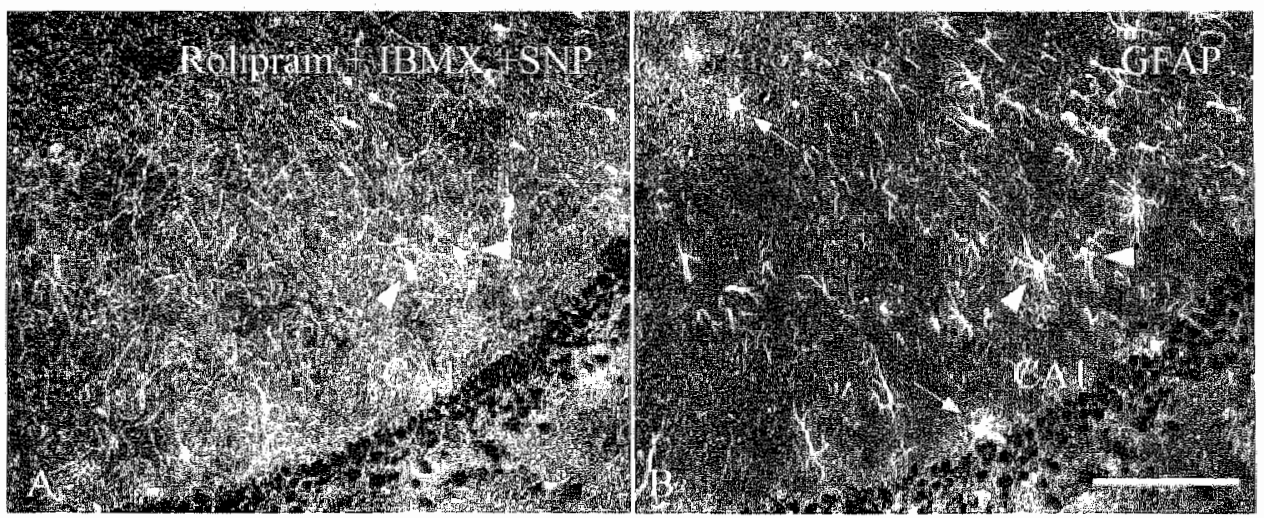

Figure 6. Localization of CGMP-immunoreactivity (A) in the hippocampal slice incubated in the presence of $0.1 \mathrm{mM}$ SNP and $0.1 \mathrm{mM}$ rolipram in combination with $1 \mathrm{mM}$ IBMX. GFAP immunostaining in $B$ shows the same field as in A indicating cGMP accumulation in a subpopulation of astrocytes. Arrowheads present. colocalization of CGMP and GFAP in astrocytes, arrows indicate astrocytes not stained for cGMP. Bar represents $100 \mu \mathrm{m}$ for hoth pictures. 

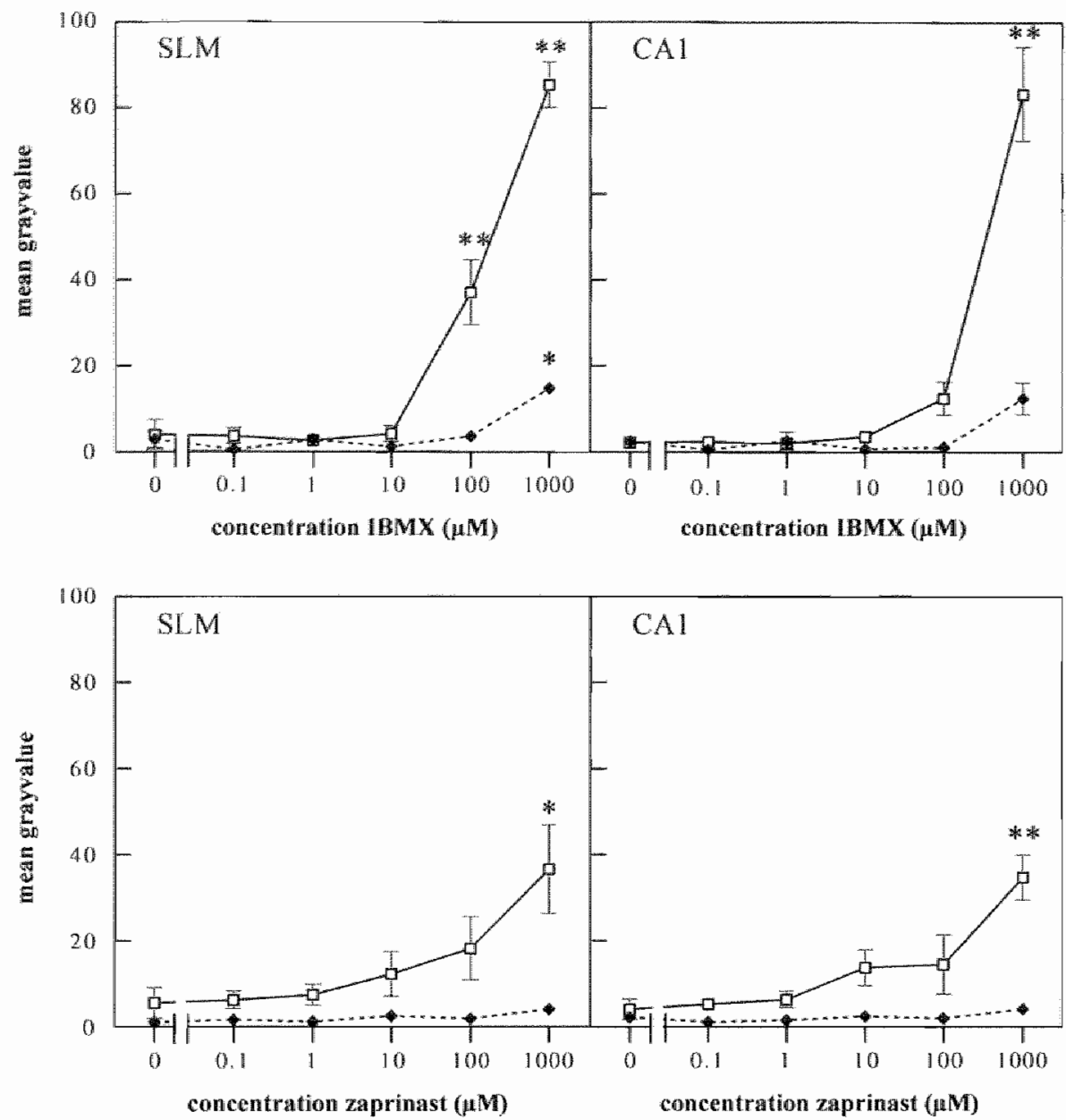

Figure 7. The effect of IBMX and raprinast on the lluorescence intensity of the CGMPimmunostaining in the stratum lacunosum moleculare (SLM) and the CA1 area of hippocampal slices of the rat, in the absence ( or presence ( $a$ ) of $0.1 \mathrm{mM}$ SNP, measured by image analysis. Each value is the mean (* S. I.M) of three animals. For each concentration three different. sections were annalysed per animal. Values which were different from control $(0 \mathrm{M})$ (Student: Nowman Kauls test) were manked as $*(p<0.05)$ and $* *(p<0.01)$.

\section{Discussion}

In this study, the effects of different PDE inhibitors on cGMP and cAMP levels in the hippocampus were investigated. In addition, we used cGMPimmunocytochemistry to localize the structures synthesising cGMP in the presence of PDE inhibitors and an NO donor. cGMP production was quantified by two different methods, i.e. by a radioimmunoassay and by taking the immunofluorescence intensity as a measure for the cGMP content. Both methods showed a similar pattern in the dose response curves 
when TBMX and zaprinast were analysed. It was found that the radioimmunoassay was more sensitive than the image analysis. At low concentrations, a significant effect could be detected by the radioimmunoassay but not by the use of image analysis. However, the use of cGMP-immunocytochemistry has the advantage that CGMP increases can be tracked which could otherwise escape detection. This is examplified by Fig. 5 where it is shown that low concentrations of EHNA and dipyridamole indeed increased cGMP in varicose fibers and (probably) astrocytes, whereas in the radioimmunoassay no significant increase in CGMP was measured. Thus we decided to localize the structures, which accumulate cGMP in the presence of highly selective PDE inhibitors in combination with an $\mathbb{N O}$ donor.

At present, several PDE types have been localized in the rat hippocampus. It has been shown with in situ hybridisation or immunocytochemistry that PDE1, PDE2, PDE3 and PDE4 are present in this brain area of the rat (Ludvig et al., 1991; Repaske et al., 1993; Furuyama et al., 1994; Reinhardt and Bondy, 1996; Suda et al., 1998). In an attempt to gain more insight in the localization of PDEs with different selectivity profiles, several PDE type inhibitors were used in this study. The PDE inhibitors studied include the highly selective inhibitors vinpocetine, calmidazolium (both PDE1 inhibitors), EHNA (PDE2) (Michie et al., 1996) and rolipram (PDE4). In addition, we used zaprinast and dipyridamole, which were until recently, considered to be highly selective inhibitors of PDE5 (Lugnier et al., 1986; Coste and Grondin, 1995). Recent evidence showed that zaprinast inhibited PDE9 also (Fisher et al., 1998a) and dipyridamole has affinity for PDE7 (Hetman et al., 2000), PDE8 (Fisher et al., 1998b; Soderling et al., 1998), PDE10 (Fujishige et al., 1999; Soderling et al., 1999) and the recently cloned PDE11 (Fawcett et al., 2000). In this study IBMX was used as a non-specific PDE inhibitor.

Selective inhibitors have a high affinity for a particular PDE. In our study, the effects in the radioimmunoassay are found at a relative high concentration of most inhibitors which could point to unspecific inhibition. However, if all the effects found would be due to unspecific reactions then it was expected that all the staining patterns were the same. Boulton and coworkers reported that $2 \mu \mathrm{M}$ zaprinast increased the cGMP content in the hippocampus. As shown in Fig. 1. we did not measure an effect of zaprinast at such low concentrations. To investigate if strain or sex differences might cause this difference we repeated the experiments using female Wistar rats, as used by Boulton and coworkers, and compared them with female Lewis rats. As shown in Table 1, we were not able to reproduce the effects that were found with zaprinast.

In literature, it has been shown that the potency of a PDE inhibitor might be higher on purified enzymes than found in cells or tissues. Coste and Grondin (1995) reported differences in the potency of the PDE5 inhibitor 1,3-dimethyl-6-(2-propoxy-5-methanesulfonylamidophenyl) pyrazolo[3,4d]-pyrimidin-4-(5H)-one (DMPPO) when an enzymatic PDE5 assay was compared to a cell model. A lower potency for inhibitors in a cell 
model or slices might be explained by cell permeability or intracellular metabolism. These factors are not involved when the purified enzyme is used. Furthermore, it is not known whether more than one PDE type is present in one cell. Therefore, it is possible that if a certain PDE is inhibited this could have an effect on another PDE type in this cell as well, which in turn can influence the cyclic nucleotide levels also.

Using immunocytochemistry for cGMP, it was found that the largest part of the $\mathrm{NO}$-mediated cCMP-immunostaining was present in varicose fibers. As shown previously (De Vente and Steinbusch, 1992; De Vente et al., 1996), inhibition of the PDE activity using non-specific PDE inhibitors as methylxanthines like IBMX (caffeine and theophylline not shown) in combination with an NO donor resulted in cGMP accumulation in varicose fibers throughout the hippocampus. As a somewhat varying response between experiments, cGMP-immunostaining was also found in astrocytes and a few interneurons under these conditions. In some experiments a very low level of cGMP-immunoreactivity was possibly observed in pyramidal cells in unstimulated slices. However, in the stimulated slice the cGMPstaining in these cells could not normally be observed, probably due to the intensity of the cGMP-immunofluorescence in the surrounding fibers (Fig. $3 \mathrm{~B}$ ), although a redistribution of cGMP through an as yet unknown mechanism might, also be involved. If cGMP-immunoreactivity is to be present in cell somata in the pyramidal cell layer, as has been suggested (Boulton et al., 1994), the concentration must be very low.

The cGMP-immunoreactive fibers in the hippocampus have not yet been characterized in terms of the major neurotransmitters and it is known neither from which projections area(s) these fibers originate. cGMPimmunostaining has been observed only in an occasional NOS immunoreactive hippocampal interneuron. The hippocampal cGMP-positive fibers in our study do not correspond in any aspect to the localization and direction of pyramidal dendritic or axonal fibers as visualized using eNOS antibodies or the modified NADPH-diaphorase stain (Dinerman et al., 1994).

It must be noted that EHNA, dipyridamole and IBMX exert different actions in adenosine pharmacology. EHNA is a potent inhibitor of adenosine deaminase whereas dipyridamole is an inhibitor of adenosine uptake, and IBMX is an adenosine receptor antagonist. If adenosine was involved in the cGMP response, we would expect EHNA and dipyridamole to have similar effects, because both compounds increase the adenosine concentration outside the cell (see e.g. Cunha et al., 1998). Indeed, the cGMPimmunostaining is rather similar when EHNA or dipyridamole is used in the presence of SNP. IBMX is an adenosine antagonist and, following the above reasoning, in the presence of IBMX it might be expected that the cGMP-staining would be less than the immunoreactivity obtained in the presence of EHNA or dipyridamole. However, in the presence of IBMX, cGMP-immunoreactivity was found in the hippocampus and was strongly increased in the presence of SNP. Furthermore, we did not observe any effect with a non-selective adenosine receptor agonist 5 - $-\mathrm{N}$ - 
ethylcarboxamidoadenosine (NECA) in a concentration of $0.1 \mathrm{mM}$, in the presence or absence of different PDE inhibitors on CGMP-immunostaining in the hippocampus slice. Therefore, we conclude tentatively that adenosine in not involved in the cGMP-response in the hippocampus slice.

Mayer and coworkers (1992) reported that especially the calcium dependent PDE1 activity is responsible for CGMP breakdown in the rat brain. Although we did observe a small increase in cGMP levels in the presence of vinpocetine alone, no effect was measured in the presence of SNP and vinpocetine. In addition, we did not find any effect of calmidazolium on cGMP levels in the hippocampus, the frontal brain, or the cerebellum of the rat. Under the conditions used, our results indicate that the inhibition of PDE1 does not have a major effect on cGMP breakdown in the hippocampus. In addition, no effect was found of the inhibition of PDE3 by SK\&F 95654 in oux" study also.

The results obtained with rolipram were unexpected. It was found that rolipram influenced both cGMP and cAMP levels. Rolipram alone increased the cAMP concentration in the hippocampus slice till a very high level, whereas a small raise in the cGMP content was detected also. When the effect of rolipram was studied by immumocytochemistry, cGMP positive astrocytes were found. These data suggest an interaction between cGMP and cAMP signaling pathways in the hippocampus, resulting in a massive increase in cAMP and a more restricted increase in cGMP in a subpopulation of astrocytes. This effect of rolipram on cGMP levels does not appear to be a general effect in all brain tissue as we found little, if any, cGMP-immunostaining in frontal cortical areas after incubation of slices in the presence of rolipram and SNP (not shown). Nevertheless, this observation is not completely without precedent, because recently it was reported that rolipram increased CGMP levels in endothelial cells through an NO-dependent mechanism (Kessler and Lugnier, 1995). A difference between our results and the observations of Kessler and Lugnier (1995) is that the effect of rolipram on cGMP levels in the hippocampus was unaffected by the presence of L-NAME, suggesting that NO was not involved.

Our results permit the following conclusions. First, our results indicate that several PDE isoforms are present in the rat hippocampus and function as part in the NO-cGMP signal transduction pathway. Nevertheless, the non-selective component in the pharmacological profile of the inhibitors used in the present study, makes it unlikely that the approach of cGMP. immunocytochemistry can be used for further characterization of the localization of PDE-isoforms. Secondly, the results obtained with rolipram strongly suggest that PDE 4 is present in a subpopulation of astrocytes in the hippocampus. 
Table 1. "Whe wects of waprinast and IBMX on oMP lewels (pmolme protein) in the absence or presence of 0.1 mW SNP in hippocampal slices from lemath Lewis (n = 3) and Wistan (n $=3$ )

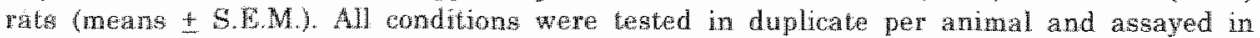

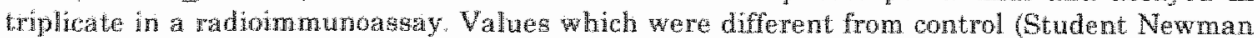

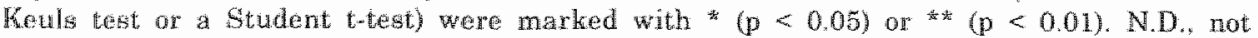
deteriable.

\begin{tabular}{lcccc} 
& \multicolumn{2}{c}{$\begin{array}{c}\text { without SNP } \\
\text { (pmol/mg protein) }\end{array}$} & \multicolumn{2}{c}{$\begin{array}{c}\text { in the presence of SNP } \\
\text { (pmol/mg protein) }\end{array}$} \\
\cline { 2 - 5 } & Lewis & Wistar & Lewis & Wistor \\
\hline Control & $0.03 \pm 0.16$ & $0.96 \pm 1.19$ & $1.25 \pm 0.54$ & $1.33 \pm 0.51$ \\
1 HM zaprinast & N.D. & $0.27 \pm 0.46$ & $1.08 \pm 0.19$ & $0.98 \pm 0.68$ \\
$10 \mu M$ zaprinast & N.D. & $0.06 \pm 0.26$ & $1.51 \pm 0.28$ & $1.56 \pm 0.61$ \\
100 HM zaprinast & N.D. & N.D. & $2.54 \pm 0.20^{*}$ & $2.36 \pm 0.83$ \\
1 mM zaprinast & $0.13 \pm 0.26$ & $0.17 \pm 0.32$ & $5.66 \pm 0.30^{\circ}$ & $5.40 \pm 1.63^{\circ}$ \\
1 mM IBMX & $2.69 \pm 0.32^{*}$ & $1.62 \pm 0.24$ & $20.33 \pm 3.39^{*}$ & $15.98 \pm 3.75^{\circ}$ \\
\hline
\end{tabular}

\section{References}

BEAVO JA. (1995) Cychic nucleotide phosphodiesterases: functional implications of multiple isoforms. Physiol Reu 75: 725-748.

BILLINGSLEY ML, POLAL JW, BALABAN CD, KINCAID RL (1990) Developmental exprassion of calmodulin dependent cyclic nucleotide phosphodiesterase in rat brain. Brow Res Dew Bratin Res 53: 253-263.

BOULTON CL, IRVING AJ, SOUTHAM F, POTITR B, GARTHWATTE I, COLLINGRIDGE GT. (1994) The nitric oxidemeyclic GMP pathway and synaptic depression in rat hippocampal slices. Eur of Neurose 6: $1528-1535$.

BREDT DS, SNYDER SH. (1989) Nitric oxide mediates glutamatelinked enhancement of cGMP levels in the cerebellum. Proe Nat Acad Sci U S A 86: 9030-9033.

BREDT DS, HWANG PM, SNYDER SH. (1990) Lacalization of nitric oxide synthase indicating a netral role for nitric oxide. Nature $347: 768-770$.

CONTI M, JIN SLC. (1999) The molecular biology of cyclic nucleotide phosphodiesterases. Prog Nublec Acid Res Mol Diol 65: 1-38.

COSTE H, GRONDLN P. (1995) Characterization of a movel potent and specific inhibitor of type $\mathrm{V}$ phosphodicsterase. Biochem Phamacol 50: 1577-1585.

CUNHA RA, SEBASTIAO AM, RIBEIRO JA. (1998) Inhibition by ATP of hippocampal synaptic transmission requires localized extracellular catobolism by ecto-nucleotidases into adenosine and channeling to adenosine Al receptons. of Neurosei 18: 1987-1995.

DE VENTE d, BOL JGM. HUDSON L, SCHIPPRR J, STEINBUSCH INWM. (1988) Al natriuretic factormesponding and cyclic guanosine monophosphate (cCMP)-producing cells in the rat hippocampus: a combined mirropharmacological and immunocytochemical. apposeh. Broin Ras 446:387-395.

DE VENTE . STEINBUSCH HWM. (1992) On the stmatation of soluble and particulate guanylate cychse in the rat brain and the involvement of nitric oxide as studied by cGMP immunoytochemistry. Acta Hishochem 92: 13-38.

DE VENTE D. HOPKINS DA. MARKERINK-VAN ITTERSUM M. STEINBUSCH HWM. (1996) Effects of the 3,5'phosplodiesterase inhibitors isobutylmethylxanthine and zaprinast, on NO-mediated cGMP accumulation in the hippocampus slice preparation: an

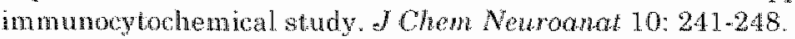

DE VENTE I, HOPKINS DA, MARKERINK-VAN ITTERSUM M, EMSON PC, SCHMIDT HHHW, SHENBUSCH HWM. (1998) Distribution of nitric oxide synthese and nitric oxidereceptive, cyclio CMP-producing stuctures in the rat brain. Neuroscrence $87: 207-241$. 
DINERMAN JL, DAWSON TM, SCHELL MJ, SNOWMAN A, SNYDER SH, (1994) Endothelial nitric oxide synthase localised to hippocampal pyranidal cells: implications for aynaptic plasticity. Proc Noll Acod Sci U S A 91: 4214-4218.

FAWCETT L, BAXENDALE $R$, STACEY P, MCGROUTHER C. HARROW I, SODERLING $S$, HETMAN J, BEAVO JA, PHILAIPS SC (2000) Molecular cloning and characterigation of a distinct human phosphodiesterase gene family: PDE11A. Proc Natl Acod Sei O S A7: $3702 \times 3707$.

FISHER DA, SMITH JF, PILLAR JS, ST DENIS SH, CHENG JB. (1998a) Isolation and characterization of $P D E 9 A$, a novel human CGMP-specific phosphodiesterase. \& Biol Chem 273: 15559-155564.

PISHER DA, SMITH JF, PLLLAR JS, ST DENES SH, CHENG JB. (1998b) Lsolation and characterization of PDE8A, a novel human eAMP-specific phosphodiesterase. Biochem Blophys Res Commun 246: 570-577.

FOWLER JC, ODONNELL JM. (1988) Antagonism of the responses to isoproterenol in the rat hippocampal slice with subtype-selective antagonists. Eur el Pharmacol 158: 105-110.

FUJISHIGE K, KOTERA J, MICHIBATA H, YUASA $K$, TAKEBAYASHI S, OKUMURA $K$, OMORI K. (1999) Cloning and characterization of a novel human phosphodiesterase that hydrolyzes both cAMP and CGMP (PDE10A). I Biol Chem 274: 18438-18445.

FURUYAMA "T, IWAHASHI $Y$, TANO Y, TAKAGI H, INAGAKI S. (1994) Localization of 63 . kDa calmodulin-stimulated phosphodiesterase mRNA in the rat brain by in situ hybridization histochemistry. Broin Res Mol Brain Res 26: 331 -336.

GARTHWAITE J. (1991) Glutamate, nitric oxide and cellocell signalling in the nervous system. Trends Meurosci 14: 60-67.

GARTHWAITE d, BOULTON CL. (1995) Nitric oxide signaling in the central nervous system. Annu Rev Physiol 57: 683-706.

HETMAN JM SODERLING SH, GLAVAS NA. BEAVO JA. (2000) Cloning and characterization of PDE7B, a cAMP-specific phosphodiesterase. Proc Natl Acad Sci U SA 97: $472 \cdot 476$

HOUSLAY MD. (1996) The N-treminal alternately spliced regions of PDE4A CAMP-specific phosphodiesterases determine intracellular targeting and regulation of catalytic nctivity. Biochem Soc Trans 24: 980-986.

IWAIFASHT $Y$, FURUYAMA "T, TANO Y, ISHIMOTO I, SHIMOMURA Y, INAGAKI S. (1996) Differential distribution of $m R N A$ encoding CAMP-specific phosphodiesterase isoforms in the rat brain. Brain Res Mol Broin Res 38: 14-24.

JUTLFS DM, FULLE HeI, ZHAO AZ, HOUSLAY MD, GARBERS DL, BEAVO JA (1997) A subset of olfactory neurons that selectively express CGMP.stimulated phosphodiesterase

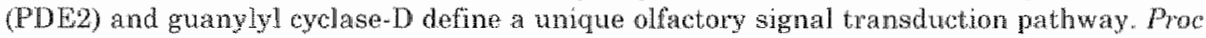
Natl Acod Sci US A 94: 3388.3395.

KESSLER T: LUGNIER C. (1995) Rolipram increases cyclic GMP content in L-aryinine-treated cultured bovine aortic endothelial cells. Fur of Pharnacol 290: $163-167$.

KTNCAD RL, BALABAN CD, BLLINGSLEY ML. (1987) Differential localization of calmodulin-dependent enzymes in rat brain: evidence for selective expression of oyclic nurleotide phosphodiesterase in specific neurons. Proc Noll Acad Sci U S A 84: $1118-1122$.

KNOWLES RG, PALACIOS M, PALMER RM, MONCADA S. (1989) Formation of nitric oxide from $\mathrm{L}$-arginine in the central nervous system: a transduction mechanism for stimulation of the soluble guanylate cyclase. Proc Natl Acad Sci U SA 86: $5159-5162$.

LEV-RAM V, JIANG T, WOOD d, LAWRENCE DS, TSIEN RY. (1997) Symergies and coincidence requirements between $\mathrm{NO}, \mathrm{CMMP}$, and $\mathrm{Ca}{ }^{2}$ in the ind uction of corobellas longterm depression. Nezron 18: 1025-1038.

LOWRY OH, ROSEBROUGH NJ, FARR AL, RANDALL FU, (1951) Protein meaturements with the Folin reagent of Biol Chem 193: 267-275.

LUDVIG N, BURMEISTER $V$, JOBE PC, KEINCAID RL, (1991) Electron nicruscopic immunocytochemical evidence that the calmodulin-dependent cyclic nucleotide phosphodiesterase is localized predominantly at postsynaptic sites in the wat brain Neuroscience 44: 491.500.

LUGNIER C, SCHOEFFTER P, LE BEC A, STROUTHOU E, STOCLITT JC. (1986) Selective inhibition of cyclic nucleotide phosphodiesterases of human, bovine and rat aorta. Biochem Pharmocol 35: 1743-1751. 
MAYER B, KLATT P, BOHME E, SCHMIDT K. (1992) Regulation of newronal nitric oxide and cyclic GMP formation by $\mathrm{Ca}^{23}$. I Neurochem 59: 2024-2029.

MICHE AM, LOBPAN M, MULLER T, HARNETI" MM, HOUSI AY MD. (1996) Rapid regulation of PDE-2 and PDE-4 cyclic AMP phosphodiesterase activity following ligation of the $T$ cell antigen receptor on thy mocytes: analysis using the selective inhibitors erythro- $9-$ (2-hydroxy-3-nonyl)-adenine (EHNA) and rolipram. Cell Signal 8: 97-110.

ODELL TJ, HAWKINS RD, KANDEL ER, ARANCIO O. (1991) Tests of the roles of two diffusible substances in long-term potentiation: evidence for nitric oxide as a possible early retrograde messenger. Proc Nall Acad Sci U S A 88: 11285-11289.

POLLI JW, KINCAID RL. (1994) Expression of at calmodulin-dependent phosphodiesterase isoform (PDE1B1) correlates with brain regions having extensive dopaminergic innervation. I Neurosei 14: 1251-1261.

REINHARDT RR, BONDY CA. (1996) Differential cellular pattern of gene expression for two distinct cGMP-inhibited cyclic nucleotide phosphodiesterases in developing and mature rat brain. Neurascience 72: 567-578.

REPASKE DR, CORBIN JG, CONTI M, GOY MF. (1993) A cyclic GMP-stimulated cyclic nucleotide phosphodiesterase gene is highly expressed in the limbic system of the rat brain. Neuroscience 53: 673-686.

SAKAGAMI H, SAWAMURA Y, KONDO H. (1995) Synchonous patchy pattern of gene expression for adenylyl cyclase and phosphodiesterase but discrete expression for G-protein in developing rat striatum. Brain Res Mol Brain Res 33: 185-191.

SHUTWLEWORTH CW, XUE C, WARD SM, DE VENTE J, SANDERS KM. (1993) Immunohistochemical localization of $3^{\prime}, 5$ '-cyclic guanosine monophosphate in the canine proximal colon: responses to nitric oxide and electrical stimulation of enteric inhibitory neurons. Neuroscience 56: 513.522 .

SODERLING SH, BAYUGA SU, BEAVO JA. (1998) Cloning and characterization of a CAMPspecific cyclic nucleotide phosphodiesterase. Proc Natl Acad Sci U S A 95: 8991-8996.

SODERLING SH, BAYUGA SJ, BEAVO JA. (1999) Isolation and characterization of a dualsubstrate phosphodiesterase gene family: PDE10A. Proc Natl Acad Sci U S A 96: 7071 . 7076.

SODERLING SH, BEAVO JA (2000) Regulation of CAMP and CGMP signaling: new phosphodiegterases and new functions. Curr Opin Celt Biol 12: 174-179.

STEINER AL, PARKER CW, FIPNIS DM. (1972) Radioimmunoassay for cyclic nucleotides. II. Preparation of antibodies and iodinated cyclic nucleotides. ef Biol Chem. 247: 1106-1113.

SUDA S, NIBUYA M, ISHIGURO T, SUDA H. (1998) Transcriptional and translational regulation of phosphodiesterase type IV isozymes in rat brain by electroconvulsive seizure and antidepressant drug treatment. I Neurochen 71: 1554-1563.

VINCENT SR, KIMURA H. (1992) Histochemical mapping of nitric oxide synthase in the rat brain. Neurascience $46: 755-784$.

YAN C, BENTLEY JK, SONNENBURG WK, BEAVO JA, (1994) Differential expression of the $61 \mathrm{kDa}$ and $63 \mathrm{kDa}$ calmodulin-dependent phosphodiesterases in the mouse brain. I Nenrosci 14: 973-984. 


\section{Comparison of NO-dependent and NO- independent stimulation of soluble guanylyl cyclase in rat forebrain slices: a micropharmacological study}

Wilma C.G. van Staveren, ${ }^{1}$ Harry W.M. Steinbusch, ${ }^{1}$ Marjanne Markerink-

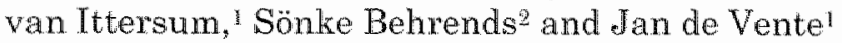

Dept. of Psychiatry and Neuropsychology, Division Cellular Neuroscience, Maastricht University, European Graduate School of Neuroscience (EURON), P.O. Box 616, 6200 MD Maastricht, The Netherlands; 'Institute of Experimental and Clinical Pharmacology and Toxicology, University Clinic Hamburg-Eppendorf, Hamburg, Germany

Submitted to Neuropharmacology

\section{Abstract}

Nitric oxide (NO) plays a key role in cellular neurotransmission by stimulation of soluble guanylyl cyclase ( $\mathrm{sGC}$ ) to produce cGMP. The effect of number of $\mathrm{NO}$-dependent and NO-independent $\mathrm{SGC}$ activators on cGMP accumulation was investigated in rat frontal brain slices incubated in vitro. The NO-dependent activation was investigated by using the NO donors sodium nitroprusside, S-nitrosoglutathione, 3-morpholinosydnonimine and diethylamino NONOate. The NO donors showed dose-dependent activation of cGMP synthesis as measured by two independent ways: a standard radioimmunoassay and by measurements of cGMP-immunofluorescence using image analysis. A high correspondence was found between these methods to evaluate cGMP levels in slices. All NO donors induced similar cGMP-staining patterns in frontal cortex, hippocampus, and thalamus. NO. dependent activation of $\mathrm{sGC}$ was completely abolished by the $\mathrm{sGC}$ inhibitor ODQ in frontal cortex and hippocampus however not in the thalamus. Double labeling with markers for neurotransmitter systems revealed that cGMP accumulation in the frontal cortex was predominantly present in fibers that were positively stained for the acetylcholine transporter, whereas occasionally double labeling was observed with the GABAergic marker parvalbumin or the neuronal glutamate transporter. Similar observations were made with the $\mathrm{NO}$-independent activators $\mathrm{YC}-1$ and $\mathrm{BAY}$ 41-2272. In contrast, combination of an $\mathrm{NO}$ donor with $\mathrm{YC}-1$ or $\mathrm{BAY} 41.2272$ potentiated cGMP synthesis and resulted in more abundant cGMP. immunoreactivity in GABAergic and glutamatergic cells.

To summarize, our results show that, although NO donors differ in potency to stimulate cGMP synthesis, the cellular patterns of cGMP accumulation are similar in the three brain areas studied. In the frontal 
cortex, cGMP was predominantly present in cholinergic fibers after NOdependent or NO-independent activation of $\mathrm{sGC}$. In the majority of the GABA-ergic and glutamatergic neurons $\mathrm{s} G \mathrm{GC}$ becomes responsive to $\mathrm{NO}$ only after sensitization of the enzyme by YC-1. or BAY $41-2272$.

\section{Introduction}

Endogenous nitric oxide (NO) formation and the subsequent stimulation of soluble guanylyl cyclase (sGC, GTP pyrophosphate-lyase (cyclizing), E.C. 4.6.1.2) is an essential cellular communication pathway in the nervous system of all animal species studied to date (Garthwaite, 1991, 1995; Jacklet, 1997; Bicker, 2001). $\mathrm{sGC}$, which is abundantly expressed in the brain (Schmidt et al., 1992; Burgunder and Cheung, 1994; Gibb and Garthwaite, 2001; Mergia et al., 2003), converts guanosine 5'-triphosphate (GTP) into guanosine 3',5'-cyclic monophosphate (cGMP) after binding of NO to the prosthetic hemegroup of the enzyme (Stone and Marletta, 1995). The second messenger cGMP, exerts its action by influencing the activity of a number of intracellular targets including cGMP-dependent protein kinases (Lohmann et al., 1997), cyclic nucleotide ion channels (Wei et al., 1998) and 3',5'-cyclic nucleotide phosphodiesterases (PDEs) (Beavo, 1995; Conti and Jin, 1999; Francis et al., 2001).

sGC can be activated in an NO-dependent way by using NO donors such as sodium nitroprusside (SNP), S-nitrosoglutathione (SNOG), 3morpholinosydnonimine (SIN-1) or diethylamino NONOate (DEA/NO). These compounds are often used in an indiscriminate manner, although the mechanisms of NO release from these compounds are different (Feelisch, 1998) and in the case of SNP is still controversial (Bates et al., 1991; Kowaluk et al., 1992; Kruszyna et al., 1993; Feelisch, 1998). In addition to the activation of $\mathrm{sGC}$ by $\mathrm{NO}$, it has been described recently that $\mathrm{sGC}$ can be stimulated in an NO-independent way by compounds like $\mathrm{YC}-1$ (3-(5"hydroxymethyl-2'-furyl)-1-benzylindazole) (Ko et al., 1994; Friebe and Koesling, 1998) and BAY 41-2272 (Stasch et al., 2001; Koglin et al., 2002).

Recently it was suggested that there are important differences in the efficiency of NO donor metabolism in different regions of the central nervous system or in the mechanism of $\mathrm{SGC}$ activation by NO donors (Nedvetslsy et al., 2002a). Furthermore, differential sensitivity among NO donors towards ODQ (1H-[1,2,4]oxadiazolo[4,3-a]-quinoxalin-1-one\}, a potent inhibitor of sGC through oxidation of the hemegroup (Garthwaite et al., 1995), has been reported in vascular tissue (Tseng et al., 2000). In addition, differences have been demonstrated towards $O D Q$ sensitivity comparing aortic rings and cardiomyocytes (Wegener et al., 1999), indicating not all cell types respond in a similar manner to these compounds.

To our knowledge it has not been described whether different $\mathrm{NO}$ donors cause cGMP accumulation in different cellular compartments. Southam and Garthwaite (1991) compared four different NO donors quantitatively on cGMP synthesis in cerebellar slices. It was reasoned that the effective NO 
concentration is governed by dissociation of $\mathrm{NO}$, rather than by diffusion of the NO donor. The effect of an NO donor is dependent on its degradation rate which might be influenced by the properties of cells or tissue, and therefore the cellular localization of $\mathrm{CGMP}$ accumulation might be different, depending on the NO donor used. Hence, the aim of our study was to compare the effects of four commonly used NO donors on cGMP accumulation in slices of rat frontal cortex, hippocampus and thalamus. The NO donors used were SNP, SNOG, SIN-1 and DEA/NO. The studies were performed either by using a classical cGMP-radioimmunoassay or by cGMP. immunofluorescence measurements evaluated by image analysis. In addition, we investigated the effects of the NO-independent activators of $\mathrm{sGC}$, $\mathrm{YC}-1$ and $\mathrm{BAY}$ 41-2272. cGMP-immunoreactive structures were characterized in relation to the neurotransmitters acetylcholine, GABA and glutamate, using respectively antibodies directed against the acetylcholine transporter (VAch T), parvalbumin and the neuronal glutamate transporter $(\mathbb{E A A C 1})$ as marker molecules.

\section{Materials and Methods}

\section{Materials}

SNP, SIN-1, DEA/NO and IBMX were from Sigma-Aldrich (Steinheim, Germany). SNOG was synthesized according to Hart (1985). YC-1 was purchased from Alexis (San Diego, CA, USA). BAY 41-2272 was obtained from BAYER AG (Wuppertal, Germany). ODQ was from Tocris Cookson Ltd. (Avonmouth, United Kingdom). Rabbit anti-vesicular acetylcholine transporter (VAchT) was from Phoenix Pharmaceuticals (Belmont, CA, USA). Rabbit anti parvalbumin was a gift of P.C. Emson (Cambridge, United Kingdom), rabbit antinglutamate transporter was a gift of J.D. Rothstein (Baltimore, MD, USA). Antiserum directed against $\beta 1$ subunit was from S. Behrends (Hamburg, Germany). Sheep anti cGMP serum was raised by $J$. de Vente (Maastricht, The Netherlands). Alexa fluor 488 donkey anti-sheep IgG conjugate was from Molecular Probes (Leiden, The Netherlands) and CY-3 conjugated donkey anti-rabbit antiserum was obtained form Jackson (Pennsylvania, USA).

\section{Animals}

Adult male Lewis rats (aged two to three months) were reared under standard conditions at the local animal facility. Experiments were approved by the committee on animal welfare according to Dutch governmental rules.

In vitro incubation of brain slices

Animals were decapitated and their brains were immediately transferred into ice-cold Krebs-Ringer bicarbonate buffer (Krebs buffer) of the following composition: 121.1 mM NaCl, $1.87 \mathrm{mM} \mathrm{KCl,} 1.17 \mathrm{mM} \mathrm{KH} \mathrm{mO}_{4}, 1.15 \mathrm{mM}$ 
$\mathrm{MgSO}_{*}, 26.2 \mathrm{mM} \mathrm{NaHCO}_{3}, 2.0 \mathrm{mM} \mathrm{CaCl}$ and $11.0 \mathrm{mM}$ ghucose, aerated with $95 \% \mathrm{O}_{2}$ and $5 \% \mathrm{CO}_{2}$ at pH 7.4 .

Coronal slices (400 $\mathrm{\mu m}$ ) were cut using a Vibroslicer (Campden Instruments) containing the hippocampus, frontal cortex and thalamus (Bregma $-2.30 \mathrm{~mm}$ to $-4.16 \mathrm{~mm}$ ). For the biochemical assay of cGMP the hippocampus was dissected and cut into slices $(400 \mu \mathrm{m})$ with a Mcllwain tissue chopper. Throughout the procedure, slices were kept under aeration with $95 \% \mathrm{O}_{2}$ and $5 \% \mathrm{CO}_{2}$. After sectioning in ice-cold Krebs buffer, slices were brought to room temperature and then transferred to incubation wells and incubated for 30 minutes at $35.5^{\circ} \mathrm{C}$ in Krebs buffer containing $1 \mathrm{mM} 3$ isobutyl-1-methylxanthine (IBMX) to inhibit PDE activity. Next, the slices were incubated with different concentrations of an NO donor for another 10 minutes. The NO donors used were SNP, SNOG, SIN-1 and DEANO. To inhibit $\mathrm{sGC}, \mathrm{ODQ}$ was added to the slices in different concentrations, and was present throughout the incubation period. NO-independent stimulation of $\mathrm{sGC}$ was investigated with $\mathrm{YC}-1$ and $\mathrm{BAY} 41-2272$ and these compounds were also present throughout the entire incubation period. The $\mathrm{NO}$ donors and IBMX were dissolved in Krebs buffer. ODQ, YC-1 and BAY 41-2272 were dissolved in dimethylsulfoxide (DMSO), resulting in a final concentration of $0.5 \%$ DMSO during the incubation. A similar concentration of DMSO was used in the appropriate controls.

After a total incubation time of 40 minutes, incubations were terminated by fixation of the slices for immunocytochemistry or by placing slices in trichloroacetic acid solution for determination of cGMP levels by a radioimmunoassay, as described below.

\section{Immunocytochemistry}

After the incubation period, slices were fixed with ice-cold fixative solution of $4 \%$ freshly prepared depolymerised paraformaldehyde in $0.1 \mathrm{M}$ phosphate buffer ( $\mathrm{pH} 7.4$ ) for 30 minutes at $4{ }^{\circ} \mathrm{C}$. Thereafter, slices were fixed for another 90 minutes with $4 \%$ paraformaldehyde containing $10 \%$ sucrose. After washing at $4^{\circ} \mathrm{C}$ in $0.1 \mathrm{M}$ phosphate buffer $(\mathrm{pH} 7.4$ ) containing $10 \%$ sucrose, slices were aligned in a plane and snap-frozen with $\mathrm{CO}_{2}$ in Tissue. Tek O.C.T. compound. Cryostat sections $(10 \mu \mathrm{m})$ were cut and thawed onto chrome-alumn/gelatin coated slides and processed for immunocy tochenistry.

Frozen sections were dried for 20 minutes at room temperature, followed by three 5 minutes washes with Tris-buffered saline (TBS). Sections were incubated overnight at $4{ }^{\circ} \mathrm{C}$ with primary antibodies diluted in TBS containing $0.3 \%$ Triton X-100 (TBS-T). cGMP was visualized with sheep anti-formaldehyde fixed cGMP (1:4000). "The specificity of the cGMP antibody has been detailed elsewhere (De Vente et al., 1998). Sections were incubated with the anti-cGMP alone or in combination with other primary antibodies. The primary antisera used for double staining were rabbit antiacetylcholine transporter (VAchT) (1:2000), rabbit anti-parvalbumin (1:1500), rabbit anti.glutamate transporter (EAAC1, 1:300) (Furuta et al, 1997). The $B 1$ subunit of SGC was visualized with rabbit antibodies directed 
against this subunit (1:2000) (Behrends et al, 2001), After incubation with primary antibodies, sections were washed with TBS-T, TBS and TBS-T, each step lasted $10 \mathrm{~min}$. For the visualization of the primary antibodies sections were incubated with Alexa fluor 488 donkey anti-sheep $\operatorname{IgG}$ conjugate (1:100) for sheep antibodies, whereas rabbit antibodies were visualized with CY.3 conjugated donkey anti-rabbit antiserum (1:800). Incubations with the secondary antibodies lasted for $90 \mathrm{~min}$ in the dark at room temperature. Thereafter, sections were washed in TBS-T and TBS, and mounted with TBS-glycerol.

\section{Image analysis}

For the semi-quantitative measurement of the cGMP content, sections were immunostained for cGMP as described above, taking into account that al] sections from one experiment were processed in one series under identical conditions. Each condition was tested in three animals or more. From each slice, three thin sections were analyzed. From each section, different pictures of were taken at a magnification of $10 \mathrm{x}$ using a Sony Power HAD camera or an Olympus F-view cooled CCD camera (Paes, Zoeterwoude, The Netherlands). All pictures were analyzed with the computer program analySISB Vers.3.0. (Soft Imaging System, Münster, Germany). For each image, the mean fluorescence intensity was calculated over the entire field as a measure for the cGMP content of the hippocampal area. Details of the measurements are given in the figure legends. All measurements were corrected for control sections which were incubated without the primary antibody.

\section{Radioimmunoassay}

cGMP levels were determined in individual hippocampal slices, using a radioimmunoassay as described previously (De Vente et al, 1.988). Briefly, the incubations were terminated by placing slices in $5 \%$ trichloroacetic acid solution. Subsequently, the samples were sonicated and centrifuged. After diethylether extraction, the supernatant was analyzed for the cGMP content, using a radioimmunoassay according to Steinet" et al. (1972). The pellet was analyzed for the protein content according to Lowry et al. (1951). cGMP levels were measured in triplicate and the median was taken for each sample. For each hippocampal slice, the cGMP level was corrected for the protein content.

\section{Statistical analysis}

To determine whether different concentrations of a compound tested, differed from its control, a Student Newman Keuls test and a Student t-test were used. 


\section{Results}

The effects of four frequently used NO donors on cGMP levels were studied in rat frontal brain slices. These studies were all done in the presence of 1 mM IBMX to inhibit PDE activity. As reported previously, inhibition of PDE activity during in vitro incubation of rat forebrain slices is necessary to visualize the structures where NO donors stimulate cGMP synthesis (De Vente et al., 1998; Van Staveren et al., 2001).
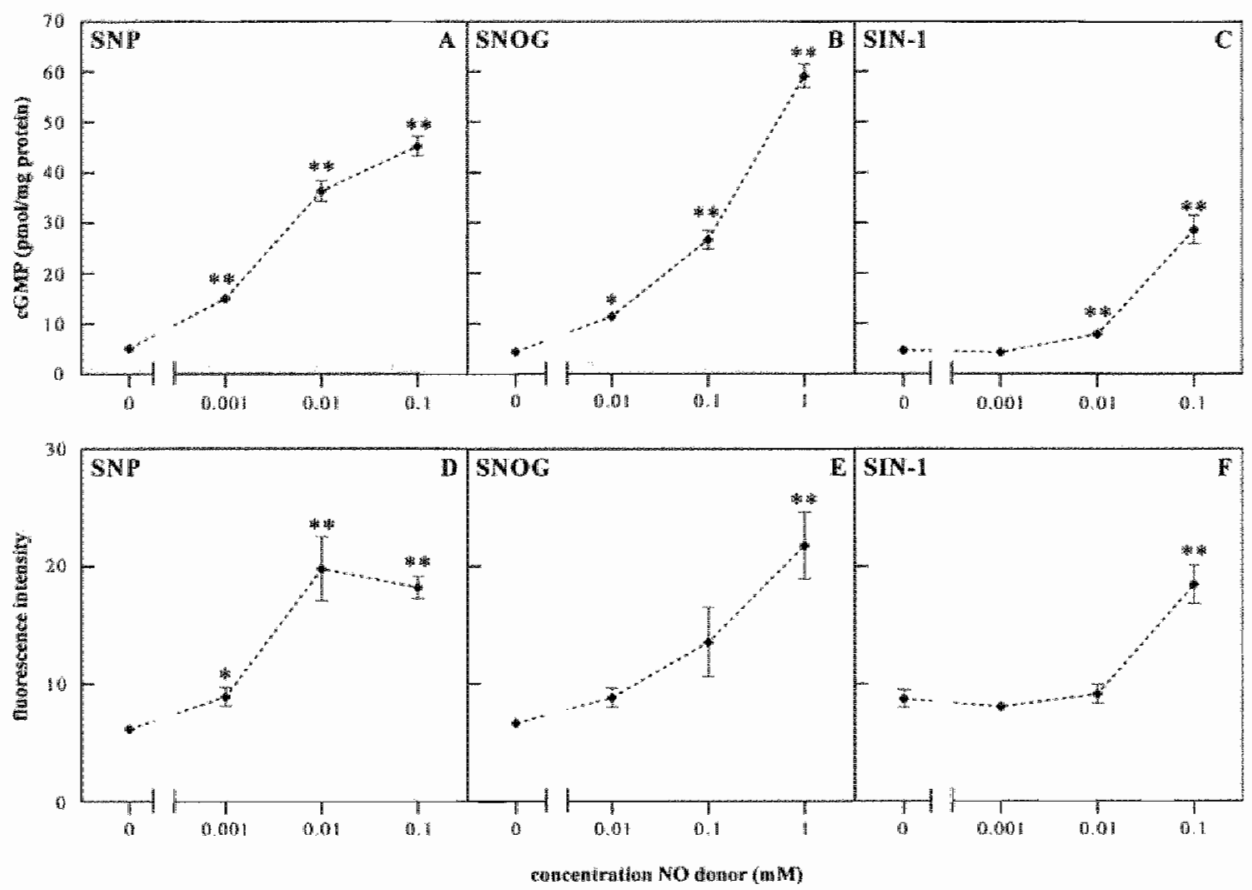

Figure 1. Stimulation of CQMP synthesis in rat hippocampal slices by the NO donors SNP. SNOG and SIN- 1 as determined with a radioimmunoassay (A-C) or by measurement of cGMP. immunofluorescence intensity by using image analysis (D-F). All incubations were performed in the presence of $1 \mathrm{mM} I \mathrm{IBMX}$. For image analysis, immunofluorescence in the hippocampal regions CA1 and dentate gyrus was recorded using a Sony power-HAD CCD color camera. Pictures were stored digitally using the program analysis. After color separation of the image. the intensity values were converted into gray values, divided in classes 0.265 , and the mean intensity was calculated over the complete area of each photograph using analySIS image processing software. For both methods, three animals per NO donor were used and each NO donor concentration was tested in duplicate per animal. Values which were different from control are marked as ** $(\mathrm{P}<0.01)$ or * $(\mathrm{P}<0.05)$.

Characterization of NO-mediated cGMP synthesis in brain slices

Dose response curves were established of the NO donors SNP, SNOG and SIN-1 for the stimulation of cGMP synthesis in hippocampal slices. cGMP levels in slices were evaluated in two independent ways. First, cGMP levels 
were determined using the classical radioimmunoassay (Fig. 1A-C). Second, the immunofluorescence signal, as shown for SNP in Fig. 4A, was quantified for these three compounds by measuring cGMP-immunofluorescence intensity, using image analysis (Fig. 1D-F). Both methods revealed that SNP was the most potent NO donor with an $\mathbb{E C}_{50}$ of $5 \mu \mathrm{M}$. The potency of SNOG was about tenfold less, and the dose-response curve for SIN-1 was not complete at $0.1 \mathrm{mM}$. Comparison of the dose response curves obtained with both methods indicates a good correspondence between the increase in immunofluorescence intensity and the increase in cGMP measured using a radioimmunoassay. Thus, the semi-quantitative analysis of the visualized cGMP-immunoreactivity gives a reliable representation of the cGMP increase. Therefore it was chosen to quantify cGMP by image analysis in further experiments. By this approach the cellular structures containing cGMP can be further characterized in the same tissue section and thereby additional information valuable for further pharmacological manipulation can be obtained.

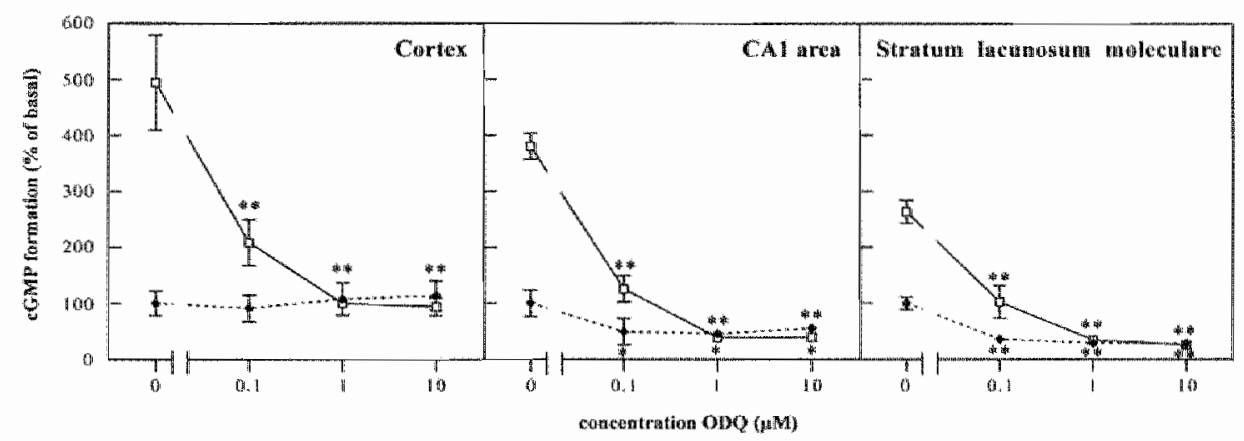

Figure 2. Inhibition of SGC by ODQ in rat frontal cortex and in CA1 area and stratum Jacunosum moleculare of the hippocampus, in the absence (-) or presence (i.) of $0.1 \mathrm{mM}$ SNP, measured by image analysis. All incubations were performed in the presence of 1 mM IBMX. CGMP-immunofluorescence was recorded using an Olympus F-view cooled CCD chmern, and the mean intensity was calculated over the total recorded area using analysis soft ware. Bach condition was tested in three animals. From each slice, three sections were analyzed. From. each section, pictures were recorded from the frontal cortex and the hippocampal areas CA1 area and the stratum lacunosum moleculare. cGMP-immunofluorescence is expressed as percentage of basal (without SNP). Values which were different from control are mankud as w.* $(\mathrm{P}<0.01)$ or $*(\mathrm{P}<0.05)$

\section{Inhibition of $S G C$ by $O D Q$ in brain slices}

The effect of $O D Q$ on NO-mediated. CGMP synthesis was evaluated in three brain areas, hippocampus, frontal cortex and thalamus, to investigate if similar responses were obtained in these areas. Measurements of cGMP. immunofluorescence in hippocampus tissue sections were done separately in CA1 and stratum lacunosum moleculare. As shown in Fig. 2, under basal conditions ODQ already decreased cGMP levels by $51 \%$ and $64 \%$ at the 
lowest dose tested $(0.1 \mu \mathrm{M})$ in $\mathrm{CA1}$ and stratum lacunosum moleculare respectively, demonstrating inhibition of ongoing cGMP synthesis in the hippocampus slice. In contrast, even at the highest dose of ODQ tested ( 10 $\mu M$ ), no significant inhibition of cGMP synthesis was measured in cortical slices under basal conditions. Using SNP as an NO donor, the NO-mediated cGMP synthesis was dose-dependently inhibited by ODQ in all three areas studied (Fig. 2). At a concentration of $0.1 \mu \mathrm{M}$ ODQ, $67 \%$ and $61 \%$ inhibition of SNP stimulated cGMP synthesis was measured in CAI and stratum lacunosum moleculare, respectively. At this concentration, an inhibition of $58 \%$ was measured in the frontal cortex. The stimulation of $\mathrm{SGC}$ in the CA1 region and in the frontal cortex by SNOG, SIN-1, and DEANO was inhibited by ODQ to a similar extent compared to SNP (Table 1). At higher ODQ concentrations, cGMP synthesis was at the level as found under basal conditions (see also Fig. 2 and Fig. 3).

Large differences between brain areas have been reported with respect to the activation of $\mathrm{sGC}$ by DEA/NO (Nedvetsky et al., 2002a). Therefore we investigated the effect of DEANO on cGMP accumulation in the frontal cortex and two hippocampal areas. The $\mathrm{EC}_{50}$ for $\mathrm{DEA} / \mathrm{NO}$ was $5 \mu \mathrm{M}$ both for frontal cortex and the CAl area, whereas an $\mathrm{EC}_{50}$ of $14 \mu \mathrm{M}$ was obtained for the stratum lacunosum moleculare. The averaged maximum response in the CA1 area was slightly higher than in the stratum lacunosum moleculare or in the frontal cortex (Fig. 3). cGMP levels in the sections were reduced to almost basal levels or even slightly below in the stratum lacunosum moleculare at $10 \mu \mathrm{M} O D Q$.

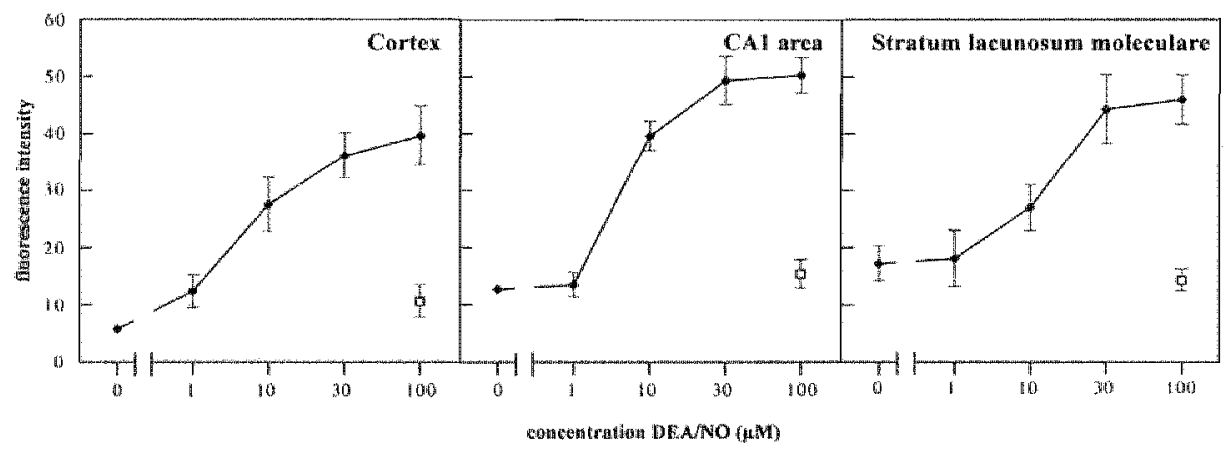

Figure 3. Stimulation of cGMP spnthesis by DEA/NO in rat frontal cortex and in CAI region and stratum lacunosum moleculare of the hippocampus, as measured by image analysis. All incubations were performed in the presence of $1 \mathrm{mM}$ IBMX. cGMP levels were evaluated by recording cGMP-immunofluorescence intensity with an Olympus $\mathrm{F}$-view cooled CCD camera. Intensity values were converted into gray values using the analySIS software and mean gray walues were calculated over the total recorded area. Open squares document cGMP. immunofluorescence after incubation with $10 \mu \mathrm{M} \mathrm{ODQ}$ in the presence of the highest dose DEANO. Each condition was tested in four animals. Note that the ordinate scale is different whan the one shown in Fig. 1. This is caused by differences in instrumentation. 
Localization of NO-mediated CMP synthesis

As already reported previously (De Vente et al., 1998), incubation of slices with SNP results in cGMP accumulation mainly in varicose fibers, and to some extent in astrocytes and cell bodies throughout the rat brain. It was investigated if the NO donors SNOG, SIN-1 and DEANO caused similar cGMP accumulation patterns using cGMP-immunocytochemistry. It was a similar observation for each NO donor that cGMP-immunofluorescence was predominantly present in varicose fibers and occasionally in cell somata in frontal cortex and hippocampus (Fig. 4A, 4C, Figs. 5-7). In subregions of the thalamus, intense cGMP-immunofluorescence was observed in neuronal cell somata (Fig. 4E). A detailed description of NO-mediated CGMP synthesis in the thalamus will be published elsewhere. No clear differences were observed in cellular cGMP patterns, comparing the four NO donors. $\mathrm{NO}$ mediated cGMP synthesis was strongly inhibited by $O D Q$ both in varicose fibers as well as in cell bodies in frontal cortex and hippocampus (Fig. 4B, 4D). In the thalamus cGMP synthesis in fibers was almost completely inhibited by $10 \mu \mathrm{M}$ ODQ treatment, however in this brain region there were numerous cell somata in which NO stimulated cGMP synthesis was not completely inhibited by ODQ (Fig. $4 F$ ). These results were similar for all NO donors used.

Table 1. Inhibition of NO-stimulated $\mathrm{SGC}$ by $0.1{ }_{1} \mathrm{M}$ ODQ in rat frontal cortex and CA 1 area of the hippocampus, measured by image analysis. All incubations were performed in the presence of $1 \mathrm{mM}$ IBMX. Values are expressed as percentage inhibition compared to incubation of the No donor alone (100\% stimulation). cGMP-immunofluorescence was recorded using an Olympus F. view cooled COD camera, and the mean intensity was calculated over the total reconded area using analySIS software. Each condition was measured in slices from three animals. From each slice, three sections were analyzed.

\begin{tabular}{|c|c|c|c|c|}
\hline \multirow[b]{2}{*}{ Brain area } & \multicolumn{4}{|c|}{ NO donor } \\
\hline & $0.1 \mathrm{MMSNP}$ & $1 \mathrm{MMSNO}$ & $0.1 \mathrm{mMSM}-1$ & 0.I mM DEA $/ \mathrm{NO}$ \\
\hline CAl & $66.59 \pm 6.63$ & $61.81+5.86$ & $70.87+4.18$ & $27.48 \pm 3.37$ \\
\hline Frontal contex & $53.45+13.33$ & $45.58+6.54$ & $37.09 \pm 7.32$ & $56.62+1217$ \\
\hline
\end{tabular}

\section{Characterization of CGMP-immunoreactive struchures}

To characterize the structures in the frontal cortex showing cGMP accumulation after in vitro incubation with the NO donor, tissue sections were double labeled with cGMP and the following markers of the neurotransmitter systems: EAAC1 for glutamatergic neurons, parvalbumin for GABAergic neurons, and VAchT for cholinergic neurons (Figs. 5-7). Extensive colocalization was observed between cGMP-immunoreactivity and VAchT, whereas colocalization between cGMP and parvalbumin was considerable less extensive. Double labeling for cGMP and EAAC1 was only incidental. No qualitative differences in the localization of cGMP. immunoreactivity in combination with the aforementioned markers were 
observed for the four NO donors studied, i.e. SNP. SNOG, DFANO (Figs. 5. 7) and STN-1 (not shown).

Surprisingly, colocalization between cGMP-immunoreactivity and the BI subunit of $\mathrm{GGC}$ was observed in the somata only occasionally. No clear immunoreactivity was observed for the 31 subunit in axonal or dendritic filbers.

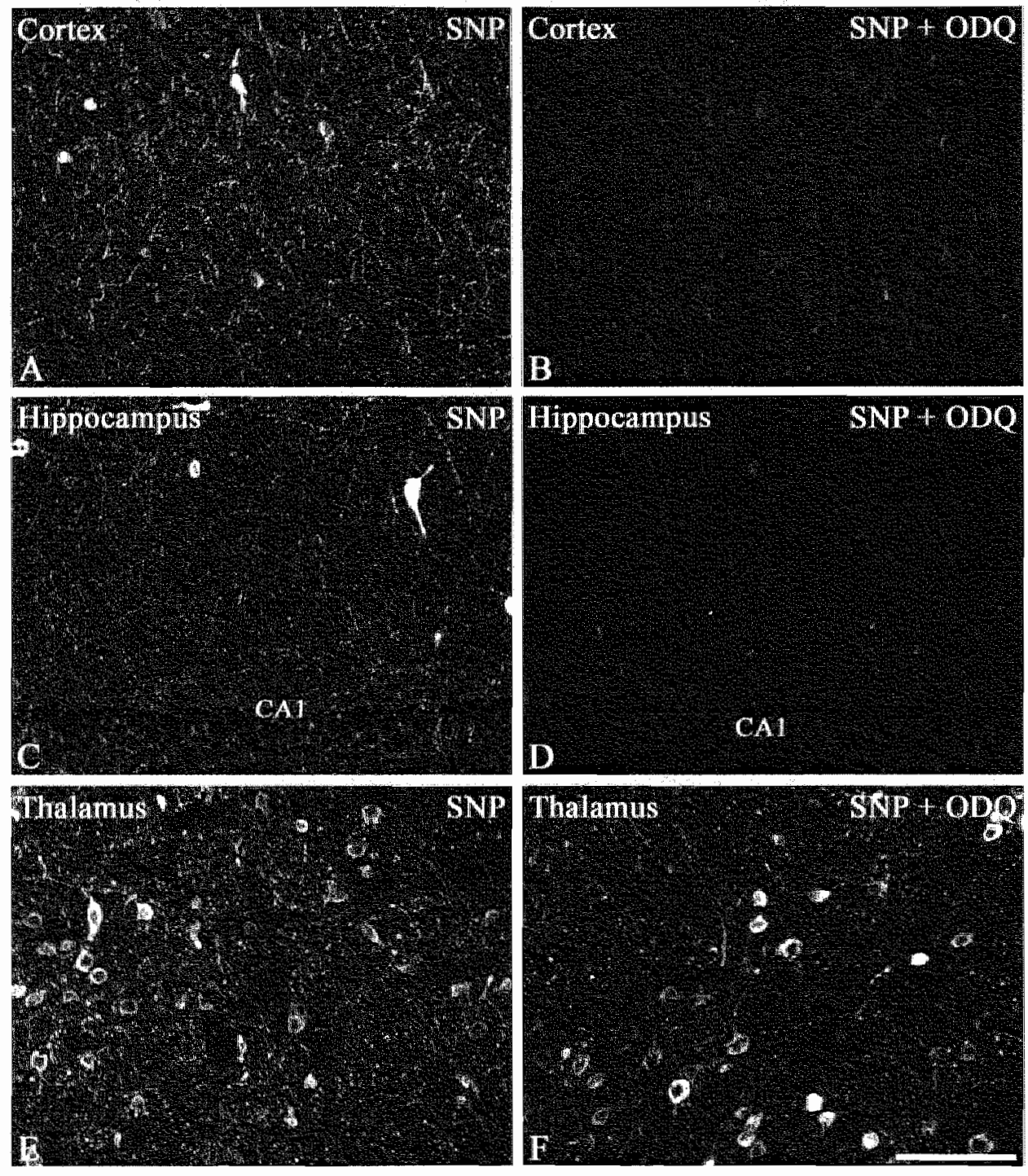

Figure 4. OCMP immunostaning in frontal cortex (A, B), hippocampus (C, D) and dorsolateral thalamus $\left(\mathbb{E}, F^{2}\right)$ of the rat. Rat brain slices were incubated in vitro in the presence of $0.1 \mathrm{mM}$ SNP and I $\mathrm{mM} I B M X$, without (left panels) or in the presence of I $\mathrm{MM}$ ODQ (right panels). Bar represents $100 \mu \mathrm{m}$ for all pictures. 

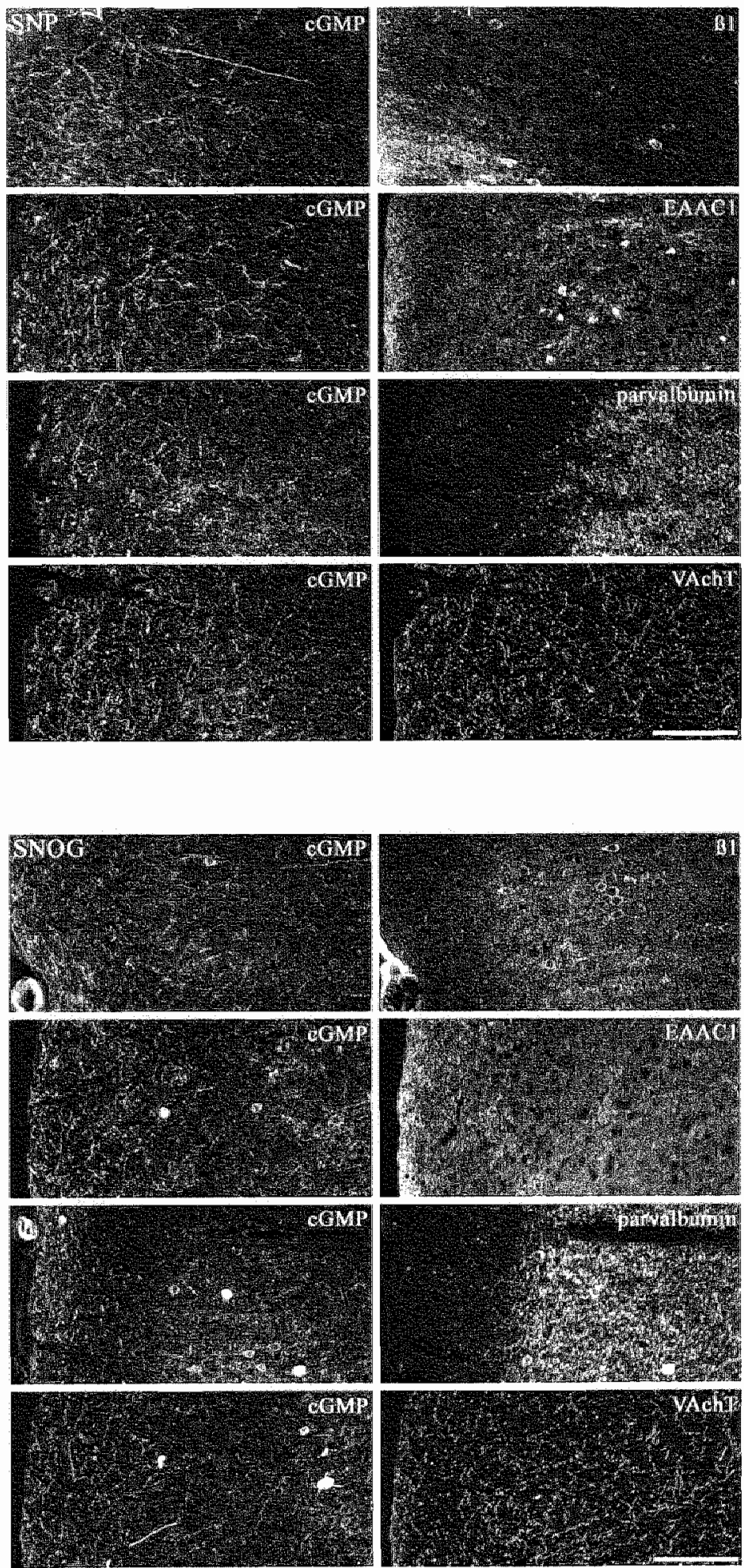

8I
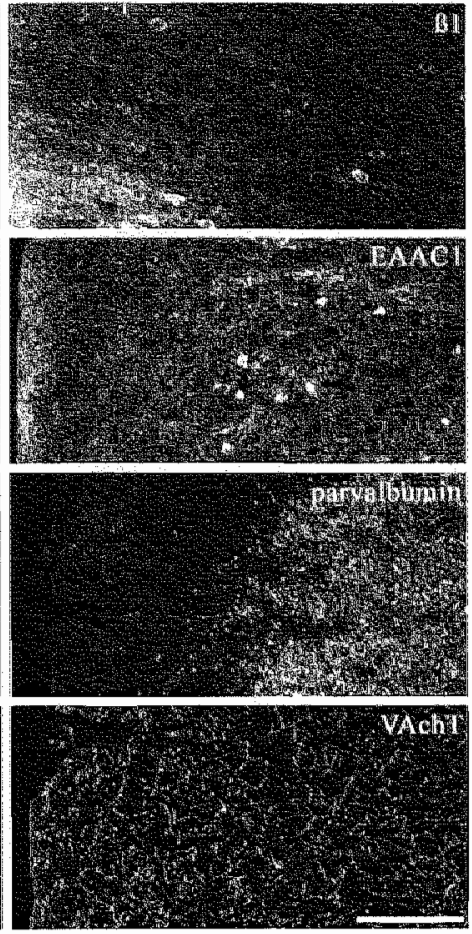

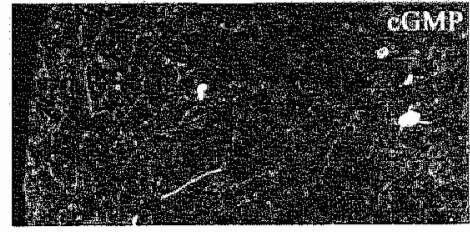

E.T.NT
Figure $5.0 \mathrm{GP}$. immunostaining (left panels) in combination with double staining for at number of cellular markers (right panels) in rat. frontal cortex after incubation with 0.1 mM SNP in the presence of $1 \mathrm{mM}$ IBMX. Pains of photographs show cGMPinmunoreacti. vity (let picture) and the comresponding field with the marker. (right picture) as indicated in the right upper corner. Bar represents 100 um for all pictures, B1, BI subunit of $\mathrm{sGC}$.
Figure 6. cGMP. immunocy bohemistry (left panels) in combination with double staining for" a number of cellular makers (right panels) in rat fromal comtex after" incubation with $1 \mathrm{mM}$ SNOC in the presence of $1 \mathrm{mM}$ IBMX Pairs of photographes show cGMP-immunorodi. vity (left picture) and the corresponding field with the marker (right pieture) as indicated in the right. upper corner. Bar represents $100 \mathrm{fm}$ for all pictures. 31,83 subunit of $\mathrm{BGC}$. 

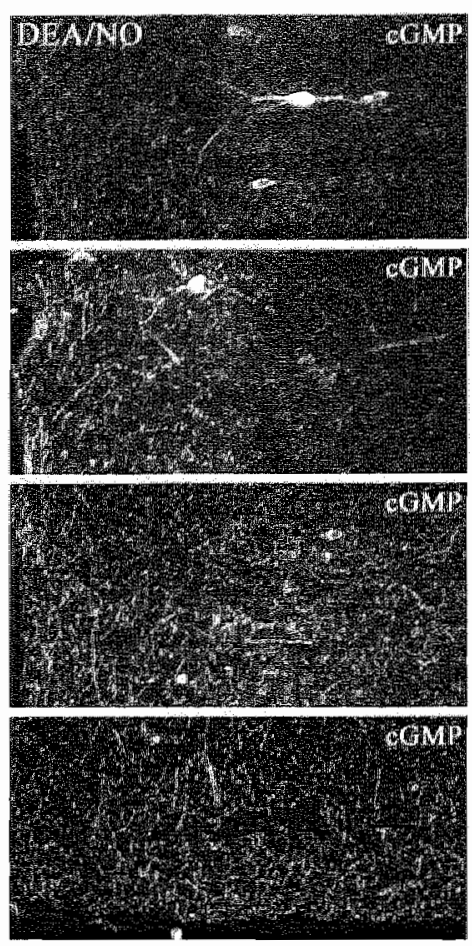
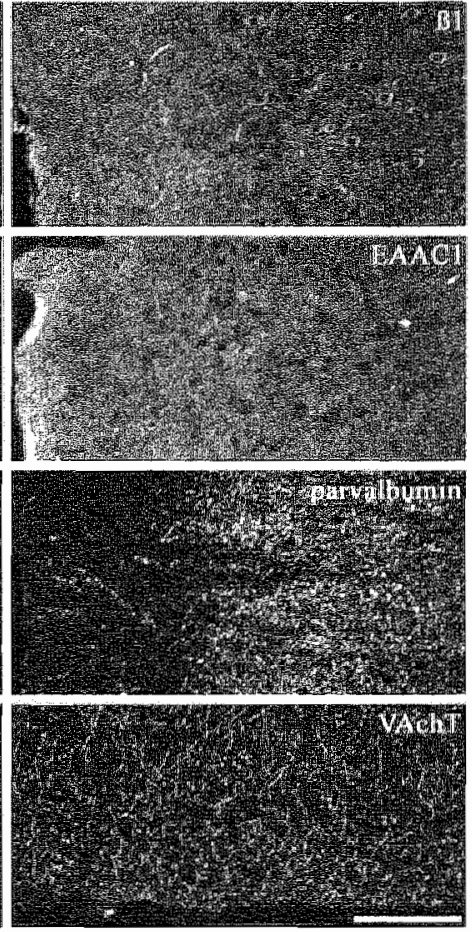

Figure 7. cGMP. immunostaining (left panels) in combination with double staining for a number of cellular markers (right panels) in rat frontal cortex after incubation with 0.1 MM DEANO in the presence of $1 \mathrm{mM}$ IBMX. Pairs of photographs show cCMP-immunoreacti. vity (left picture) and the corresponding field with the marker (wight picture) as indicated in the right upper corner. Bar represents $100 \mu \mathrm{m}$ for all pictures. $81, B 1$ subunit of $\mathrm{sGC}$.

\section{NO-independent stimulation of $S G C$ in frontal cortex}

Stimulation of $\mathrm{sGC}$ by BAY $41-2272$ increased eGMP-immunoreactivity in varicose fibers in cortical tissue dose dependently, from $0.01 \mu \mathrm{M}$ till $10 \mu \mathrm{M}$ (Fig. 8 left panels). Combination of BAY 41.2272 with a concentration of 0.1 mM SNP potentiates oGMP synthesis (Fig. 8 right panels) and resulted in cGMP accumulation in neuronal somata, dendrites and varicose fibers in frontal cortex (Fig. 8). Quantification of these large increase of cGMP accumulation under these conditions is shown in the inset of Fig. $8 \mathrm{~A}$. Maximal stimulation of sGC by $0.1 \mathrm{mM}$ SNP and $10 \mu \mathrm{M}$ BAY $41-2272$ resulted in more than 100 fold increase in cGMP-immunfluorescence. The effects of $\mathrm{BAY} 41.2272$ on sGC can be completely antagonized by $10 \mu \mathrm{M}$ ODQ (not shown).

CGMP-immunoreactivity in the frontal cortex after incubation of the slice in the presence of $0.1 \mu \mathrm{M}$ BAY $41-2272$ was found almost exclusively in structures that were also immunopositive for VAchT (Fig. 9 upper row). A lower concentration of BAY 41-2272 (0.01 $\mu \mathrm{M})$ in combination with $0.1 \mathrm{mM}$ SNP gave similar results. Higher concentration of BAY 41-2272, 1 MM with SNP or $10 \mu \mathrm{M}$ alone, resulted in an additional cGMP-immunoreactivity localized in parvalbumin immunopositive somata and fibers (Figs. 9 middle panel). Colocalization of CGMP-immunoreactivity with EAAC1 is abundant in slices incubated with $10 \mu \mathrm{M}$ BAY 41.2272 in combination with $0.1 \mathrm{mM}$ SNP (Fig. 9), although this colocalization was also observed at lower concentrations of BAY 41-2272 in combination with a NO donor (not shown). 
Under the latter conditions also extensive colocalization was observed between cGMP and the $\beta 1$ subunit of $\mathrm{sGC}$ in neuronal somata, however, not in dendrites or axonal fibers (Fig. 9).

The effects of $\mathrm{YC}-1$ as $\mathrm{SGC}$ stimulator in cortical slices are similar to those obtained with $\mathrm{BAY}$ 41-2272. As an example the colocalization is demonstrated between CGMP and parvalbumin after stimulation of the slice with $100 \mu \mathrm{M}$ YC-1 in combination with $0.1 \mathrm{mM} \mathrm{SNP}$ (Fig. 10).
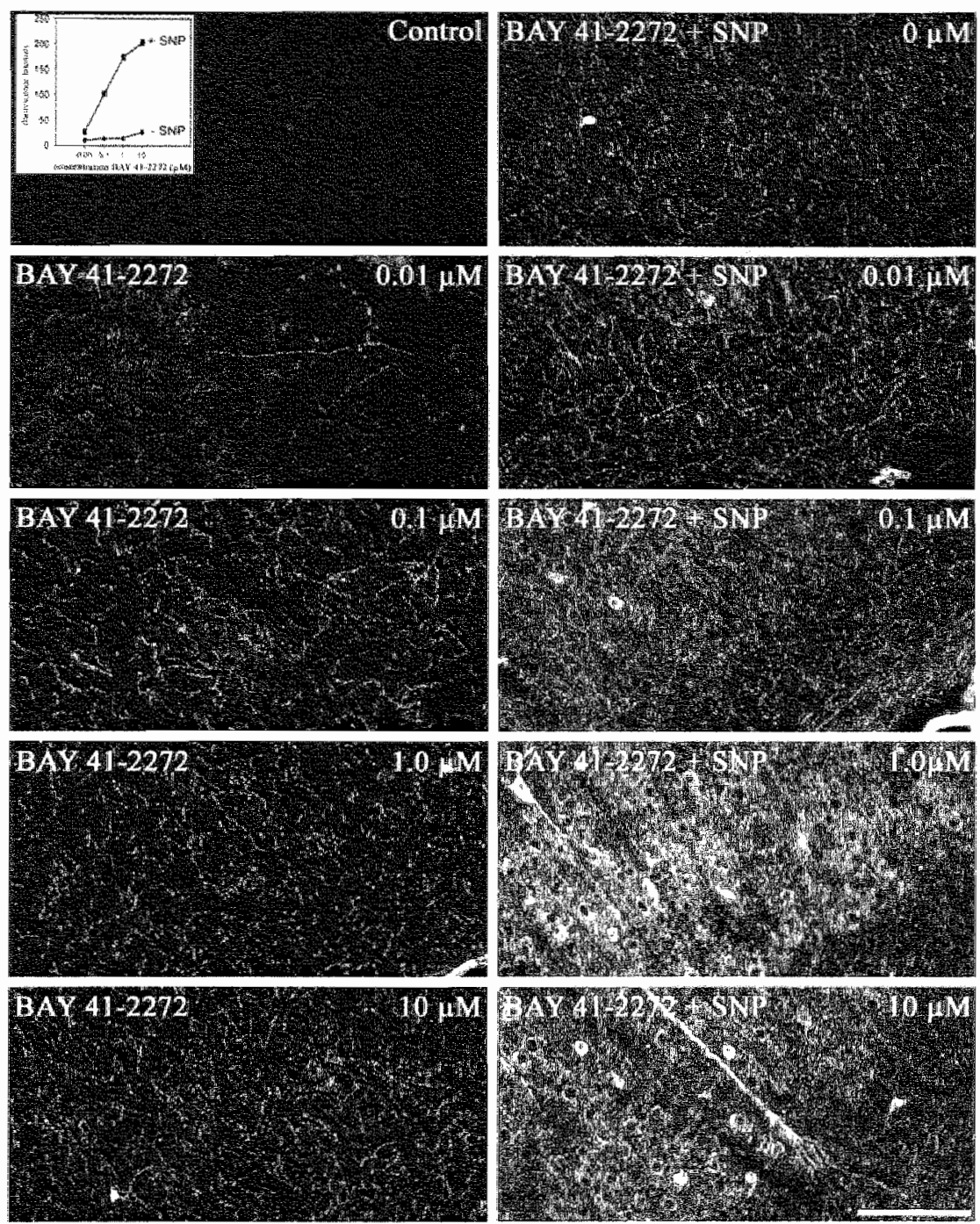

Figure 8. GMP-immunoreactivity in rat frontal cortical slices after incubation with diferent: concentrations of BAY 41.2272 (left panels) or in combination with $0.1 \mathrm{mM} S \mathrm{SN}^{3}$ (righ panols). All incubations were performed in the presence of 1 mM IBMX. Bar represents 100 fim for all pictures. The inset shows dose response curves for BAY 11.2272 in the athence and prosence of SNP in the frontal cortex as measured by image analysis, as described in the legend of fig. 3. 

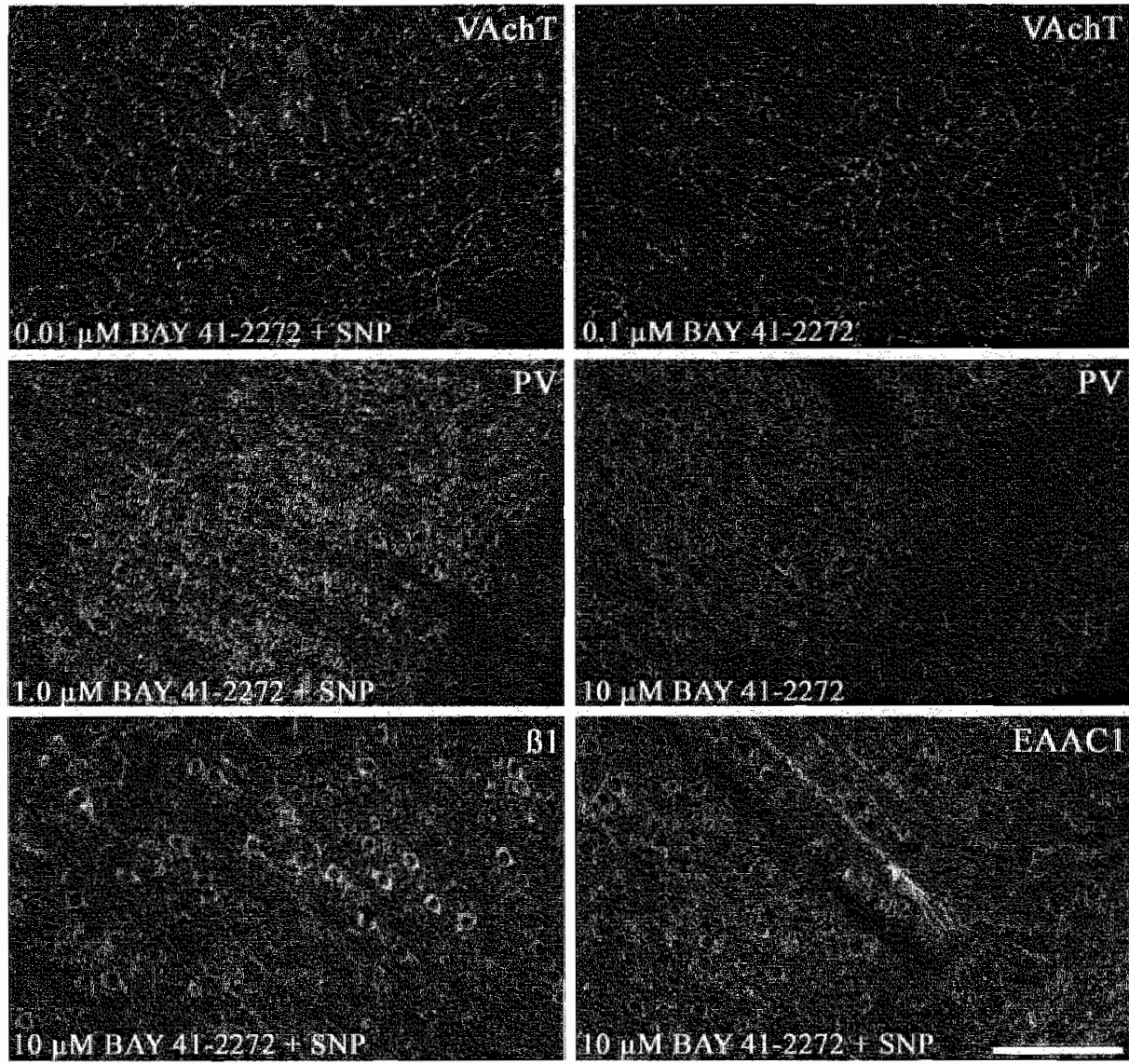

Figure 9. Double immunostaining of cCMP-immunoreactivity (green) with the marker molecules (red) VAchT, parwalbumin (PV), s1 subunit of $\mathrm{SGC}$, and $\mathrm{EAACl}$ in cortical slices incubated with BAY 41.2272 in the absence or in the presence of $0.1 \mathrm{mM}$ SNP as indicated in each picture. All incubations were performed in the presence of $1 \mathrm{mM}$ IBMX. Yellow colored structures indicate colocalization of cGMP with the marker indicated. Bar represents $100 \mathrm{~mm}$ for all pictures.
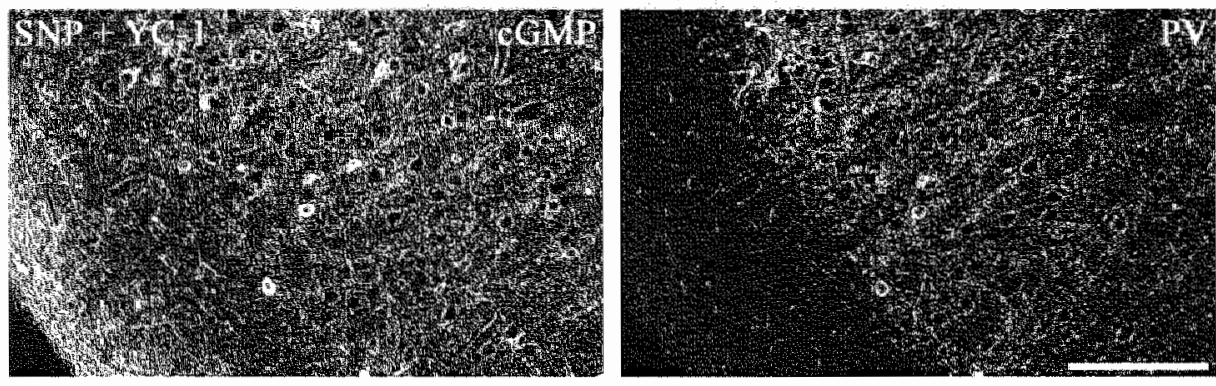

Figure 10. Double immunostaining of cGMP-immunoreactivity (left pand) with parvalbumin (PV, right panely on the same section of rat frontal cortex incubated in vitro in the presence of $100 \mu \mathrm{M} \mathrm{YC}-1$ in combination with 0.1 mM SNP and $1 \mathrm{mM}$ IBMX. Bar represents $100 \mu \mathrm{m}$ for all pictures. 


\section{Discussion}

In the present study we compared the effects of $\mathrm{NO}$-dependent and $\mathrm{NO}$. independent stimulation of sGC in a quantitative and qualitative manner in three different regions of the rat brain. Analysis of the results using four different NO donors indicated that quantification of CGMP levels by measuring the fluorescence intensity of the cGMP-immunoreactivity in the sections gives similar results as measuring cGMP levels using a classical radioimmunoassay. The use of image analysis has the advantage that besides the possibility of quantification of the signal, the cellular structures can be studied which are responsive to the treatment.

Among NO donor compound classes, the pathway leading to NO production by enzymatic or non-enzymatic processes will be different. Moreover, decomposition of an NO donor can lead to the formation of byproducts and thereby influence the experimental outcome (Feelisch, 1998). The mechanism of NO release from SNP has not been resolved completely and is dictated by prevailing conditions (Bates et al., 1991; Kruszyna et al., 1993; Garcia-Pascual et al., 1999). It has been suggested that tissue constituents, or certain enzymes, including a membranebound NADH. oxidoreductase, are necessary to release NO from SNP (Marks et al., 1.991; Rao et al., 1991; Kowaluk et al., 1992; Kleschyov et al., 1994; Mohazzab et al., 1999; Terwel et al., 2000). In addition it has been demonstrated that NO release from SNP is light sensitive (Feelisch, 1998).

There are a number of reports which describe differential effects of $\mathrm{NO}$ donors in different pharmacological paradigms (MacAllister et al., 1995; Garcix-Pascual et al., 1999; Tseng et al., 2000; Nedvetsky et al., 2002a). Differences might be observed depending on the tissue investigated or the method used. This may be caused by either differences in NO release mechanisms giving rise to $\mathrm{NO}^{+}, \mathrm{NO}$, or $\mathrm{NO}$, or by differences in $\mathrm{sGC}$ properties or sGC regulation. The mechanism of $\mathrm{NO}$-release from $\mathrm{DEA} / \mathrm{NO}$, SNOG, and SIN-1. is rather well known (Feelisch, 1991; Hogg et al., 1992). NO release from DEA/NO is the result of acid catalyzed dissociation with gives a free nucleophile and NO. SNOG belongs to the class of $\mathrm{S}$ nitrosothiols. SNOG is reported to decompose rather rapidly in physiological buffers, yielding NO through homolytic fission of the S.N bond (Stamler et al., 1992; Lipton et al., 1993; Feelisch, 1998) and trace metals, which are present in the buffers, like $\mathrm{Cu}^{+}$and $\mathrm{Fe} \mathrm{e}^{2+}$ ions will catalyze this reaction (Askew et al., 1995; Dicks and Williams, 1996; Smith and Dasgupta, 2000). The activity of a disulfide isomerase has also been described as catalyzing NO release from this compound (Zai et al., 1999) and in addition the thioredoxin system can release NO from SNOG (Nikitovic and Holmgren, 1996). SIN-1 undergoes rapid non-enzymatic hydrolysis at physiological $\mathrm{pH}$, which reaction is catalyzed by oxygen, giving rise to $\mathrm{O}_{2}$ (Feelisch, 1991; Hogg et al., 1992). As $\mathrm{O}_{2}$ and $\mathrm{NO}$ react at an almost diffusion controlled rate (Huie and Padmaja, 1993), there will always be some formation of ONOO.

There are a few studies in which the properties of NO donors are compared in stimulating $\mathrm{sGC}$ in brain tissue. Our results are in agreement 
with the data presented by Southam and Garthwaite (1991) by comparing SNP and SIN-1 in relation to cGMP synthesis in rat cerebellum. Nevertheless, recent data presented by Nedvetsky et al. (2002a) suggest differences between SNP and DEA/NO in stimulation of SGC from cortical tissue. Using the different approach of stimulation of cGMP levels in at least partly intact cortical tissue slices, we did not observe any significant difference between these two compounds. Furthermore, identical cGMP. staining patterns were obtained for the two compounds (see below).

Inhibition of $\mathrm{sGC}$ by $\mathrm{ODQ}$ was investigated in detail in frontal cortex and hippocampus. Under basal conditions already strong inhibition was observed in the hippocampus whereas in contrast no effect was found in the frontal cortex. This indicates that endogenous NO synthesis in the hippocampus slices is higher than in the cortical slices.

Apparent tissue differences for $\mathrm{SGC}_{\mathrm{H}}$ have been reported concerning the sensitivity of the enzyme for inhibition by ODQ in aortic rings and cardiomyocytes (Wegener et al., 1999). In the thalamus it was observed that cGMP-immunoreactivity was present in cell bodies and varicose fibers whereas an inhibition of cGMP accumulation was observed only in varicose fibers after ODQ treatment. 'This observation suggests a regional difference in the sensitivity of $\mathrm{SGC}$ towards ODQ. However, it is at least equally possible that differences in the kinetics of synthesis and degradation of cGMP are present in the respective cellular compartments.

Although the NO donors differ in potency in stimulating $\mathrm{sGC}$, which can be explained by differences in the degradation rate of the compounds, cGMP-immunostaining showed that incubation of the slices with maximal doses of the NO donors resulted in similar cellular cGMP-staining patterns. The localization of the cGMP response in the frontal cortex was compared in detail between the four NO donors using neuroanatomical characteristics and by assessing colocalization of the CGMP-immunoreactivity with markers for neurotransmitters. NO donors increased cGMP-immunoreactivity mainly in varicose fibers, and to some extent in neuronal cell bodies, and, less frequently in astrocytes.

The colocalization studies showed that irrespective of the NO donor, cGMP-immunoreactivity is found in cholinergic fibers in the frontal cortex, as has been reported before for SNP (De Vente et al., 2001). NO-mediated cGMP-immunoreactivity is found only for a very small part in GABAergic neurons (parvalbumin as the marker), and only incidentally in glutamatergic neurons (EAAC1 as the marlser). These observations, and the biochemical and pharmacological data presented above, lead to the conclusion that there is no regional selectivity of any of the NO donors investigated in this study with respect to activation of $\mathrm{sGC}$ in the rat frontal brain.

Furthermore, it was demonstrated that maximal cGMP synthesis is not reached in brain tissue by stimulation of $\mathrm{sGC}$ with $\mathrm{NO}$ donor compounds. Coadministration of SNP with YC-1 or BAY $41-2272$ strongly increased cGMP levels and abundant colocalization was observed of cGMP. immunoreactivity in GABAergic and glutamatergic neurons. $\mathrm{YC}-1$ is an NO- 
independent activator of $\mathrm{SGC}$ which also affects cGMP degradation by inhibition of PDE activity (Galle et al., 1999), although the latter is minor compared to IBMX (unpublished observation). Thus the effect of $\mathrm{YC}-1$ on cGMP synthesis cannot be explained by its PDE inhibiting properties. BAY $41-2272$ is devoid of an effect on PDEs (Stasch et al., 2001).

It is remarkable that the potentiating effect of $\mathrm{BAY} 41-2272$ and $\mathrm{YC}-1$ is observed especially in parvalbumin and EAAC1 immunopositive neurons as these neurons do not generally synthesize cGMP in response to a maximal concentration of an $\mathrm{NO}$ donor alone. Furthermore, the effects of $\mathrm{YC}-1$ or BAY $41-2272$ in the absence of $\mathrm{NO}$ donors is not observed in cell somata. These findings point to a $\mathrm{sGC}$ which is not responsive to $\mathrm{NO}$, and needs to be sensitized. This also raises the question to the presence of an endogenous substance which has a similar effect as BAY 41.2272. Recent evidence indeed points to the existence of such a compound (Schmidt et al., 2001). The finding that $\mathrm{NO}$ donors or NO-independent activators of sGC do not stimulate $\mathrm{SGC}$ in these somata, but that the combination is extremely effective in increasing cGMP levels, points to the presence of an endogenous inhibitor of $\mathrm{SGC}$ which is overcome by $\mathrm{YC}-1$ or $\mathrm{BAY} 41-2272$ or to high $\mathrm{PDE}$ activity not inhibited by IBMX such as the TBMX-insensitive cGMP-specific PDE9 (Fisher et a1., 1998; Soderling et al., 1998). Double immunostaining of cGMP-immunoreactivity with the 31 subunit of $\mathrm{sGC}$ was not as widespread as expected. Only somata showed immunoreactivity for the B1-subunit and frequent colocalization with cGMP-immunoreactivity was observed only after sGC was stimulated maximally with an NO donor in combination with YC-1 or BAY 41-2272. No B1. subunit was observed in dendrites or axons. The reason for this is not clear, since $\mathrm{sGC}$ has been reported in dendrites/axons (Burette et al., 2002), although epitope shielding because of heterodimerization with the al or $\alpha 2$ subunit has been suggested before (Kummer et al., 1996). Epitope shielding might also be caused by interaction of $\mathrm{SGC}$ with other membrane bound proteins such PSD-95 or PSD-93 (Russwurm et al., 2001; Nedvetsky et al., 2002b; Zabel et al, 2002). This would imply that a free B1 subunit exists in the cortical somata and that no inferences can be made from the $B 1$ subunit immunostaining with regard to the functionslity of $\mathrm{sGC}$ in these structures. On the other hand, recent data show that al and $\alpha 2$ subunits are both expressed to similar levels as the B1 subunit in cortical tissue, which is not suggestive of a pool of free $\mathbb{B} 1$ subunit (Mergia et al., $2003)$.

In conclusion, we did not find evidence for regional differences in tissue constituents which might determine the sGC-activating potency of the different NO donors used. Treatment of the rat frontal brain slices with the NO donors resulted in cGMP-immunostaining in similar cellular compartments, i.e. mainly the cholinergic fibers. In contrast to the cholinergic fibers in the frontal cortex, the results suggest that most of the sGC in GABAergic and glutamatergic neurons need to be sensitized by $\mathbb{N O}$. independent activators like $\mathrm{YC}-1$ and $\mathrm{BAY}$ 41-2272 before the enzyme can be activated by NO. 


\section{References}

ASKEW SC, BARNETT DJ, MCANINLY J, WILLIAMS DLH (1995) Catalysis by Cu+ of nitric oxide release from s-nitrosothole (RSNO). I Chem Soc Perkin Trans 2.741.745.

BATES eN, BAKER MT, GUERRA R, JR, HARRISON DG. (1991) Nitric oxide generation from nitroprusside by vascular tissue. Evidence that reduction of the nitroprusside anion and cyanide loss are required. Biochem Pharmacal 42 Suppl: S157-165.

BEAVO JA. (1995) Cyclic nucleotide phosphodiesterases: functional implications of multiple isolorms. Physiol Red 75: 725.748.

BEHRIUNDS S, KEMPFERT J, METENS A, KOGLIN M, SCHOLZ H, MIDDENDORFF R. (2001) Developmental changes of nitric oxidesensitive guanylyl cyclase expression in pulmonary arteries. Biochem Biophys Res Commun 283: 883-887

BICKER G. (2001) Sources and targets of nitric oxide signalling in insect nerwous systems. Cell Thisue Res 303: $137-1.46$.

BURETTE A, ZABEL, U, WEINBETG RJ, SCHMTDT HH, WALTSCHANOFF JG. (2002) Symaptic localization of nitric oxide synthase and soluble guanylyl cyclase in the hippocampus. \& Neurosci 22: 8961.8970.

BURGUND JER NM, CHEUNG PT. (1994) Expression of soluble guanylyl cyclase gene in adult rat brain. Eur \& Neurosci 6: 211-217.

CONTI M, IIN SL. (1999) The molecular biology of cyclic nucleotide phosphodiesterases. Prog Nucleic Acid Res Mol Biol 63: 1.38.

DE VINTE J, BOL JG, HUDSON L, SCHTPPER J, STEINBUSCH HWM. (1988) Atrial natriuretic factor-responding and cyclic guanosine monophosphate (cGMP)-producing cells in the rat hippocampus: a combined micropharmacological and immunocytochemical approach. Brain Res 446: 387-395.

DE VINTE J, HOPKINS DA, MARKJERINK-VAN ITTERSUM M, EMSON PC, SCHMTDT MHF, STEINBUSCH HWM. (1998) Distribution of nitric oxide synthase and nitric oxidereceptive, cyclic GMP-producing structures in the rat brain. Neuroscience 87: 207-241.

DE VENTE J, MARKERINK-VAN ITTERSUM M, AXER H., STEINBUSCH HWM. (2001) Nitric-oxide-induced cGMP synthesis in cholinergic neurons in the rat brain. Exp Brain Res 136: $480-491$.

DICKS AP, WILLIAMS DL. (1996) Generation of nitric oxide from S-nitrosothiols using protein-bound $\mathrm{Cu}^{2 *}$ sources. Chem Biol 3: 655-659.

FEELLISCH M. (1991) The biochemical pathways of nitric oxide formation from nitrovasodilators: appropniate choice of exogenous NO donors and aspects of preparation and handling of aqueous NO solutions. \& Cardiovase Pharm 17 : S25-S33.

FEELISCH M. (1998) The use of nitric oxide donors in phamacological studies. Naunyn Schmiedebergs Arch Pharmacol 358: 113-122.

FISHER DA, SMITH JF, PLLLAR JS, ST DENIS SH, CHENG JB. (1998) Isolation and charmcterization of PDEQA, a novel human CGMP-specific phosphodiesterase. of Biol Chem 273: $15559-15564$

FRANCIS SH. TURKO IV, CORBIN J. (2001) Cyclic Nucleotide phosphodiesterases: regulating structure and function. Prog Nucleic Acid Res Mol Biol 65: 1.52.

PRIEBE A, KOESLING D. (1998) Mechanism of YC-1-induced activation of soluble guanylyl cyclase. Mol Pharmacol 53: 123-127.

FURUTA A, ROTHSTELN JD, MARTIN Le. (1997) Glutamate transporter protein subtypes are expressed diflerentially during rat CNS development. I Neurosei 17 : 83638375 .

GALAL J, ZABELL U, HUBNER U, HATZELMANN A, WAGNER B, WANNER C, SCHMIDT HHHW. (1999) laffects of the soluble guanylyl cyclase activator, $\mathrm{YC} \cdot 1$, on vascular tone, cyclic GMP levels and phosphodiesterase activity. Br of Pharmacol 127: 195-208.

GARCIA-PASCUAL A, COSTA G, LABADIA A, JMENEZ E, TRIGULRO D. (1999) Differential mechamisms of urethral smooth muscle relaxation by several NO donors and nituic oxide. Naunyn Schmiedebergs Arch Pharmacol 360: 80-91.

GAR"YHWAII' d. (1991) Gutamate, nitric oxide and cell-cell signalling in the nervous system Trends Neurosei 14: 60.67 .

GARTHWAITE J. (1995) Neural nitric oxide signalling. Trends Neurosic 18: 51-52. 


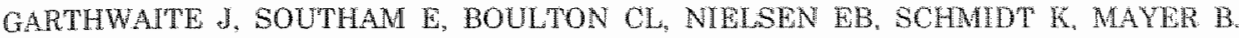
(1995) Potent and selective inhibition of nitric oxide-sensitive guanylyl cyclase by $1 \mathrm{H}$. $[1,2,4]$ oxadiazolo[4,3-a]quinoxalin-1-one. Mol Phormacol 48; 184-188.

GIBB BJ, GARTHWAITE J. (2001) Subunits of the nitric oxide receptor, soluble gumnyly cyclase, expressed in rat brain. Eur of Neurosci $13: 539-544$.

HART TW. (1985) Some observations conceming the S-nitroso and S-phenylsulphonyl derivatives of L-cysteine and glutathione. Tetrahedron Lett 26:2013-2016.

HOGG N, DARLEY-USMAR VM, WILSON MT, MONCADA S. (1992) Production of hydroxyl radicals from the simultaneous generation of superoxide and nitric oxide. Biochem of 281 : 419.424.

HUIE RE, PADMAJA S. (1993) The reaction of NO with superoxide. Free Radic Res Commun 18: $195-199$.

JACKLET JW. (1997) Nitric oxide signaling in invertebrates. Inweri Neurosei 3: 1-14.

KLESCHYOV AL, SEDOV KR, MORDVINTCIEV PI, VANIN AF. (1994) Biotraneformation of sodium nitroprusside into dinitrosyl inon complexes in tissue of ascites tumors of mice. Biochen Biophys Res Cammun 202: 168-173.

KO FN, WU CC. KUO SC, LEE FW, TENG CM. (1994) YC-1, a novel activator of platelet guanylate cyclase. Blood 84: 4226 4233.

KOGLIN M. STASCH JP, BEHRENDS S, (2002) BAY 41.2272 activates two isoforms of nitwic oxide-sensitive guanylyl cyclase. Biochem Biophys Res Coman 29: $1057-1062$.

KOWALUK EA, SETH P, FUNG HL. (1992) Metabolic activation of sodium nitroprusside to nitric oxide in vasculat smooth muscle. of Phomacol Exp Ther 262: 916.922.

KRUSZYNA H, KRUSZYNA R, ROCHELLE LG, SMITH RP, WILCOX DE. (1993) Effects of temperature, oxygen, hene ligands and sulfhydryl alkylation on the reactions of nitroprusside and nitroglycerin with hemoglobin. Biochem Pham macal 46: 95-102.

KUMMER W, BEHRENDS S, SCHWARZLMULLER T, FISCHER A, KOESLING D. (1996) Subunits of soluble guanylyl cyclase in rat and guinea-pig sensory ganglia. Brain Res 721: 191-195.

LIPTON SA, CHOI YB, PAN ZH, LEI SZ, CHEN HS, SUCHER NJ, LOSCALZO J, SINGEL, DJ. STAMLER JS. (1993) A redox-based mechanism for the neuroprotective and neurodestructive effects of nitric oxide and related nitrosowcompounds. Nature 364: 626. 632 .

LOHMANN SM, VAANDRAGER AB, SMOLENSKI A, WALTER U, DE IONGE FR. (1997) Distinet and specific functions of eGMP-dependent protein kinases. Trends Biochem Sci 22: $307-312$

LOWRY OH, ROSEBROUGH NJ, FARR AL, RANDALL FJ. (1951) Protein measurement with the folin reagent. $J$ Biol Chem 193: 265-275.

MACALLISTER RJ, CALVER AL, RIEZEBOS J, COLLIER II. VALLANCE P. (1990) Relatiwo potency and arteriovenous selectivity of nitrovasodilators on human blood vesseds: an insight into the targeting of nitric oxide delivery, of Pharmacol Exp Ther 273: 154-160.

MARKS GS, MCLAUGHLIN BE, BROWN LB, BEATON DE, BOOTH BP. NAKATSU K, BR.IEN J]" (1991) Interaction of glycery] trinitrate and sodium mitroprusside with bovine pulmonary vein homogenate and $10.000 \times \mathrm{g}$ supernatant: biotransformation and nitric oxide formation. Can of Physiol Pharmacol 69: 889-892.

MERGIA E, RUSSWURM M, ZOIDL G, KOESLING D. (2003) Major occurrence of the new alpha(2)beta(1) isoform of NO. sensitjve guanylyl cyclase in brain. Cell Signal 15: 189-195.

MOHAZZAB HK, KAMINSKI PM. AGAFWAL R, WOLIN MS. (1999) Potential rolus of a membrane-bound NADH oxidoreductase in nitric oxide ralease and arterial restaxation to nitroprusside. Circ Res 84:220.228.

NEDVETSKY PI, KLEINSCHNYTZ C, SCHMIDT HHHW. (2002a) Regional distribution of protein and activity of the aitrie oxide receptor, soluble guanylyl cyclase, in rat brain suggests multiple mechanisms of regulation. Brain Res 950: 148-154.

NEDVETSKY PI, SESSA WC, SCHMIDT HH. (2002b) There"s NO binding like NOS binding: proteinmprotein interactions in NO/cGMP signaling. Proc Naul Acad Sci U S A 95: 16510. $16 \overline{12}$

NIKITOVIC D. HOLMGREN A. (1996) S-nitrosoglutathione is clesved by the thioredoxin system with liberation of glutathione and redox regulating nitric oxide. of Biol Chem 271 . $19180-19185$. 
RAO DN, ELGUINDI S, OBREEN PJ. (1991) Reductive metabolism of nitroprusside in rat hepatocytes and human erythrocytes. Arch Biochem Biophys 286: 30-37.

RUSSWURM M, WTTAU N, KOESLING D. (2001) Guanylyl cyclase/PSD-95 interaction: targeting of the mitric oxide-sensitive alpha2beta 1 guanylyl cyclase to synaptic membranes. J Biol Chem 276: $44647-44652$

SCHMIDT HH, GAGNE GD, NAKANE M, POLLOCK JS, MLLER MF, MURAD F. (1992) Mapping of neural nitric oxide synthase in the rat suggests frequent co-localization with NADPH diaphorase but not with soluble guanylyl cyclase, and novel paraneural functions for nitrinergic signal transduction. I Fistochem Cyochem 40:1439.1456.

SCHMIDT K, SCHRAMMEL A, KOESLING D. MAYER B. (2001) Molecular mechanisms inwolved in the synergistic activation of soluble guanylyl cyclase by $\mathrm{YC}-1$ and nitric oxide in endothelial calls. Mol Pharmacol 59: 220-224.

SMITH JN, DASGUPTA TP. (2000) Kinetics and mechanism of the decomposition of $\mathrm{S}$. nitrosoglutathione by l-ascorbic acid and copper jons in aqueous solution to produce nitric oxide. Nitric Oxide 4: 57-66.

SODERLING SH, BAYUGA SJ, BEAVO JA. (1998) Identification and characterization of a novel family of cyclic nucleotide phosphodiesterases. I Biol Chem 273: 15553-15558.

SOUTHAM E, GARTHWAITE J. (1991) Comparative effects of some nitric axide donors on cyclic GMP levels in rat cerebellar slices. Neurosci Lett 130: 107-111.

STAMLER JS, SINGEI, DJ, LOSCALZO J. (1992) Biochemistry of nitric oxide and its redox. activated forms. Science 258: 1898-1902.

STASCH JP, BECKER EM, ALONSO-ALIJA C, APELER H, DEMBOWSKY K, FEURER A, GERZER R, MINUTH T, PERZBORN E, PLEISS U, SCHRODER H, SCHROEDER W, STAHL E, STETNKE W, STRAUB A, SCHRAMM M. (2001) NO-independent regulatory site on soluble guanylate cyclase. Nature $410: 212-215$.

STEINER AL, PARKER CW. KIPNIS DM. (1972) Radioimmunoassay for cyelic nucleotides. I. Preparation of antibodies and iodinated cyclic nucleotides. of Biol Chem 247: 1106-1113.

STONE JR, MARLETTA MA. (1995) Heme stoichiometry of heterodimeric soluble guanylate cyclase. Biochemistry 34: 14668-14674.

TTEWEL D, NTELAND IJJ, SCHUTTE B, REUTELINGSPERGER CP, RAMAEKERS FC, STELNBUSCH HW. (2000) S-nitroso- $\mathrm{N}$-acetylpenicillamine and nitroprusside induce apoptosis in a neuronal cell line by the production of different reactive molecules. Eur of Pharmacal 400: 19-33.

TSENG CM, TABRIZI-FARD MA, FUNG HL. (2000) Differentia』 sensitivity among nitric oxide donors toward ODQ-mediated inhbition of vascular relaxation. of Pharmacol Exp Ther 292: 737-742.

VAN STAVEREN WCG, MARKERINK-VAN ITTERSUM M, STEINBUSCH HWM, DE VISNTE e. (20011) The effects of phosphodiesterase inhibition on cyclic GMP and cyclic AMP necumulation in the hippocampus of the rat. Brain Res 888: 275-286.

WEGRNER JW, CLOSS EI, WORSTERMANN U, NAWRATH H. (1999) Failure of $1 \mathrm{H}$ $11,2,4$ |oxadiazolo $4,3-$ alquinoxalin-1-one (ODQ) to inhibit soluble guanyly cyclase in rat ventricular cardiomyocytes. $\mathrm{Br}$ of Pharmacol 127 : $693-700$.

WET ,WY, ROY DS, TECONTE J, BARNSTABLE Cel. (1998) Molecular and pharmacological analysis of cyclic nucleotide gated channel function in the central nervous system. Prog Neurobial 56: $87-64$.

ZABEL U, KLEINSCHNITZ $C$, OH $P$, NEDVETSKY P, SMOLENSKI A, MULLER H, KRONICH P, KUGLER P, WALTER U, SCHNITZER JE, SCHMIDT HH. (2002) Calciumdependent membrane association sensitizes soluble guanylyl cyclase to nitric oxide. $\mathrm{Nat}$ Cell Biol 4: $307-311$.

ZAI A, RUDD MA, SCRIBNER AW, LOSCALZO J. (1999) Cell-surface protein disulfide isomerase catalyzes transnitrosation and regulates intracellular transfer of nitric oxide $d$ Clin Invest 103: $393-399$. 


\section{Cloning and localization of the cGMP- specific phosphodiesterase type 9 in the rat brain}

Wilma C.G. van Staveren," Jennifer Glick," Marjame Markerink-van Ittersum, ${ }^{1}$ Masami Shimizu, Joseph A. Beavo, ${ }^{2}$ Harry W.M. Steinbusch ${ }^{1}$ and Jan de Vente ${ }^{1}$

Dept. of Psychiatry and Neuropsychology, Division Cellular Neuroscience, Maastricht University, European Graduate School of Neuroscience (EURON), P.O. Box 616, 6200 MD Maastricht, The Netherlands; ${ }^{2}$ Dept. of Pharmacology, University of Washington, Seattle, Washington 98195

Journal of Neurocytology 31.(8/9): 729-741, (2003)

\section{Abstract}

In this study, we report the cloning of the rat cGMP-specific phosphodiesterase type 9 (PDE9A) and its localization in rat and mouse brain by non-radioactive in situ hybridization. Rat PDE9A was $97.6 \%$ identical to mouse PDE9A1 and showed $92.1 \%$ similarity on the amino acid level to the human homologue. PDE9A mRNA was widely distributed throughout the rat and mouse brain, with the highest expression observed in cerebellar Purkinje cells. Furthermore, strong staining was detected in areas such as cortical layer $\mathrm{V}$, olfactory tubercle, caudate putamen and hippocampal pyramidal and granule cells. Comparison of PDE9A mRNA expression by double staining with the cellular markers NeuN and glial fibrillary acidic protein demonstrated that PDE9A expression was mainly detected in neurons and occasionally in astrocytes. To investigate the localization of PDE9A substrate, cGMP, cerebellar slices of rat, mouse and rabbit were incubated in the presence of the non-selective phosphodiesterase inhibitor 3-isobutyl-1-methylxanthine (IBMX) with and without soluble guanylyl cyclase activators. Strong cGMP-immunoreactivity was observed in the molecular layer with IBMX alone. After treatment with solublle guanylyl cyclase activators the granular layer also showed cGMP. staining, whereas no clear immunostaining was detected in Purkinje cells under all conditions investigated, which might be due to the presence of PDE9A in these cells.

The present findings indicate that PDE9A is highly conserved between species and is widely distributed throughout the rodent brain. PDE9A is probably involved in maintenance of low cGMP levels in cells and might play an important role in a variety of brain functions involving cGMP. mediated signal transduction. 


\section{Introduction}

Cellular levels of adenosine 3',5'cyclic monophosphate (cAMP) and guanosine $3^{\prime}, 5^{\prime}$-cyclic monophosphate (cGMP) are determined by the rate of synthesis of these second messengers by cyclases and their degradation rate by 3',5'.cyclic nucleotide phosphodiesterases (PDEs) (Beavo, 1995; Dousa, 1999; Soderling and Beavo, 2000; Francis et al., 2001; Houslay, 2001; Meluats et al., 2002). In the central nervous system (CNS), cGMP synthesis can be increased after activation of the $N$-methyl- $D$-aspartic acid (NMDA) type glutamate receptor, which leads to a rise in intracellular calcium and activation of the calcium-calmodulin sensitive nitric oxide synthase (NOS) (Garthwaite, 1991). The nitric oxide (NO) produced by NOS in turn stimulates the soluble guanylyl cyclase (sGC) to convert guanosine 5'triphosphate (GTP) into cGMP (Schmidt et al., 1992; Murad, 1.994; Koes'ling, 1998, Koesling, 1999). The activation of $\mathrm{SGC}$ by $\mathrm{NO}$ and the subsequent rise in cGMP levels causes activation of downstream elements of the signaling pathway which are cGMP-dependent protein kinases (Lohmann et al., 1997; Pfeifer et all, 1999) and cGMP-gated ion channels (Biel et al., 1999). In addition, cGMP can regulate the activity of several PDE isoforms (Beavo, 1995; Dousa, 1999; Francis et al., 2001).

Presently, 11 different PDE families (PDE1-PDE11) have been described based on their distinct kinetic and substrate characteristics, inhibitor profiles, allosteric activators and inhibitors, and amino acid sequence (Beavo, 1995; Francis et al., 2001). Among famillies, multiple genes and splice variants have been detected, indicating the existence of a large number of PDE isozymes and thereby a complex regulation of cyclic nucleotides.

To study in which cells cGMP can be produced, cGMPimmunocytochemistry on sections from brain slices incubated in vitro can be used. Since PDE activity in the brain is high, it is generally necessary to include PDE inhibitors in the incubation medium of these slices e.g. the nonselective inhibitor 3-isobutyl-1-methylxanthine (IBMX) for the visualization of cGMP in cells (De Vente et al., 1989; De Vente et al., 1998). However, cGMP synthesis has never been observed in Purkinje cells in the cerebellum (Southam and Garthwaite, 1993; De Vente and Steinbusch, 2000). In the late seventies, Chan-Palay and Palay (1979) showed that cGMP synthesis in the cerebellum was primarily in neuroglia whereas the expression of cGMP in Purkinje cells and granule cells could not be ascertained. Nevertheless, there are several reports describing the presence of $\mathrm{sGC}$ in Purkinje cells (Zwiller et al., 1981; Schmidt et al., 1992). Therefore, PDE activity which is not sensitive to IBMX might be present in these cells.

Cloning of the mouse and human PDE9A revealed that this enzyme has the highest affinity for CGMP of any PDE known to date and is insensitive to IBMX (Fisher et al., 1998; Guipponi et al., 1998; Soderling et al., 1998). Recently, the mRNA distribution of PDE9 in the rat brain was shown by a radioactive in situ hybridization, indicating the highest expression in cerebellar Purkinje cells (Andreeva et al., 2001). In other brain areas also 
PDE9 mRNA expression was observed, however it was not reported if this enzyme is only expressed in neurons or also in glial cells. The exact cellular localization of the enzymes and their targets is of high importance to obtain more insight in the role of the cGMP signal transduction pathway in brain functions. Therefore, the aim of our study was to investigate PDE9A mRNA expression patterns in more detail by a non-radioactive in situ hybridization and to compare this expression to the localization of the neuronal marker NeuN and the glial cell marker glial fibrillary acidic protein (GFAP). Since species differences in the localization have been observed in the expression of PDE isoforms (Engels et al., 1994; Pérez-Torres et al., 2000), we decided to study the PDE9A expression both in rats and mice. The mouse PDE9A sequence was compared to the rat sequence which was obtained by screening of rat expressed sequence tag (EST) clones and combined with rapid amplification of $C D N A$ ends ( $R A C E$ ) on a rat brain library. In addition, the localization of the PDE9A substrate, cGMP, was studied in the cerebellum using cGMP-immunocy tochemistry.

\section{Materials and Methods}

\section{Cloning and sequencing of the rat PDE9A}

The nucleotide sequence of the mouse PDE9A1 (GenBank accession no. AF031147) was used as a query to search the database of rat ESTs. The program used was the Basic Local Alignment Search Tool (BLAST). The search resulted in several rat EST clones with homology to the mouse sequence. Clones UI-R-BO0-AHJ-H-09-0-UI, UI-R-CA0-AZZ-A-03-0-UI, UIR-BT1-AQM-D-01-0-UI and UI-R-C1-KT-E-07-0-UI were obtained from Research Genetics (Huntsville, AL, USA). Clone RKIBS81 was ordered from ATCC (Manassas, VA, USA). The clones were plated onto LB plates containing $50 \mu \mathrm{g} / \mathrm{ml}$ ampicillin and incubated overnight at $37^{\circ} \mathrm{C}$. From each clone, colonies were cultured and plasmids were purified by the use of QIAprep Spin Miniprep Kit (QIAGEN). Sequencing of the plasmids was performed with M13 forward and reverse primers by the use of an ABI PRISM dye terminator cycle sequencing kit (Perkin-Elmer, Applied Biosystems). Sequencing reactions were purified by Centri-sep columns (Princeton Separations, Adelphia, NJ, USA).

\section{5'RACE}

In order to obtain the full-length rat PDE9A, 5* RACE was performed on a Rat Brain Marathon-Ready cDNA library (7470-1, ClONTECH, Palo Alto, CA, USA) by using Advantage 2 Polymerase Mix (CLONTECH). RACE reactions on the library were performed according to the Marathon-Ready cDNA Protocol-at-a-Glance (PT1156-2, CLONTECH) in which primers AP1 and Seq9.AS1 (Table 1) were used for the first reaction, followed by nested RACE with AP2 and the primer Rat-PDE9-RACE2 or KRACE.AS1 (Table 1). Primers were developed with the program Amplify. PCR products were cloned into a pCRIITOPO TA cloning vector (Invitrogen) and processed 
according to the manufacturer's protocol. Sequences from the EST clones and $5^{\prime} \mathrm{RACE}$ were used to construct the full-length rat PDE9A, which was analyzed by the use of numerous programs available on the ExPASy Molecular Biology Server (http://us.expasy.org).

\section{Riboprobe synthesis}

The mouse PDE9A1 was used as a template for the development of RNA probes derived from different parts of the PDE9A1. For the first and the second riboprobes, primer wvsforw 1 (Table 1) containing a BamHI site and primers wysrev1 or wvsrev2 (Table 1), both containing a NotI site, were used for PCR on mouse PDE9A1 (nucleotides $10-828$ or $10-357$ respectively from mouse PDE9A1 AF031147). "The PCR product was digested with both restriction enzymes and then the product was ligated into the BamHI and NotI site of a pCRIITOPO vector (Invitrogen). For construction of the third riboprobe, primer ISHPDE9forward containing a SacI site and primer ISHPDE9reverse (Table 1) containing a $\mathrm{KpnI}$ site were used for PCR on mouse PDE9A (nucleotides 879-1437 from mouse PDE9A1, AF031147). After digestion, the product was ligated into the SacI and KpnI sites of a pBluescript vector. All constructs were analyzed by DNA sequencing.

Riboprobes were made from $5 \mu \mathrm{g}$ DNA template by in vitro transcription with digoxigenin (DIG) labeled UTP using a DIG RNA labeling kit (Roche, Mannheim, Germany) according to manufacturer's instructions. Antisense probes were transcribed with T7 polymerase from the pCRIITOPO plasmid linearized with BamHI and from $\mathrm{pBluescript}$ vector after SacI digestion. Sense probes were produced by Sp6 RNA polymerase after linearization of pCRIITOPO vector with XhoI or NotI or by T3 polymerase after digestion of pBluescript with $\mathbb{K p n I}$.

"Table 1. Primers used for 5" RACE and construction of RNA in situ hybridization probes.

\begin{tabular}{|c|c|c|}
\hline Primer name & Position & Sequence $\left(5^{\prime \prime}\right.$ to $\left.3^{\prime \prime}\right)$ \\
\hline Seq9AS1 & $491 \cdot 460$ & CAGTTO GTC CTC TWOTTT OTA GCT GCC AGC TC \\
\hline RaA-POWG-RACEZ & $401-378$ & "DCO AAT TCO ACC CGI" "WTC TOC AGC \\
\hline KRACGASI & $271-245$ & CAG ACA CTI GCT TCA CAG CCA CAG GTC \\
\hline 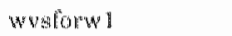 & $10 \cdot 2 \pi$ & ACG CTT GGATCC ATG GGGGCO GGCTCC TCA \\
\hline Wwarey! & $828 \cdot 800$ & GCI TOT ATC COG COG COT GGA GOC CAC AGA GCO AOA CCA T \\
\hline wwstrey i & $356-339$ & CGC GAT CAG CGG COG CTT OGG CTP TCA GOT COT T \\
\hline ISHPDESOforward & $879 \cdot 896$ & GOA AT" COO AGC TCO CAT GAC OTO GAC CAC CC \\
\hline ISHPDV Hereverse & $1437 \cdot 1420$ & GGOGTA COC TCO TCA ACA AOGGGGAA \\
\hline
\end{tabular}

"Indicated positions conespond to the mouse PDE9Al (GenBank accession no. AF031147).

In situ hybridization

Adult male Lewis rats (12 weeks) and Swiss mice (12 weeks) were obtained from the local animal facility (Maastricht, The Netherlands). The experiments were approved by the committee on animal welfare according to Dutch governmental rules. The animals were decapitated and their brains were dissected, frozen in $\mathrm{CO}_{2}$ and stored at $.80^{\circ} \mathrm{C}$ until sectioning. Frozen serial sagittal sections (14 $\mu \mathrm{m})$ were cut and thawed onto SuperFrost 
Plus slides (Menzel-Glaser, Germany) and stored at $-80{ }^{\circ} \mathrm{C}$ until use. Sections were thawed for $10 \mathrm{~min}$ at $50^{\circ} \mathrm{C}$ and thereafter post-fixed with $4 \%$ paraformaldehyde in $0.1 \mathrm{M}$ phosphate buffered saline (PBS) for 20 min at room temperature (RT), followed by three short washes with PBS. Then, sections were incubated for 10 min at RT with $0.1 \mathrm{M}$ triethanolamine containing $0.25 \%$ acetic anhydride. Slides were washed two times with $2 x$ $\mathrm{SSC}$ for 5 min and thereafter washed at $37^{\circ} \mathrm{C}$ with $2 \times \mathrm{SSC}$ containing $50 \%$ $(\mathrm{v} / \mathrm{v})$ formamide before the start of the hybridization.

Hybridization was performed overnight in a humid chamber at $55{ }^{\circ} \mathrm{C}$ under coverslips in $100.200 \mu$ hybridization mix $(50 \%(\mathrm{v} / \mathrm{v})$ deionized formamide, $250 \mu \mathrm{g} / \mathrm{ml}$ salmon sperm DNA, $1 \mathrm{mg} / \mathrm{ml}$ tRNA, $10 \%$ dextran sulfate, $2 \mathrm{x}$ SSC, $1 \mathrm{x}$ Denhardt's solution and $200 \mathrm{ng} / \mathrm{ml}$ DIG-labeled RNA probe). After hybridization, sections were washed in $2 \times$ SSC, IX SSC and $0.1 \mathrm{SSC}$, all solutions containing 50\% formamide. Each wash step was performed at $45^{\circ} \mathrm{C}$ for $20 \mathrm{~min}$. Next, the sections were treated with RNAse T1 (2 U/ml, Roche) in $2 \mathrm{x}$ SSC containing $1 \mathrm{mM}$ ethylenediaminetetraacetate (EDTA) for 15 min at $37^{\circ} \mathrm{C}$ followed by a 20 min wash with $1 \mathrm{x}$ SSC at $45^{\circ} \mathrm{C}$. After washing for 10 min with $2 \mathrm{x}$ SSC at RT, sections were incubated for $5 \mathrm{~min}$ with buffex 1. (150 $\mathrm{mM} \mathrm{NaCl}$ and $100 \mathrm{mM}$ maleic acid ( $\mathrm{pH} 7.5)$ ) followed by blocking for 1 hr at $\mathrm{RT}$ with buffer $2(150 \mathrm{mM} \mathrm{NaCl}$, $100 \mathrm{mM}$ maleic acid ( $\mathrm{pH} 7.5$ ) and 1\% blocking reagent (Roche, \#1096176)) containing $5 \%$ sheep serum. Next, slides were incubated overnight with a 1:2000 dilution of anti-DIG-alkaline phosphatase in buffer 2 containing $1 \%$ sheep serum. Thereafter, slides were washed three times with buffer 1 followed by washing for $10 \mathrm{~min}$ with Tris-buffered saline (TBS) containing $0.025 \%$ "Tween 20 and thereafter, three times 5 min with TBS. After two washes of 5 min in buffer 3 (100 mM Tris-HCl (pH 9.5), 0.1 M NaCl and 0.05 $\mathrm{M} \mathrm{MgCl}_{2}$ ), the sections were incubated with freshly prepared nitro-blue tetrazolium and 5-bromo-4-chloro-3-indolyl-phosphate in buffer: $4.50 \mathrm{mM}$ Tris ( $\mathrm{pH}$ 9.5), $100 \mathrm{mM} \mathrm{NaCl}, 6 \%$ polyvinylalcohol, $50 \mathrm{mM} \mathrm{MgCl}, 1 \mathrm{mM}$ levamisole) and stained for $2-3$ days in the dark at $25{ }^{\circ} \mathrm{C}$. The buffer was replaced by fresh buffer after the first day. The color reaction was stopped with $10 \mathrm{mM}$ Tris-HCl and I mM EDTA (pH 8.0). Sections were dried at 37 ${ }^{\circ} \mathrm{C}$ after addition of Imsol Mount (Klinipath, Duiven, The Netherlands) which was diluted 5 times with Tris-EDTA buffer and therealter mounted with D.P.X. mounting medium (Klinipath).

\section{Immunocytochemistry}

After the development of the in situ hybricization, sections were counterstained with different cellular markers. Neurons were visualized with mouse anti-neuronal nuclei (NeuN) (Chemicon International, Temecula, CA, USA) diluted 1:50 with TBS containing $0.8 \%$ Triton (TBS-T). Astrocytes were stained by using a monoclonal antibody against anti-glial fibrillary acidic protein (GFAP) (Sigma) diluted 1:1000 or a polyclonal antibody directed against GFAP (diluted 1:25) which was kindly donated by Dr. F. Ramaekers (Maastricht, The Netherlands). Sections were incubated overnight with the primary antibodies at $4{ }^{\circ} \mathrm{C}$ and thereafter washed with 
TBS-T, TBS and TBS-T, each step lasted $10 \mathrm{~min}$. For the visualization of the primary antibodies sections were incubated with 1:800 Cy3-conjugated affinipure donkey anti mouse IgG (Jackson, Pennsylvania, USA) or 1:100 Alexa fluor 488 goat anti-rabbit IgG conjugate (Molecular Probes, Leiden, The Netherlands) for 90 min at RT. After being washed in TBS-T and TBS, some sections were counterstained for $20 \mathrm{~min}$ with 1:500 Hoechst (Sigma) to visualize cell nuclei and thereafter mounted with TBS-glycerol.

In vitro incubation of cerebellum slices

Animals were decapitated and their brains were immediately transferred into ice-cold Krebs-Ringer bicarbonate buffer, aerated with $95 \% \mathrm{O}_{2}$ and $5 \%$ $\mathrm{CO}_{2}$ at $\mathrm{pH} 7.4$ as described in detail in (De Vente et al., 1990; De Vente and Steinbusch, 1992). Slices $(400 \mu \mathrm{m})$ from the cerebellum were cut using a Vibroslicer (Campden Instruments) and incubated in vitro for $40 \mathrm{~min}$ in the presence of the non-selective PDE inhibitor IBMX $(1 \mathrm{mM})$ in the absence or in the presence of the NO donors sodium nitroprusside (SNP, $0.1 \mathrm{mM}$ ) or DEA/NO (0.1. mM), which were present the last $10 \mathrm{~min}$ of the incubation time. The NO-independent $\mathrm{sGC}$ activator $\mathrm{YC}-1(10 \mu \mathrm{M})$ was present throughout the entire incubation time. After the incubation, slices were processed for cGMP-immunocytochemistry as described in (De Vente et al., 1990; De Vente and Steinbusch, 1992).

\section{Microscopical evaluation}

All sections were examined using an Olympus AX70 microscope equipped with a cooled CCD Olympus Digital video camera F-view (Paes, Zoeterwoude, The Netherlands). Images were stored digitally by using the computer program Analysis (Soft Imaging System, Münster, Germany), then arranged and adjusted to match for contrast with the program Adobe Photoshop 5.5.

\section{Results}

\section{Cloning of rat PDE9A}

An $\mathbb{E S T}$ database was screened with the mouse PDE9A1 as a query in order to isolate the rat homologue. Screening of the database resulted in severa] EST clones with homology to the mouse PDE9A1 sequence. Sequencing of live different clones resulted in fragments of various lengths with a high homology to the mouse PDE9A1, however no clone contained the full-length sequence with the start initiation site. Comparison of the largest EST clone (obtained from UI-R-BO0-AHJ-H-09-0-UI) with the mouse PDE9A1 demonstrated that nearly the full-length sequence was present, however 23 bases were absent at the 5 -end. In order to obtain the full-length rat PDE9A sequence, 5' RACE was performed on a rat brain library. The fulllength rat PDE9A sequence was constructed from EST and 5' RACE sequencing (Fig. 1). 


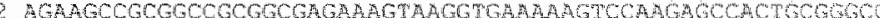

62 ma

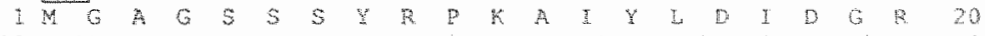

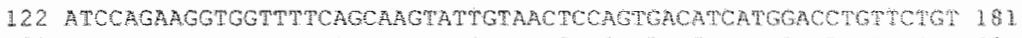

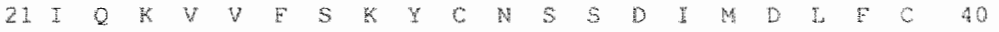

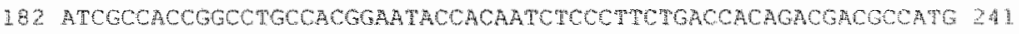

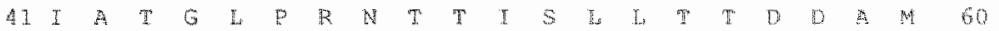

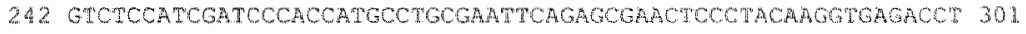

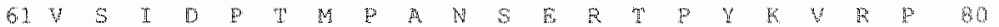

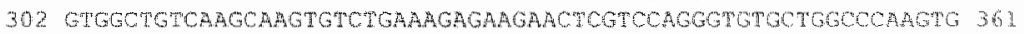

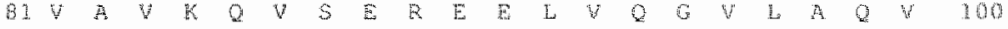

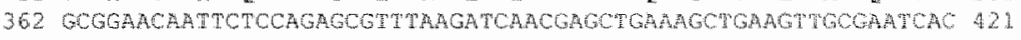

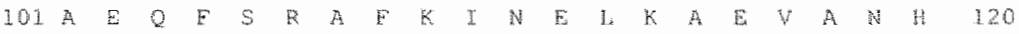

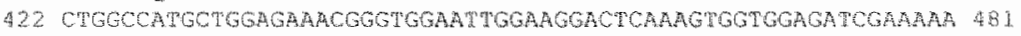

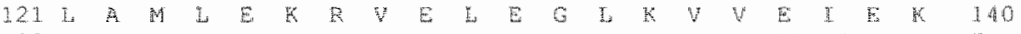

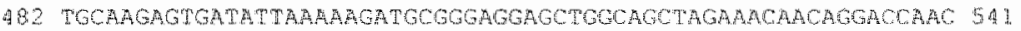

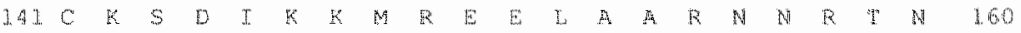

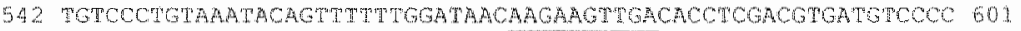

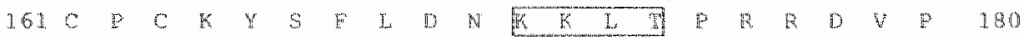

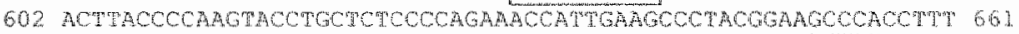

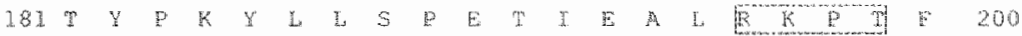

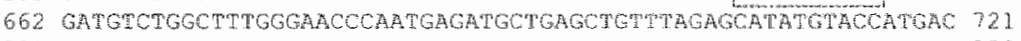

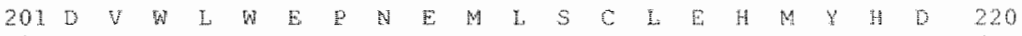

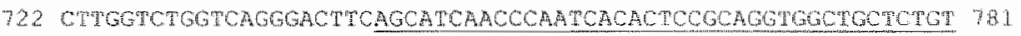

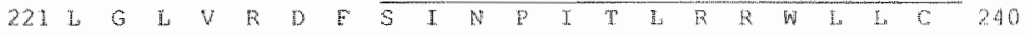

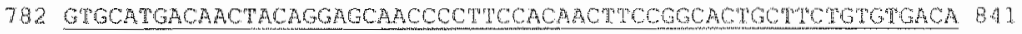

2a $V$ G

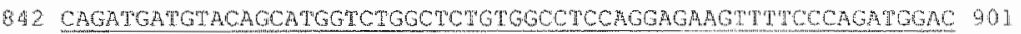

2612 M M Y 5 M V W L C 6 L

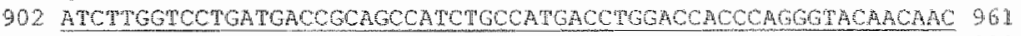

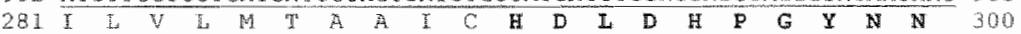

962 ACATACCAGATCAACGCOCGCACGGAACTAGCGGTGCGTACARCGACATCTCGCOCCTE 1021

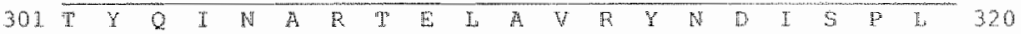

1022 GAGAACCACCAMTGCGCOATCGCCHTCCAGATCCTGGCGAGACOCGAGTGCAACATCYTO 1091

321. $E$ IN

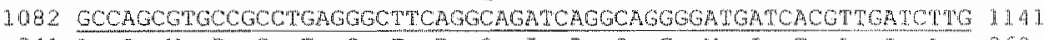

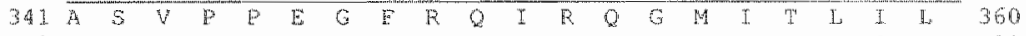

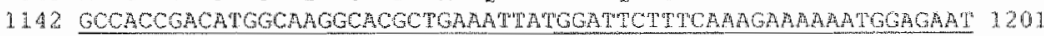

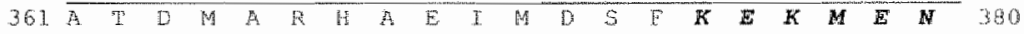

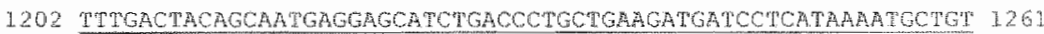

381 F D Y S N E E

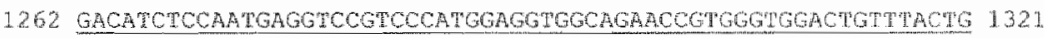

401. D I S M E V R P M E V A E P W V D C L I 420

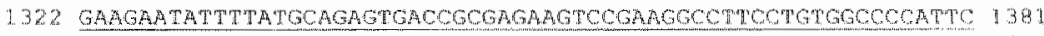

A21.

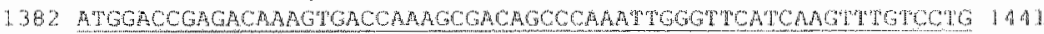

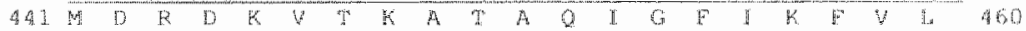

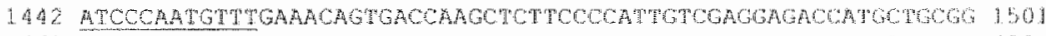

$461 \mathrm{I}$ ?

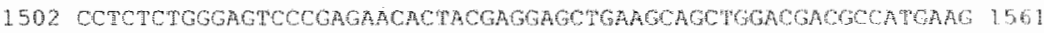

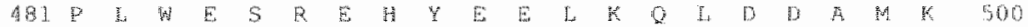

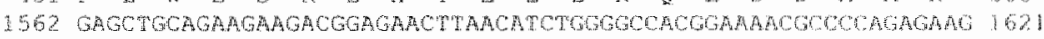

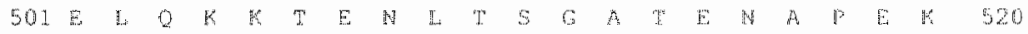

1622 MCCAMGA

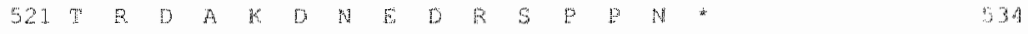

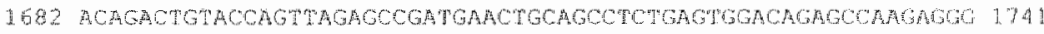

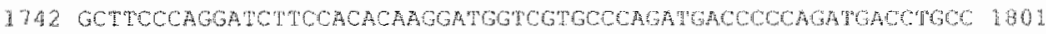

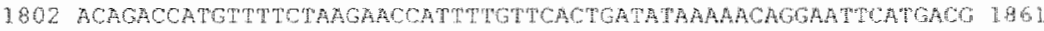

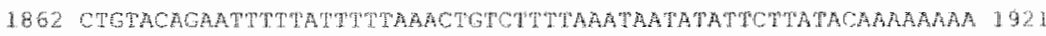

922 ARAARAMADA

11931

Figure 1. Nucleotide sequence and predicted amino acid sequence of rat PDE9A. "lhe predicted amino acid sequence is shown below the nucleotides as a single-letter code. The sequence of the catalytic domain is underlined. "The start codon ATG is boxed, the asterisk ( ${ }^{5}$ ) indicates the termination codon of translation. In bold the PDEase signature motif is shown. Amino acids in bold-italics indicate tyrosine kinase phosphorylation sitee, boxes with dashed lines indicate CAMP-and CGMP-dependent protein kinase phosphorylation sites. 


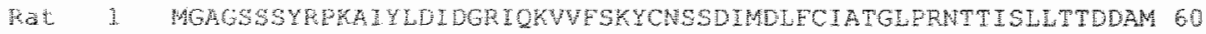

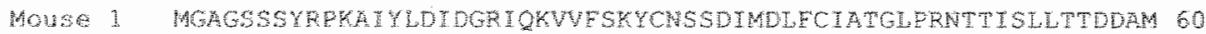

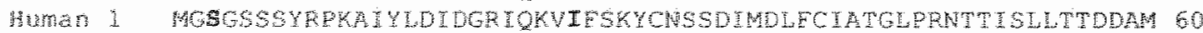

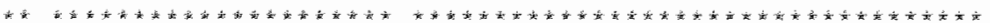

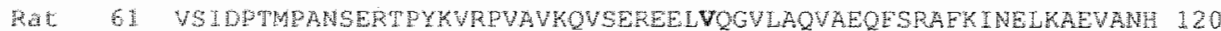

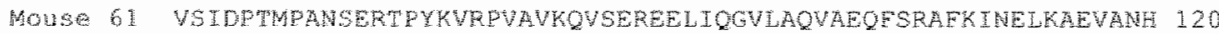

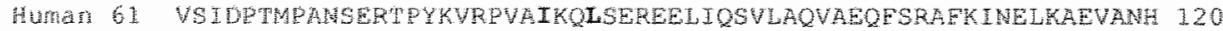

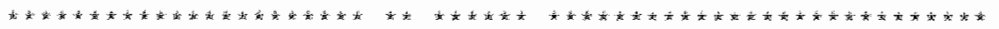

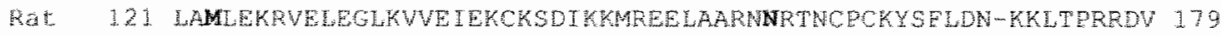

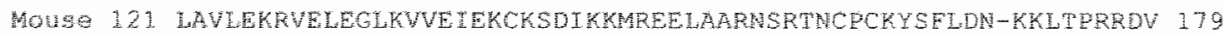

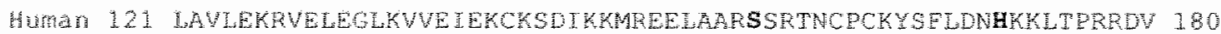

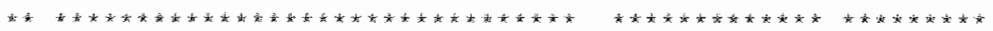

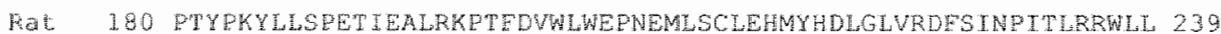

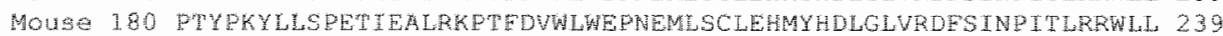

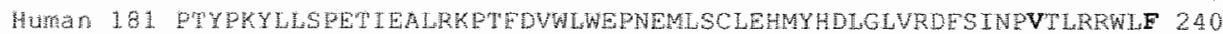

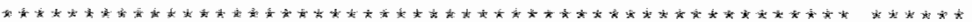

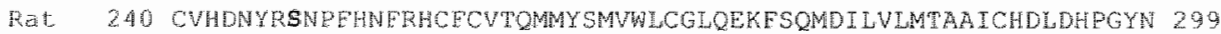

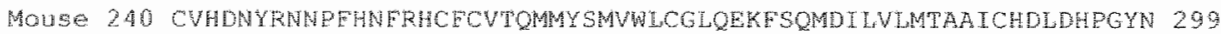

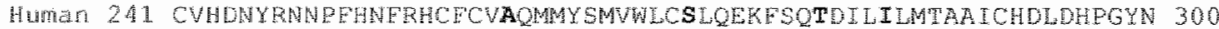

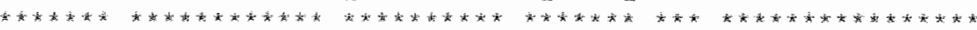

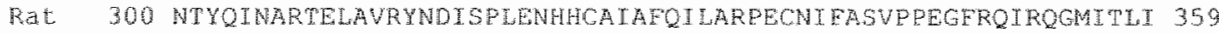

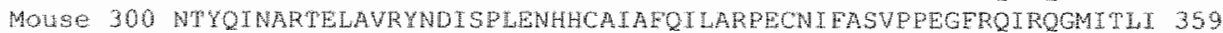

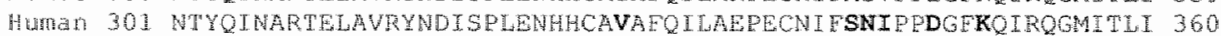

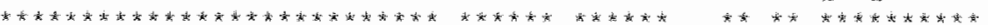

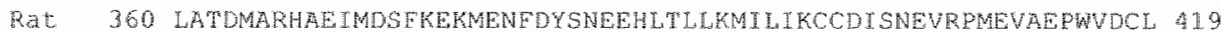

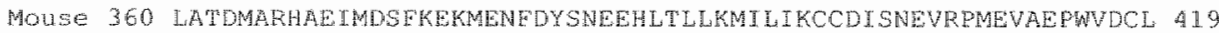

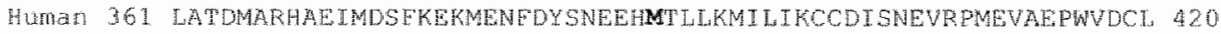

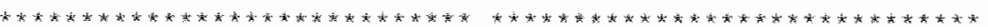

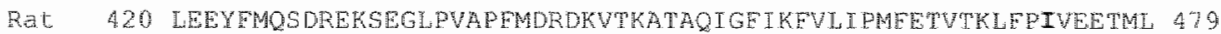

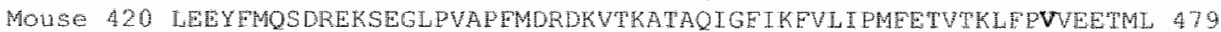

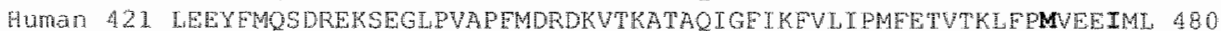

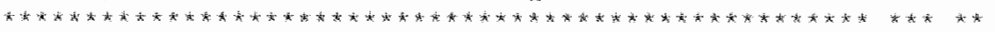

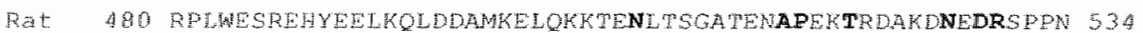

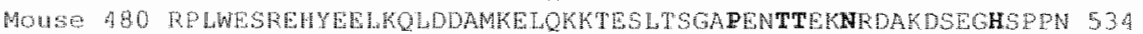

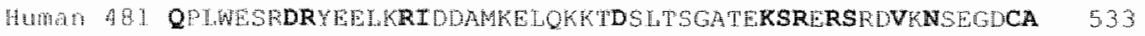

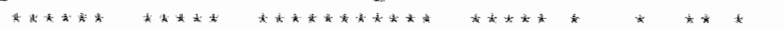

Figure 2. Alignment of the rat PDE9A sequence with mouse PDEQA1 (GenBank Accession no. AF031147) and human (GenBank Accession no. AFo67224) amino acid sequences. Identical amino acids are indicated with an asterisk ("). Amino acids depicted in bold differ between the three species.

The combination of EST and 5' RACE sequencing, resulted in a sequence of 1931 base pairs in length, the open reading frame of 1602 nucleotides spanned from the first initiation codon ATG to the termination codon TGA (nucleotides 62-1664). The open reading frame encodes for a protein of 534 amino acids with a predicted molecular mass of $61,756 \mathrm{kDa}$. The sequence contained a structure which encodes for a PDE catalytic domain in which the PDEase signature motif of HDX2HX4N (Beavo and Reifsnyder, 1990) was found. Throughout the rat sequence, various potential sites for 
phosphorylation by CAMP- and cGMP-dependent protein kinase and tyrosine kinase (Fig. 1) were found, as well as for phosphorylation by protein kinase $\mathrm{C}$ and casein kinase $\mathbb{I I}$ and for $\mathrm{N}$-glycolisation and $\mathrm{N}$-myristoylation (not shown). A possible PEST (proline (P), glutamic acid (E), serine (S), and threonine (T)) region was present at the $\mathrm{C}$ terminal part (amino acids 505. 520 ) of the rat PDE9A, indicating the presence of a proteolytic recognition signal (Sekhar and Freeman, 1998).

Comparison of the rat with the mouse PDE9AI sequence (Soderling et al., 1998), showed an identity of $95 \%$ on the nucleotide level from the coding region and a homology of $97.6 \%$ was found on the amino acid level (Fig. 2). An identity of $82.7 \%$ on the amino acid level was found in 589 residues of overlap, comparing the rat sequence with the largest form of the human PDE9A, indicated as PDE9A1 (593 amino acids, (Fisher et al., 1998; Guipponi et al., 1998)). Comparison of the different 5 splice-variants of the human PDE9A showed an identity on the amino acid level of $92.1 \%$ (in 529 residues) for PDE9A2 (533 AA, Fig. 2), 91.2\% (in 456 residues) for PDE9A3 (466 amino acids) and $91.5 \%$ identity in 424 residues of overlap for PDE9A4 (465 AA).

\section{Localization of PDE9A $m$ RNA in the rat and mouse brain}

In order to study PDE9A mRNA expression in the rat and mouse brain, in situ hybridization was performed with DIG-labeled RNA probes. Using sagittal sections of mouse and rat brains, it was readily apparent that PDE9A mRNA was widely distributed with varying intensities throughout the CNS in both species (Fig. 3B and 3C). Comparison of the expression of PDE9A between rat and mouse showed that the staining patterns were similar.

During the development of the staining, Purkinje cells in the cerebellum, cells of the subiculum and in layer $V$ in the cortex were visible first. Thereafter, the staining developed progressively throughout the whole brain. These results have been obtained with three probes derived from different regions of the PDE9A. Sections processed with sense probes (Fig. $3 \mathrm{~A}$ and Fig. $4 \mathrm{~B}$ ) or with RNase (not shown) were devoid of specific staining.

In both rat and mouse, the strongest PDE9A expression was detected in the Purkinje cells (Fig. 3B, 3C and 4A) of the cerebellum, followed by a moderate staining in the granule cell layer and some scattered cells in the molecular layer.

Throughout the brain, PDE9A mRNA expressing cell bodies were found with a varied staining intensity pattern (Fig. 3 and Fig. 4). PDE9A staining was found in all cortical layers with the strongest labeling in layer $V$ (Fig. $4 \mathrm{E})$. In the olfactory bulb, the mitral cell layer was labeled the strongest with intermediate expression in the granule cell layer and the olfactory glomeruli. In the external plexiform layer, scattered cell bodies were found containing PDE9A (Fig. 4C). In the olfactory tubercle there was strong PDE9A mRNA expression, and in the islands of Calleja, the granule cells also showed considerable labeling (Fig. 4G). In the caudate nucleus, PDE9A 
mRNA was only observed in gray matter and never in white matter tracts (Fig. 4F).

In the hippocampus, pyramidal cells and granule cells in the dentate gyrus were stained for PDE9A mRNA (Fig. 4D), and furthermore, some cell bodies outside these cell layers were positive. In the subiculum some densely labeled cells were observed. Thalamic nuclei and in the hypothalamic area, stained cell bodies were detected with varied intensity. Strong staining was observed in the supraoptic nucleus (Fig. $4 \mathrm{H}$ ). In the superior and inferior colliculi., a moderate PDE9A signal could be detected. Throughout the brain stem groups of stained nuclei were found, including the pontine nucleus and the inferior olive nucleus.

To investigate in which cell types PDE9A mRNA was expressed, sections were double labeled with the neuronal markex NeuN (Fig. 5 D-I) and the glial cell marker GFAP (Fig. 5 A-C). Labeling with NeuN demonstrated that PDE9A was detected in many neurons (Fig. 5 D-I) throughout different brain areas. Double labeling of sections with NeuN, GFAP and Hoechst strongly suggested expression of PDE9A in a subpopulation of astrocytes in rat and mouse (Fig. $5 \mathrm{~J}-\mathrm{Q}$ ).

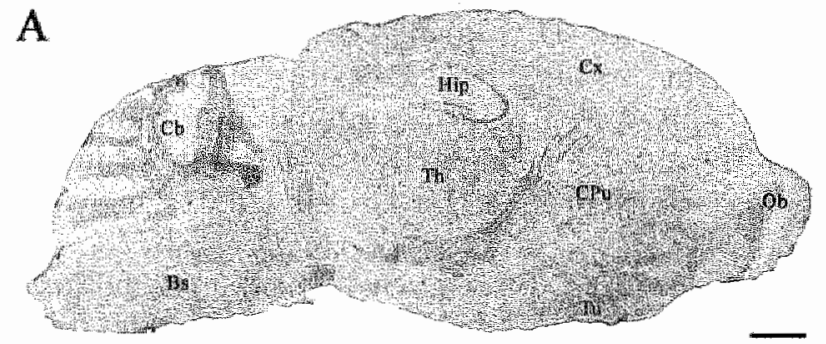

B
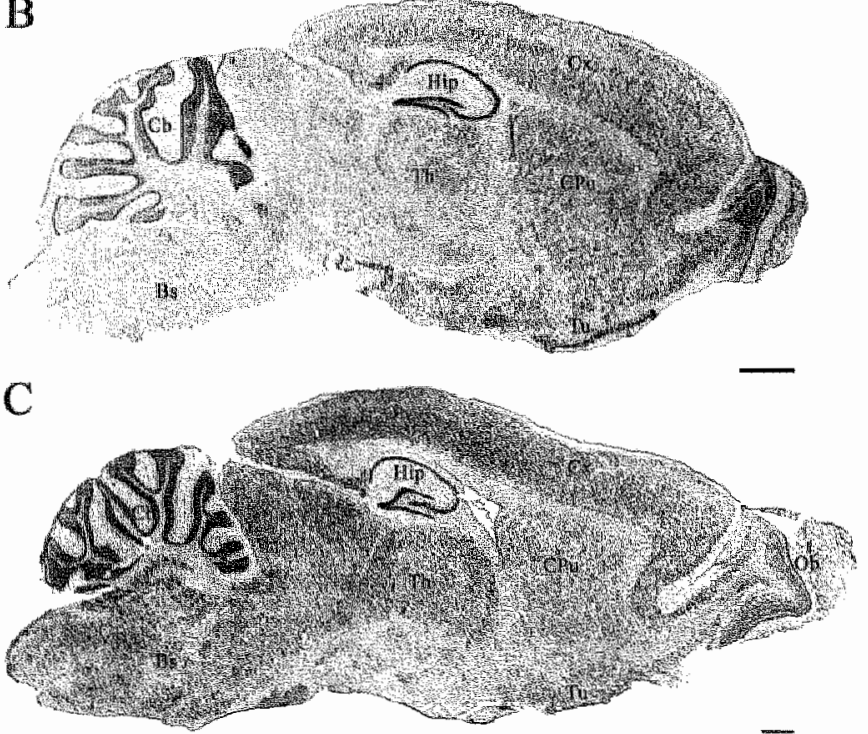

Figure 3. Localization of PDE9A mRNA in sagittal brain sections of adult mouse (A and $B$ ) and rat (C) by non-radioactive in situ hybridization. Section in A was hybridized with sense probe, $\mathbb{B}$ and $C$ were hybridized with antisense probes. $\mathbb{B s}$, brain stem:

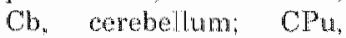
caudate putamen: $\mathrm{Cx}$, cortex; Hip, hippocampus; Ob, olfactory bulb; Th, thalamus; Tu, olfactory tubercle. Bar indicates $1000 \mu \mathrm{m}$. 

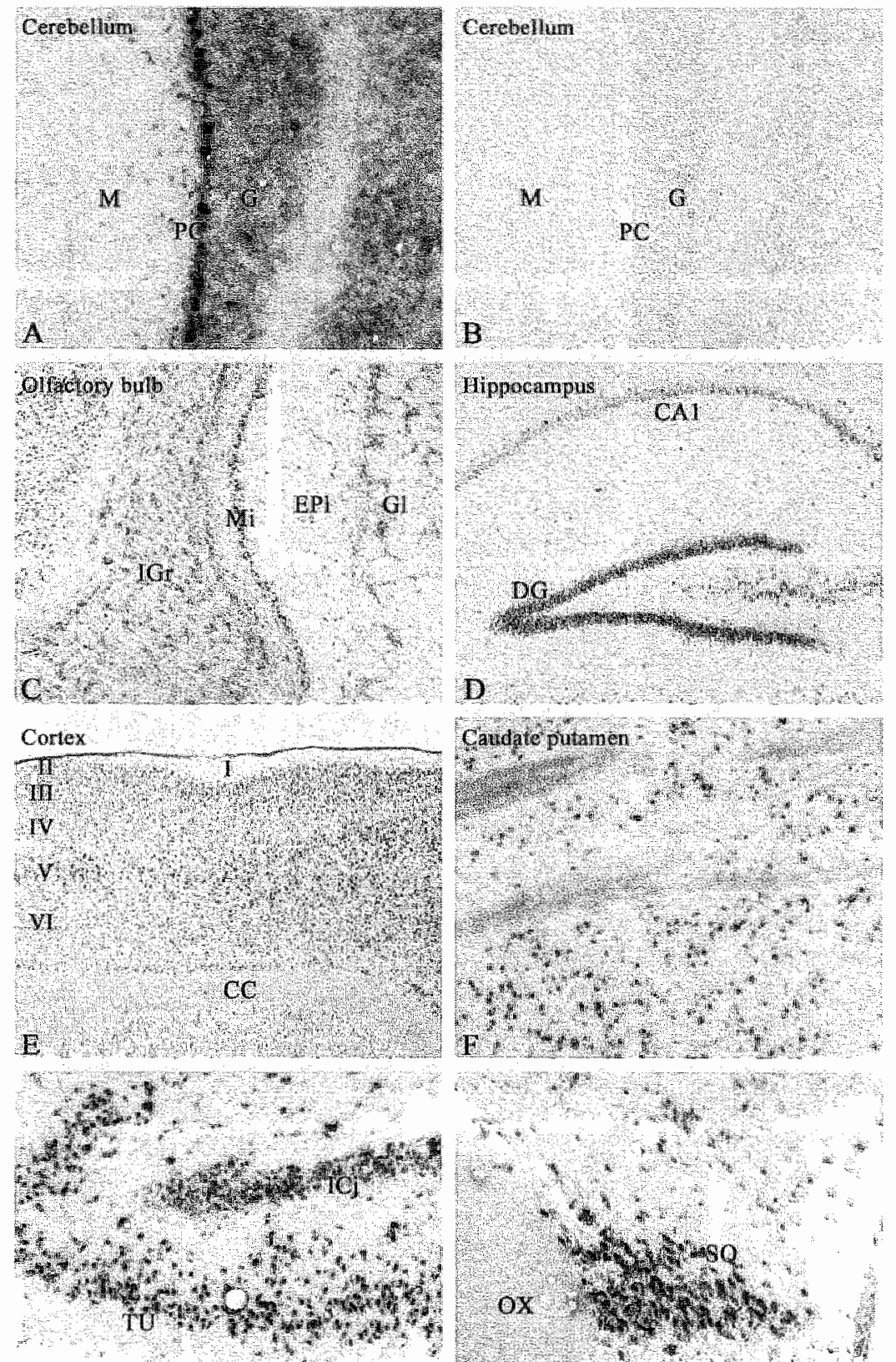

G

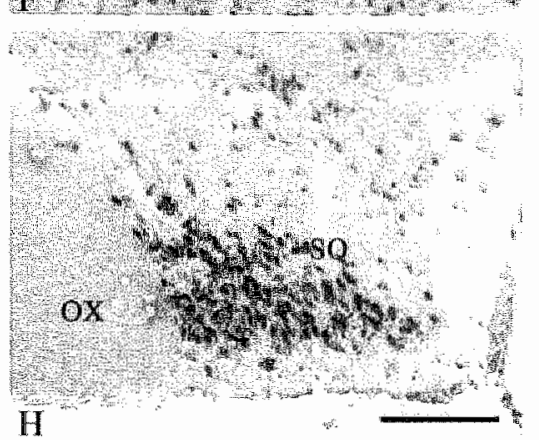

Figure 4. Localization of PDE9A transcripts in several areas of the nat brain by an nonradioative in situ hybridization. The different brain areas are indicated in the leot uppor corner. A and $\mathrm{C}$-H were hybridized with antisense probes, $\mathrm{B}$ was hybridized with sense probe. CC. corpus callosum; DG dentate gyrus; EPl. external plexiform layer; $G$, granular layor; $G$, glomerular layer; ICj, islands of Calleja; IGr, internal granular layer; $\mathrm{M}$, molecular layer; $\mathrm{Mi}$, mitral cell layer; $O X$, optic chiasm; PC, Purkinje cell layer; SO, supraptic nueleus: TU. olfactary tubercle. Bar indicates $200 \mu \mathrm{m}$ for $\mathrm{A}, \mathrm{B}$ and $\mathrm{F} . \mathrm{H} ; 500 \mu \mathrm{m}$ for $\mathrm{C}$ and $\mathrm{D} ; 1000 \mu \mathrm{m}$ for $\mathrm{F}$. 

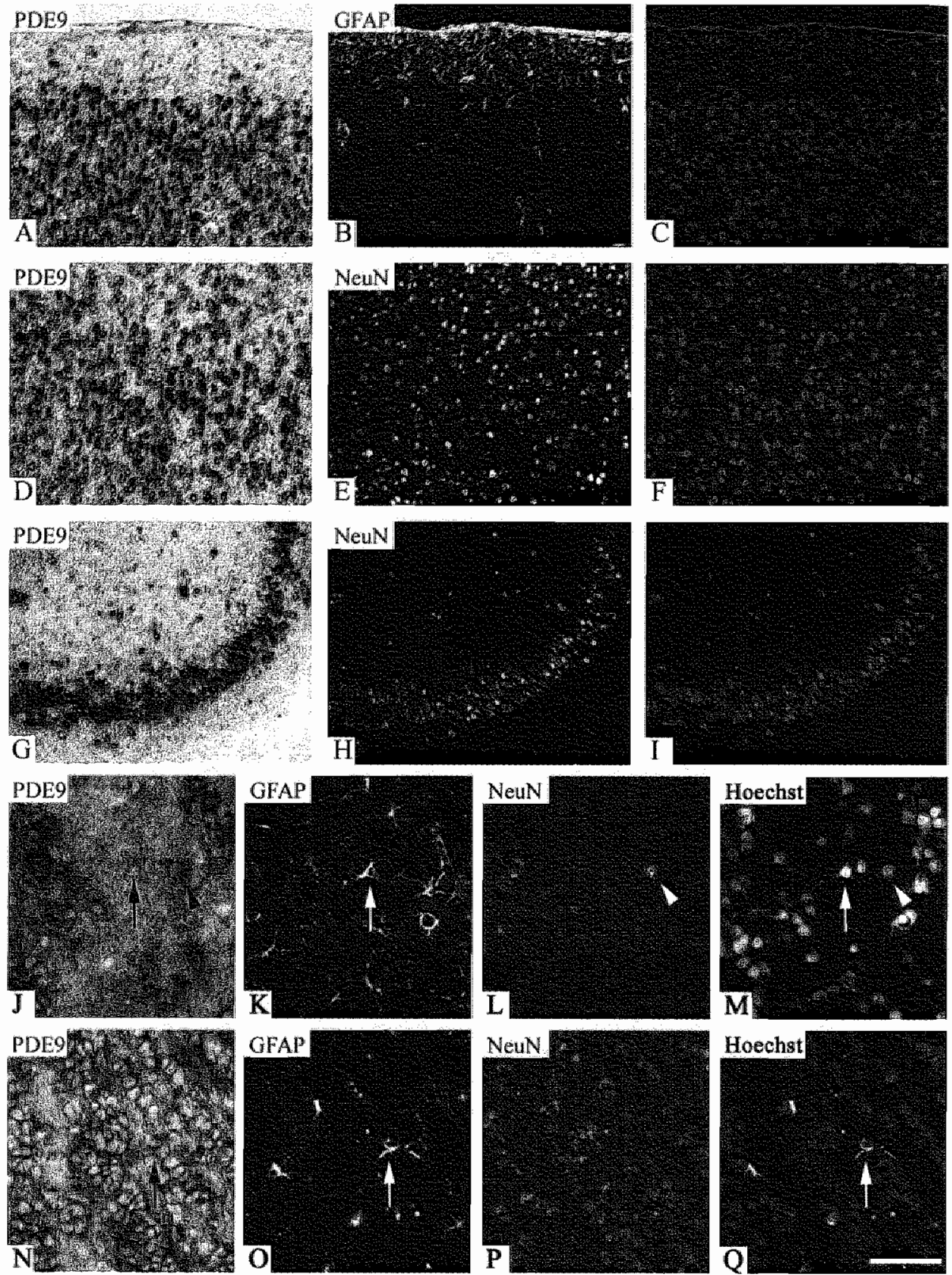

Figure 5. Double staining of PDEMA mRNA with GFAP or NenN in outer cortical layers (A-C) or layer $V(D-B)$ and in CA3 area of the hippocampus (G-1) from the rat brain. Sections hybridided wh antisense probes shown in $A, D$, G were double labeled for GFAP (B) or Neu (E and H). In $\mathrm{C}$, fand I, PDE9A mRNA (red) is combined with GAP (green, C) ar NeuN (green, Fand I). PDE9A in situ hybridizations in the olfactory bulb from rat (JM) or mouse (N. Q) were stained with NeuN, GFAP and Hoechst on the same section. Bar indicates $200 \mu \mathrm{m}$ for A.I and $50 \mathrm{fm}$ tor I.Q. Arrows indicate astrocytes, arrowheads neurons. 
cGMP-immunoreactivity in cerebellum

To investigate the localization of the PDE9 substrate, cCMP, the cerebellum which showed the highest PDE9A expression, was investigated in more detail using cGMP-immunocytochemistry. Therefore, cerebellum slices of rat, mouse and rabbit were incubated with IBMX alone or in combination with the sGC activators SNP, DEANO or $\mathrm{YC}-1$ (Fig. 6). In the presence of IBMX alone, cGMP-immunoreactivity was observed in the molecular layer, whereas no cGMP-immunoreactivity was observed in the granular layer or in Purkinje cells in all three species investigated. Coadministration of IBMX with an NO donor as SNP (D) or DEA/NO (E) or the NO-independent $\mathrm{SGC}$ activator $\mathrm{YC}-1$, resulted in increased cGMP-immunoreactivity in the molecular layer and the granular layer, compared to IBMX alone. Under all the incubation conditions tested, no strong cGMP-staining was observed in Purkinje cells.
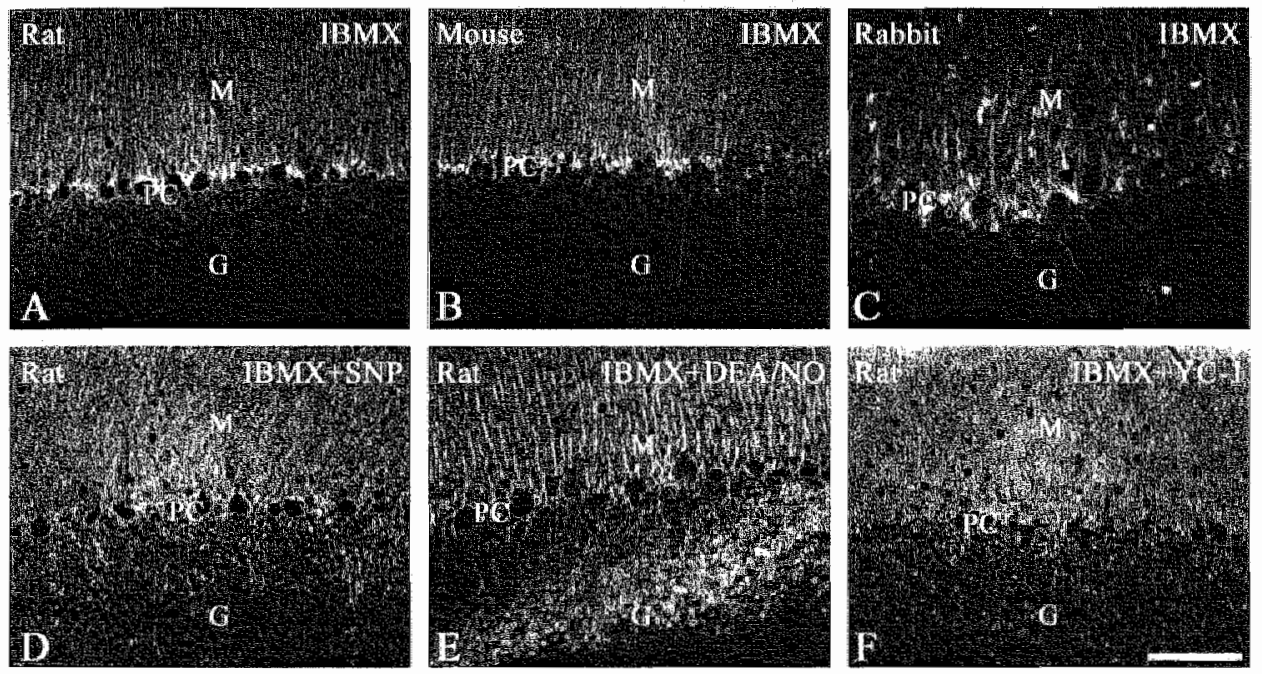

Figure 6. cGMP-imnunoreactivity in cerebellar slices of rat (A. D. F), monse (B) or rabbit (C) incubated an vitro in the presence of 1 m.M IBMX. To stimulate sCG slices ware incubnted with

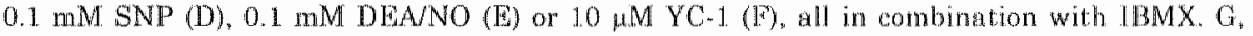
granular layer; M, mollecular layer; PC, Purkinje cell layer. Bar indicates loo fim for all pictures.

\section{Discussion}

In this study, the rat PDE9A cDNA was cloned and the localization of this PDE was studied on the InRNA level in the mouse and rat brain. The rat PDE9A sequence demonstrated a high homology at the amino acid level when compared to the mouse and the human PDE9A, which is in agreement with the high conservation found between different species in other PDI families like the recently cloned PDE10 (Fujishige et al., 1999) and PDE11 
(Yuasa et al., 2001). Like the mouse and the human PDE9A, the rat PDE9A lacks a region homologous to the allosteric cGMP-binding domains as found in the cGMP-hydrolyzing PDEs: PDE2, PDE5, PDE6, PDE10 and PDE11. (Soderling and Beavo, 2000; Francis et al., 2001).

The rat PDE9A sequence contains several potential phosphorylation sites for different protein kinases. Modification of PDE activity by phosphorylation by cAMP- and cGMP-dependent kinases has been described for some PDFs (Macphee et al., 1988; Florio et al., 1994; Corbin et al., 2000). PDE9 might be regulated by cAMP- and cGMP-dependent kinases and/or tyrosine kinase, protein kinase $C$, casein kinase II, since in the structure several potential phosphorylation sites exist. However, further studies are needed to determine if phosphorylation of PDE9 is a necessary step in the regullation of PDE9 activity.

The high conservation between the mouse and rat PDE9A, made it possible to use the same RNA probes on rat and mouse tissue. "The use of a non-radioactive in situ hybridization for PDE9A MRNA permitted a detailed analysis of the localization of this enzyme. PDE9A expression was found throughout the brain with varying intensities. Our results strongly suggested that PDE9A mRNA was mainly localized in neurons throughout the rat and mouse brain. No specific mRNA staining was found in white matter tracts, like corpus callosum, optic chiasm or in white matter bundles in the caudate putamen complex. In both species PDE9A expression was also found to some extent in astrocytes after counterstaining of sections with GFAP. However the expression of PDE9A in astrocytes was difficult to determine since astrocytes often surround the neurons (Fig. 5C) and furthermore, it is known that NeuN does not stain all neurons in the brain. It has been shown that astrocytes in the hippocampus, cortex and some other brain regions, contain particulate $\mathrm{GC}$ and respond to natriuretic peptides (De Vente et al., 1989; Herman et al., 1996). We also showed that hippocampal astrocytes express both the particulate and the $\mathrm{sGC}$ (Teunissen et al., 2001.). These findings suggest the existence of cGMPhydrolyzing PDEs in astrocytes.

"The specificity of our" results is supported by several obserwations. First, using three probes derved from different parts of the PDEQA resulted in identical staining patterns. Second, in sections hybridized with sense probes, the strong staining as found with antisense probes was absent. Third, treatment of sections with RNase before application of the probes resulted in no staining, indicating the antisense probes bound specifically to RNA. Our results are in good agreement with the results described by Andreeva et al. (2001) with radioactive in situ hybridization for PDE9A.

PDE9A mRNA was found in cell bodies throughout the brain. The structure predicts that PDE9A is a cytoplasmic protein. However, membrane localization cannot be ruled out since there are several potential sites for myristoylation present in the sequence. Presently, there are no data on compartmentalization of this enzyme. In addition, for some PDE families differences in cellular expression was found comparing splice-variants in one family, 1.e. PDE1, PDE4, PDE8, PDE10 and PDE11 (Kotera et al., 1999; 
McPhee et al., 2001; Michibata et al., 2001; Wang et al., 2001; Yuasa et al., 2001). The presence of PDE9A splice variants might be expected since for human PDE9A four splice variants have been described (Fisher et al., 1998; Guipponi et al., 1998). However, so far we have not been able to detect splice variants of the rat PDE9A by performing $5:$ RACE.

Comparison of our data on the PDE9A expression with other published results on PDE families indicates that several PDE isoforms can be present in the same cell type such as the pyramidal cells in the hippocampus or Purkinje cells in the cerebellum of the rat. Both pyramidal and Purkinje cells contain PDE1 (Kincaid et al., 1987; Furuyama et al., 1994), PDE3 (Reinhardt and Bondy, 1996), PDE4 (Iwahashi et al., 1996), and PDE7 (Miro et al., 2001). In addition, PDE2 (Repaske et al., 1993) is present in pyramidal cells and PDE5 (Kotera et al., 1997) could be detected in Purkinje cells. Of the PDE families that can hydrolyse cGMP, PDE9 has the lowest $\mathrm{Km}$ for cGMP of any PDE known to date (Fisher et al., 1998, Soderling et al., 1998; Juilfs et al., 1999). Since PDE9 has the highest affinity for cGMP, this suggests that PDE9 may function in cells at lower cGMP concentrations than the other PDEs that are present in the same cell.

cGMP-immunocytochemistry has been used to describe NO-stimulated cGMP accumulation in the brain (De Vente et al., 1998; De Vente and Steinbusch, 2000; Van Staveren et al., 2001). Most of these studies have been performed using brain slices incubated in vitro in the presence of IBMX as a non-selective PDE inhibitor. NO-mediated cGMP accumulation was detected throughout the brain, however, these studies have failed to demonstrate cGMP-immunoreactivity in cells such as hippocampal pyramidal cells (Van Staveren et al., 2001) or in cerebellar Purkinje cells (Southam and Garthwaite, 1993; De Vente et al., 1998; De Vente and Steinbusch, 2000\%. Even at the electron-miscroscopical level, Chan-Palay and Palay (1979) did not detect cGMP synthesis in Purkinje cells. The fact that PDE9, which is IBMX-insensitive (Fisher et al., 1998; Soderling et al., 1998), is present in these cells might be a partial explanation for the failure to visualize cGMP. However, it must be noted that the demonstration of strong PDE9A mRNA expression in cell bodies does not give a straight forward answer to the expression level of the PDE9 protein or the PDE9 activity. For instance PDE9A mRNA could be detected by in situ hybridization in granule cells, and as shown in Fig. 6, cGMP accumulation could be demonstrated in these cells. A reason might be that in granule cells the PDE9 protein is not present or at a very low level of expression. However, these findings may also point to a certain regulation of PDE9 activity which might differ between cell types. Therefore, incubation with PDE9 selective inhibitors might give a more clear answer on the function and the working mechanism of PDE9 in different cell types, however these inhibitors are not available at this moment.

In conclusion, we have shown that the rat PDE9A sequence has a high homology to the mouse and human PDE9A. Both in the rat and mouse brain, PDE9A mRNA demonstrated the highest expression in Purkinje cells of the cerebellum. PDE9A was widely distributed throughout the CNS and 
the expression was mainly detected in neurons. The presence of PDE9 expression in cell bodies might cause the lack of cGMP-immunoreactivity in certain cell types such as cerebellar Purkinje cells or hippocampal pyramidal cells. Based on the high affinity of PDE9 for cGMP and the broad distribution throughout the CNS, it is likely that PDE9 has a function in regulation of low cGMP levels in cells and is involved in many different brain functions involving cGMP-mediated signal transduction pathways.

\section{Acknowledgments}

The nucleotide sequence reported in this paper has been submitted to GenBank with accession number AY 1.45898. This work was supported by a grant R90-174 (W.C.G. van Staveren) of the Dutch Science Foundation N.W.O. (Nederlandse Organisatie voor Wetenschappelijk Onderzoek) and grant NIH DK-21723 (J.A. Beavo).

\section{References}

ANDREEVA SG, DIKKGS P, EPSTEIN PM, ROSENBERG PA. (2001) Expression of cGMPspecific phosphodiesterase 9A mRNA in the rat brain. of Newrose 21: 9068-9076.

BEAVO JA. RETFSNYDER DH. (1990) Primary sequence of cyclic nucleotide phosphodiesterase isozymes and the design of selective inhibitors. Trends Pharmacol Sci 11: 150-1.55.

BEAVO JA. (1995) Cyclic mucleotide phosphodiesterases: functional implications of multiple isoforms. Physiol Rev 75: 725-748.

BIEL M, ZONG X, LUDWIG A, SAUTTER A, HOFMANN F, (1999) Structure and function of cyclic nucleotide-gated channels. Rev Physiol Biochem Phormacol 135: 151-171.

CFIAN-PALAYY V, PAIAY SL. (1979) Immunocytochemical localization of cyclic GMP: light and electron microscope evidence for involvement of neuroglia. Proc Nat Acad Sci U S A 76: $1485-1488$.

CORBIN JD, TURRO IV, BEASLEY A, FRANCLS SH. (2000) Phosphorylation of phosphodisterase - by cyclic nucleotide-dependent protein kinase alters its catalytic and allosteric cOMP-binding activities. En of Biochen 267: 2760-2767.

DE VENTE J, BOL JGEM, STERTBUSCH HWM, (1989) Cyclic GMP-producing atrial natriuretic factor responding cells in the rat brain: an immunocytochemical study. Eur of Netrose 1: 436.460.

DE VENTE I, BOL, JG, BERKELMANS HS, SCHIPPER J, STEINBUSCH HWM. (1990) Immunocytochemistry of CGMP in the cerebellum of the immature, adult, and aged rat the involvement of mitric oxide. A micropharmacological study. Eur J Neurosci 2: 845-862.

DE VENTE J, STISINBUSCH HWM. (1992) On the stimulation of soluble and particulate guanylate cyclase in the rat brain and the involvement of nitric oxide as studied by cGMP immunocy tochemistry. Acta Histochen 92: 13-38.

DE VENTE J HOPKINS DA, MARKERINK.VAN ITTERSUM M, EMSON PC, SCHMTDT HHH, STEINBUSCH HWM. (1998) Distribution of nitric oxide synthase and nitric oxidereceptive, cyclic GMP producing structures in the rat brsin. Neuroscience 87: 207-241.

DE VENTE \&, STEINBUSCH HWM (2000) Nitric oxide-cGMP signaling in the brain. In: Handbook of Cheminal Nenroanalomy, Vol. 17 (STELNBUSCH HWM, DE VENTE J, VINCENT SR, eds), pp 355-415. Elsewier.

DOUSA TP. (1999) Cyclic-3,5'-nucleotide phosphodiesterase isozymes in cell biology and pathophysiology of the kidney. Kidney In 55:29-62. 
ENGELS P, EICHTEL K, LUBBERT H. (1994) Expression and regulation of toman and rat phosphodiesterase type IV isogenes. FEBS Lelt 350: 291-295.

FISHER DA. SMITH JF, PLLIAR JS, ST DENIS SH, CHENG JB. (1998) Isolation and characterization of PDE9A a novel human cGMP-specific phosphodiesterase. J Biol Chem 273: $15559 \cdot 15564$.

FLORIO VA, SONNENBURG WK, JOHNSON R, KWAK KS, JENSEN GS, WALSH KA, BEAVO JA. (1994) Phosphorylation of the 61-kDa calmodulim-stimulated cyclic nucleotide phosphodiesterase at serine 120 reduces its affinity for calmodulin. Biochemistry 38.8948 . 8954.

FRANCIS SH, TURKO IV, CORBIN JD. (2001) Cyclic nucleotide phosphodiesterases: relating structure and function. Prog Nucleic Acid Res Mol Biol 65: 1-52.

FUJISHIGE K, KOTERA J, OMORI K. (1999) Striatum- and testis-specific phosphodiesterase PDE10A isolation and characterization of a rat PDF10A. Eur ef Biochem 266: 1118-1127.

EURUYAMA T, IWAHASHI Y, TANO Y, TAKAGI H, INAGAKI S. (1994) Localization of 63$\mathbb{K D a}$ calmodulin-stimulated phosphodiesterase mRNA in the rat brain by in situ hybridization histochemistry. Mol Brain Res 26: 331-336.

GARTHWAITE J. (1991) Glutamate, nitric oxide and cell-cell signalling in the nervous system. Trends Neurosci 1.4: 60-67.

GUIPPONI M, SCOTT HS, KUDOH J, KAWASAKI K, SHBBUYA K, SHINTANI A, ASARAWA $S$, CHEN H, LALIOTI MD, ROSSIER C, MINOSHIMA S, SHIMIZU N, ANTONARAKIS SE. (1998) Identification and characterization of a novel cyclic nucleotide phosphodiesterase gene (PDE9A) that maps to 21.q22.3: alternative splicing of mRNA transcripts, genomic structure and sequence. Hum Gener 1.03: 386-392.

HERMAN JP. DOLGAS CM, RUCKER D, LANGUB MC. (1996) Localization of natriuretic peptide-activated guanylate cyclase mRNAs in the rat brain. of Comp Neural 369: 165-187.

HOUSLAY MD. (2001) PDE4 cAMP-specific phosphodiesterases. Prog Nucleic Acid Res Mol Biol 69: 249-315.

IWAHASHT Y, FURUYAMA T, TANO Y, ISHIMOTO I, SHIMOMURA Y, INAGALI S. (1996) Differential distribution of $\mathrm{mRNA}$ encoding CAMP-specific phosphodiesterase isolorms in the rat brain. Mol Broin Res 38: 14-24.

JUIJFS DM, SODERUING S, BURNS F, BEAVO JA. (1999) Cyclic GMP as substrate and regulator of cyclic nucleotide phosphodiesterases (PDEs). Rev Phystol Biochem Phomacol 135: $67-104$.

KINCAID RLs, BALABAN CD, BILLINGSLEY ML. (1987) Differential localization of calmodulin-dependent enzymes in rat brain: evidence for selective expression of cyclic nucleotide phosphodiesterase in specific neurons. Proc Natl Acad Sci US A 84: 11.8-1122.

KOESLING D. (1998) Modulators of soluble guanylyl cyclase. Nawny Schrniedebergs Arch Pharmacol 358: 123-126.

KORSLING D. (1999) Studying the structure and regulation of soluble guanylyl cyclase. Methods 19: 485-493.

KOPERA J, YANAKA N, FUJISHIGE K, IMAI Y, AKATSULA H, ISHIZUKA T,

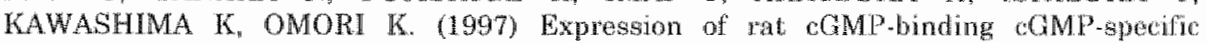
phosphodiesterase mRNA in Purkinje cell layers during postnatal neuronal dowelopment. Eur If Biochem 249: 434-442.

KOTERA \&, FUJISHIGE K, YUASA $K$, OMORI $K$, (1999) Characterization and phosphorylation of PDE10A2, a novel alternative splice variant of human phosphodiesterase that hydrolyzes cAMP and COMP. Biochem Biophys Res Conmun 261: 551.557 .

LOHMANN SM, VAANDRAGER AB, SMOLENSKI A, WALTER U, DE JONGE HR. (1997) Distinct and specific functions of cGMP-dependent protein kinases. Trends Biochem Sci 22 : 307-312.

MACPHEE CH, REIFSNYDER DH, MOORE TA, LEREA KM, BEAVO JA (1988) Phosphorylation results in activation of a cAMP phosphodiesterase in human platelets, $J$ Biol Chem 263: 10358.10358.

MCPHEE I. COCHRAN S, HOUSLAY MD. (2001) The novel long PDE4A10 cyclic AMP phosphodiesterase shows a pattem of expression within brain that is distinct from the long PDE4A5 and short PDE4A lisoforms. Cell Signal 13:911-918. 
WEHATS C, ANDERSEN CB, FILOPANTI M, IIN SL, CONTI M. (2002) Cyclic mucleotide

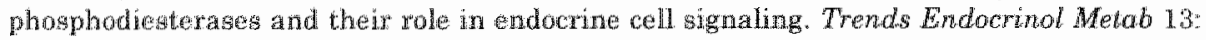
29.35 .

MICHIBATA H, YANAKA N, FANOH $Y$, OKUMURA $K$ OMORL K (2001) Human $\mathrm{Ca}+\mathrm{calnodulin-dependent} \mathrm{phosphodiesterase} \mathrm{PDE1A:} \mathrm{novel} \mathrm{splice} \mathrm{variants,} \mathrm{their} \mathrm{specific}$ expression, genomic organization, and chromosomal localization. Biochim Biophys Acto 1517.278 .287

MIRO X, PEREZ,TORRES S, PALACIOS JM, PUIGDOMENECH P, MENGOD G. (2001) Differential distribution of cAMP.specific phosphodiesterase $7 \mathrm{~A}$ mRNA in rat brain and peripheral argans. Synapse 40: $201-214$.

MURAD F. (1994) Regulation of cytosolic guanylyl cyclase by nitric oxide: the NO cyclic GMP signal trandiugtion system. Adv Pharmacol 26: 19-33.

PEREZTORRES S, MIRO X, PALACIOS JM, CORTES R, PUIGDOMENECH P, MENGODG. (2000) Phosphodiesterase type 4 isozymes expression in human brain exammed by in situ hybridization histochemistry and [3H] rolipram binding autoradiography. Comparison with monkey and rat brain. of Chern. Neuroanat $20: 349-374$.

PFEIFER A, RUTH P, DOSTMANN W, SAUSBIER M, KLATT P, HOFMANN F. (1999) Structure and function of cGMP-dependent protein kinases. Rev Physiol Biochem. Pharmacol $135: 105-149$.

RENHARDT RR. BONDY CA. (1996) Differential cellular pattern of gene expression for two distinct cGMP-inhibited cyclic nucleotide phosphodiesterases in developing and mature rat brain. Netroscherce $72: 567-578$.

REPASKE DR, GORBIN JG, GONTH M, GOY MF. (1993) A cyclic GMP-stimulated cyclic nucleotide phosphodiesterase gene is highly expressed in the limbic system of the rat brain. Neuroscience $56: 673-686$.

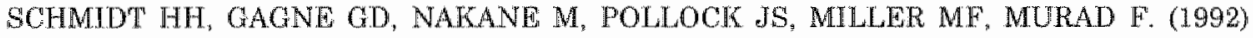
Mapping of neural nitric oxide synthase in the rat suggests frequent co-localization with NADPH diaphorase but not with soluble guanylyl cyclase, and novel paraneural functions for nitrinergic signal transduction. I Histochem Cytochem 40: 1439-1456.

SEKHAR KR, FTEEMAN ML. (1.998) PEST secuences in proteins involved in cyclic nucleotide signalling pathways. I Recept Signal Transduct Res 18. 113.132.

SODERLING SH, BAYUGA SJ, BFAVO JA. (1998) Identification and charactemization of a novel family of welic nucleotide phosphodiestereses. I Biol Chem 273: 15553-15558.

SODERI NG SH, BEAVO JA (2000) Regulation of CAMP and cGMP signaling: new phosplodiesterases and new functions. Curr Opin Cell Brol 12:174-179.

SOUTHAM E, GARTHWAITE J. (1993) The nitric oxide-cyclic GMP signalling pathway in rat brain. Neuropharmacology 32, 1267-1277.

TEUWLSEN C, SITINBUSCH HWM, MARKERINK-VAN TTTERSUN M, KOESLMG D, DE VENTE d. (2001) Presence of soluble and particulate guanylyl cyclase in the same hippocampat asitrocyles. Anain Res 891: 206-2112.

VAN STAVRREN WCG, MARKERINK-VAN ITIRRSUM M, STENBUSCH HWM, DE VENTE \&. (2001), The effects of phosphodiesterase inhibition on cyclic GMP and cychic AMP accumulation in the hippocampus of the rat: Bran Res 888.275.286.

WANG P, WU P, EGAN RW, MOTASTM BILLAH M. (2001) Human phosphodiesterase 8A splice variants; cloning, gene organization, and tissue distribution. Gene $280: 183-194$.

YUASA K, OHGARU T, ASAHINA M, OMORI K. (2001) Identification of pat cyclic nucleotide phosphodieterse 11A (PDIE 1.A): comparison of rat and human PDE11A splicing variants. Bur Bjochem 268 : $4440-448$.

7WILLER I, GHANDOUR MS, REVEL MO, BASSHT P. (1981) Immumohistochemical locklization of guanylate cychse in rat cerebellum. Neurosci Lett 23: 31-36. 


\section{mRNA expression patterns of the cGMP. hydrolyzing phosphodiesterases types \\ 2, 5 and 9 during development of the rat brain}

Wilma C.G. van Staveren, ${ }^{1}$ Harry W.M. Steinbusch," Marjanne Markerinkvan Ittersum," David R. Repaske," Michael F. Goy," Jun Kotera," Kenji Omori, Joseph A. Beavo ${ }^{5}$ and Jan de Ventel

Dept. of Psychiatry and Neuropsychology, Division Cellular Neuroscience, Maastricht University, European Graduate School of Neuroscience (EURON), P.O. Box 616, 6200 MD Maastricht, "The Netherlands; 2Division of Endocrinology, Children's Hospital Medical Center, Cincinnati, Ohio, USA; Dept. of Cell and Molecular Physiology, University of North Carolina, Chapel Hill, North Carolina, USA; "Discovery Research Laboratory, Tanabe Seiyaku Co. Ltd, Saitama, dapan; Dept. of Pharmacology, University of Washington, Seattle, USA

Adapted from The Journal of Comparative Neurology 467 (4): 566.580 (2003)

\section{Abstract}

Recent evidence indicates that cGMP plays an important role in neural development. Since cGMP levels depend critically on the activities of phosphodiesterase (PDE) enzymes, mRNA expression patterns were examined for several key cGMP-hydrolyzing PDEs [type 2 (PDE2), 5 (PDE5) and 9 (PDE9)] in rat brain at defined developmental stages. Riboprobes were used for non-radioactive in situ hybridization on sections derived from embryonic animals at 15 days gestation (F15) and several postnatal stages (P0, P5, P10, P21) until adulthood (3 months). At all stages, PDE9 mRNA was present throughout the whole central nervous system, with highest levels observed in cerebellar Purkinje cells, whereas PDEL and PDES mRNA expression was more restricted. Like PDE9, PDE5 mRNA was abundant in cerebellar Purkinje cells, though it was observed only on and after postnatal day 10 in these cells. In other brain regions, PDE5 mRNA expression was minimal, detected in olfactory bulb, cortical layers and in hippocampus. PDE2 mRNA was distributed more widely, with highest levels in medial habenula, and abundant expression in alfactory bulb, olfactory tubercle, cortex, amygdala, striatum and hippocampus. Outside the brain (in E15 animals), PDE2 was most highly expressed in dorsal root ganglia, whereas lung, liver and duodenum showed strong PDE5 expression. PDE9 $m$ RNA was present throughout the body in many tissues.

Our data indicate that three cGMP-hydrolyzing PDE families have distinct expression patterns, though specific cell types co-express mRNAs for all three enzymes. Thus it appears that differential expression of PDE 
isoforms may provide a mechanism to match cGMP hydrolysis to the functional demands of individual brain regions.

\section{Introduction}

The second messengers adenosine $3^{\prime}, 5^{\prime}$-cyclic monophosphate (cAMP) and guanosine $3^{\prime}, 5^{\prime}$-cyclic monophosphate (cGMP) help to regulate a number of important biological processes, including phototransduction, olfaction (Broillet and Firestein, 1999), smooth muscle contraction and relaxation (Carvajal et al., 2000), neurotransmission (Garthwaite, 1991; Kind and Neumann, 2001), and neural development (Truman et al., 1996; Gibbs and Truman, 1998; Schachtner et al., 1999; Van Wagenen and Rehder, 1999; Gibbs et al., 2001; Simpson et al., 2002). Intracellular levels of these messengers are controlled by their rate of synthesis via adenylyl and guanylyl cyclases respectively (Lucas et al., 2000; Watts, 2002), and by their rate of degradation via 3',5'-cyclic nucleotide phosphodiesterases (PDEs) (Beavo, 1995; Houslay, 1998; Conti and Jin, 1999; Dousa, 1999).

The synthesis of cGMP is catalyzed by two distinct families of guanylyl cyclases (GCs). One family, comprised of seven homodimeric isoforms (GC-A to GC-G), is membrane associated (particulate, pGC) and activated by natriuretic peptides (Forte et al., 2000; Wedel and Garbers, 2001). In contrast, the other family is cytosolic (soluble, sGC) and activated principally by nitric oxide (NO) (Garthwaite, 1991; Lucas et al., 2000). Besides the GCs which produce cGMP, a large group of cGMP-degrading enzymes has been described, which hydrolyze the $33^{\prime}, 5^{\prime}$-cyclic nucleotides to their 5'-derivates. Numerous PDE genes have been cloned, representing 11 different PDE families (PDE1-PDE11), and many of these genes are expressed in several alternately spliced forms, indicating the existence of a large number of PDE isoforms which are expressed with distinct localization patterns in the brain (Repaske et al., 1993; Furuyama et al., 1994; Yan et al., 1994; Beavo, 1995; Kotera et al., 1997; Fujishige et al., 1999; Fawcett et al., 2000; Soderling and Beavo, 2000; Andreeva et al., 2001; Francis et al., 2001). Three PDE families specifically use CGMP as a substrate: PDE5 (Thomas et al., 1990; Kotera et al., 1997; Loughney et al., 1998), PDE9 (Fisher et al., 1998; Guipponi et al., 1998; Soderling et al., 1998) and the photoreceptor specific PDE6 (Gillespie and Beavo, 1988). Furthermore, cGMP can be degraded by dual-substrate PDEs which are PDE1 (Furuyama et al., 1994; Yan et al., 1994), PDE2 (Sonnenburg et al., 1991; Repaske et al., 1993; Yang et al., 1994; Rosman et al., 1997; Juilfs et al., 1999), PDE10 (Fujishige et al., 1999; Kotera et al., 1999a; Soderling et al., 1999) and PDE11 (Fawcett et al., 2000; Hetman et al., 2000).

At present, functions of cGNP in the central nervous system (CNS) are slowly emerging. For natriuretic peptides, as well as for NO, a role during development of the CNS has been proposed (Truman et al., 1996; Markerink.Van Ittersum et al., 1997; Bicker, 1998; Gibbs and Truman, 1998; Schachtner et al., 1999; Van Wagenen and Rehder, 1999; Bicker, 
2001; Gibbs et al, 2001; Simpson et al., 2002). cGMP has a function in network formation during neuronal maturation (Scholz and Truman, 2000; Bicker, 2001). Furthermore, a role of cGNCP has been described in network pattern switching (Scholz et al., 2001). Recently, it was demonstrated that cyclic nucleotides regulate the directional guidance of growth cones (Song et al, 1998; Song and Poo, 1999), and it has been demonstrated that cGMP is involved in the directional outgrowth of cortical neurons during maturation. (Polleux et al., 2000).

In addition to the role of cGMP during development, evidence from several in vivo models has been presented which suggest that cGMP is involved in processes of learning and memory in the adult. Inhibition of $\mathrm{SGC}$ impaired olfactory memory (Kendrick et al., 1997) or retention of acquired passive avoidance (Bernabeu et al., 1997; Edwards et al., 2002). In contrast, administration of the cGMP analogue 8-Br-cGMP (Bernabeu et al., 1996) or application of the PDE5 inhibitor sildenafil (Baratti and Boccia, 1999), enhanced rentention in an inhibitory avoidance learning paradigm. Recently, several selective PDE5 inhibitors (Prickaerts et al., 1997; Prickaerts et al., 2002b), or a cGMP analogue (Prickaerts et al., 2002a) have been shown to enhance retention in an object recognition task. Furthermore it was shown that in vitro incubation of hippocampal slices with PDE5 inhibitors in combination with an NO donor resulted in a local cGMP accumulation (Van Staveren et al., 2001; Prickaerts et al., 2002b). These findings suggest that augmentation of cGMP levels during training, through inhibition of PDE5, though inhibition of other PDE families can not be excluded, might improve learning in a variety of different contexts.

From a more general point of view, the above findings suggest the involvement of cGMP in synaptic plasticity both during neural development and in learning and memory processes. Since PDEs critically influence cGMP levels by regulating its hydrolysis, knowledge about the localization of PDEs is of high importance in obtaining more insight in the complex cGMP-signaling pathway. Besides developmental changes in PDF1 (Billingsley et al., 1990) and PDE3 (Reinhardt and Bondy, 1996) expression, limited literature is available about the cellular localization of cGMP. hydrolyzing PDE families during development of the rat brain. Therefore we have compared the cellular mRNA expression of three different cGMP. hydrolyzing PDE families by non-radioactive in situ hybridization at embryonic stage E15 and four different postnatal stages (P0, P5, P10 and P21) into adulthood (3 months). We focused initially on PDE5, due to work from our laboratory and others, described above, indicating that PDE5 inhibitors affect learning and memory. The mRNA expression of PDE5 was then compared to PDE2 which has already been described earlier as preferentially expressed in the limbic system (Repaske et al., 1993), suggesting that it might also a role in learning and memory processes. Finally, PDE9 was included in our study since this PDE has been described as having the highest affinity for CGMP, and therefore could play a fundamental role in keeping cGMP at low basal levels (Fisher et al., 1998; Soderling et al., 1998). 
Here we show that distinct expression patterns for PDE2, PDE5 and PDE 9 mRNA are already established at early stages of brain development and maintained into adulthood, suggesting a role for these PDE families in neural development and neurotransmission. Moreover, it is shown for the first time that besides the PDE5 mRNA expression in Purkinje cells, as has been reported earlier (Kotera et al., 1997), PDE5 is also present in other brain areas, such as hippocampus, cortex and olfactory bulb. In addition, expression of the three cGMP-hydrolyzing PDEs is shown in several tissues in the periphery at the earliest stage examined.

\section{Materials and Methods}

\section{Animals}

Lewis rats were obtained from the local animal facility at the Maastricht University. Experiments were approved by the committee on animal welfare according to Dutch governmental rules. In order to study mRNA expression of the different cGMP-hydrolyzing PDEs during development, animals were used at the age of embryonic day 15 ( $\mathbb{E} 15)$, postnatal day 0 ( $\mathbb{P} 0$, day of birth), day 5 (P5), day 10 (P10), day 21 (P21) and adult rats (3 months).

\section{Riboprobe synthesis}

For the in situ hybridization of PDE2, a pBS+ vector containing a part of rat PDE2 (nt 1964-2314, GenBank accession no. NM_031079) was used. This construct (GenBank accession no. M94540) and the specificity of the probe has been previously described (Repaske et al., 1993). The construct was linearized using EcoRI or HindIII, to generate antisense or sense probes with $\mathrm{T} 3$ or $\mathrm{T} 7$ polymerase, respectively.

The expression of PDE5 was studied by cloning a part of the rat PDE5 sequence (nt 2206-2580, GenBank accession no. D89093) into the SacI and EcoRI sites of a pCRIITOPO vector (Invitrogen). A probe comprising this part of PDE5 has been earlier described (Kotera et al., 1997). Sense probes were made after BstXI digestion by Sp6 RNA polymerase and antisense probes after linearization with HindIII and T7 RNA polymerase.

PDE9 riboprobes were constructed from the mouse PDE9A1 as a template. Primer wroforw1 (5'ACG CTT GGA TCC ATG GGG GCC GGC TCC (TCA-3') containing a BamHI site and primer wvsrev1 (5'-GCT TGT ATG CGG CCG CCT GGA GGC CAC AGA GCC AGA CCA T-3') containing a NotI site were used for PCR (nucleotides 10-828 from mouse PDE9A1, AF031147). The PCR product was digested with both restriction enzymes and then the product was ligated into the BamHI and NotI site of a pCRII TOPO vector. (Invitrogen). Antisense PDE9 probes were made with T7 polymerase from the pCRIITOPO plasmid linearized with BamHI, while sense probes were produced by Sp6 RNA polymerase after linearization of pCRIITOPO vector with Xhol.

All constructs were analyzed by DNA sequencing before probe synthesis. After restriction digestion of each construct, as described above, antisense 
and sense riboprobes were made from $5 \mu \mathrm{g}$ DNA template by in vitro transcription with digoxigenin (DIG) labeled UTP using a DIG RNA labeling kit (Roche) according to the manufacturer's instructions.

\section{In situ hybridization}

Animals were decapitated and their brains were dissected, frozen in $\mathrm{CO}_{2}$ and stored at $-80^{\circ} \mathrm{C}$ until sectioning. Animals aged 15 were frozen as a whole. Frozen serial sagittal sections $(14 \mu \mathrm{m})$ were cut and thawed onto SuperFrost Plus slides (Menzel-Glaser, Germany) and stored at $-80^{\circ} \mathrm{C}$ until use. From each age group, three amimals were studied and from each animal consecutive sections were used for hybridization of PDE2, PDE5 and PDE9 with sense and antisense probes. In addition, coronall sections from adult rats were cut at different levels related to Bregma's: $1.60 / 1.20,-0.40 /-0.80$, $3.14 /-3.30,-4.52 /-4.80$ and $-7.30 /-7.64$, according to Paxinos and Watson, (1986). Sections were thawed for 10 minutes at $50{ }^{\circ} \mathrm{C}$ and thereafter postfixed with $4 \%$ paraformallehyde in $0.1 \mathrm{M}$ phosphate buffered saline (PBS) for 20 minutes at room temperature $(R T)$, followed by three short washes with PBS. Then, sections were incubated for 10 minutes at RT with $0.1 \mathrm{M}$ triethanolamine containing $0.25 \%(\mathrm{v} / \mathrm{v})$ acetic anhydride. Slides were washed two times with $2 \times$ SSC for 5 minutes and thereafter washed at $37{ }^{\circ} \mathrm{C}$ with $2 \times$ SSC containing $50 \%(\mathrm{v} / \mathrm{v})$ formamide before the start of the hybridization.

Hybridization was performed overnight in a humid chamber at $55^{\circ} \mathrm{C}$ under coverslips in 100-200 $\mu$ l hybridization $\operatorname{mix}(50 \%(\mathrm{w} / \mathrm{w})$ deionized formamide, $250 \mu \mathrm{g} / \mathrm{ml}$ salmon sperm DNA, $1 \mathrm{mg} / \mathrm{ml}$ tRNA, $10 \%$ dextran sulfate, 2x SSC, 1x Denhardt's solution and 200-400 ng/ml DIG-labeled RNA probe). After the hybridization, sections were washed in $2 \times \mathrm{SSC}, 1 \mathrm{x}$ SSC and $0.1 \times$ SSC, all solutions containing $50 \%$ formamide. Fach wash step was performed at $55{ }^{\circ} \mathrm{C}$ and lasted 20 minutes. Next, to eliminate single stranded (unhybridized) probe, the sections were treated with RNAse TI (2 U/ml, Roche) in $2 \mathrm{x}$ SSC containing $1 \mathrm{mM}$ ethylenediaminetetra-acetate (EDTA) for 15 minutes at $37^{\circ} \mathrm{C}$ followed by a 20 minute wash with $1 \times$ SSC at $55^{\circ} \mathrm{C}$. After washing for 10 minutes with $2 \times \mathrm{SSC}$ at RT, sections were incubated for 5 minutes with buffer 1 (150 $\mathrm{mM} \mathrm{NaCl}$ and $100 \mathrm{mM}$ maleic acid $(\mathrm{pH} 7.5)$ ) followed by blocking for $2-3$ hours at $\mathrm{RT}$ with buffer 2 (1.50 $\mathrm{mM} \mathrm{NaCl}, 100 \mathrm{mM}$ maleic acid $(\mathrm{pH} 7.5)$ and $1 \%$ blocking reagent (Roche, \#1096176) containing 5\% sheep serum. Next, slicles were incubated overnight at $4{ }^{\circ} \mathrm{C}$ with a 1:2000 dilution of anti-DIG-alkaline phosphatase in buffer 2 containing $1 \%$ sheep serum. Thereafter, slides were washed three times with buffer 1 followed by washing for 10 minutes with Tris-buffered saline (TBS) containing $0.025 \%$ Tween 20 and thereafter, three times 5 minutes with TBS. After two washes of 5 minutes in buffer 3 (100 mM Tris-

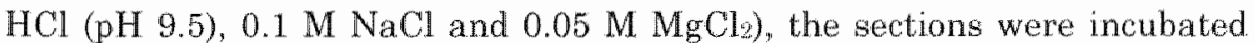
with freshly prepared nitro-blue tetrazolium and 5-bromo-4-chloro-3-indolylphosphate in buffer 4 (50 mM Tris (pH 9.5), $100 \mathrm{mM} \mathrm{NaCl,} 50 \mathrm{mM} \mathrm{MgCl}, 1$ mM levamisole) and stained for 1.2 days in the dark at RT. The buffer was replaced by fresh buffer after the first day. The color reaction was stopped 
Table 1. PDE2, PDE5 and PDE9 mRNA expression in the adult rat brain by non-radioactive in situ hybridization.

\begin{tabular}{|c|c|c|c|c|c|c|c|}
\hline Mroin areát & DDE2 & PDE: & DDEg & Bróntu zrea & $\mathrm{BPEZ}$ & $\mathbb{P D E}$ & PDES \\
\hline Probsuin & & & & 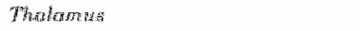 & & & \\
\hline 9 & & & & 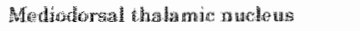 & - & - & $4+$ \\
\hline Glomatular layos: & . & $t^{5}$ & + & 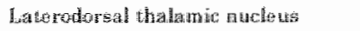 & - & . & ++ \\
\hline 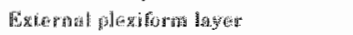 & $H$ & . & 4 & Ventral posteromed that thate & - & - & $4+$ \\
\hline 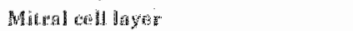 & $\frac{i}{3}, k$ & + & +4 & 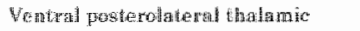 & - & - & $4+4$ \\
\hline 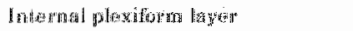 & - & . & - & 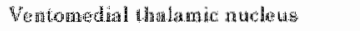 & . & - & + \\
\hline 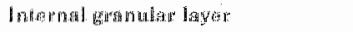 & 4 & " & dit. & Reticulat thatamio nucleas & + & -. & $4+4$ \\
\hline \multirow[t]{2}{*}{ 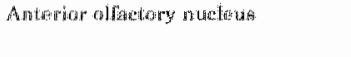 } & $\frac{2}{3}+4$ & + & $+4+$ & 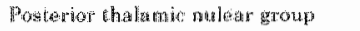 & - & * & $4+4$ \\
\hline & & & & 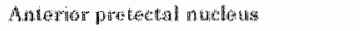 & " & - & $+t$ \\
\hline 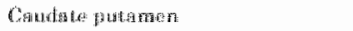 & $4+4$ & $\neq^{*}$ & $1.4+$ & 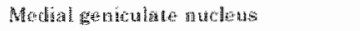 & . & . & +4 \\
\hline 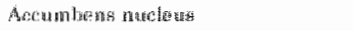 & $j_{1}+x_{i}$ & + & $4+4$ & 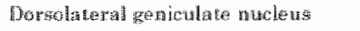 & " & - & ++ \\
\hline Groptal nuelei & 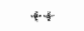 & + & $\operatorname{sith}$ & 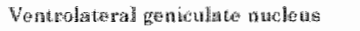 & 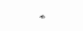 & . & ++ \\
\hline 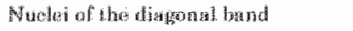 & + & - & 40,40 & 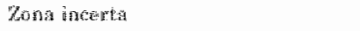 & . & - & ++ \\
\hline OHfochery tuberch & $+4+4$ & . & $4+1,4$ & & & & \\
\hline 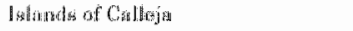 & + & - & $+\rightarrow$ & Hypodintantas & & & \\
\hline 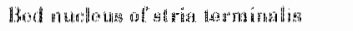 & + & + & +4 & Supure opt be naclens & +4 & +4 & $f+4$ \\
\hline 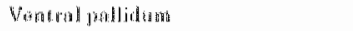 & is & - & + & Medial preoplic frea & $\dot{\psi}$ & $\cdot$ & +4 \\
\hline 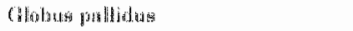 & . & . & $\dot{\psi}$ & 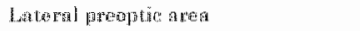 & . & is. & +4 \\
\hline 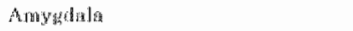 & 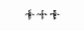 & - & $4+4$ & Morting emo inence & + & . & ++ \\
\hline 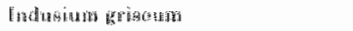 & +4 & + & in & Arentate bypolhatamic audlets & $\phi$ & . & +4 \\
\hline \multirow[t]{2}{*}{ fouraix } & $\cdot$ & . & . & 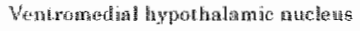 & 4 & - & +4 \\
\hline & & & & Dorsonednd bypothatantic ancleus & . & - & 4 \\
\hline 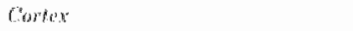 & & & & 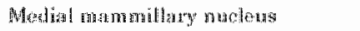 & $\therefore$ & . & 4.4 \\
\hline (rager) & . & $\cdot$ & 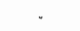 & 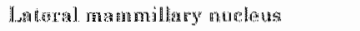 & 4 & . & $+\dot{t}$ \\
\hline Gagenell & $+x^{-1}$ & $+t^{\circ}$ & ++ & & & & \\
\hline 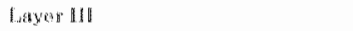 & $y+4$ & $+t^{2}$ & $4+$ & Miduran & & & \\
\hline Layper IV & $4+x$ & $+\cdots z^{*}$ & $*$ & Stupotian rothon & $\sim$ & - & + \\
\hline Lityent $\mathrm{K}^{\prime}$ & $4+4$ & $+\varepsilon^{*}$ & $+4+$ & Intertor eollioulus & & - & $\lambda^{*}$ \\
\hline \multirow[t]{2}{*}{ lenyen it } & +4 & $+\alpha^{2}$ & +1 & 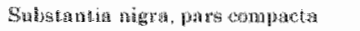 & $* 4$ & . & 4 \\
\hline & & & & 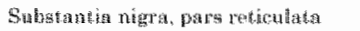 & - & * & $4+3$ \\
\hline 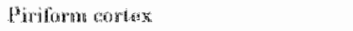 & 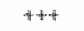 & +4 & 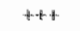 & Venerenl tefmantal area & - & - & +4 \\
\hline Cingulate wartes & 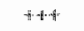 & fir. & $+1+$ & Rotrontural fredand andens & . & - & th \\
\hline \multirow[t]{2}{*}{ Whathinat contes } & inh 4 - sotit & 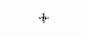 & 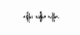 & Rontho extes & 3.+ & . & के \\
\hline & & & & Ceateral grey & " & $\therefore$ & + \\
\hline Mippomapars & & & & Ponting nuch & . & $\div$ & 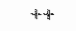 \\
\hline 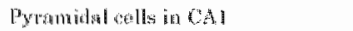 & H. & $4+\omega^{\circ}$ & $+\infty$ & & & & \\
\hline Pyrantiol colls in cyz & that in & $1+w^{*}$ & +4 & Cerebothian & & & \\
\hline 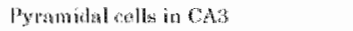 & +4 & $A+w^{*}$ & $+4+9$ & Molecontar layer & $4 x^{2}$ & $+*$ & $+*$ \\
\hline 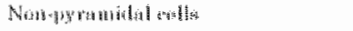 & $4+\omega^{\circ}$ & $-1+k^{*}$ & $+x+4$ & 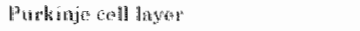 & $a-$ & 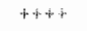 & +4 \\
\hline 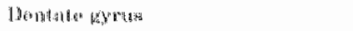 & +4 & 小和 & 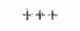 & 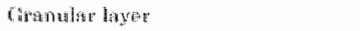 & + & +4 & +4 \\
\hline 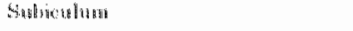 & $1+5$ & it." & $+f$ & 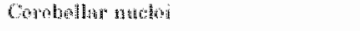 & - & + & +4 \\
\hline 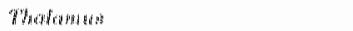 & & & & Herthstapts & & & \\
\hline 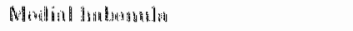 & 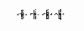 & . & $+\mathrm{i}-$ & 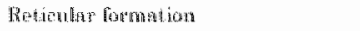 & . & f & $+\frac{c}{2}+k$ \\
\hline 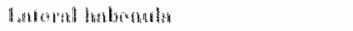 & - & . & + & & & & \\
\hline 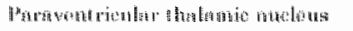 & . & . & $1+$ & 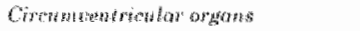 & & & \\
\hline 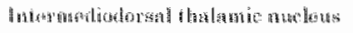 & : & . & $+\infty$ & Chomedidexus & * & t & $4+4$ \\
\hline 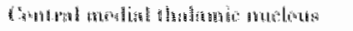 & . & - & $1+$ & lipendymalcels & . & . & + \\
\hline In & . & . & +3 & 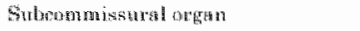 & s.t. 舫 & . & H- \\
\hline 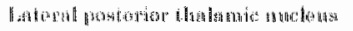 & - & . & क小 & & & & \\
\hline
\end{tabular}

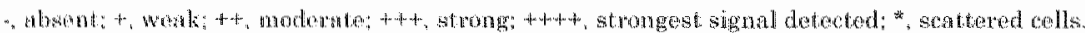

Basal forebrain and striatum

During development of the brain, PDE2 and PDE9 mRNAs were expressed strongly in the caudate putamen (Fig. 1), whereas PDE5 mRNA expression was low to hardly detectable at all stages in this area. mRNA expression of all three PDE families was present in cell bodies and not in white matter 
tracts (Fig. 6M-O). Furthermore, during development, PDE2 and PDE9 mRNA were detected in the olfactory tubercle (Fig. 1), the islands of Calleja, the nucleus accumbens and the amygdala (Table 1). In these regions, PDE5 expression was low to hardly detectable at all developmental stages (Fig. 1, Table 1).

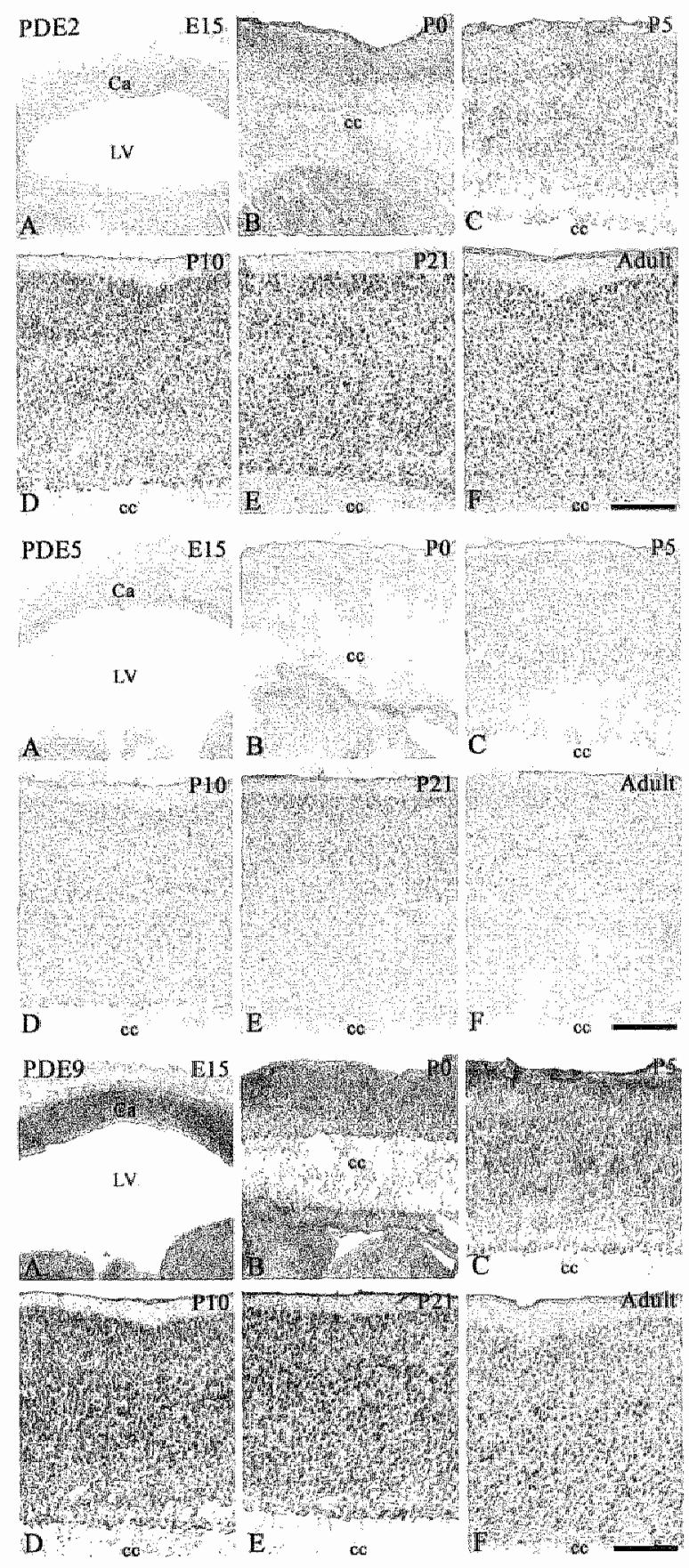

Figure 2. Localization of PDFE, PDE5 and PDE9 WRNA in the cortex during development of the rat brain by non-radiaactive in situs. hybridiation. The different ages, labelled A.F in each panel, are indicated in the right upper conner. Recording conditions were kept. constant for each PDE riboprobe. Bar indicates 500 pm for all pictures. Ca, cortical area: $\mathrm{cc}$, corpus callosum; LV " lateral ventricle.

A

D

LV
B

B co 


\section{Hippocampus}

In the hippocampal area both PDE2 and PDE9 mRNAs were expressed at stage E15, whereas no PDE5 expression was observed at this time point (Fig. 4). After birth, PDE2, PDE5 and PDE9 mRNAs were present in pyramidal cells of the CA1-CA3 and in the granule cells of the dentate gyrus, and some scattered cell bodies outside these layers (Fig. 4, Fig. 6J-L, Table 1). At all stages, PDE2 expression was stronger in pyramidal cells compared to the granule cells in the dentate gyrus (Fig. 4 upper panel), whereas PDE9 mRNA was strongly expressed in both cell types (Fig. 4 lower panel). In contrast, PDE5 mRNA expression in the hippocampus was weakly detected, and from P5 onwards (Fig. 4 middle panel) pyramidal cells and granule cells were weakly stained with some dispersed cells inside these layers which were stained more robustly (Fig. 6K).
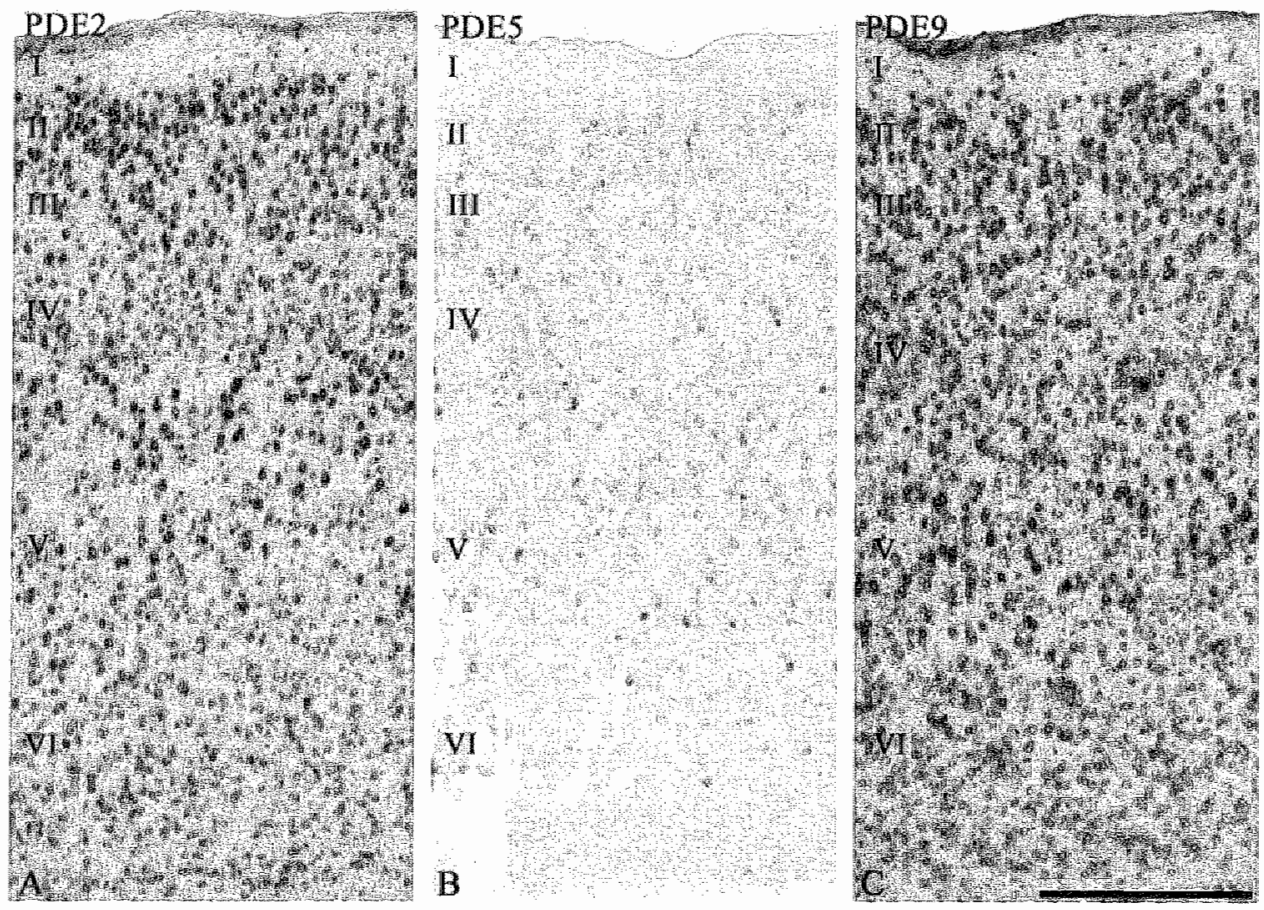

Figure 3. Locmlization of PDE2, PDE5 and PDE9 mRNA in the frontal cortex of an adult rat by non-radionctive in situ hybridization. Bar indicates 500 um for all pictures.

\section{Thalamus and hypothalamus}

At F15, PDE2 and PDE9 mRNA expression was detected in the thalamic area, whereas no PDE5 was present (Fig. 1). In addition, at this stage PDE9 $m R N A$ expression was also observed in hypothalamic area which did not show PDE2 or PDE5 mRNA expression. From P0 into adulthood, PDE2 and PDE5 mRNA expression levels were low to hardly detectable in the 
thalamus and hypothalamus (Table 1). However, in coronal sections from adult rats, very strong PDE2 expression was observed in the medial habenula, whereas PDE9 showed a moderate level of expression and PDE5 mRNA was undetectable (Fig. 6G, Table 1). Furthermore, PDE2 mRNA was detected in hypothalamic subnuclei (Table 1), such as in the histaminergic cell group in the tubero mammillary area (Fig. 6I). In addition, moderate PDE2 and PDE5 mRNA expression was observed in the supraoptic nucleus.

PDE9 mRNA was moderate to strongly present in thalamus and hypothalamus throughout development of the brain (Table 1). In the thalamus from the adult, PDE9 mRNA expression was detected in the medial habenula, and the lateral habenula (Fig. 6H) with the strongest expression in the reticular thalamic nucleus (Table 1). The expression of PDE9 mRNA in the hypothalamus was strongest in the supra optic nucleus (Table 1).

\section{Midbrain}

PDE2 and PDE5 mRNAs were hardly detectable in the superior or inferior colliculus at all stages investigated. PDE2 mRNA was observed in the substantia nigra pars compacta (Fig. 6D) and raphe nuclei (Table 1), PDE5 mRNA was not detected in the midbrain with the exception of weak expression in the pontine nuclei (Table 1). The expression of PDE9 mRNA was observed in several midbrain areas including superior and inferior colliculus, and substantia nigra (Fig. 6E).

\section{Cerebellum}

At E15, neither PDE2 (Fig. 5A upper panel) nor PDE5 (Fig. 5A middle panel) mRNA was detected in the cerebellum, in contrast to PDE9 mRNA which was weakly expressed, and exhibited a rather diffuse appearance (Fig. 5A lower panel). Low PDE2 expression was found in Purkinje cells, first observed at P10 (Fig. 5D upper panel) and maintained into adulthood (Fig. 5 upper panel, Fig. 6P, Table 1). PDE5 and PDE9 mRNAs were also detected in Purkinje cells, however, at relatively higher levels of expression than PDE2 mRNA (Fig. 5, Fig. 6P-R). The expression of PDE5 in Purkinje cells was first seen at $\mathrm{P} 10$ and maintained into adulthood (Fig. 5 middle panel), whereas PDE9 mRNA was detected from P0 onwards (Fig. 5 lower panel).

Furthermore, PDE2 and PDE9 mRNAs, and to some extent PDE5 mRNA, were observed in isolated cells in the molecular layer (Fig. 5, Fig. 6P-R). In addition, PDE2, PDE5 and PDE9 mRNAs were present in the granule cell layer. PDE2 mRNA was present in cells that have the characteristics of Golgi cells (Fig. 6P) which apparently also express PDE9 mRNA (Fig. 6R) but not PDE5 mRNA (Fig. 6Q). PDE5 and PDE9 mRNAs were also detected in the external granule cell layer at P5 and P10 (Fig. 5). 


\section{Hippocampus}

In the hippocampal area both PDE2 and PDE9 mRNAs were expressed at stage E15, whereas no PDE5 expression was observed at this time point (Fig. 4). After birth, PDE2, PDE5 and PDE9 mRNAs were present in pyramidal cells of the CA1-CA3 and in the granule cells of the dentate gyrus, and some scattered cell bodies outside these layers (Fig. 4, Fig. 6J.L, Table 1). At all stages, PDE2 expression was stronger in pyramidal cells compared to the granule cells in the dentate gyrus (Fig. 4 upper panel), whereas PDE9 mRNA was strongly expressed in both cell types (Fig. 4 lower panel). In contrast, PDE5 mRNA expression in the hippocampus was weakly detected, and from P5 onwards (Fig. 4 middle panel) pyramidal cells and granule cells were weakly stained with some dispersed cells inside these layers which were stained more robustly (Fig. 6K).
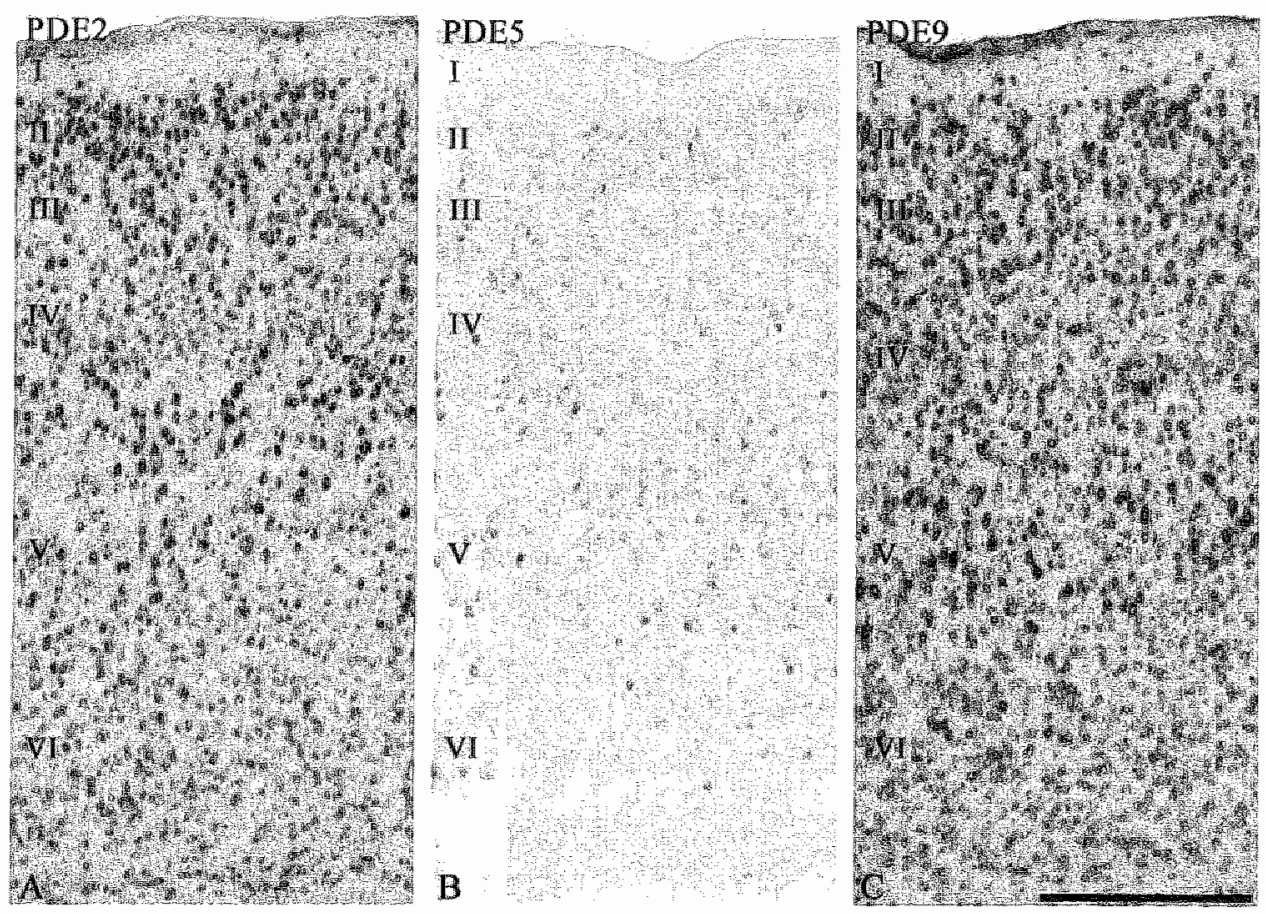

Figure 3. Localization of PDE2, PDE5 and PDE9 mRNA in the frontal cortex of an adult rat by non-radioactive in situ hybridisation. Bar indicates $500 \mu \mathrm{m}$ for all pictures.

\section{Thalamus and hypothalamus}

At E15, PDE2 and PDE9 mRNA expression was detected in the thalamic area, whereas no PDE5 was present (Fig. 1). In addition, at this stage PDE9 mRNA expression was also observed in hypothalamic area which did not show PDE2 or PDE5 mRNA expression. From P0 into adulthood, PDE2 and PDE5 mRNA expression levels were low to hardly detectable in the 
thalamus and hypothalamus (Table 1). However, in coronal sections from adult rats, very strong PDE2 expression was observed in the medial habenula, whereas PDE9 showed a moderate level of expression and PDE5 mRNA was undetectable (Fig. 6G, Table 1). Furthermore, PDE2 mRNA was detected in hypothalamic subnuclei (Table 1), such as in the histaminergic cell group in the tubero mammillary area (Fig. 6I). In addition, moderate PDE2 and PDE5 mRNA expression was observed in the supraoptic nucleus.

PDE9 mRNA was moderate to strongly present in thalamus and hypothalamus throughout development of the brain (Table 1). In the thalamus from the adult, PDE9 mRNA expression was detected in the medial habenula, and the lateral habenula (Fig. 6H) with the strongest expression in the reticular thalamic nucleus (Table 1). The expression of PDE9 mRNA in the hypothalamus was strongest in the supra optic nucleus (Table 1).

\section{Midbrain}

PDE2 and PDE5 mRNAs were hardly detectable in the superior or inferior colliculus at all stages investigated. PDE2 mRNA was observed in the substantia nigra pars compacta (Fig. 6D) and raphe nuclei (Table 1). PDE5 mRNA was not detected in the midbrain with the exception of weak expression in the pontine nuclei (Table 1). The expression of PDE9 mRNA. was observed in several midbrain areas including superior and inferior colliculus, and substantia nigra (Fig. 6E).

\section{Cerebellum}

At E15, neither PDE2 (Fig. 5A upper panel) nor PDE5 (Fig. 5A middle panel) mRNA was detected in the cerebellum, in contrast to PDE9 mRNA which was weakly expressed, and exhibited a rather diffuse appearance (Fig. 5A lower panel). Low PDE2 expression was found in Purkinje cells, first observed at P10 (Fig. 5D upper panel) and maintained into adulthood (Fig. 5 upper panel, Fig. 6P, Table 1). PDE5 and PDE9 mRNAs were also detected in Purkinje cells, however, at relatively higher levels of expression than PDE2 mRNA (Fig. 5, Fig. 6P-R). The expression of PDE5 in Purkinje cells was first seen at P10 and maintained into adulthood (Fig. 5 middle panel), whereas PDE9 mRNA was detected from P0 onwards (Fig. 5 lower panel).

Furthermore, PDE2 and PDE9 mRNAs, and to some extent PDE5 mRNA, were observed in isolated cells in the molecular layer (Fig. 5, Fig. 6P-R). In addition, PDE2, PDE5 and PDE9 mRNAs were present in the granule cell layer. PDE2 mRNA was present in cells that have the characteristics of Golgi cells (Fig. 6P) which apparently also express PDE9 mRNA (Fig. 6R) but not PDE5 mRNA (Fig. 6Q). PDE5 and PDE9 mRNAs were also detected in the external granule cell layer at P5 and P10 (Fig. 5). 


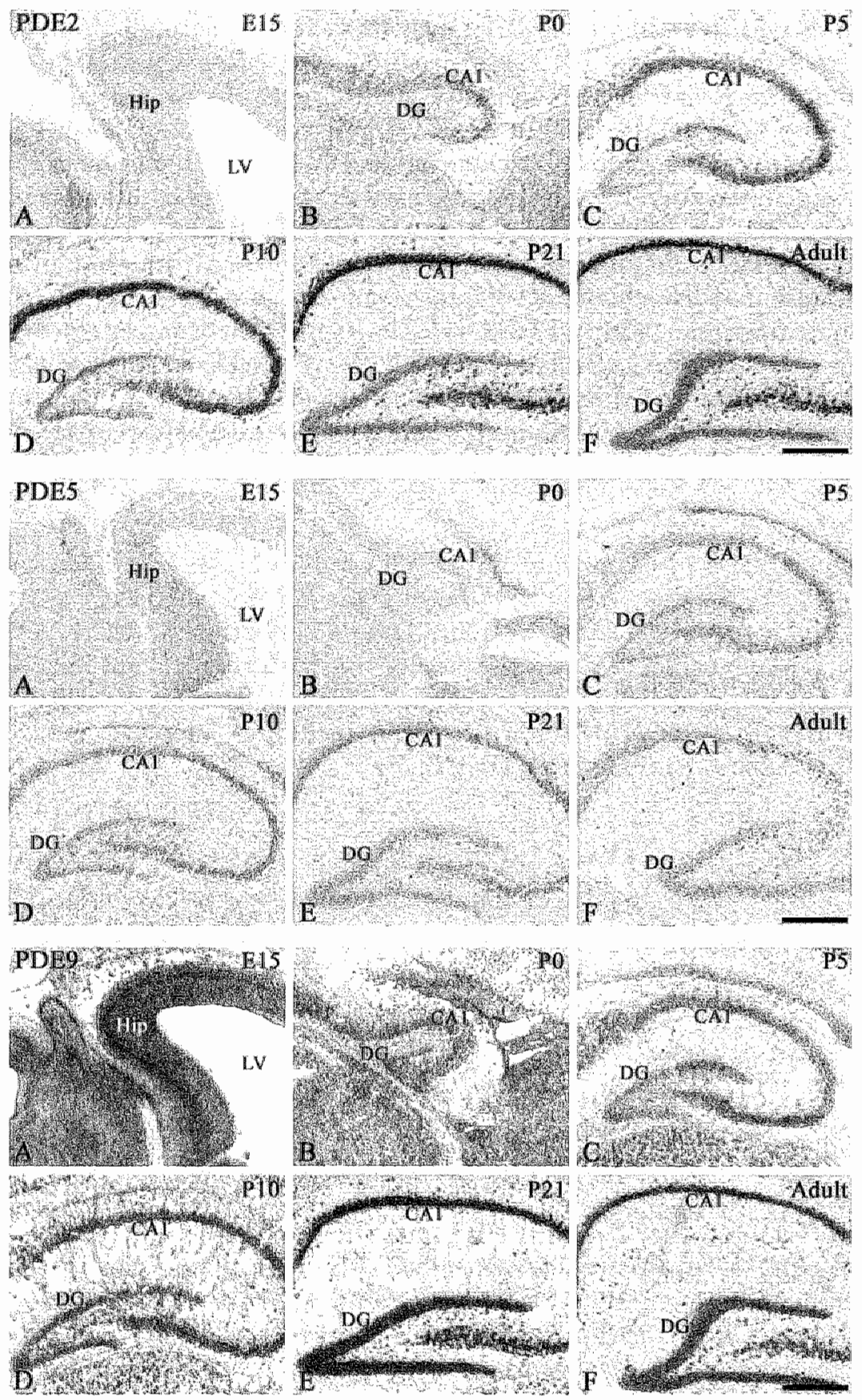

Figure 4. Localization of PDE2, PDE5 and PDE9 mRNA in the hippocampus during development of the rat brain by non-radioactive in situ hybridization. The different ages, labelled A-F in each panel, are indicated in the right upper corner. Recording conditions were kept constant for each PDE riboprobe. Bar indicates $500 \mu \mathrm{m}$ for all pictures. DG, dentate gyrus; Hip, hippocampal area; $L V$, lateral ventricle. 

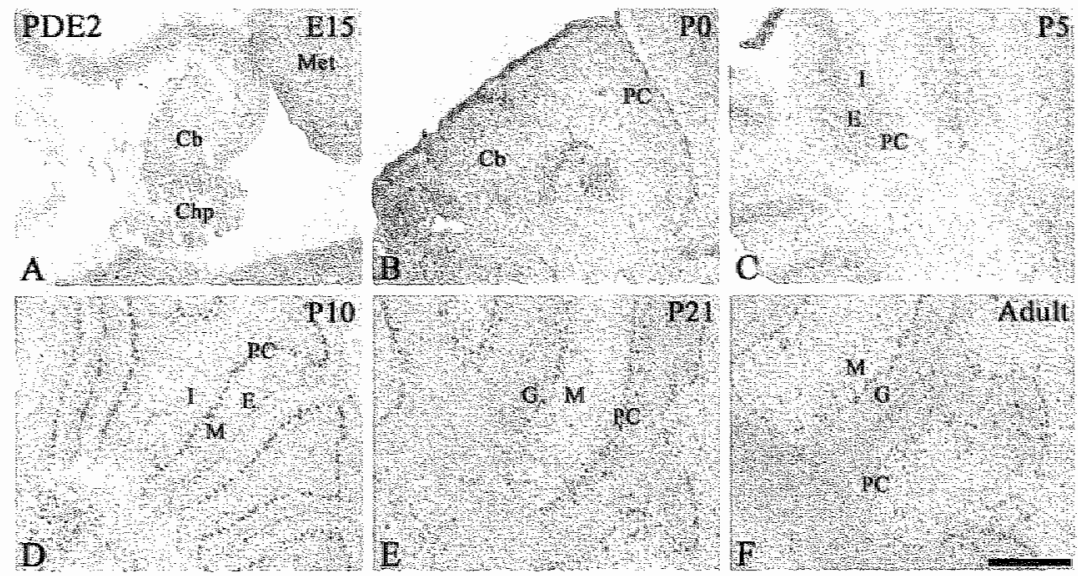

D

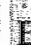
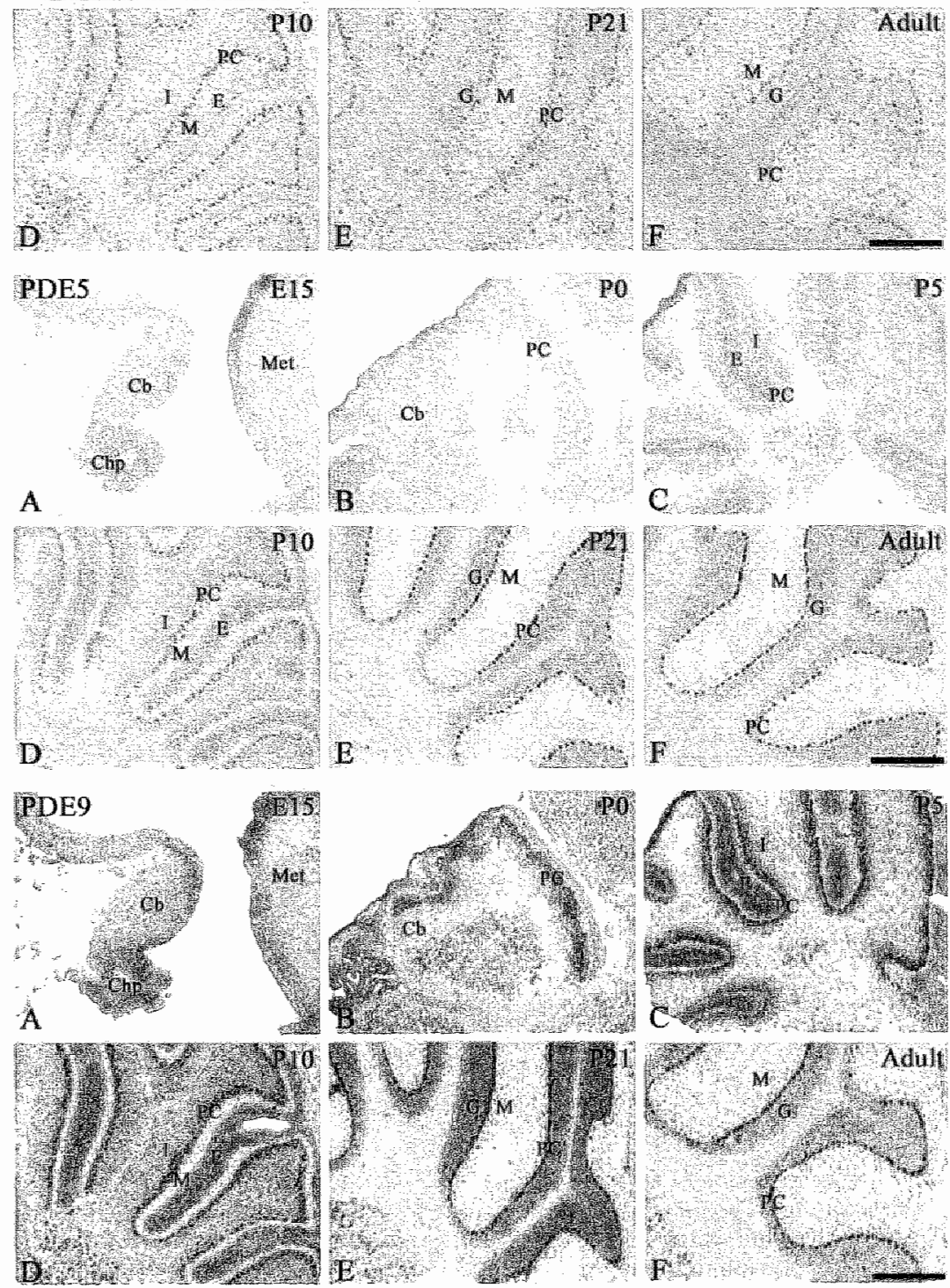

Figure 5. Localization of PDE2, PDE5 and PDEg mRNA in the cerebellum during development of the rat brain by non-radioactive in situ hybridization. The different ages, labelled $A \cdot F$ in each panel, are indicated in the right upper corner. Recording conditions were liept constant for each PDE riboprobe. Bar indicates $500 \mu \mathrm{m}$ for all pictures. Cb, cerebellum; Chp, choroid plexus; E, external granule cell layer; G, granule cell layer; I, internal gramule cell layer; M, molecular layer; Met, metencephalon; PC. Purkinje cell layer. 

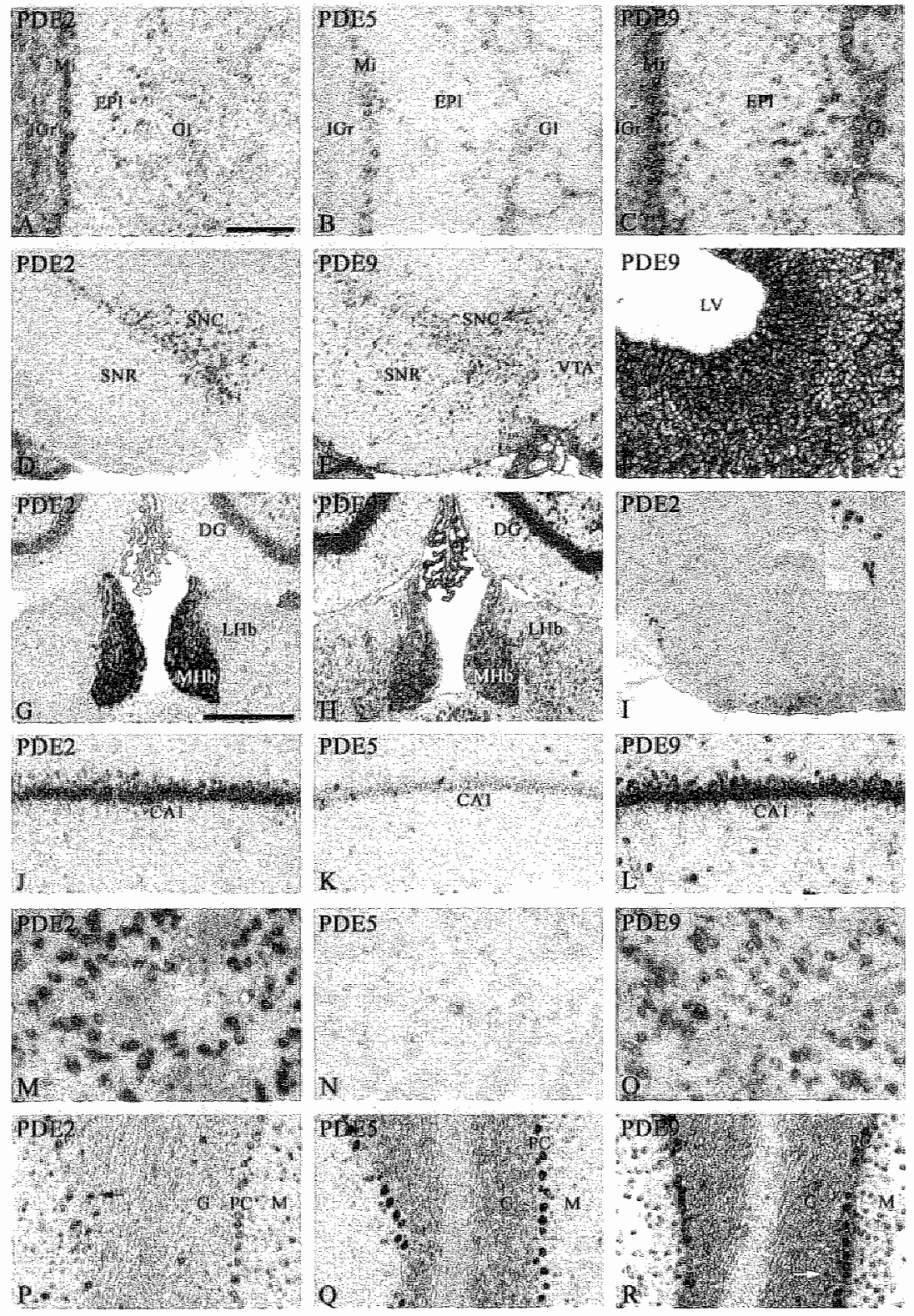

Figure 6. mRNA expression of cGMP-hydrolyzing PDEs in rat brain areas by non-radioactive in situ hybridization. The antisense probes used are indicated in the left upper corner. Olfuctory bulb from adult anmal (A-C) and at E15 (F); substantia nigra (D, E); habenula and choroid plexus $(\mathrm{G}, \mathrm{H})$; mammillary area with magnification of the histaminergic cell group (inset) (I); hippocampus (d-L); caudate putamen (M-O) and cerebellum (P-R). Bar in A indicates $500 \mu \mathrm{m}$ for $\mathrm{D}, \mathbb{E}, \mathrm{Y}, 200 \mu \mathrm{m}$ for $\mathrm{A}-\mathrm{C}$, inset $\mathrm{I}$, J.L, P.R; $100 \mu \mathrm{m}$ for $\mathrm{F}, \mathrm{M}-\mathrm{O}$. Bar in $\mathrm{G}$ indicates 500 $\mu \mathrm{m}$ for $\mathrm{G}$ and $\mathrm{H}, \mathrm{DG}$, dentate gyrus; $\mathrm{EPl}$, external plexiform layer; $\mathrm{G}$, gramule cell layer; $\mathrm{GL}$, glomerular layer; IGr, internal granular layer; $\mathrm{LHb}$, lateral habenula; LV. lateral ventricle; $M$, molecular layer; MHb, medial habenula; Mi, mitral cell layer; PC, Purkinje cell layer; SNC, substantia nigra pars compacta: $\mathrm{SNR}$, substantia nigra pars reticulata; VTA, ventral tegmental area. Arrow indicates possible Golgi cell. 


\section{Brain stem}

In the brain stem, no PDE2 mRNA expression was detected in sagittal sections in the brain stem at any stage. PDE5 mRNA was present in the metencephalon at E15 (Fig. 5A middle panel) and was detected in some nuclei of the reticular formation during maturation (not shown). PDE9 mRNA expression was also observed in sub-nuclei of the reticular fomation. (not shown).

\section{Expression of CGMP-hydrolyzing PDEs in the periphery}

The expression of PDE2, PDE5 and PDE9 mRNA was studied in the periphery at E15. Comparison of the three cGMP-hydrolyzing PDEs at this stage demonstrated that, like in the brain, PDE9 also showed the widest distribution throughout the body (Fig. 7A, 7B, 7D, 7G). PDE2 mRNA expression was strongest in dorsal root ganglia (Fig. 7C). In other tissues like lung, liver, duodenum, nasal cavities and tongue, low PDE2 mRNA expression was detected. PDE5 mRNA expression was strong in liver (Fig. 7D-F), lung (7D), aorta (Fig. 7D) and duodenum (Fig. 7E). PDE9 mRNA expression was detected in all organs, including heart, aorta and lung (Fig. $7 \mathrm{G}$ ), with the strongest expression found in liver (Fig. 7G) and intestine (Fig. 7H, 7l).

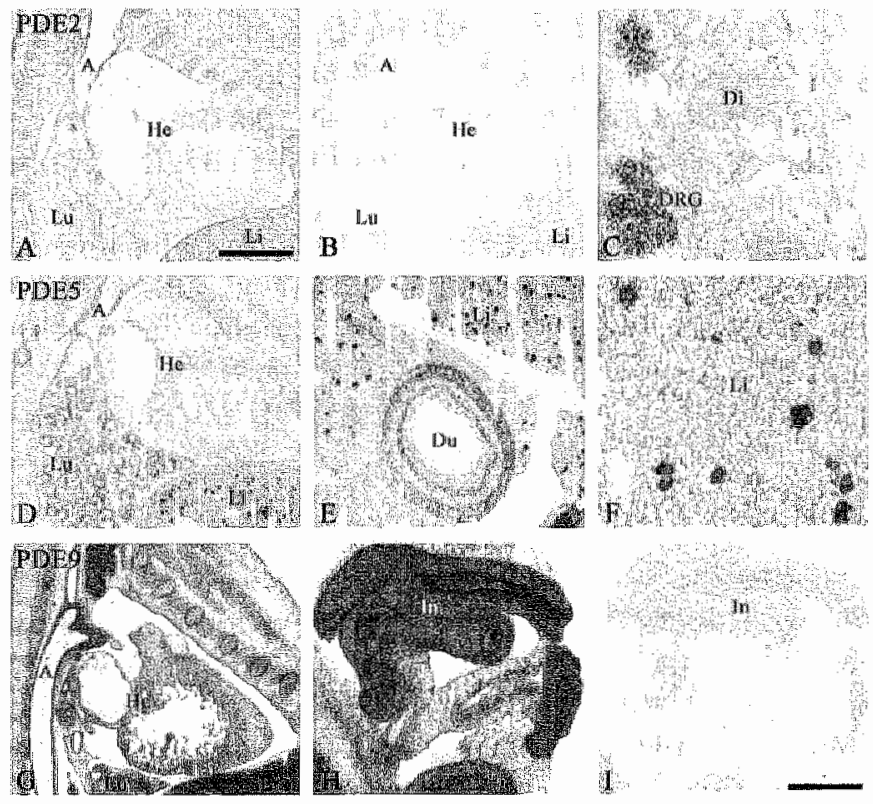

Figure 7. Expression of PDE2, PDEs and PDE9 mRNA th the periphery of the rat at 15 by

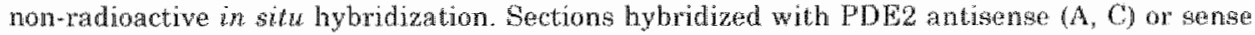

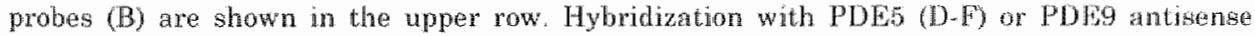
probes $(G, H)$ are shown in the midde and lower row respectively. I indicates hybridication with PDE9 sense probe. A, aorta; Di, disk; DRG, dorsal root ganglion; Du, duodenum; Ha, heart; In, intestine; Li, liver; Lu, lung. Bar in $A$ indicates 1000 am for $A, B$. D and $O$. Bar in indicates $500 \mu \mathrm{m}$ for $\mathrm{E}, \mathrm{H}$ and $\mathrm{r} ; 200 \mathrm{~m}$ for $\mathrm{C}, 100 \mu \mathrm{m}$ for $\mathrm{F}$. 


\section{Discussion}

In this study, we have shown that the mRNAs encoding three cGMPhydrolyzing PDEs have distinct localization patterns, both in the mature rat brain, and at embryonic and postnatal stages when significant developmental and maturational events are in progress. This suggests that these PDEs may have a function in the development of tissues. However, it is important to note several caveats. First, our studies have focused on mRNA expression, and do not necessarily provide an accurate index of protein expression. Second, a variety of splice variants have been described. for PDE2, PDE5 and PDE9 in such species as bovine, canine, rat, mouse and human (Sonnenburg et al., 1991; Yang et al., 1994; Rosman et al., 1997; Guipponi et al., 1998; Kotera et al., 1998; Loughney et al., 1998; Soderling et al., 1998; Kotera et al., 1999b). With the probes used in our study, we cannot distinguish among the splice variants in each family.

Previous studies have shown that NO synthase and $\mathrm{sGC}$ are expressed with distinct localization patterns during brain development and are widely distributed throughout the adult CNS (Bredt and Snyder, 1994; Burgunder and Cheung, 1994; Giuili et al., 1994). Furthermore, targets of cGMP like cGMP-dependent protein kinases (El-Husseini et al., 1999; De Vente et al., 2001) and cyclic nucleotide-gated channels (Wei et al., 1998; Kingston et al., 1999) are also widely expressed in the adult rat brain. The broad distribution of cGMP-hydrolyzing PDEs throughout the CNS, as reported here, is in accordance with the wide distribution of other elements that are involved in the cGMP signaling pathway, supporting the hypothesis that cGMP signal transduction plays widespread physiological roles, both in the mature and the developing brain.

The expression patterns of the three PDE families are not identical, although overlapping to some extent (see below), indicating a diversity in the involvement of cGMP-mediated signal transduction pathways. Of the three different families investigated, PDE9 mRNA expression is most abundant throughout the brain, followed by PDE2, and thereafter PDE5. This pattern is consistent during maturation, although not always present at younger stages, as shown for instance for PDE2 and PDE5 in Purkinje cells.

Previous studies have already indicated changes in PDE mRNA and protein expression or PDE activity during development of the brain (Billingsley et al., 1990; Reinhardt and Bondy, 1996). An increase in PDE activity was reported during development of the brain from fetus to adulthood (Smoake et al., 1974; Davis and Kuo, 1976). Furthermore, lower basal cGMP levels in aged brain areas compared to adult have been reported as a consequence of a more active degradation of cGMP by PDEs (Chalimoniuk and Strosznajder, 1998). Differences in responsiveness of both pGC and $\mathrm{sGC}$, as investigated by cGMP-immunocytochemistry, in such brain areas as cortex, caudate putamen, hippocampus and cerebellum have been reported comparing young and adult rats (De Vente and Steinbusch, 1992; Markerink-Van Ittersum et al., 1997). Visualization of cGMP in adult 
rat hippocampal slices requires the presence of a broad-spectum PDE inhibitor during incubation, since PDE activity in the hippocampus is high (De Vente and Steinbusch, 1992). This is in significant contrast to young rats (postnatal 10 days), where cGMP-immunoreactivity in the hippocampus can readily be observed without a PDE inhibitor being present (Fig. 8A, C, see also De Vente and Steinbusch, 1992). Addition of the NO donor sodium nitroprusside further increases cGMP-immunoreactivity in hippocampal slices from young rats (Fig. 8B) whereas incubation of adult slices with an NO donor alone hardly results in detectable cGMP-immunoreactivity (Van Staveren et al., 2001). These data point to a difference in cGMP formation and/or cGMP degradation during maturation, which could be due to differences in regulation of $\mathrm{GC}$ or PDE activity during development. Our data on the mRNA localization of the cGMP-hydrolyzing PDEs in the hippocampus do not indicate large differences in mRNA expression in hippocampus when comparing adult with younger stages. However it must be noted that this does not exclude differences in PDE protein expression, PDE activity or regulation of PDEs by other factors such as protein kinases.

Our present study, in conjunction with previous work (Repaske et al., 1993; Kotera et al., 1997), demonstrates that Purkinje cells and hippocampal pyramidal cells express the mRNA of all three cGMP. hydrolyzing PDEs. Other studies have shown that both pyramidal and Purkinje cells also express PDE1. (Kincaid et al., 1987; Furuyama et al., 1994), PDE3 (Reinhardt and Bondy, 1996), PDE4 (Iwahashi et al., 1996; McPhee et al., 2001), and PDE7 (Miro et al., 2001). In adult rat brain slices it has been a common observation that, irrespective of the PDE inhibitor or the NO donor used, neuronal fibers and/or astrocytes can be cGMPimmunoreactive, whereas in neuronal cell bodies in the cortex and hippocampus, almost without exception, no cGMP is visualized (De Vente et al., 1998; Van Staveren et al., 2001). In particular, cGMP-immunoreactivity has not been observed in hippocampal pyramidal cell bodies or cerebellar Purkinje cell bodies. Abundant somatic expression of multiplle PDE family members could prowide an explanation for the absence of cGMP. immunoreactivity in the cell bodies of many neurons. Alternatively, the sensitivity of the cGMP antibodies might be a limiting factor, as has been suggested by (Prabhakar et al., 1997). However, the good correspondence observed when standard biochemical assays of cGMP are compared to the (semi) quantitative measurement of cGMP by immunofluorescence, suggests that the sensitivity of the immunocytochemical method is adequate (De Vente et al., 1987; Van Staveren et al., 2001). Thus, the cause of the lack of cGMP-immuoreactivity in neuronal cell soma in rat cortex and hippocampus remains unclear, although these cells are known to express $\mathrm{sGC}$ (Burgunder and Cheung, 1994; Giuili et al., 1994).

Comparison of the Km values for cGMP of PDE1 (1.1-5.0 $4 \mathrm{M})$, PDE2 (15$30 \mu \mathrm{M})$, PDE5 (1-5 $\mu \mathrm{M})$, PDE9 (70-170 nM), PDE10 $(3 \mu \mathrm{M})$ and PDE11 (1 HM) (values abtained from Francis et al., 2001), indicates that PDE9 has the highest affinity for cGMP. In addition, PDE9 mRNA is the most widely distributed of the PDEs that we analyzed. Furthermore, comparison of 
PDE9 mRNA expression with published data for other cGMP-hydrolyzing PDE family members, such as PDE1 (Furuyama et al., 1994; Yan et al., 1994), PDE10 (Fujishige et al, 1999) and PDE11 (Fawcet et al., 2000), indicates that PDE9 has the broadest CNS distribution of all known PDEs. The restricted distribution of other PDEs suggests that they could be involved in more specific signaling pathways. The broad expression pattern of PDE9 and its low $\mathrm{Km}$ value for cGMP suggest that PDE9 could function as a "housekeeping" PDE that keeps levels of cGMP low in most cells. In this respect it should be noted that in most tissues intracellular levels of cGMP compared to cAMP, are usually 10-50 times lower (Ferrendelli, 1978).

In contrast to PDE9, PDE5 mRNA expression is very limited. The highest expression is observed in Purkinje cells, and PDE5 expression in these cells is visualized for the first time at P10. These results are in agreement with Northern blot analysis during development of the rat cerebellum (Kotera et al., 1997), and with immunocytochemical studies showing PDE5 protein expression in cell bodies from Purkinje cells and in the major branches of their extensive dendritic tree (Juilfs et al., 1999; Kotera et al., 2000; Giordano et al, 2001). Additionally, we detected PDE5 mRNA expression in cells throughout the cortical areas, in the hippocampus and the olfactory bulb, a finding that has not been mentioned in previous PDE5 expression studies (Kotera et al., 1997; Juilfs et al., 1999; Kotera et al., 2000; Giordano et al., 2001). The PDE5 expression found in hippocampus suggests that it potentially might function in learning and memory processes. In this regard, the presence of PDE5 MRNA in hippocampus and entorhinal cortex supports the concept that PDE5 is involved in object recognition (Prickaerts et al., 1997; Prickaerts et al., $2002 b)$.

It is unlikely that our current observations are the result of artifactual localization of PDE5 mRNA. First, hybridization with sense probes or pretreatment with RNase did not result in any "false" positive cells simillar to those found with antisense probes. Second, Northern blot analysis in different brain areas from rat, human and canine indicate that while highest expression is found in the cerebellum, lower levels are also present in other brain areas such as hippocampus, cortex and olfactory bulb (Kotera et al., 1997; Loughney et al, 1998, Kotera et al., 1999b). Finally, in agreement with previous studies (Kotera et al., 1997; Hanson et al., 1998; Kotera et al., 1999b), we have found high PDE5 expression in lung, aorta and intestine, providing further support for the reliability of the PDE5 riboprobe used.

PDE2 mRNA expression was strong in structures that belong to the limbic system, i.e. olfactory cortex, amygdala, and hippocampus, in agreement with our previous study involving adult animals (Repaske et al., 1993). PDE2 protein has been described in similar areas in cell bodies from neurons and in axons and dendrites (Juilfs et al., 1999). This places PDE2 in an appropriate location for the imvolvement in learning, memory, emotion and synaptic plasticity. In addition, we have observed PDE2 mRNA in the substantia nigra pars compacta, dorsal raphe nucleus and histaminergic cell 
groups of the tubero mammillary region. This could point to role for PDF2 in dopaminergic, serotonergic and histaminergic neurotransmission. Surprisingly, when $\mathrm{NO}$ is applied in combination with a PDE inhibitor (either a non-selective inhibitor, such as 3-isobutyl-1-methylxanthine (IBMX) or a PDE2-specific inhibitor, such as erythro 9-(2-hydroxy-3nonyl)ademine (EHNA), to brain slices incubated in vitro, somata in these regions were not cGMP-immunoreactive (De Vente et al, 1998). Indeed, we have never observed colocalization of cGMP-immunoreactivity in dopaminergic, serotonergic or histaminergic fibers in any region of the rat brain (De Vente et al., 2000, Steinbusch et al., 2001). This suggests either that, although sGC is demonstrably present in many of these regions (Schmidt et al., 1992; De Vente et al., 1998), basal and NO-stimulated cGMP synthesis must be very low in these cell bodies, or that the activity of an IBMX-resistant PDE (such as PDE9) may be dominant in this cellular region.

To summarize, our results show that PDE2, PDE5 and PDE9 $\mathrm{MRNAs}$ are present throughout the developing $\mathrm{CNS}$, and that each $\mathrm{PDE}$ family has a distinct localization pattern. The expression patterns are by and large maintained during brain development. PDE9 mRNA has the widest distribution and could function in cells to maintain low basal cGMP levels. PDE2 mRNA is strongly expressed in structures of the limbic system. PDE5 mRNA expression is the most limited, being highly expressed only in cerebellar Purkinje cells, and to lesser extent in cortex, hippocampus and olfactory bulb. In addition, some cell types, such as Purkinje cells, pyramidal cells, mitral cells, and possibly some cortical neurons, express all three PDE families. The mRNA localization patterns suggest involvement of these cGMP-hydrolyzing PDE families in many different brain functions, including learning and memory processes and motor behavior.
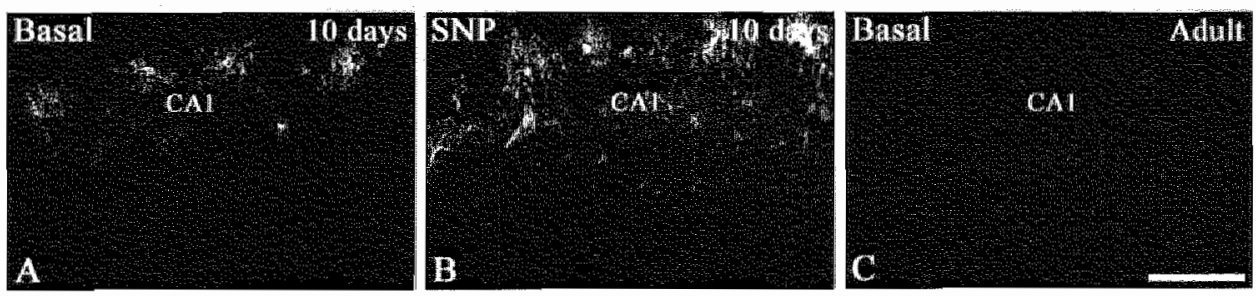

Figure 8. cGMP-immunocytochemistry in the GA area of the rat hippocampus of a 10 anys old $(A$ and $B$ ) or an adult (C) amimal. Slices were incubated under basal condidons $(A$ and $C$ ) or in the presence of the $N O$ donor sodium nitropmsside $(S M P, 0.1 \mathrm{mM}$ ) in the absence of a PDE inhbitor. The incubations lasted 40 minutes, of which in $B$ the last 10 minutes in the presence of the NO donor. The incubation procedure of hippocampal slices has been described in detail before (De Vente et al., 1998; Van Staveren et al. 2001). Pictures were taken under aimilar conditions and depicted without further processing. Ban indicates 100 fm tor all pictures. 


\section{Acknowledgments}

The authors would like to thank Hellen P.J. Steinbusch for her histological advices and Marjo P.H. van de Waarenburg for her technical assistance. A part of the work was supported by Universiteitsfonds Limburg/SWOL to W. van Staveren.

\section{References}

ANDREEVA SG, DIKKES PA EPSTEIN PM, ROSENBERG PA. (2001) Expression of cGMP. specific phosphodiesterase 9A mRNA in the rat brain. I Neurasci 21: 9068-9076.

BARATTI CM, BOCCIA MM. (1999) Effects of sildenafil on long-term retention of an inhibitory avoidance response in mice. Behav Plarmacol 10:731-737.

BEAVO JA. (1995) Cyclic nucleotide phosphodiesterases: functional implications of multiple isoforms. Plysiol Rev 75: 725-748.

BERNABEU R, SCHMITZ P, FALLLACE MP, IZQUIERDO I, MEDINA JH. (1996) Hippocampal cGMP and CAMP are differentially involved in memory processing of indibitory avoidance learning, Neuroreport $7: 585-588$.

BERNABEU R, SCHRODER N, QUEVEDO J, CAMMAROTA M, IZQUIERDO I, MEDINA JH. (1997) Further evidence for the invalvement of a hippocampal CGMP/cGMP-dependent. protein kinase cascade in memory consoliclation. Neuroreport $8: 2221.2224$.

BICKER G. (1998) NO news from insect brains. Therds Neurosci, 21: 349.355.

BICKER $G$. (2001) Sources and targets of nitric oxide signalling in insect nervous systems. Cell Tissue Res 303: 137-146.

BILLINGSLEY ML, POLLI JW, BALABAN CD, KINCAID RL. (1990) Developmental expression of calmodulin-dependent cyclic nucleotide phosphodiesterase in rat brain. Dev Broin Res 58: 253-263.

BREDT DS, SNYDER SH. (1994) Transient nitric oxide synthase neurons in embryonic cerebral cortical plate, sensory ganglia, and olfactory epithelium. Neuron 13: 301-313.

BROILLET MC, FIRESTEIN S. (1999) Cyclic nucleotide-gated channels. Molecular mechanisms of activation. Arn $N$ Y Acad Sci 868: 730-740.

BURGUNDER JM, CHEUNG PT. (1994) Expression of soluble guanylyl cyclase gene in adult rat brain. Eur of Neurosci 6: 211-217.

CARVASAL JA, GERMAIN AM, HUTDOBRO-TORO JP, WEINER CP. (2000) Molecular mechanism of CMP-mediated smooth muscle relaxation. J Cell Physiol 184: 409-420.

CHALIMONUK M, STROSZNAJDER JB. (1998) Aging modulates nitric oxide synthesis and cCMP levels in hippocampus and cerebellum. Eiffects of amyloid beta peptide. Mol Chem Neuropathol 35: $77-95$.

CONTI M, JJN SL, (1999) The molecular biology of cyclic nucleotide phosphodiesterases. Prog Nucleic Acid Res Mol Biol 63; 1-38.

DAVIS CW, KUO JF. (1976) Ontogenetic changes in levels of phosphodiesterase for adenosine $3^{\prime}: 5^{\prime}$ monophosphate and glucosine $3^{\prime}: 5^{\prime}$-monophosphate in the lung, brain and heart from guinea pigs. Biochim Bhophys Acta 444: 554-562.

DE VENTE I, GARSSEN J, THLDERS FJH, STEINBUSCH HWM, SCHIPPER J. (1987) Single cell quantitative immunocy tochemistry of cyclic GMP in the superior cervical ganglion of the rat. Broin Res $411: 120 \times 128$.

DE VENTE $J$, STEINBUSCH HWM. (1992) On the stimulation of soluble and particulate guamylate cyclase in the rat brain and the involvement of nitric oxide as studied by cGMP immunocytochemistry. Acta Histochem 92: 13-38.

DE VENTW J, HOPKINS DA, MARKERINK-VAN ITTERSUM M, EMSON PC, SCHMIDT HHHW. STEINBUSCH HWM. (1998) Distribution of nitric oxide synthase and nitric oxide. receptive, cychic GMP-producing structures in the rat brain. Neuroscience 87: 207-241.

DE VENTE J, MARKERINK-VAN ITTERSUM M, VAN ABEELEN J, EMSON PC, AXER H, STEINBUSCH HWM. (2000) NO-mediated cGMP synthesis in cholinergic neurons in the 
rat forebrain: effects of lesioning dopaminergic or serotonergic pathways on nNos and cGMP synthesis. Eur I Neurosci 12: 507.519 .

DE VENTE I, ASAN E, GAMBARYAN S, MARKERINK-VAN ITTERSUM M, AXER H, GALLATZ K, LOHMANN SM, PALKOVITS M. (2001) Localization of CGMP-dependent protein kinase type II in rat brain. Neuroscience 108: $27-49$.

DOUSA TP. (1999) Cyclic-3,5'-nucleotide phosphodiesterase isorymes in cell biology and pathophysiology of the kidney. Kidney Int 55: 29-62.

EDWARDS TM, RICKARD NS, NG KT. (2002) Inhibition of guanylate cyclase and protein kinase $G$ impairs retention for the passive avoidence task in the day-old chick. Neurobiol Learn Men 77: 313-326.

EL-HUSSEINI AE, WILLIAMS J, REINER PB, PELECH S, VINCENT SR. (1999) Localization of the cGMP-dependent protein kinases in relation to nitric oxide synthase in the brain. If Chem Neuroanat 17: 45-55.

FAWCETT L, BAXENDALE R, STACEY P, MCGROUTHER C. HARROW I, SODERLING $\mathrm{S}$, HETMAN J, BEAVO JA, PHLLIPS SC (2000) Molecular cloning and characterization of a distinct human phosphodiesterase gene family: PDE11A. Proc Natl Acad Sci U S A 97: $3702-3707$.

FERRENDELLI A. (1978) Distribution and regulation of cyclic GMP in the central nervous system. Adv Cyclic Nucleotide Res 9: 453-464.

FISHER DA, SMITH JE, PILLAR JS, ST DENIS SH, CHENG JB. (1998) Isolation and characterization of PDE9A, a novel human cGMP-specific phosphodiesterase of Biol Chem 273: $15559-15564$.

FORTE LR, LONDON RM, KRAUSE WJ, FREEMAN RH. (2000) Mechanisms of guanylin action via cyclic GMP in the kidney. Annu Reu Physiol 62: 673-695.

FRANCIS SH, TURKO IV, CORBIN JD. (2001) Cyclic nucleotide phosphodiesterases: relating structure and function. Prog Nucleic Acid Res Mol Biol 65: 1.52.

FUJISHIGE K, KOTERA J, OMORT K. (1999) Striatum- and testis-specific phosphodiesterase PDE1.0A isolation and characterization of a rat PDE10A. Eur \& Biochem 266: 11.18-1127.

FURUYAMA T, IWAHASHI Y, "TANO Y, TAKAGI H, INAGAKI S. (1994) Localization of 63$\mathrm{kDa}$ calmodulin-stimulated phosphodiesterase mRNA in the rat brain by in situ hybridization histochemistry. Brain Res Mol Brain Res 26: 331-336.

GARTHWAITE J. (1991) Glutamate, nitric oxide and cell-cell signalling in the nervous system. Trends Neurosci 14: 60-67.

GIBBS SM, TRUMAN JW. (1998) Nitric oxide and cyclic GMP regulate retinal patterning in the optic lobe of Drosophila. Neuron 20: 83-93.

GIBBS SM, BECKER A, HARDY RW, TRUMAN JW. (2001) Soluble guanylate cyclase is required during development for visual system function in Drosophila. J Neurosci 21: 77057714.

GILLESPIE PG, BEAVO JA. (1988) Characterization of a bovine cone photoreceptor phosphodiesterase purified by cyclic GMP-sepharose chromatography. \& Brol Chem 263: $8133-8141$.

GIORDANO D, DE STEFANO ME, CITRO G, MODICA A, GHORGI M. (2001) Expression of cGMP-binding cGMP-specific phosphodiesterase (PDE5) in mouse tissues and cell lines using an antibody against the enzyme amimo-terminal doman. Biochim Biophys Acta 1539: $16-27$.

GIUILI G, LUZI A, POYARD M, GUELLAEN G. (1994) Expression of monse brain soluble guanylyt cyclase and NO synthase during ontogeny. Brain Kies Dev Brain Res 81: 269-283.

GUTPPOND M, SCOTT HS, KUDOH J, KAWASAKT K, SHIBUYA K, SHINTANI A, ASAKAWA S, CHEN H. LALIOTY MD, ROSSIER C. MINOSHIMA S, SHIMIZU N, ANTONARAKIG SE. (1998) Identification and characterization of a novel cyclic nucleotide phosphodiesterase gene (PDE9A) that maps to 21q22.3: alternative splicing of mRNA transcripts, genomic structure and sequence. Hun Genel 103: 386-392.

HANSON KA, BURNS F, RYBALRIN SD, WAGER MILLER J, BEAVO „, CLARKE WR. (1998) Developmental changes in lung cGMP phosphodiesterase-5 activity, protein, and message. An el Respir Crit Care Med 158: 279.288.

HETMAN JM. ROBAS N, BAXENDALE R, FIDOCK M, PHILLJPS SC, SODERLING SH, BEAvO JA. (2000) Cloning and characterization of two splice variants of humarn phosphodiesterase 11A. Proc Nall Acad Sci U S A 97: 12891-12895. 
HOUSLAY WD. (1998) Adaptation in cyclic AMP signalling processes: a central role fon cyclic AMP phosphodiesterases. Semin Cell Dev Biol 9: 161-167.

IWAHASHI $Y$, EURUYAMA T, TANO $Y$, ISHMOTO $I$, SHIMOMURA Y, INAGAKI S. (1996) Differential distribution of mRNA encoding cAMP-specific phosphodiesterase isoforms in the rat brain. Brain Res Mol Brain Res 38: 14-24.

JULFS DM, SODERLING 8 , BURNS F, BEAVO JA. (1999) Cyclic GMP as substrate and regulator of cyclic nucleotide phosphodiesterases (PDEs). Rev Physiol Biochem Phannacol 135: $67-104$

KENDRICK KM, GUEVARA-GUZMAN R, ZORRILLA I, HNTON MR, BROAD KD, MMMACK M, OHKURA S. (1997) Formation of olfactory memories mediated by nitric oxide Nolure 388: 670-674

KINCAD RL, BALABAN CD, BILLINGSIEYY ML. (1987) Differential locallization of calmodulin-dependent enzymes in rat brain: evidence for selective expression of cyclic nucleotide phosphodiesterase in specific neurons. Proc Notl Acad Sci U S A 84: 1118-1122.

KIND PC, NGUMANN PE. (2001) Plasticity: downstream of glutamate. Thends Neurosci 24: $553-555$

KINGSTON PA, 7UFALL F, BARNSTABULE CU. (1999) Widespreacl expression of olfactory cyclic nucleotide-gated channel genes in rat brain: implications for neuronal signalling. Synapse 32: 1-12

KOTERA 』, YANAKA N, FUJISHGE K, IMAI Y, AKATSUIKA H, ISHIZUKA T, KAWASHIMA $K^{*}$, OMORI $K$. (1997) Expression of rat cGMP-binding cGMP-specific phosphodiesterase mRNA in Purkinje cell layers during postnatal neuronal development. Eur of Biochem 249:434-442.

KOTERA , FUJSHTGE K, AKATSUKA H, LMAI Y, YANAKA N, OMORT K. (1998) Novel alternative splice variants of CGMP-binding cGMP-specific phosphodiesterase. If Biol Chem $273: 26982-26990$.

KOTERA J, FUASHIGE K, YUASA K, OMORI K. (1999a) Characterization and phosphorylation of PDE 10A2, a novel alternative splice variant of human phosphodiesternse that hydrolyzes cAMP and CGMP. Biochem Biophys Res Commun 261: $551-557$.

KO'WERA J, FUJTSHIGE K, IMAI Y, KAWAJ E, MICHIBATA H, AKATSUKA H, YANARAN, ONORI $K$. (1999b) Genomic origin and transcriptional regulation of two variants of COMPbinding cGMP-specific phosphodiesterases. Eur J Biochem 262: 866-873.

KOTERA J, FUIASHIGE $K$, OMORI K. (2000) Immunohistochemical localization of eGMP. binding cGMP-specific phosphodiesterase (PDE5) in rat tissues. of Histochen Cytochen 48 : $685-693$.

LOUGHNEY K, HILL TR, FLORIO VA, UHER L, ROSMAN GJ, WOLDA SL, JONES BA, HOWARD ML, MCALILISTER IJUCAS LM, SONNENBURG WT, HRANCIS SH, CORBIN J1.), BEAVO \#A, FEIRGUSON K. (1998) Isolation and characterization of CDNAs encoding PJESA, a human cGMP.binding, cCMP-specific 3"5'-cychic nucleotide phosphodiesterase. Gene $216: 139-147$.

LUCAS KA, PITARI GM, KAZRROUNIAN S, RUIZ-STEWART I, PARK d, SCHULZ S, CHEPENIK KP, WAL.DMAN SA. (2000) GuanylyL cyclases and signaling by cyclic CMP? Pharmacol Rew 52: 375m-414.

MARTERINK WAN ITTERSUM M, STEINBUSCH HWM, DE VENTE J. (1997) Regionspecific developmental patterns of atrial natriuretic factor and nitric oxideractivated guanylyl cyclases in the postnatal frontal at brain. Neuroscience 78: $571-587$.

MCPHEE 1, COCHRAN S, HOUSLAY MD. (2001) The movel long PDE4A10 cyclic AMP phosphodiesterase shows a pattern of expression within brain that is distinct from the long PDEAAS and short PDEAAl isofon'ms. Cell signal 13:911.918.

MIRO X, PEREZ TORRES S, PALACIOS JM, PUIGDOMENECH P, MENGOD G. (2001) Differential distribution of CAMP-specific phosphodiesterase 7A mRNA in rat brain and peripheral organs. Symopse 40: 201.214.

PAXINOS G. WATSON G (1986) The Rat Brain in Stereotaxic Coordinates. Second Edition. Acadenic Press

PAXINOS G, ASHWELL KWS, TORK I (1994) Atlas of the Developing Rat Nerwous System. Second Edition. Academix Press. 
POLLEUX F, MORROW T, GHOSH A. (2000) Semaphorin $3 A$ is a chemottractant for cortical apical dendrites. Nature 404: 567-573.

PRABHAKAR S, SHORT DB, SCHOLZ NL, GOY MF. (1997) Identification of nitric oxidesensitive and -insensitive forms of cytoplasmic guanylate cyclase. If Netrochem 69 : 1650 . 1660 .

PRICKAERTS J, STEINBUSCH HWM, SMITS JF, DE VENTEZ J. (1997) Passible role of nitric oxide-cyclic GMP pathway in object recognition memory: effects of 7-nitroindazole and raprinast. Eur J Pharnacol 337: 125-136.

PRICKAERTS J, DE VENTE J, HONIG W, STEINBUSCH HWM, BLOKLAND A. (2002a) cGMP, but not CAMP, in rat hippocampus is involved in early stages of object memory consolidation. Eur J Plrarmacol 486: 83-87.

PRICKAERTS J, VAN STAVEREN WCG, SIK A, MARKERINK-VAN ITTERSUM M. NIEWÖHNER U, VAN DER STAAY FJ, BLOKLAND A, DE VENTE J. (2002b) Effects of two selective phosphodiesterase type 5 inhibitors, sildenafil and wardenafil, on object. recognition memory and hippocampal cyclic GMP levels in the rat. Neurosciesce 113: 851 361.

REINHARDT RR, BONDY CA. (1996) Differential cellular pattem of gene expression for two distinct CGMP-inhibited cyclic nucleotide phosphodiesterases in developing and mature rat. brain. Newroscience $72: 567-578$.

REPASKE DR, CORBIN JG, CONTI M, GOY MF, (1993) A cyclic GMP-stimulated cyclic nucleotide phosphodiesterase gene is highly expressed in the limbic system of the rat brain. Neurascience 56: 673-686.

ROSMAN GJ, MARTINS TJ, SONNENBURG WK, BEAVO JA, FERGUSON $K$, LOUGHNEY K. (1997) Isolation and characterization of human cDNAs encoding a cGMP-stimulated 3',5"-cyclic nucleotide phosphodiesterase. Gene 191: $89-95$.

SCHACHTNER J, HOMBERG U, TRUMAN JW. (1999) Regulation of cyclic GMP elevation in the developing antennal lobe of the Sphinx moth. Manduca sexta. J Neurobiol 41: 359-375.

SCHMIDT HH, GAGNE GD, NAKANE M, POLLOCK JS, MLLLER MF, MURAD F. (1.992) Mapping of neural nitric oxide synthase in the rat suggests frequent co-localization with NADPH diaphorase but not with soluble guanylyl cyclase, and novel paraneural functions for nitrinergic signal transduction. of Histachem Cytochem 40: 1439-1456.

SCHOLZ NL, TRUMAN JW (2000) Invertebrate models for studying NO-mediated signaling. In: Handbook of Chemical Neuroanatomy (STEINBUSCH HWM, DE VENTE, J, VINCENT

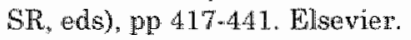

SCHOLZ NL, DE VENTE J, TRUMAN JW, GRAUBARD K. (2001) Neural network partitioning by NO and CGMP. I Neurosci 21: 1610-1618.

SIMPSON PJ, MILLER I, MOON C, HANLON AL, LIEBL DJ, RONNETT GV. (2002) Atrial natriuretic peptide type $C$ induces a cell-cycle switch from proliferation to differentiation in brain-derived neurotrophic factor- or nerve growth factor-primed olfactory receptor neurons. ANeurosci 22:5536-5551.

SMOAKE JA, SONG SY, CHEUNG WY (1974) Cyclic $3^{\prime}, 5^{\circ}$-nucleotide phosphodiesterase. Distribution and developmental changes of the enzyme and its protein anctivator in mammalian tissues and cells. Biochim Blophys Acta $341: 402-411$.

SODERLING SH. BAYUGA SJ, BEAVO JA. (1998) Identification and characterization of a novel family of cyclic nucleotide phosphodiesterases. of Biol Chem 273: 15553-15558.

SODERLING SH, BAYUCA SJ, BEAVO JA. (1999) Isolation and characterization of an dualsubstrate phosphodiesterase gene familly: PDE 10A. Proc Natl Acad Sci U S 4 96: 7071. 7076.

SODERLING SH, BEAVO JA. (2000) Regulation of CAMP and cGMP signaling: new phosphodiesterases and new functions. Curr Opin Coll Biol 12: 174-179.

SONG H, MING G, HE Z, LEHMANN M, MCKERRACHER L, TESSIER-LAVIGNE M, POO M. (1998) Conversion of neuronal growth cone responses from repulsion to attraction by cyclic nucleotides. Science 281: 1515-1518.

SONG HJ, POO MM. (1999) Signal transduction underlying grow th cone guidance by diffusible factors. Curr Opin Neurobiol 9: 355-363.

SONNENBURG WK, MULLANEY PJ, BEAVO JA (1991) Molecular cloning of a cyclic GMP. stimulated cyclic nucleotide phosphodiesterase cDNA. Identification and distribution of isozyme variants. I Biol Chem 266: 17655-17661. 
STEMBUSCH HWM, ALLEN GV, DE WWWE, HOPKINS DA (2001) The interaction between the histaminergic system and the NO-cGMP pathway a functional newornamical dudy in the mammillary reston and cerebral conter of the rat Im: Hislamine heseanch in the New Milenim (WATANABE T, TMMERMAN H, YANAI K. eds), pp b1-59. El Isevigr Science BV.

THOMAS MK IHANCIS SH, CORBIN JD. (1990) Characterization of a purified bovime lung: cGMP-binding cGMP phosphodiesterase. I Bhol Chem 265: 1.4964-14970.

TRUMAN JW, DE VENTH H, BALL ER. (1996) Nitric oxide-sensitive guanylate cyclase activity is associated with the maturational plase of neuronal development in insects. Development $122 * 3949 \times 3958$

VAN STAVEREN WCG, MARKERINK-VAN ITTEPSUM M, STELNBUSCH HWM, DE VENTE J. (2001) The eflects of phosphodiesterase inhibition on cyche GMP and cyclic AMP accumulation in the hippocampus of the rat. Bran Res 888:275-286.

VAN WAGENEN S, REHDER V. (1999) Regulation of neuronal growth cone filopodia by nitric oxide. N Newrobiol 39: $168 \cdot 185$.

WATTS VJ. (2002) Molecular mechanisms for theterologous sensitization of adenylate cyclase. I Phormacol Exp Ther 302: $1-7$.

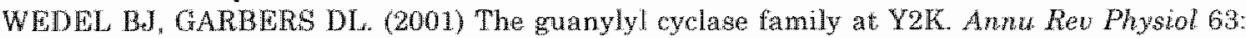
$21.5-233$.

WEY JY, ROY DS, LECONTE L, BARNSTABLE CI. (1998) Molecular and pharmacological analysis of cyclic nucleotide-gated channel function in the central newous system. Prog Neurobiol $56: 37-64$.

YAN C, BENTLEY JK, SONNENBURG WK, BEAVO JA. (1994) Differential expresenon of the 61. $\mathrm{kDa}$ and $63 \mathrm{kDa}$ calmodulimodependent phosphodiesterases in the mouse brain. $f$ Newrosei 14: $973-984$.

YANG Q, PASKIND M, BOLGER G, THOMPSON WJ, REPASKE DR, CUTLER IS, EPSTEIIN PM. (1994) A novel cyclic GMP stimulated phosphodiesterase from rat bain. Biochem Biophys Res Commun 205: 1850-1858. 


\section{Species differences in the localization of cGMP-producing and NO-responsive elements in the mouse and rat hippocampus using cGMP- immunocytochemistry}

Wilma C.G. van Staveren, ${ }^{1}$ Harry W.M. Steinbusch, ${ }^{9}$ Marjanne Markerinkvan Ittersum, ${ }^{1}$ Sönke Behrends ${ }^{2}$ and Jan de Vente ${ }^{1}$

Dept. of Psychiatry and Neuropsychology, Division Cellular Neuroscience, Maastricht University, European Graduate School of Neuroscience (EURON), P.O. Box 616, 6200 MD Maastricht, The Netherlands; 'Institute of Experimental and Clinical Pharmacology and Toxicology, University Clinic Hamburg-Eppendorf, Hamburg, Germany

Submitted to European Journal of Neuroscience

\section{Abstract}

The aim of the study was to compare the localization of the nitric oxide (NO)-cGMP pathway between rats and mice after in vitro incubation of hippocampus slices using cGMP-immunocytochemistry. Incubation of hippocampus slices in the absence of a guanylyl cyclase (GC) stimulator or a phosphodiesterase inhibitor, resulted already in cGMP-positive astrocytes mainly in the CA1 area in mouse slices, whereas no cGMPimmunoreactivity was observed under this basal condition in the rat hippocampus. Treatment with an NO synthase inhibitor or inhibitors of soluble or particulate $\mathrm{GC}$, did not result in abolishment of cGMPimmunoreactivity in astrocytes. NO-dependent or NO-independent stimulation of soluble GC in the presence of PDE inhibitors resulted in an increase of cGMP-immunoreactivity in numerous astrocytes throughout the mouse hippocampus, whereas under these conditions in the rat hippocampus cGMP-immunoreactivity was primarily observed in varicose fibers. Comparison of the cellular localization of the $\beta 1$ subunit of soluble GC and the mRNAs of three different cGMP-hydrolyzing phosphodiesterase families (PDE2, PDE5 and PDE9) revealed that in both species the $\beta 1$ subunit of $\mathrm{sGC}$ was observed in pyramidal and granule cells, which also expressed the mRNAs of the three PDE families. Although the $\beta 1$ subunit was detected in astrocytes, none of the cGMP-hydrolyzing PDEs were observed in these cells.

We conclude that although the expression profiles of the $\mathrm{SGC} \beta 1$ subunit and cGMP-hydrolyzing PDEs mRNAs were identical, the cellular patterns of cGMP-immunoreactivity differ between rat and mouse hippocampus. 


\section{Introduction}

In many species varying from slime molds, insects to mammals, $\mathrm{NO}$ is known to be an important modulator of cellular communication (Garthwaite et al., 1988; Garthwaite, 1995; Jacklet, 1997; Bicker, 2001). A major target of NO is soluble guanylyl cyclase ( $\mathrm{GGC}$ or $\mathrm{NOGCR}$ ), which upon stimulation converts guanosine 5'triphosphate (GTP) into guanosine $3^{*}, 5^{\prime}$-cyclic monophosphate (cGMP). cGMP can activate downstream intracellular elements such as cGMP-dependent protein kinases (PKG) (Lohmann et al., 1997), cGMP-gated ion channels (Wei et al., 1998; Biel et al., 1999) and influence the activity of $3^{3}, 5^{3}$-cyclic nucleotide phosphodiesterases (PDEs) (Beavo, 1995; Conti and Jin, 1999; Dousa, 1999; Francis et al., 2001).

In recent years a considerable body of evidence has accumulated indicating a key role for NO and cGMP in specific forms of memory consolidation and/or retrieval. This has been demonstrated in species such as snails (Kemenes et al., 2002), honey bees (Hosler et al., 2000), chicken (Holscher and Rose, 1992; Rickard et al., 1998), sheep (Kendrick et al., 1997), rats (Chapman et al., 1992; Bernabeu et al., 1995; Bernabeu et al., 1997; Prickaerts et al., 1997; Qiang et al., 1997; Blokland et al., 1998; Izquierdo et al., 2000) and mice (Baratti and Kopf, 1996). Our group has presented evidence which indicates that cGMP-hydrolyzing PDEs have an important role in the object recognition task in the rat. Administration of selective PDE5 inhibitors zaprinast, sildenafil or vardenafil increased the memory performance in this task (Prickaerts et al., 1997; Prickaerts et al., 2002). Furthermore, it has been reported that sildenafil can improve retention in a passive avoidance task in mice (Baratti and Boccia, 1999). The precise mechanism of how administration of PDE5 inhibitors can lead to an enhanced memory is unknown, therefore knowledge about the cellular structures involved is a necessary condition. Little attention has been given to possible species differences in relation to the localization of the molecular components of the NO-cGMP signal transduction cascade which might be important when discussing experimental outcomes using transgenic mouse models. Therefore the aim of our study was to investigate the effects of NOdependent and NO-independent activation of $\mathrm{SGC}$ on the cellular localization of cGMP synthesis in rat and mouse hippocampus slices in combination with inhibition of PDE activity. In addition, the localization of the $B 1$ subunit of $\triangle \mathrm{GC}$ and the mRNA expression patterns of three cGMPhydrolyzing PDE families PDE2, PDE5 and PDE9 were compared between rat and mouse hippocampus.

\section{Materials and Methods}

\section{Animals}

Adult Swiss or C57BI mice (aged 12 weeks) and Lewis rats (aged 12 weeks) were obtained from the local animal facility. All experiments were approved 
by the committee on animal welfare according to Dutch governmental rules.

\section{In vitro incubation of hippocampus stices}

Rats and mice were decapitated without anesthesia and the brains were removed immediately and transferred into ice-cold Krebs incubation buffer (Krebs buffer, pH 7.4) of the following composition: 121.1 $\mathrm{mM} \mathrm{NaCl}, 1.87$ $\mathrm{mM} \mathrm{KCl}, 1.17 \mathrm{mM} \mathrm{KH}_{2} \mathrm{PO}_{4}, 1.15 \mathrm{mM} \mathrm{MgSO}, 24.9 \mathrm{mM} \mathrm{NaHCO}, 2.0 \mathrm{mM}$ $\mathrm{CaCl}$ and $11.0 \mathrm{mM}$ glucose, aerated with $5 \% \mathrm{CO}_{2} / 95 \%$ O . Coronal brain slices containing the hippocampal formation $(300 \mu \mathrm{m}$ for mice or $400 \mu \mathrm{m}$ for rats) were cut in aerated ice-cold Krebs buffer using a Vibroslicer (Campden Instruments). Next, slices were equilibrated at room temperature for 15 min in aerated Krebs buffer and thereafter placed in superfusion chambers. The total incubation time was 45 minutes and was performed at $35.5^{\circ} \mathrm{C}$ with a superfusion rate of $1 \mathrm{~mL} / \mathrm{min}$.

The incubation of the slices was performed under a number of conditions. Slices were incubated with $\mathbb{K}$ rebs buffer alone (basal) and the effect of inhibition of PDE activity was investigated by treatment of slices with 3isobutyl-1-methylxanthine (IBMX, $1 \mathrm{mM}$, Sigma-Aldrich Steinheim, Germany), erythro-9-(2-hydroxy-3-nonyl)adenine (EHNA, 0.1 mM, SigmaAldrich), sildenafil (0.1 $\mathrm{mM}$ ) or dipyridamole (0.1 $\mathrm{mM}$, Sigma-Aldrich), which were all present from the start of the superfusion. To inhibit NOS or sGC activity, NG-nitro-L-arginine (L-NAME, $0.1 \mathrm{mM}$, Sigma-Aldrich) or $1 \mathrm{H}$ [1,2,4]oxadiazolo[4,3-a]-quinoxalin-1-one (ODQ, $10 \mu \mathrm{M}$, Tocris Cookson Ltd. Avonmouth, United Kingdom) respectively, were added to the slices at the start of the incubation and were present throughout the entire incubation procedure. Isatin (10 and $100 \mu \mathrm{M}$, Fluka) was added to the slices to investigate inhibition of particulate GC. Superfusion of the slices with the NO donor sodium nitroprusside (SNP) or diethylamino NONOate (DEA/NO) (both $0.1 \mathrm{mM}$, Sigma-Aldrich) or $N$-methy 1 -D-aspartate (NMDA 10, 30, 100 or $300 \mu \mathrm{M}, \mathrm{RBI}$, Natick, MA, USA) was only performed during the last 10 minutes of the incubation. For NO-indlependent stimulation of $\mathrm{sGC}$ slices were incubated with 3-(5'-hydroxymethy 1 -2'furyl)-1-benzylindazole (YC-1, $100 \mu \mathrm{M}$, Alexis, San Diego, CA, USA) or $10 \mu \mathrm{M}$ BAY 41.2272 (BAYER AG. Wuppertal, Germany) in the presence of IBMX, which were all present throughout the entire superfusion period. SNP, DEANO, NMDA, IBMX and L-NAME were dissolved in Krebs buffer, whereas EHNA, sildenafil, dipyridamole, ODQ, isatin, YC-1 and BAY 41.2272 were dissolved in dimethylsulfoxide (DMSO) and yielding a final concentration of $0.5 \%$ DMSO during the incubation. In experiments were substances were dissolved in DMSO, slices were incubated in the presence of $0.5 \%$ DMSO as controls.

\section{Immunocytochemistry}

The incubations were terminated by transferring slices into ice-cold fixative solution of $4 \%$ freshly prepared depolymerized paraformaldehyde for 30 minutes at $4{ }^{\circ} \mathrm{C}$. Then, slices were fixed for another 90 minutes with $4 \%$ paraformaldehyde containing $10 \%$ sucrose. Slices were washed overnight at $4^{\circ} \mathrm{C}$ in $0.1 \mathrm{M}$ phosphate buffer with $10 \%$ sucrose and next the slices were 
frozen in $\mathrm{CO}_{2}$. Cryostat sections $(10 \mu \mathrm{m})$ were cut and thawed on to chromealumn/gelatin-coated slides and processed for immunocytochemistry. Sections were dried for 20 minutes at room temperature followed by three washes with Tris-buffered saline (TBS, $\mathrm{pH}$ 7.6), and thereafter incubated overnight with primary antibodies at $4{ }^{\circ} \mathrm{C}$. To visualize cGMP, sheep anticGMP (1:4000) or rabbit anti-cGMP (1:300) were used. The selectivity of these antibodies has been described previously (De Vente et al., 1989; De Vente et al., 1998). Astrocytes were stained by using a monoclonal antibody against anti-glial fibrillary acidic protein (GFAP) (Sigma) diluted 1:1000. The $\beta 1$ subunit of $\mathrm{sGC}$ was visualized with rabbit antiserum (Behrends et al., 2001) by using dilutions of 1:200 to 1:2000.

All primary antibodies were diluted in TBS containing $0.3 \%(\mathrm{v} / \mathrm{v})$ Triton $\mathrm{X}-100$ (TBS-T). After overnight incubation of the primary antibodies, sections were washed in TBS, TBS-T and TBS, each wash step lasted 10 minutes. Sheep primary antibodies were visualized using Alexa 488 donkey anti-sheep $\operatorname{IgG}(\mathrm{H}+\mathrm{L})$ conjugate (Molecular Probes, Leiden, The Netherlands), diluted $1: 100$ in TBS-T. Monoclonal and rabbit primary antibodies were visualized with 1:800 Cy3-conjugated affinipure donkey anti-mouse IgG (Jackson, Pennsylvania, USA) and 1:100 Alexa fluor 488 goat anti-rabbit IgG conjugate (Molecular Probes) respectively. Sections were incubated with the secondary antibodies for $90 \mathrm{~min}$ at room temperature in the dark. After washing with TBS-T, and TBS, sections were mounted with TBS-glycerol. Sections were analyzed and photographed using an Olympus AX70 microscope equipped with a cooled CCD Olympus Digital video camera F-view (Paes, Zoeterwoude, The Netherlands). Images were stored digitally by using the computer program analySIS@ Vers.3.0. (Soft Imaging System, Münster, Germany) and arranged with the program Adobe Photoshop 5.5.

\section{Image analysis}

For the semi-quantitative measurement of the cGMP content in the mouse hippocampus, sections were immunostained for eGMP as described above, taking into account that all sections from one experiment were processed in one series under identical conditions. Slices from four to seven animals were used for each condition, as indicated in the figure for each condition tested. From each slice, two or three thin sections were stained with the sheep anticGMP antibody. From each section, two pictures from the area containing the pyramidal cells in the CA1 area and stratum radiatum and two images from the dentate gyrus were taken at a magnification of $10 \mathrm{x}$. All pictures were analyzed with the computer program analySIS. For each image, the mean fluorescence intensity was calculated over the entire field as a measure for the cGMP content of the hippocampal area. All measurements were corrected for control sections which were incubated without the primary antibody. To determine whether the compound tested, differed from its control, a Student Newman Keuls test and a Student t-test were used. 


\section{Riboprobe synthesis}

For the in situ hybridization of PDE2, a pBS+ vector containing a part of rat PDE2 (nt 1964-2314, GenBank accession no. NM 031079) was used. This construct (GenBank accession no. M94540) and the specificity of the probe has been previously described (Repaske et al., 1993). The construct was linearized using EcoRI or HindIII, to generate antisense or sense probes with T3 or T7 polymerase, respectively.

The expression of PDE5 was studied by cloning a part of the rat PDE5 sequence (nt 2206-2580, GenBank accession no. D89093) into the SacI and EcoRI sites of a pCRIITOPO vector (Invitrogen). Sense probes were made after BstXI digestion by Sp6 RNA polymerase and antisense probes after linearization with HindIII and $\mathbb{T} 7$ RNA polymerase, as previously described by Kotera et al. (1997).

PDE9 riboprobes were constructed from the mouse PDE9A1 as a template. Primer wvsforw1 (5'ACG CTT GGA TCC ATG GGG GCC GGC TCC TCA-3') containing a BamHI site and primer wvsrev1 (5-GCT TGT ATG CGG CCG CCT GGA GGC CAC AGA GCC AGA CCA T-3') containing a Notl site were used for PCR (nucleotides 10-828 from mouse PDE9A1, AF031147). The PCR product was digested with both restriction enzymes and then the product was ligated into the BamHI and NotI site of a pCRII TOPO vector (Invitrogen). Antisense PDE9 probes were made with T7 polymerase from the pCRIITOPO plasmid linearized with BamHI, while sense probes were produced by Sp6 RNA polymerase after linearization of pCRIITOPO vector with XhoI, as described.

All constructs were analyzed by DNA sequencing before probe synthesis. After restriction digestion of each construct as described above, antisense and sense riboprobes were made from $5 \mu \mathrm{g}$ DNA template by in vitro transcription with digoxigenin (DIG) labeled UTP using a DIG RNA labeling kit (Roche) according to the manufacturer's instructions.

\section{In situ hybridization}

Animals were decapitated and their brains were dissected, frozen in $\mathrm{CO}_{2}$ and stored at $-80^{\circ} \mathrm{C}$ until sectioning. Frozen serial sagittal sections $(14 \mu \mathrm{m})$ were cut and thawed onto SuperFrost Plus slides (Menzel-Glaser, Germany) and stored at $-80^{\circ} \mathrm{C}$ until use. Sections were thawed for $10 \mathrm{~min}$ at $50{ }^{\circ} \mathrm{C}$ and thereafter post-fixed with $4 \%$ paraformaldehyde in $0.1 \mathrm{M}$ phosphate buffered saline (PBS) for $20 \mathrm{~min}$ at room temperature (RT), followed by three short washes with PBS. Then, sections were incubated for $10 \mathrm{~min}$ at RT with $0.1 \mathrm{M}$ triethanolamine containing $0.25 \%(\mathrm{v} / \mathrm{v})$ acetic anhydride. Slides were washed two times with $2 \times$ SSC for $5 \mathrm{~min}$ and thereafter washed at $37^{\circ} \mathrm{C}$ with $2 \mathrm{x}$ SSC containing $50 \%(\mathrm{v} / \mathrm{v})$ formamide before the start of the hybridization.

Hybridization was performed overnight in a humid chamber at $55{ }^{\circ} \mathrm{C}$ under coverslips in 100-200 $\mu \mathrm{l}$ hybridization mix $(50 \%(\mathrm{v} / \mathrm{v})$ cleionized formamide, $250 \mu \mathrm{g} / \mathrm{ml}$ salmon sperm DNA, $1 \mathrm{mg} / \mathrm{ml} \mathrm{tRNA}, 10 \%$ dextran sulfate, $2 \times$ SSC, $1 \times$ Denhardt's solution and 200-400 ng/ml DIG-labeled RNA probe). After the hybridization, sections were washed in 2x SSC, 1x SSC and 
$0.1 \times$ SSC, all solutions containing 50\% formamide. Each wash step was performed at $55^{\circ} \mathrm{C}$ and lasted $20 \mathrm{~min}$. Next, to eliminate single stranded (unhybridized) probe, the sections were treated with RNAse T1 (2 U/ml, Roche) in $2 \mathrm{x}$ SSC containing $1 \mathrm{mM}$ ethylenediaminetetra-acetate (EDTA) for $15 \mathrm{~min}$ at $37^{\circ} \mathrm{C}$ followed by a 20 min wash with $1 \times \mathrm{SSC}$ at $55^{\circ} \mathrm{C}$. After washing for 10 min with $2 \times \mathrm{SSC}$ at $\mathrm{RT}$, sections were incubated for $5 \mathrm{~min}$ with buffer $1(150 \mathrm{mM} \mathrm{NaCl}$ and $100 \mathrm{mM}$ maleic acid ( $\mathrm{pH} 7.5)$ ) followed by blocking for $2-3$ hrs at RT with buffer $2(150 \mathrm{mM} \mathrm{NaCl}, 100 \mathrm{mM}$ maleic acid ( $\mathrm{pH} 7.5)$ and $1 \%$ blocking reagent (Roche, \#1096176)) containing 5\% sheep serum. Next, slides were incubated overnight at $4{ }^{\circ} \mathrm{C}$ with a $1: 2000$ dilution of anti-DrG-alkaline phosphatase in buffer 2 containing $1 \%$ sheep serum. Thereafter, slides were washed three times with buffer 1 followed by washing for $10 \mathrm{~min}$ with Tris-buffered saline (TBS) containing $0.025 \%$ Tween 20 and thereafter, three times $5 \mathrm{~min}$ with TBS. After two washes of 5 min in buffer $3(100 \mathrm{mM}$ Tris-HCl $(\mathrm{pH} \mathrm{9.5),0.1} \mathrm{M} \mathrm{NaCl}$ and $0.05 \mathrm{M} \mathrm{MgCl})$, the sections were incubated with freshly prepared nitro-blue tetrazolium and 5-bromo-4-chloro-3-indolyl-phosphate in buffer 4 (50 mM Tris (pH 9.5), $100 \mathrm{mM} \mathrm{NaCl}, 50 \mathrm{mM} \mathrm{MgCl}, 1 \mathrm{mM}$ levamisole) and stained for 1.2 days in the dark at RT. The buffer was replaced by fresh buffer after the first day. The color reaction was stopped with $10 \mathrm{mM}$ Tris- $\mathrm{HCl}$ and $1 \mathrm{mM}$ EDTA (pH 8.0). After washing in TBS, sections were double labeled with cellular markers to visualize in which cell types PDE mRNA was expressed. Neurons were visualized with mouse anti-neuronal nuclei (NeuN) (Chemicon Intemational, Temecula, CA, USA) dilluted 1:50 in TBS-T and. astrocytes were stained with a polyclonal antibody directed against GFAP (diluted 1:25) which was kindly donated by Dr. F. Ramaekers (Maastricht, The Netherlands), using the staining protocol as described above.

\section{Results}

To compane cGMP immunoreactivity (cGMP-IR) patterns in hippocampal slices between rats and mice, the same experimental protocol was used for both species. Since cGMP-IR in rat hippocampus slices incubated in vitro has been described in detail previously (De Vente and Steinbusch, 1992; De Vente et al., 1996; De Vente et al., 1998; Van Staveren et al., 2001) results obtained with rat hippocampus slices will be presented here only in brief.

\section{Basal condition (absence of any drug)}

cGMP.IR was completely absent in the rat hippocampus slice incubated under basal conditions (Fig. 1C). This was in contrast to the results obtained with mouse hippocampus slices, where cGMP-IR was localized in astrocytes (Fig. 1A), as confinmed by double labeling with the glial cell marker GFAP (Fig. 1B). cGMP.IR in astrocytes was observed in stratum oriens and stratum radiatum allong the CAl pyramidal cell layer under basal conditions. Only a few astrocytes were observed along the CA2-CA3 area and in the dentate gyrus, showing less intense cGMP-IR when compared to 
the cGMP-IR astrocytes in the CAI area. Antibodies raised against cGMP in sheep or in rabbits gave identical staining patterns (not shown). The observation of cGMP-IR astrocytes after incubations under basal conditions was made in both Swiss and C57Bl mice.
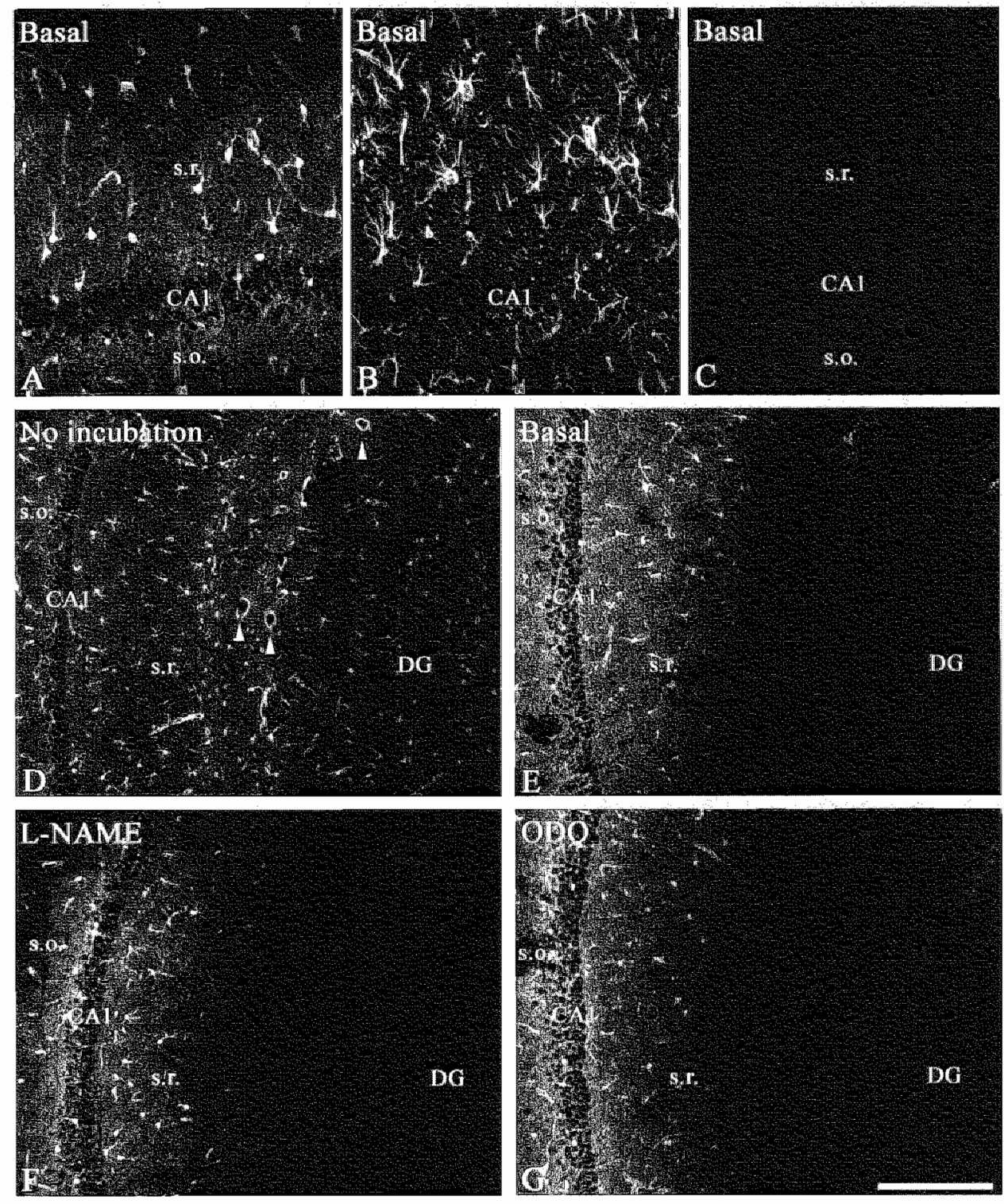

Figure 1. cGMP.IR in mouse $(A$, and $D-G$ ) or rat (C) hippocampes shices incubated in titn under the conditions as indicated in the left upper corner of each photograph. Section shown in A was double immunostained for GFAP as shown in B. Pictures D.G were obtained from the same anmal, and photographed under identicall settings. Bar indicates $100 \mu \mathrm{m}$ for $A-C$ and 200 $\mu \mathrm{m}$ for D-G. DG, dentate gyrus; s.o., stratum oriens; s.r., strutum radiatum. Arrowheads indicate blood vessels. 
As these results were obtained with slices that had been incubated without PDE inhibitors, we investigated if the cGMP.IR in astrocytes was already present before the start of the incubation period. Therefore, slices were immediately fixed with paraformaldehyde after slicing, and as shown in Figure 1D, cGMP.IR astrocytes were already observed in all regions of the hippocampus. In addition cGMP-IR was clearly present in blood vessels walls.

To investigate if the cGMP-IR already present after incubation of the slices under basal conditions was NO-mediated, slices were incubated in the presence of the NOS inhibitor L-NAME $(0.1 \mathrm{mM})$ or the $\mathrm{SGC}$ inhibitor ODQ (10 $\mu M$ ) (Fig. 1F-G). cGMP.IR was completely abolished in the CA3 region and the dentate gyrus after treatment with each of the compounds, nevertheless, cGMP-IR in astrocytes could still be detected in the CA1 region (Fig. 1F-G). Comparison of basal incubations with slices treated with L NAME or ODQ revealed that astrocytic ramifications were more pronounced in the CA1 area under basal conditions.
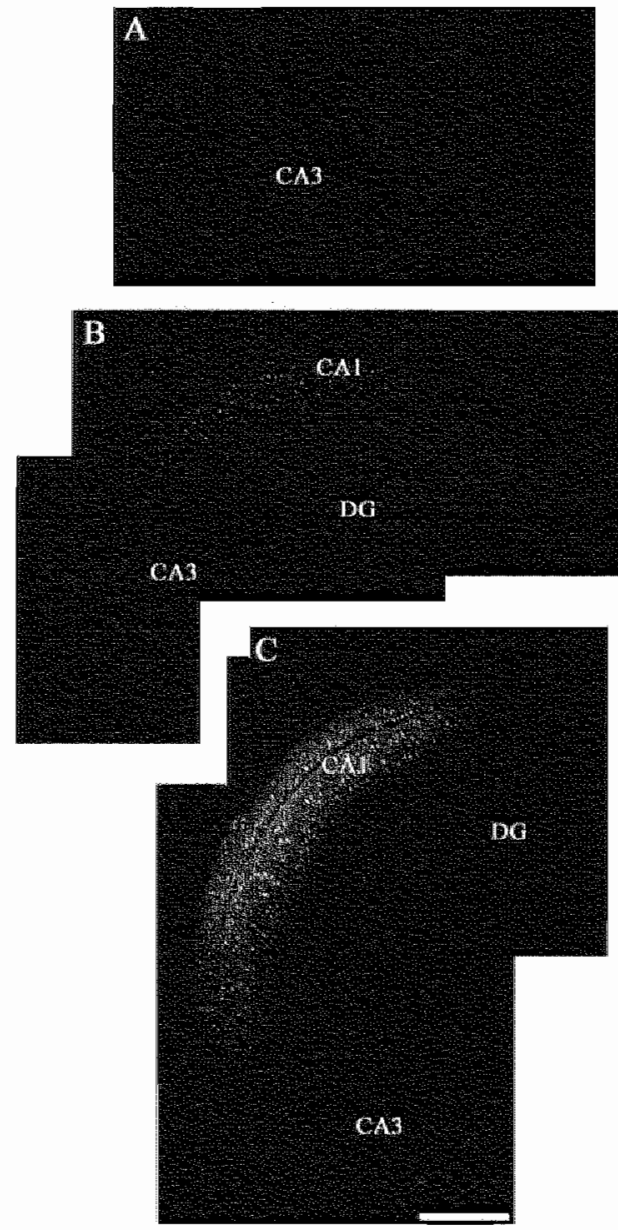

Figure 2. cGMP-IR in mouse hippocampus slices incubated under basal conditions. The hippocampus was sliced from Bregma -0.94 (rostral) to Bregma $-2.92 \mathrm{~mm}$ (caudal). Three cononal sections (indicated $A-C$ ) are shown at different rostrocaudal levels. Al pictures were taken at a magnification of $4 \mathrm{x}$ undel identical settings. Pictures were assembled by the use of Adobe Photoshop and depicted without further processing. Bar indicates $500 \mathrm{um}$ for all pictures. DG, dentate gyrus. 
To examine if the cGMP-immunoreactivity under basal conditions was due to activation of the particulate $\mathrm{GC}$, slices were incubated with different concentrations of isatin (10 and $100 \mu \mathrm{M})$. After incubations with isatin cGMP-immunoreactivity was not different from basal slices (not shown).

Astrocytes were observed after incubation of the slices under basal conditions, it was also found that the intensity of the cGMP-IR and the extend of the immunostaining in the CAl region was variable depending on the position of the slice related to Bregma. To investigate this in more detail the entire hippocampus was sliced from rostral to caudal and all slices were incubated under basal conditions. As shown in Figure 2, the number of CGMP-IR astrocytes along with the increasing length of the CAI region in the slices increased in the rostral-caudal direction.
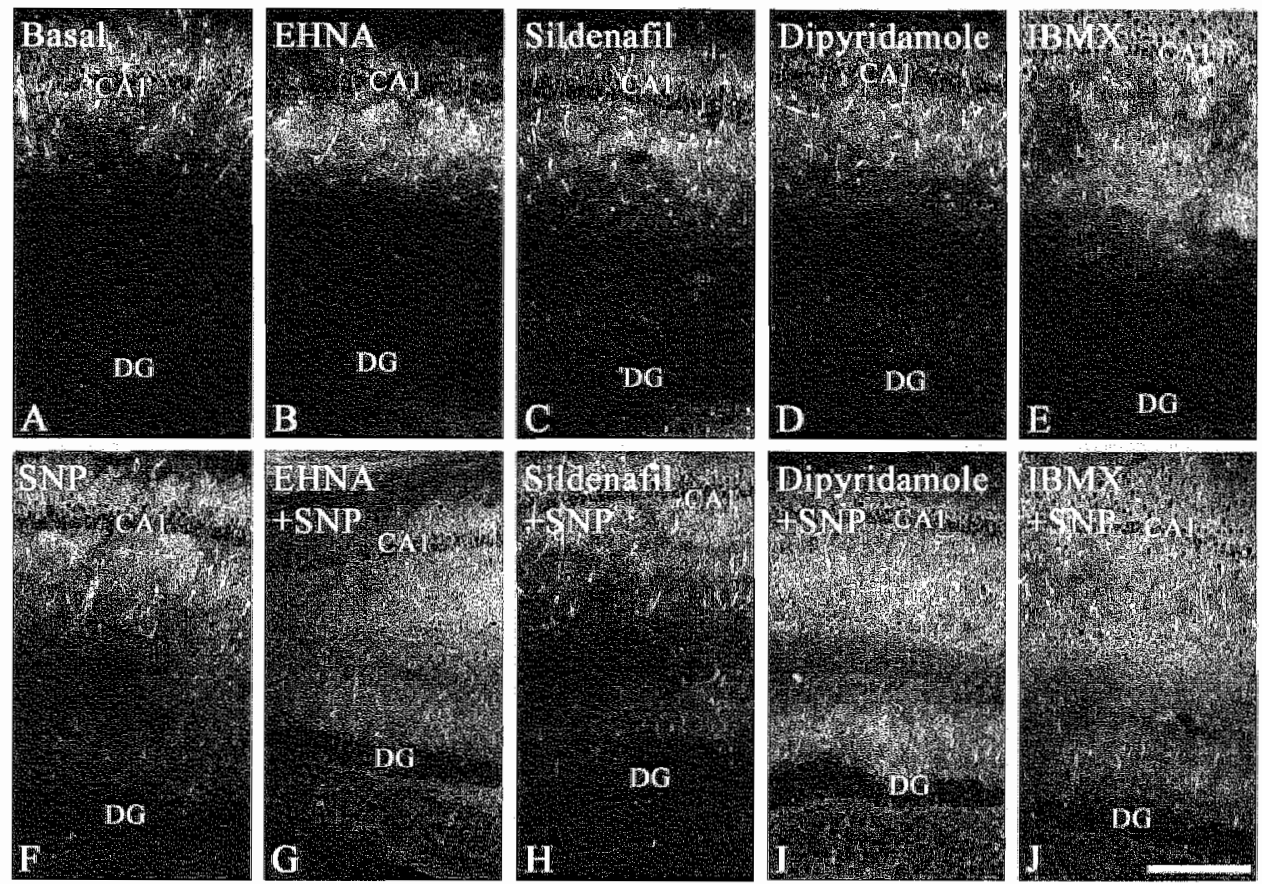

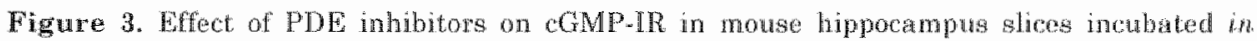

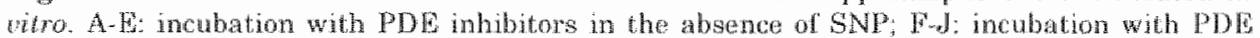
inhibitors in combination with SNP (0.1 mM). All inhibitors were used in a concentrathon of 100 HM, with the axception of IBMK which was $1 \mathrm{mM}$ Bar indicates 200 frn for all pictures. DG, dentate gyms.

\section{Effect of PDE inhibitors on CGMP-IR in the absence or presence of an NO} donor

We studied the effects of the PDE inhibitiors EHNA, sildenafil, dipyridamole and IBMX on cGMP accumulation in slices incubated in the absence or presence of an NO donor. In the presence of each of the PDE 
inhibitors cGMP.IR was observed in astrocytes in the region of the stratum oriens and stratum radiatum bordering on the CAl pyramidal cell layer (Fig. 3A-E). Stimulation of $\mathrm{SGC}$ with $0.1 \mathrm{mM}$ of the NO donors SNP (Fig. 3F) or DEA/NO (not shown) alone, resulted in an increase of the surface area in which cGMP-IR was observed (Fig. 3F). Combination of an NO donor with a $\mathrm{PDE}$ inhibitor resulted in a further increase in the area in which cGMP-IR could be observed (Fig. 3G-J). In the rat, incubation of hippocampus slices with the combination of IBMX and SNP resulted in an abundant cGMP-IR in varicose fibers and wealk cGMP.IR in astrocytes (compare Fig. $6 \mathrm{~B}$ with Fig. 6D).

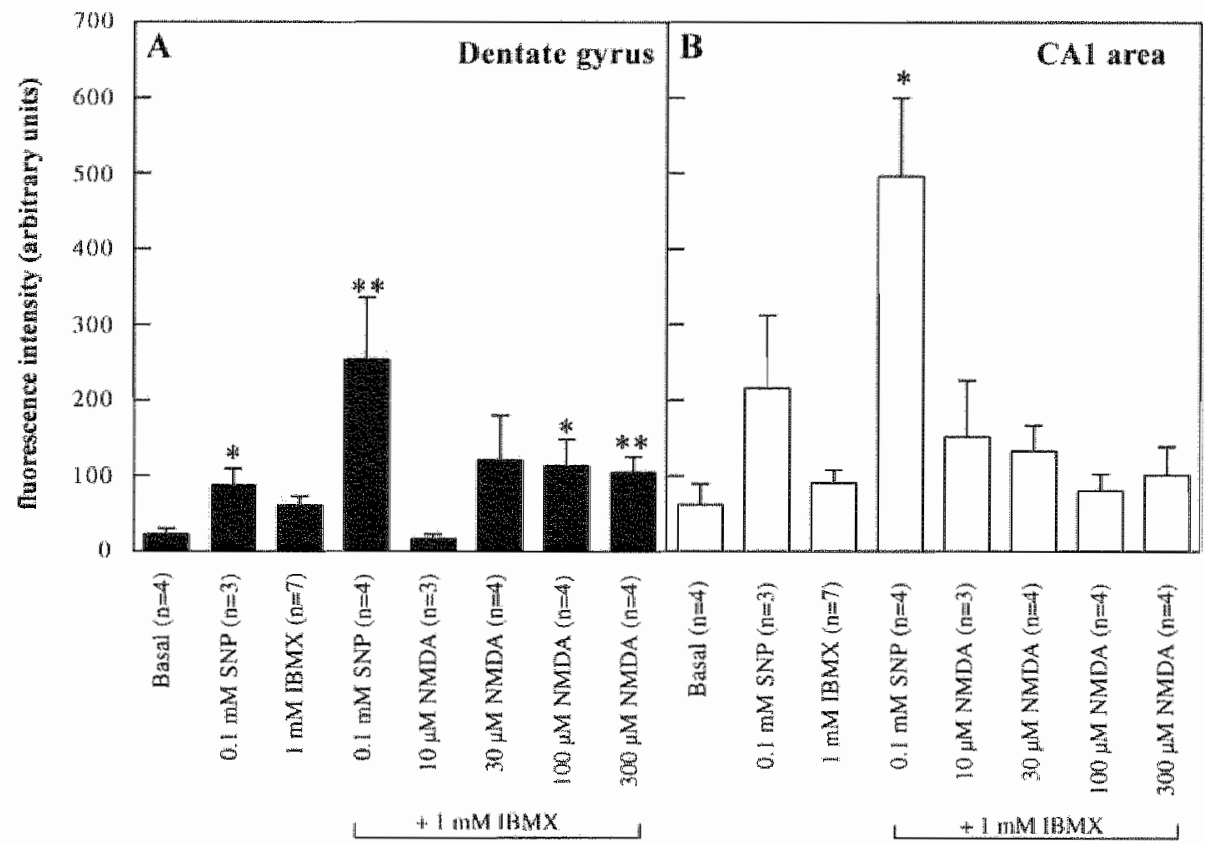

Figure 4. CGMP" levels in the dentate gyrus $(A)$ and CA1 area (B) of mouse hippocampal slices. Fluorescenee intensities were measured by image analysiss after ineubation of the slices under the indicated conditions. Each walue is the mean (+ S.E.M.) of three to seven animals, as indicated for each condition. from each animal two or three sections were analyzed as described in the Materials and Methods. Values which were different from basal are marked with ** $(\mathrm{P}<0.01)$ or * $(\mathrm{P}<0.05)$.

The effects of SNP, IBMX or their combination on cGMP accumulation, was determined in the hippocampus using semi-quantitative analysis of cGMP-immunofluorescence intensity. Measurements of cGMPimmunofluorescence in hippocampus tissue sections were done separately in CA1 and in dentate gyrus. As shown in Figure 4, under basal conditions, cGMP-immunofluorescence was 2.7 -fold higher in the CA1 area compared to 
the dentate gyrus. Measurement of cGMP-immunofuorescence after incubation of the shces with SNP revealed that cGMP-immunofluorescence was increased 3.8 -fold in the dentate gymus compared to basal, whereas no significant increase was measured in the $C A 1$ region. Inhibition of PDE activity with IBMX (1 $\mathrm{mM}$ ) did not result in increased cGMPimmunofluorescence whereas caadministration of IBMX and SNP to the slices resulted in an average increase of 11.1 -fold in the dentate gyrus and of 8.1-fold in the CAl area.

NMDA receptor activation has been linked to stimulation of NOS activity. Therefore, the effect of incubation of the slices in the presence of different doses of NMDA in the presence of IBMX $(1 \mathrm{mM})$ was evaluated on cGMP-immunofluorescence. A significant increase in cGMP. immunofluorescence under these conditions was found only at the two highest doses of NMDA in the dentate gyrus.
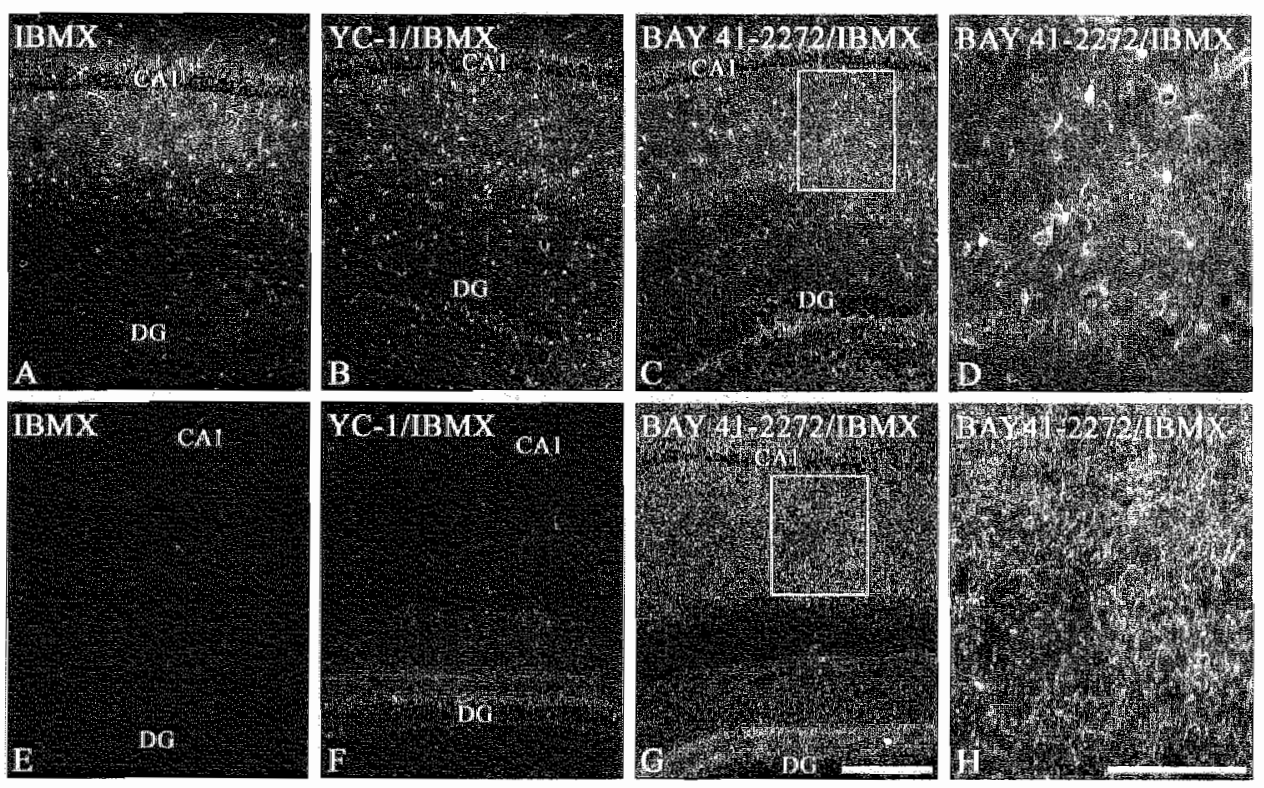

Figure 5. cCMP-TR in monse (A-D) and rat (E H) hippocampus slices after in whto inctabuton of the slices with $1 \mathrm{mM}$ IBMX alone or in combination with the No-independent eGC activators YC.1 (100 MM) or BAY 41.2272 (10 HM). D and H are enlargements of the boxed areas in $\mathrm{C}$ and G respectively. Bar indicates $200 \mu m$ for $A-\mathrm{C}$ and $\mathrm{F}_{\mathrm{A}} \mathrm{G} ; 100$ un for $\mathrm{D}$ and $\mathrm{H}$. DG, dentate grys.

\section{NO-independent stimulation of $\mathrm{s} C \mathrm{C}$}

Mouse and rat hippocampus slices were incubated with the NO-independent SGC stimulators $\mathrm{YC}-1(100 \mu \mathrm{M})$ or $\mathrm{BAY} 41-2272(10 \mu \mathrm{M})$ in combination with IBMX (1 $\mathrm{mM}$ ) (Fig. 5). Addition of $\mathrm{YC}-1$ to hippocampus shees increased CGMP-JR in both mouse and rat slices. Under these conditions, cGMP-IR astrocytes were observed throughout the mouse hippocampus 
slices. A similar observation was made for the effect of BAY $41-2272$ on cGMP.R, however at a tenfold lower concentration. Both compounds also increased eCMP-IR in blood vessel walls of mouse hippocampus slices. In contrast to mouse hippocampus, addition of NO-independent stimulators to rat hippocampus slices resulted in cGMP-IR varicose fibers throughout the slices, with BAY 41-2272 being more potent than YC-1. Neither NOdependent nor NO-independent stimulation of $\mathrm{SGC}$ was observed in pyramidal cells in both species (Fig. 5). Nevertheless, $s \mathrm{GC}$ BI subunit was present in pyramidal cells (Fig. 6) in both mouse and rat hippocampus. In addition, the $\beta 1$ subunit was visualized in astrocytes in the hippocampus of both species which were also cGMP-IR (Fig. 6). Granule cells of the hippocampus showed a punctate staining for the 11 subunit (not shown) however, cGMP-IR was not observed in these cells.
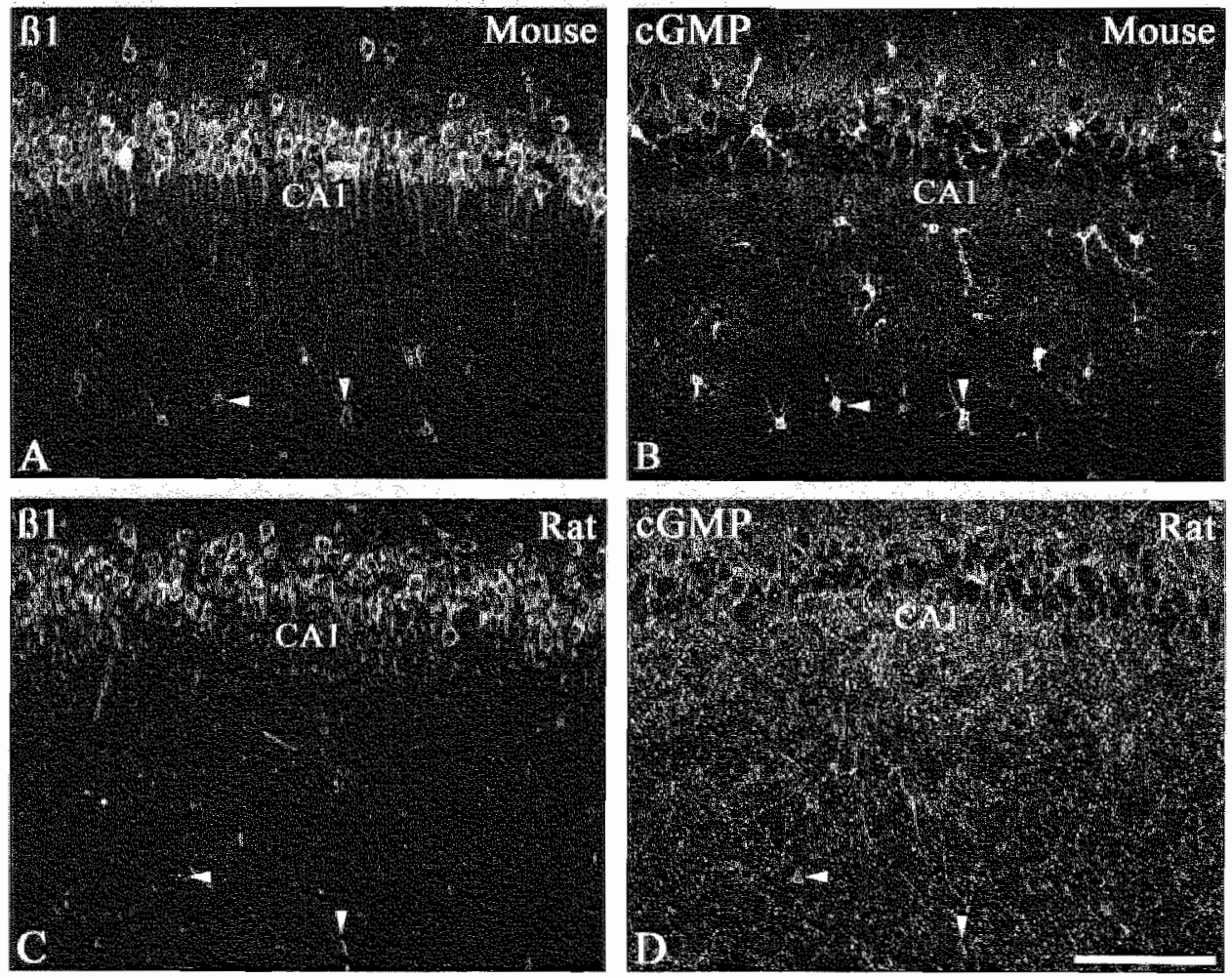

Figure 6. Localization of $\mathrm{SGC}$ pl subunit in combination with CGMP-IR in mouse $(\mathrm{A}, \mathrm{B})$ and rat. (C, D) hippocampus, after incubation of the slices with $1 \mathrm{mM}$ IBMX in combination with SNP. Bar indicates $100 \mu \mathrm{m}$ for all pictures. Arrowheads indicate astrocytes, double immenostained for the $\beta 1$ subunit and cGMP.IR. 
mRNA expression of CGMP-hydrolyzing PDEs in the hippocampus

To investigate if the differences as observed between rat and nouse cGMP. IR in the hippocampus might be caused by differences in the expression of cGMP-hydrolyzing PDEs, a non-radioactive in situ hybridization was performed for PDE2, PDE5 and PDE9 on hippocampus sections from both species (Figs. 7 and 8). PDE2, PDE5 and PDE9 mRNAs were expressed in pyramidal cells of CA1 to CA3 and in granule cells in the dentate gyrus in both rats and mice. Furthermore, in other regions of the hippocampus of both species isolated cells were observed which expressed the mRNA of one of the three cGMP-hydrolyzing PDEs. These mRNA expression patterns did not differ between both species. No specific signal was found after incubation of sections with corresponding sense probes (Fig. 7G). Double labeling of the sections with the neuronal marker. NeuN or the glial cell marker GFAP, revealed that the PDE mRNAs were double labeled with NeuN but not with GFAP in both species (Fig. 8).

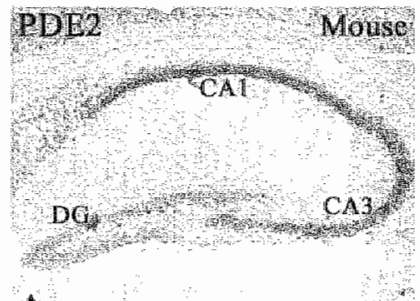

A
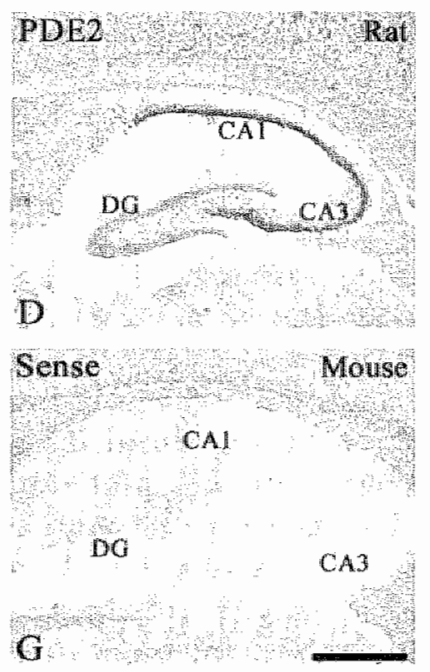
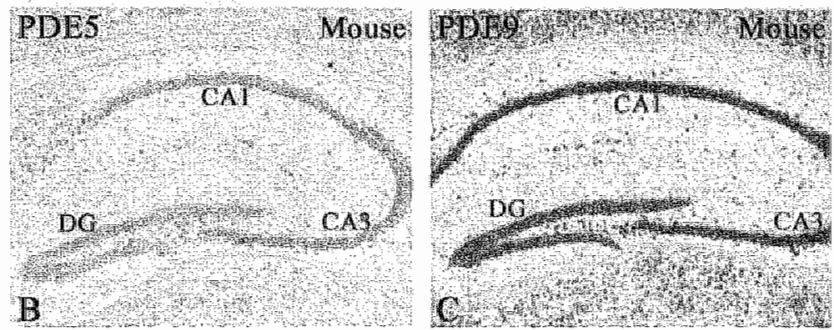

(1)
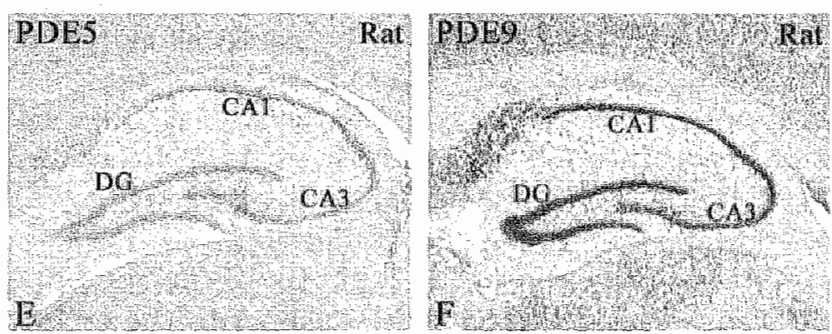

Figure 7. Fixpression of PDED, PDEs and Plotes mRNAs in

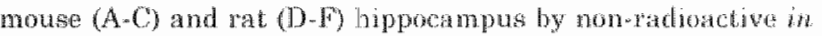
situ hybridization. Soctons in $A$ and $D$ ware hylurdized with PD les antisense probes, B and Eith PDE5 antiscrse probes and $\mathrm{C}$ and $\mathrm{F}$ with $\mathrm{PDE} 9$ antisense probes. In $C$, hybrialization whit sense probe is shown on mouse hippocampus. Par

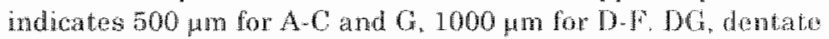
gyrasis. 

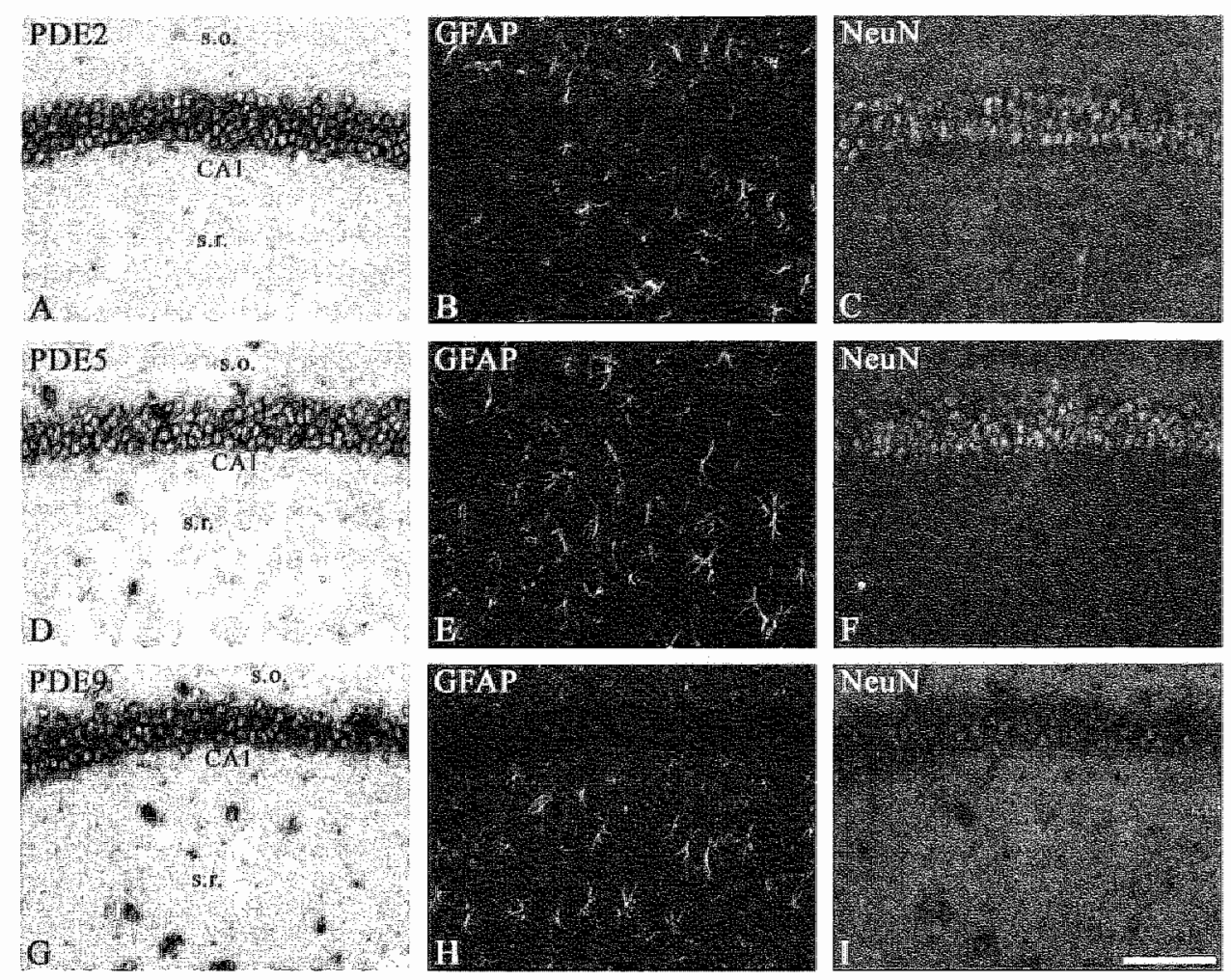

Figure 8. Characterization of cells in the mouse hippocampus expressing PDE2, PDE5 and PDES mRNAs. Sections were double immunostained on the same section for GPAP (B, $\mathrm{E}, \mathrm{H})$ and NeuN (C, F, I). Bar indicates $100 \mu \mathrm{m}$ for all pictures. s.o., stratum oriens; s.r., stratum radiation.

\section{Discussion}

Here we demonstrated that there is a remarkable species difference between mouse and rat with respect to the cellular localization of cGMP-IR in the hippocampus. Especially striking is the intense cGMP-IR in astrocytes in the mouse hippocampus under basal conditions which, using rat hippocampus slices does not result in cGMP-immunostaining at all. This observed species difference under basal conditions can be probably explained by differences in cGMP degradation rate between rat and mouse hippocampal astrocytes. There are mainly four arguments for this conclusion. First, the presence of cGMP-IR in astrocytes of mouse hippocampus slices which were fixed immediately after the slicing procedure and the presence of cGMP-IR after incubation under basal conditions, strongly suggests that cGMP was not totally degraded in all astrocytes. Second, if the presence of cGMP.IR astrocytes would be caused by exceptionally high activity of $\mathrm{sGC}$ in these cells, then it was expected that incubation of the slices in the presence of L-NAME or ODQ should abolish 
all cGMP-IR, which was not observed in our experiments. Third, addition of the particulate guanylyl cyclase inhibitor isatin did not result in abolishment of cGMP.IR. Fourth, in the presence of PDE inhibitors, cGMP. IR astrocytes were observed throughout the whole hippocampus, indicating cGMP hydrolysis could be prevented in astrocytes outside the CAl region.

The observation that after basal incubations, cGMP.IR astrocytes were mainly present in the CA1 area whereas in immediately fixed slices these astrocytes were present throughout the whole hippocampus (Fig. 1 D versus 1E) indicates regional differences in cGMP metabolism in hippocampal astrocytes. This was clearly illustrated by the observation that after basal incubation, cGMP-IR was more intense and extended in the CA1 region of the caudal mouse hippocampus compared to the rostral levels. In contrast; we have never observed a rostral-caudal gradient in CGMP.IR in the rat hippocampus. We reported previously that rat hippocampal astrocytes show cGMP-IR depending on the incubation conditions, and furthermore that the large majority of these astrocytes contain both soluble and the particulate form of GC (De Vente and Steinbusch, 1992; Teunissen et al., 2001; Van Staveren et al., 2001).

The rostral-caudal gradient in cGMP-IR in the mouse hippocampus resulted in large variation of our semi-quantitative studies of the effects of an NO donor and NMDA stimulation of cGMP synthesis in the CA1 region. Nevertheless, intensity of the cGMP-IR increased significantly in the CAI area after treatment of the slices with $0.1 \mathrm{mM}$ SNP in the presence of IBMX. In the dentate gyrus, both NMDA and SNP in the presence of IBMX significantly increased cGMP synthesis. In contrast, in rat hippocampus we did not observed any effect of treatment of slices with NMDA. The reason for this difference is not clear.

It is a striking observation that, depending of the PDE inhibitor used, the cGMP-IR varicose fibers, which are always observed in the rat brain slices (De Vente et al., 1998; Van Staweren et al., 2001) were not detectable in a similar way in the mouse, which only showed occasionally fow cGMP-IR varicose fibers. Also, the combined presence of the $\mathrm{NO}$-independent $\mathrm{SGC}$ stimulators and IBMX, resulting in strong effects on cGMP synthesis in rat brain tissue, did not result in an abundant cGMP-IR in varicose fibers in the mouse hippocampus.

A similar observation for both species was that no cGMP.IR was observed in pyramidal cells in the CA1-CA3 layer or in granule cells of the dentate gyrus. As the $\mathrm{SGC} \beta 1$ subunit is present in these cells, cGMP synthesis in these cells might be expected. However, the presence of the $\beta 1$ subunit in these cells is not a guarantee for the presence of an active $\mathrm{SCC}$ in these cells. In astrocytes in the stratum oriens or the stratum radiatum of both species, we observed the presence of the $\beta 1$ subunit in CGMP-IR astrocytes. However, no immunoreactivity of the $\mathrm{SGC} \beta 1$ subunit could be observed in cGMP-IR varicose fibers in rat, where the activity of the enzyme would be expected. Burette et al. (2002) have reported that $\mathrm{sGC}$ is localized in synapses in the rat stratum radiatum and dependent on the fixation. procedure used. An explanation for the lack of $\mathrm{sGC}$ in these structures in 
our experiments might be the fixation procedure used. However, it might also be explained by epitope shielding (Kummer et all, 1996) due to for instance the interaction of $\mathrm{SGC}$ with the postsynaptic density protein-95 (PSD-95) and resulting in the unavailability of the epitope (Burette et al., 2002).

To investigate the difference between rats and mice in cellular localization of cGMP-immunoreactivity, we decided to investigate cGMP degradation in more detail by comparison of the $\mathrm{mRNA}$ expression patterns of three cGMP-hydrolyzing PDE families since they critically determine cGMP levels in cells. Strikingly, neither in mouse nor in rat, these mRNAs were detected in astrocytes. These findings suggest that in astrocytes cGMP is not degraded by these PDE families. Strong mRNA expression of cGMP. hydrolyzing PDEs was observed in the cell bodies of CA1-CA3 and in granule cells of the dentate gyrus in both rat and mouse hippocampus. A similar finding between rat and mouse hippocampus is the absence of cGMP-IR in pyramidal and granule cells. The presence of high PDE activity might explain the lack of cGMP.IR in these cells in both species, since the mRNAs of PDE2, PDE5 and PDE9 mRNAs are expressed in these cells which also express other members of the PDE superfarmily (Kincaid et al., 1987; Furuyama et al., 1994; Iwahashi et al., 1996; Reinhardt and Bondy, 1996; Miro et al., 2001). Although the mRNA expression patterns give an indication of the presence of a PDE family, it does not give a straightforward answer on the presence of the PDE protein and the cGMP-hydrolyzing activity of the PDE family. Furthermore, differences in expression of other cGMP-hydrolyzing PDEs cannot be excluded. Of the eleven PDE families known to date, PDE1, PDE2, PDE5, PDE6, PDE9, PDE10 and PDE11 are able to hydrolyze cGMP. Based on reported findings that PDE6 is a photoreceptor (Gillespie and Beavo, 1988), PDE10 was observed only in striatum and olfactory tubercle (Fujishige et al., 1999) whereas PDE11 was detected only in pituitary (Fawcett et al., 2000; Yuasa et al., 2000) these three cGMP-hydrolyzing PDE families were excluded in our study. Furthermore, we did not include PDE1 in our study based on our earlier finding that the PDEI inhibitor vinpocetine was without effect on cGMP accumulation in rat hippocampus (Van Staveren et al, 2001). A more detailed analysis of PDE protein and activity of the different PDE families will be necessary to elucidate the differences in the cellular localization of cGMP synthesis between rat and mouse hippocampus.

Recently it was demonstrated by Bon and Garthwaite (2003) that low concentrations of NO are necessary to induce long-term potentiation (LTP) after short tetanus stimulation and to maintain late phase LTP after high frequency stimulation. It was also shown that facilitation of LTP by exogenous NO required a tonic level of endogenous NO. Endogenous NO synthesis is present in our rat hippocampus slices. Using cGMP. immunocytochemistry, we have demonstrated previously the endogenous NO-synthesis in the rat hippocampus slice preparation although this required the presence of IBMX (Van Staveren et al., 2001). In the rat CAI and CA3 regions this results in measurable and immunocytochemically 
detectable cGMP-IR, localized mainly in varicose fibers in the stratum lacunosum moleculare and $\mathrm{CA} 3$ region. In the mouse hippocampus, endogenous NO synthesis also occurs (see Fig. 1).

The functional significance of the observed differences in the localization of NO-mediated CGMP between rats and mice is not evident at this moment. Although there is ample evidence suggesting that both NO and cGMP are involved in LTP formation (Bohme et al., 1991; Zhuo et al., 1994; Lu et al., 1999; Bon and Garthwaite, 2003), other groups have also reported that this pathway is not involved in LTP (Bannerman et al., 1994; Cummings et al., 1994, for review see Prast and Philippu, 2001). However, it has been suggested that this can be dependent on the protocol (Son et al., 1998) or animal strain (Holscher, 2002) used. Nevertheless, it is interesting to note that the LTP-inducing stimulus in mice has been reported to be less by half compared to rat hippocampus slices (Namgung et at., 1995).

The involvement of the components of the NO-cGMP signaling pathway in LTP has been investigated using mice genetically modified for the enzymes involved in cGMP-signaling such as NOS or PKG knock-out mice (O'Dell et al., 1994; Son et al., 1996; Kleppisch et al., 1999; Wilson et al., 1999). With respect to the differences we have observed in the cellular localization of NO-mediated cGMP signaling between mouse and rat hippocampus, these results suggest that this observation has to be taken into account evaluating results on NO-cGMP signaling obtained in rats and mouse hippocampus.

\section{Acknowledgments}

The authors would like to thank Drs. J. Kotera and K. Omori for the PDE5 plasmid and Drs. M. F. Goy and D.R. Repaske for the PDE2 construct.

\section{References}

BANNERMAN DM, CHAPMAN PF, KELLY PA, BUTCHER SP, MORRIS RG. (1994) Inhibition of nitric oxide synthase does not prevent the induction of long-term potentiation in vivo. I Neurosci 14: 7415-7425.

BARATTI CM, KOPF SR. (1996) A nitric oxide synthase inhibitor impars memory storage in mice. Neurobiol Learn Mem 65: 1.97-201.

BARATTI CM, BOCCIA MM. (1999) Effects of: sildenafil on long-term retention of an inhibitory avoidance response in mice. Behav Pharnacol 10: 731-737.

BEAVO JA. (1995) Cyclic nucleotide phosphodiesterases: functional implications of multiple isoforms. Physiol Rev 75: 725-748.

BEHRENDS S, KEMPFERT d, MIETENS A, KOGLIN M, SCHOLZ H, MIDDENDORIF R. (2001) Developmental changes of nitric oxide-sensitive guanylyl cyclase expression in pulmonary arteries. Bhochem Biophys Res Commun 283: 883-887.

BERNABEU $R$, DE STEIN ML, FIN C, IZQUIERDO I, MEDINA JH. (1995) Role of hippocampal $\mathrm{NO}$ in the acquisition and consolidation of inhibitory avoldance learning. Neuropeport 6: $1498-1500$. 


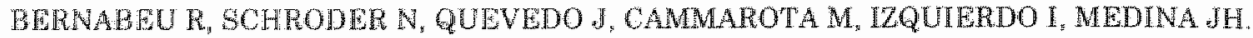
(19g7) Further evidence for the infolvement of a hipocampal cGMP/cGMP-dependent protem kinase cascade in manony consolidation. Neuroreport 8: 2221-2224.

BICKER C. (2001) Sources and targets of nitric oxide signalling in insect newous systems. Ceh Thisue leses $303: 187-146$

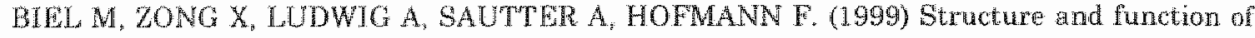

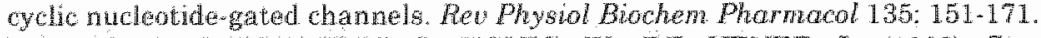

BLOKIAND A, PRICHARTS J, HOWHG W, DF VENTE J (1998) Statemependent impairment in object recognition after hippocampal Nos inthibution. Neuroreport $9: 4205$ 4208.

BOHME GA, BON C, STUTZMANM JM, DOBLE, A, BLANCHARD JC. (1991) POssible involvenent of nitric oxide in long-tern potentiation. Eur f Phornacol 199: 379-381.

BON GI, GARTHWAITE $\%$ (2003) On the role of nitric oxide in hippocampal long-tem poitentiation. of Netrosé $23: 1941-1948$.

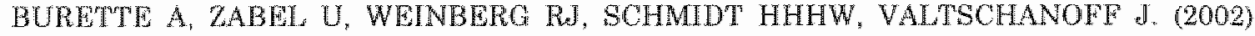
Synapic localization of ritric oxide synthase and soluble guanylyt cyclase in the hippocampus. Neusosci 22: 8961.8970 .

CHAPMAN PF, ATKINS CM, ALLEN MT, HALEY JE, STEINMETZ IE. (1992) Inhibition of nitric oxide synthesis impairs two differemt forms of leaming. Neuroreport $3: 567-570$.

CONT M, JN SH. (1999) the molecular biology of cyclic nucleotide phosphodiesterases. Prog Nuchere Acid Res Mol Biol 63: 1-38.

CUMMINGS JA, NICOLA SM, MALENLA RC. (1994) Induction in the rat hippocampus of longrem potentiation (LTP) and long-term depression (LTD) in the presence of a nitric oxide synthage inhibitor. Norrosed Lett 176: 110-114.

DE WTHE distinct celluar pook and theils recognition by different eGMP-antisera. An. immunocytochemical study into the problem of serum specificity. Histochemistry 91: 401. 412

DE VENTE I. STEINBUSCH HWM. (1992) On the stimulation of soluble and particulate guanylate cyclase in the rat brain and the inwolvement of nitric oxide as studied by COMP immunocytochemistry. Acta Histachen. 92: 13 -38.

DE VENTE J, HOPKINS DA, MARKERINK-VAN ITTERSUM M, STEINBUSCH HWM. (1996) liffects of the 3',5 phosphodiesterase inhibitors isobulylmethylxanthine and zaprinast on NO-mediated cCMP accumulation in the hippocampus slice preparation: an immonocytochemical study. I Chem Newrowat 10:241-248.

DE VENIE $J$, HOPKINS DA, MARKERTMWVAN ITTERSUM M, IMSON PC, SCHMIDT HWHW, STEINBUSCH HWM. (1998) Distribution of nitric oxide symthase and nitric oxidenecopive, cyctic GMP-producing structures in the tat brair. Newosctence $87.207-241$.

DOUSA "IP. (1999) Cyclic-3" b-molewtide phosphodiesterase isozymes in cell biology and prothophysology of the kidney. Fidney $17.55: 29-62$.

WAWODT I. BAXENDALER, STACEY P, MCGROUTHER C, HARROW I, SODERLING S,

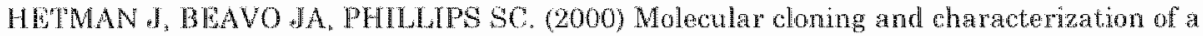
distmet human phosphodiesterase gane family: PDEIA. Proc Nath Acad So U $S$ A 97 37025007

MRANCIS SH, TURKO IV, CORDIN d. (2001) Cyclic Nucleotide phosphodiesterags: regulating siructure and furction. Prog Nuclero Achd Res Mol Biol 65: 1-52.

FU.ISHIGE K. KOTERA J, OMORI K, (1999) Stratum-and testis-specifie phosphodiesterase

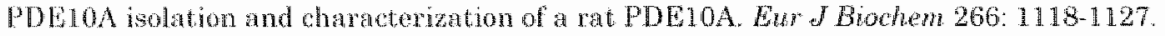

FURLYAMA T. WAHASHI Y, "HNO Y, TAKAGI H, WNAGARI S. (1994) Localization of 63kDn olmodulinstimulated phosphodiesterase mRNA in the rat bran by in situ Iybuidation histochemistry. Bram Res Mol Bran Res 26:331-336.

CARTHWAITE J, CHARLES SL, CHESS-WILLIAMS R. (1988) Endotheliumaderived relaxing factor reterse on activation of NMDA receptors suggest role as intercellular messenger in the brain. Nature $336: 385-388$.

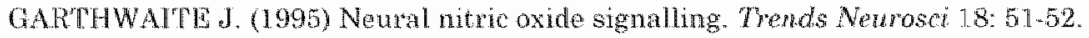

GLLESPH PG, BEAVO $\mathrm{AA}$ (1988) Characterization of a bovine cone photoreceptor phosphodiesterase purified by cych GMP-sepharose chromatography. of Biol Chem 263 . 8130111 
HOLSCHER C. ROSE SP. (1992) An mhibitor of nitric oxide synthesis prenens menory formation in the chick. Newrosch Let 145: 165-167.

HOLSCHER C. (2002) Different stains of wts show aiffarent sensitwity lo block of long-term

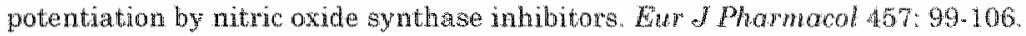

HOSLER JS, BUXTON KL, SMTWH BH. (2000) Impairment of olfactory discrimination by blockade of GABA and nitric oxide activity in the honey bee anteman lobes. Behar Nempoc: 11.4: $514-525$.

IWAHASHE Y, FURUYAMA "I", TANO Y, ISHIMOTO I, SHMOMURA Y, INAGAKI S. (1996) Differential distribution of mRNA moding CAMP-specife phosphodiesterase boforms in the rat braim. Brain Res Mol Brain Res 38 : $14-24$.

TLQUIERDO LA, VIANNA M, BARROS DN, MELLO E SOUZA T, ARDENGHI P. SANT" ANNA MUK, RODRIGUES C, MEDTNAM JH, IZQUITRDO I. 2000) Short, and long-tem memory are diferentially affected by metabolic imhitors given into hippocmpus and entominal contex. Neunobiol Lean Mam $73: 141.149$

JACKLET IW. (1997) Nitric oxide signaling in invertebrates. fnert Newrosci $3: 1-1.4$.

KEMENES I, KEMENES G, ANDREW RJ, BENJAMIN PR, OSHIAA NL. (2002) Critticall timeWindow for NO-cGMP-dependent long-term menory formation after one-trial appetitive conditioning. N Neurosici $22,1414+1425$.

KENDRICK KM, GUEVARA-GURMAN R, ZORRILLA J, HINTON MR, BROAD KD. MIMMACK M. OHKURA S. (1997) Formation of olfactory memorias mediated by nitric oxide. Noture $388: 670-674$.

KINCAID RL, BALADAN CD, BLLINGSLEX ML. (1987) Ditferential localization of calmodulin-dependent enzymes in rat brain: evidence for selective expression of cyclic nucleotide phosphodiesterase in specific neurons. Poc Nall Acad Sct U S A 84: 1118-1122.

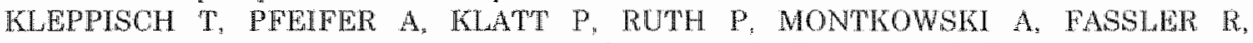
HOFMANN F. (1999) Long-term potentiation in the hippocanpal CAl region of mice lacking cGMP-dependent kinases is nomal and susceptible to inlibition of nitric oxide synthase. N Neurosei 19: 48 -55.

KOTERA I, YANAKA N, FUJISHJGE K, TMA Y, AKATSLKA H, ISHIZUKA "T, KAWASHMMA K, OMORI K. (1997) Expression of rat cGMlP-binding cGMP-specific phosphodiesterase mRNA in Puktinje cell layers during postantal netronal development. Eur of Biochem 249. 434-442.

KUMMER W, BEHRENDS S, SCHWARLLMULLRR T, FISCHER A, KOESLIING D. (1996) Subunits of soluble guanylyl cyclase in rat and guinea pig sensory ganglia. Bron Ros 721 : $191-195$

LOHMANN SM, VANDRAGER AB, SMOLENSKT A, WALTER U, DH JONGE HR. (1997) Distinct and specific functions of cQMP-dependent protein kinases. Trends Biochem $5 \mathrm{ci} 22$ : 307-312

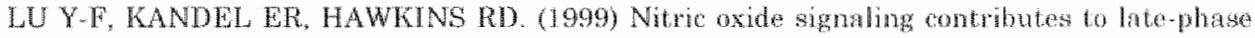
LTP and CREB phosphorylation in the hippocampus. Neurow 14: 10250-10261

MIRO X, PEREZTORRES S, PALACHOS JM, PUIGDOMLNGCH P, MENGOD G. (2001) Diferential distribution of cAMP-specific phosphodiesterase 7h mRNA in rat bran and peripheral organs. Symapse $40: 201 \cdot 214$

NAMGUNG U, VARCOURT E, ROUTFEMBERG A. (1995) Long-term potentition in wino in the intact mouse hippocampus. Brant hes $689: 85.92$.

OHDELL TU, HUANG PL, DAWSON TM, DINERMAN JH, SNYDER SH, KANDED, MR, FISHMAN MC. (1994) Endothelial NOS and the blockade of LIP by NOS inbibutas in mice lacking neuronat NOS. Science $265: 542.546$.

PRAST H. PHILIPPU A. (2001) Nitrie oxide as modulator of neuronal function. Progr Neurobiol 64: $51-68$.

PRICKAERTS J, STELNBUSCH HWM, SMITS JHM, DE VENTE I. (1997) Poseible role of

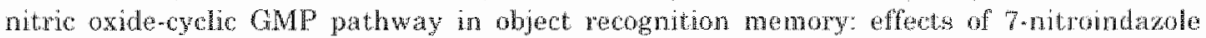
snd zaprinast. Eur of Pharmacol 3at: $125-136$.

PRICKAERTS I, VAN STAWEREN WCG, SIK A, MARKERINKVAN TTPFRSUM M, NEWOHNER U, VAN DER STAAY FJ, BLOKLAND A, DE VENTE J (20O2) Gffedt of two selective phosphodiesterase type 5 inhbitors, aldevatil and vardenatis on abject

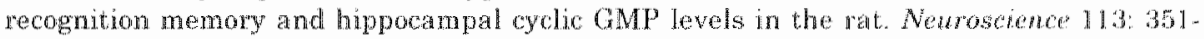
361. 
QLAN M, CHEN YC, WANO $R$, WU FW, GHO JT. (1997) Nitric oxide is involwed ime formation of ledring and hemory in 1 tats: studies using passive avoidance response and Momis wate maze task. Behau Pharmacol 8: $183-187$.

RENHARDT RR, BONDY CA. (1996) Differential cellular pattern of gene expression for two distinct cMP.inhibited cyclic nucleotide phosphodiesterases in developing and mature rat brain. Nethoscience 72: 067.578.

REPASKE TIR; CORBIN JG, CONTI M, GOY MF. (1993) A cyclic GMP.stimulated cychic rucleotide phosphodiesterase gene is highly expressed in the limbic system of the rat brain. Neuroscinte $56: 673-686$.

RTCKARD NS, NG KT, GIBBS ML (1998) Further support for nitric oxide-dependent memory procesang in the dayold chick. Neurobiol Learn Mers 69: 79-86.

SON H, HAWKINS RD, MARTIN K, KIEBLER M, HUANG PL, FISHMAN MC, KANDEL ER. (1996) long-tem potentiation is reduced in mice that are doubly mutant in endothelial and neutonal nitic oxide synthase. Cell $87: 1015-1023$.

SON H, LU YF, ZHUO M, ARANCIO O, KANDEL ER, HAWRINS RD. (1998) The specific rolle of cGMP in hippocampal LTP. Learn Mam 5: $231-245$.

TEUNISSEN C, STIUNBUSCH HWM, MARKERINK.VAN IITERSUM M, KOESLINCD, DE VENTE J. (2001) Presence of soluble and particulate guanylyl cyclase in the same hippocampall statrocytes. Broin Res $891: 206-212$.

VAN STAVRRER WCG, MARKERINK-VAN ITPERSUM M, STEINBUSCH HWM, DE VENTE I. (2001) The effects of phosphodiesterase inhibition on cyclic GMP and cyclic AMP accumulation in the hippocampus of the rat. Brain Res $888: 275-286$.

WEI \&Y, ROY DS, LLCONTE L, BARNSTABLE CJ. (1998) Molecular and pharmacollogical analysis of cyclic nucleotide-gated channel function in the central nervous syscem. Prog Neurobiol $56: 37-64$.

WLISON RI, GODECKE A, BROWN RE, SCHRADER \#, HAAS HL. (1999) Mice deficient in endothelial nituic oxide synthase exhibit selective deficit in hippocampal long-term potentiation. Neuroscience 90: $1157 \cdot 1165$

YUASA K, KOTERA J, FUJISHIGE K, MICHIBATA H, SASAKI T, OMORI K. (2000) Isolation and characterization of two novel phosphodiesterase PDE11A varianis showing unique structure and tissue-specific expression. I Biol Chem $275: 31469-31479$.

ZFUO M, HU Y, SCHULTZ C, KANDEL ER, HAWKINS RD. (1994) Rolle of guanylyl cyclase and cGMP-dependent protein kinase in long-term potentiation. Nature 368: 635-639. 


\section{General discussion}

Neuronal communication through a tight control of the cellular nitric oxide (NO) release and the subsequently produced second messenger guanosine 3',5'-cyclic monophosphate (cGMP), is an essential signal transduction pathway involved in various brain processes including learning and memory (Garthwaite, 1995). Although it is still not known how memory is precisely represented in cellular pathways in the brain, experimental results obtained with methods varying from morphology (Zhang et al., 1998; Qiang et al., 1999; Burette et al,, 2002), ellectrophysiology (Monfort et al., 2002; Bon and Garthwaite, 2003), biochemistry (Bernabeu et al., 1995; Bernabeu et al., 1996; Bernabeu et al., 1997) to behavioral paradigms (Bemabeu et al., 1995; Mogensen et al., 1995; Yamada et al., 1995; Myslivecek et al., 1996; Samama and Boehm, 1999) point to critical roles of NO and cGMP during memory formation (Prast and Philippu, 2001). The strongest evidence for a key function of NO and cGMP in this process is probably the finding that decreased NO or cGMP production leads to an impaired performance in tasks in which a specific form of memory can be addressed. These tasks have been studied in a number of animal species, such as snails (Kemenes et al., 2002), honey bees (Hosler et al., 2000), sheep (Kendrick et al., 1997), rats (Chapman et al., 1992; Bernabeu et al., 1995; Bernabeu et al., 1997; Prickaerts et al., 1997; Qiang et al., 1997; Blokland et al., 1998; Izquierdo et al., 2000; Prickaerts et al., 2002) and mice (Baratti and Kopf, 1996). The finding that blocking NO or cGMP formation leads to an impaired performance of these species in various learning and memory tasks, strongly suggests that NO and cGMP levels are critically regulated during the process of memory formation, and that the involvement of these molecules in memory is conserved in a wide variety of species.

The regulation of cyclic nucleotide degradation by the hydrolyzing action of 3',5'-cyclic nucleotide phosphodiesterases (PDEs) determines the cellular contents of both cyclic nucleotides, cGMP and adenosine 3',5'-cyclic monophosphate (cAMP). Thus, PDEs control the amplitude and duration of the second messenger signals. In contrast to the reported impaired memory performance by inhibition of NO or cGMP synthesis, a study by our group was the first to report that application of a PDE5 inhibitor (zaprinast) resulted in improved memory in a rat object recognition task (Prickaerts et al., 1997). This observation and the fact that the memory impairment in this task induced after NO synthase (NOS) inhibition could be reversed by application of the PDE5 inhibitor (Prickaerts et al., 1997), were the underlying basis for the research theme of this thesis to investigate in more 
detail the regulation of cyclic nucleotide metabolism and its involvement in learning and memory processes. One of the main goals was to investigate the cellular localization of the NO-mediated cGMP synthesis in relation to the expression of cGMP-hydrolyzing PDEs in the rodent brain.

\section{In vivo administration of selective PDE5 inhibitors}

The research on PDEs has escalated these last years due to strong development of molecular biological techniques and the availability of databases obtained from deciphering the genome of a number of species. This resulted in the expansion, in a relatively short period of time, of the seven PDE families identified until 1993 (Beavo, 1995), to the cloning of eleven PDE families and their numerous splice variants known these days (Francis et al., 2001).

Since the start of this project in the last months of 1998 , a large amount of publications on PDEs have become available. This occurred in the wake of the marketing of the selective PDE5 inhibitor Viagraß (sildenafil citrate) used as a drug for treatment of erectile dysfunction (Corbin and Francis, 1999; Gibson, 2001; Corbin et al., 2002; Rotella, 2002). The introduction of this drug has strongly renewed the interest of many scientists and pharmaceutical industries in functioning and localization of PDEs and the development of new highly selective PDE inhibitors for treatment of other diseases, e.g. chronic obstructive pulmonary disease (Sturton and Fitzgerald, 2002).

In Chapter 2 it was shown that application of PDE5 inhibitors more selective than zaprinast, like sildenafil and vardenafil, resulted in facilitation of memory retention in an object recognition task in rats. In agreement with the reported potency of these inhibitors towards PDE5 (Table 1), it was observed that vardenafil improved object memory at lower doses than sildenafil or zaprinast. At the same time, another research group also reported that sildenafil improved memory in mice in another task, a passive avoidance paradigm (Baratti and Boccia, 1999). Consistent with these findings, injection of a cGMP analogue into the hippocampus facilitated memory in the object recognition task (Prickaerts et al., 2002) or in a passive avoidance task (Bernabeu et al., 1996) in rats. From these findings it was hypothesized that the observed memory improvement in both tasks was caused by increased cGMP levels in the hippocampus. To investigate this hypothesis in more detail, a number of questions were addressed with the central question being: how can administration of a PDE5 inhibitor lead to an enhanced memory? The questions being tackled were: can selective PDE5 inhibitors indeed increase cGMP levels in vitro in the hippocampus? Are the effects induced by PDE5 inhibitors comparable to effects induced by PDE inhibitors which have different affinity profiles towards a number of PDE families, such as vinpocetine (PDE1), erythro-9(2-hydroxy-3-nonyl)adenine (EHNA, PDE2), rolipram (PDE4) or mixed type inhibitors like 3-isobutyl-1-methylxanthine (IBMX)? What is the relation 
between PDE5 and other cGMP-hydrolyzing PDEs in the hippocampus and in which cells are these enzymes expressed?

Table 1. Literature IC56 values $(\mu \mathrm{M})$ of the three PDE5 inhibitors zaprinast, sildenafil and vardenafil towards the eleven PDE families. Inhibitors were tested on purified or recombinant. PDE enzymes as indicated in the legend.

\begin{tabular}{|c|c|c|c|}
\hline PDE family & zaprinast & sildenafil & vardenafil \\
\hline PDE1 & $6.65^{\mathrm{a}}$ & $0.28^{m}$ & $0.118 i$ \\
\hline PDE2 & $>100^{a t}$ & $>30^{n}$ & $>1 i$ \\
\hline $\mathrm{PDF}_{3}$ & $>100^{*}$ & $16.2^{\mathrm{sin}}$ & $>1 i$ \\
\hline PDE4 & $77,4^{*}$ & $7.68 \mathrm{n}$ & $>1:$ \\
\hline PDE5 & $0.86^{n}$ & $0.0035^{\mathrm{a}}$ & 0.0007 \\
\hline PDE6 & $0.39^{*}$ & $0.033^{\prime \prime}$ & 0.011 \\
\hline PDE7 & $-50^{\mathrm{b}}$ & $>390^{\circ}$ & $>1 j$ \\
\hline PDES & $>100^{\circ}$ & $>4.5^{c}$ & $>11$ \\
\hline PDE9 & $29^{\circ} \cdot 35^{\circ}$ & $7^{*}$ & $>11$ \\
\hline PDE10 & $10.81-22$ & $>1^{i}$ & $>1$ \\
\hline PDE1I & $5-28^{1}$ & $>0.5^{4 n}$ & $>0.211$ \\
\hline
\end{tabular}

"Ballard et al, 1998 (PDE1-5, purified from human tissues, PDE6, isolated from bovine retina); Hetman et all, 2000a (recombinant mouse PDE7); Sodexling et al., $1998 \mathrm{~b}$ (recombinant mouse PDE8); Soderling et al., 1998a (recombinant mouse PDE9); Fisher et al, 1998 (recombinatut human PDE9); Soderling et al., 1999 (recombinant mouse PDE10); H Fujishige et al, 1999 (recombinant human PDE10); Hetman et al., 2000b (recombinant human PDE11); Saenz de Tejada et al., 2001 (recombinant human PDE engymes); inttp//www.levitra.co.uk/ levitra_smpe.htm

\section{In vitro incubation of hippocampus slices}

Experiments using in vitro incubation of hippocampus slices with PDE inhibitors provide information whether an inhibitor is able to influence cyclic nucleotide levels. This was studied in two independent ways: at the morphological level by cGMP-immunocytochemistry and biochemically by measuring cGMP and cAMP levels.

\section{PDE5 inhibitors}

It was demonstrated that application of zaprinast (Chapter 3), sildenafil or vardenafil in combination with an NO donor (Chapter 2) can result in local cGMP accumulation in varicose fibers in the CA3 region of in vitro incubated rat hippocampus slices. Incubation of the slices with PDE5 inhibitors in the absence of an NO donor did not result in cGMPimmunoreactivity. Furthermore, the effect of these PDE5 inhibitors on cGMP and cAMP were biochemically determined using a radioimmunoassay. Analysis of the effects of these PDE5 inhibitors permits the conclusion that these inhibitors can indeed increase cGMP levels, however, significantly increased cGMP levels are obtained only at high 
doses of the inhibitors used. At all the doses tested no effect on cAMP levels were found.

Attempts were made to semi-quantify the cGMP-immunofluorescence signal by using image analysis after treatment of slices with zaprinast or the non-selective PDE inhibitor IBMX at lower doses (Chapter 3). This method has the advantage that measurements can be performed in a selective area of interest and the responsive cells can be visualized, whereas in a radioimmunoassay entire hippocampus slices were analyzed. However using image analysis, no significant increases were measured at lower doses of the inhibitors used (Chapter 3). Nevertheless, it must be noted that at lower doses of the PDE5 inhibitors cGMP accumulation in varicose fibers was visualized using cGMP-immunocytochemistry (Chapter 2). This presents strong evidence that selective PDE5 inhibitors can increase cGMP levels. However, it can be questioned whether the cGMP in varicose fibers observed at those lower doses (Chapter 2, Fig. 3) is indeed due to PDE5 inhibition only or if it is the result of a combinatory inhibition of PDE5 and members of other PDE families.

The selectivity of an inhibitor towards each of the members of the eleven PDE families has been estimated for a number of compounds. Increasing cyclic nucleotide levels by a PDE inhibitor is dependent on factors such as the ability of the compound to cross cell membranes and the concentration of the substance used. For a number of PDE inhibitors selectivity profiles towards the different PDE families have been conducted by using cell lines in which a PDE protein is overexpressed. Doses can be estimated at which half of the ligand binding is inhibited ( $\mathrm{IC}_{50}$ ) due to the incubation of the cells with the compound. However, at higher concentrations, inhibition of other PDE families can also occur as shown for the PDE5 inhibitors in Table 1.

Testing of a compound on a cell line which overexpresses a PDE family provides some insight in the action of a compound. However, it needs to be realized that this is a totally different cell system compared to our model of in vilro incubation of hippocampal slices. Nowadays, it is known that a large variety of CGMP and CAMP hydrolyzing PDE families (see also the next section) are expressed in the hippocampus. However, it is still uncertain whether the PDE expression/activity profile differs between different cell types (neurons and glial cells) present in the hippocampus. Furthermore, it is not known if even in one cell type, the PDE profile in different cellular compartments (cell body/dendrites/axon) is variable, as has already been demonstrated for olfactory neurons (Juilfs et al., 1997; Beavo and Brunton, 2002). So far, cGMP-immunoreactivity was not observed in cell bodies of pyramidal or granule cells, but mainly in varicose fibers and to some extent in astrocytes. Therefore, our results obtained with the different PDE inhibitors suggest differences in PDE activity in different cellular compartments.

Another factor which needs to be taken into account using in vitro incubated hippocampus slices is the possibility of cross-talk between cGMP and CAMP signaling due to dual substrate PDEs such as PDE2 and PDE3. For instance, application of a PDE5 inhibitor to a cell which expresses both 
PDE2 and PDE5, can lead to increased cGMP levels through PDE5 inhibition, however, it is also known that increased cGMP levels can stimulate PDE2 to hydrolyze cGMP and CAMP. Therefore, the effect of a PDE5 inhibitor or in general of a selective PDE inhibitor, might not be visible in certain cells or in cellular compartments due to the presence of other PDE families. Moreover, it has been reported that PDE5 phosphorylation by PKA can severely reduce the affinity for an inluibitor (Burns et al., 1992). This mechanism might also play a role in the hippocampus slices.

Talking previous arguments into account, it may not be surprising that application of PDE5 inhibitors do not result in a strong increase in cGMP levels in the hippocampus. The increase in cGMP levels measured by a radioimmunoassay, at the highest concentration of the PDE5 inhibitors (100 $\mu \mathrm{M}$ ) can be due to the inhibition of all eleven PDE families when comparing $\mathrm{IC}_{50}$ values (Table 1). However, in this respect it is interesting to note that even at this high concentration, no increased CAMP levels were measured for all three PDE5 inhibitors tested, which might have been expected.

Incubation with $0.1 \mu \mathrm{M}$ vardenafil still resulted in cGMP. immunoreactive fibers in the hippocampus. The PDE with an ICno, which comes closest to this value, besides the photoreceptor PDE6, is PDE1. Therefore, it might be speculated that at this dose, aside from PDE5 inhibition, inhibition of PDE1 might be part of the mechanism of improving object recognition memory.

\section{Inhibitors of other PDE families}

In Chapter 3 it was demonstrated that treatment of rat hippocampal slices with PDE inhibitors, which have different selectivity profiles towards the eleven PDE families, resulted in different effects on cGMP accumulation. Strongest cGMP accumulation was observed using EHNA, dipyridamole or IBMX in the presence of the NO donor sodium nitroprusside (SNP). Incubation with these inhibitors without an $\mathrm{NO}$ donor already resulted in a slight cGMP accumulation in the hippocampus. Of these three inhibitors only EHNA is known to have appreciable affinity towards only one PDE family, PDE2. Dipyridamole was originally described as a PDE5 inhibitor but has also affinity towards the recently identified PDE7, PDE8, PDE10 and PDE11. IBMX is a kind of prototype non-selective PDE inhibitor, although this compound does not inhibit PDE8 and PDE9. Comparison of the effects of these inhibitors with the effects of zaprinast, sildenafil or vardenafil, demonstrates that in the presence of an NO donor, PDE5 inhibitors increase cGMP levels locally in the hippocampus, whereas cGMP accumulation is more widespread throughout the hippocampus after treatment with EHNA, dipyridamole and IBMX. Considering the fact that dipyridamole and IBMX are able to inhibit a number of PDE families, it is not surprising that application of these inhibitors produce a much stronger effect on cGMP accumulation than PDE5 inhibitors. Rather surjorising, EHNA as a PDE2 inhibitor induced the strongest effect of the selective PDE inhibitors tested in our studies. These were winpocetine and calmidarolium 
(PDE1), SK\&F 95654 (PDE3), SK\&F 96231, sildenafil, vardenafil (PDE5), and rolipram (PDE4). This suggests that PDE2 activity has an important role in hydrolyzing activity of cGMP in hippocampus slices. Consistent with these findings, testing of a number of PDE inlaibitors (vinpocetine, EHNA, milrinone, rolipram and zaprinast) on rat hippocampus cultures, revealed that only EHNA enhanced the increase of cGMP after $N$-methyl- $D$-aspartate (NMDA), an activator of the NMDA receptor linked to NOS stimulation, administration (Suvarna and O'Donnell, 2002).

Furthermore, it must be noted that the strongest effects on cGMP accumulation mentioned above were obtained after inculation of hippocampal slices in the presence of a PDE inhibitor in combination with a soluble guanylyl cyclase ( $\mathrm{sGC}$ ) stimulator such as an NO donor (Chapters 24) or an NO-independent sGC activator like $\mathrm{YC}-1$ and $\mathrm{BAY}$ 41-2272 (Chapter 4). Since in the literature some evidence has been presented that the metabolism of NO donors is dependent on the tissue with which they are in contact (e.g. Nedvetsky et al., 2002), the question was addressed if different classes of NO donors raise cGMP levels in different cell types or brain regions (Chapter 4). To investigate this issue, the effect of four NO donors on the cellular localization of cGMP synthesis was investigated and compared to $\mathrm{NO}$-independent stimulators of $\mathrm{sGC}$ in hippocampus, cortex and thalamus (Chapter 4). It was observed that in the presence of IBMX, NO donors of different classes stimulate cGMP accumulation in similar cellular structures. Interestingly, it was also observed that NO-independent SGC stimulators like YC-1 and BAY 41-2272 in combination with an NO donor are able to strongly potentiate cGMP levels and stimulate cGMP synthesis in structures in the cortex which do not accumulate cGMP after incubation with the NO donor alone, suggesting that in certain cell types $\mathrm{sGC}$ needs to be sensitized before NO can stimulate cGMP synthesis. This indicates that besides the cGMP-hydrolyzing PDEs, regulation of SGC is an important factor to take into account when studying cGMP signal transduction in in vitro incubated slices.

Taken together, in vitro incubation of hippocampus slices can be used as a model to test if PDE inhibitors can induce cGMP and/or cAMP levels in this brain area. The cellular structures responding to an inhibitor can be visualized by the use of antibodies directed towards cGMP, possibly in combination with cellular markers. Using a different approach, cGMP and. cAMP levels can be measured biochemically. However, it must be kept in mind that in addition to the concentration of a compound used, factors such as cell type, cellular compartment, phosphorylation processes and the expression of multiple PDE families can all be of influence in this model.

\section{Cellular targets of PDE5 inhibitors}

If we want to try to explain the behavioral findings after administration of PDE5 inhibitors in terms of NO-cGMP signaling, three critical questions need to be addressed. First, does peripheral administration of PDE5 inhibitors in vivo indeed induce cGMP accumulation in the CA3 area of the 
hippocampus as observed in vitro and is this mechanistically relevant for object memory? Second, what is the PDE5 inhibitor concentration in brain areas such as the hippocampus or in individual cells after peripheral administration of the compound? Third, and most important, where in the brain is PDE5 localized?

With respect to the first question, this thesis focused on the hippocampus because of the following reasons. Administration of a cGMP analogue improved memory in two tasks, an object recognition task (Prickaerts et al., 2002) and a passive avoidance task (Bemabeu et al., 1996). Furthermore, it has been demonstrated biochemically that the NOS and $\mathrm{SGC}$ activity increased immediately after training and that at this time point cGMP levels were raised (Bernabeu et al., 1995; Bernabeu et al., 1996; Bemabeu et al., 1997). It is known that PDE5 inhibitors such as zaprinast and sildenafil, can cross the blood brain barrier and therefore can inhibit PDE5 present in the hippocampus. However, it is also possible that other brain areas such as the rhinal cortex, thought to be involved in object recognition memory, might be affected by administration of PDE5 inhibitors and therefore memory enhancing effects may not be solely attributable to an effect in the hippocampus.

Since it is unknown at this moment what the final concentration of a PDE5 inhibitor in individual cells will be after peripheral administration of the compound, it seems possible that inhibition of a number of targets could induce the enhanced memory effects. If concentrations high above the IC 50 of the PDE5 inhibitors will be reached in cells, it might be expected that inhibition of other PDE isozymes will occur, as described above. Furthermore it may be speculated that the effect on memory after application of PDE5 inhibitors occurs through inhibition of PDE5 in vascular tissue. This could lead to increased cGMP levels in blood vessel walls and thereby cause relaxation followed by vasodilation. In guinea pig basilar arteries, PDE1A, PDE1B and PDE5 exhibited the most prominent hydrolyzing activity. PDE1 and PDE5 inhibitors such as 8-methoxymethyl1-methyl-3-(2*methylpropyl)-xanthine, zaprinast and sildenafil can induce dilatation (Kruuse et al., 2001). Also, in canine basilar arteries zaprinast induced dilatation with an increased cGMP leve] has been described (Kim et al., 1992). Recently increased cerebral blood flow has been reported after. oral administration of sildenafil (Zhang et al., 2002b). These observations suggest that peripheral administration of PDE5 inhibitors might act on vascular tissue, and therefore it cannot be excluded that vascular effects are of influence on the behavioral performance.

By the use of insidemout vesicles, it has been demonstrated that PDE inhibitors like sildenafil and zaprinast can inhibit the cyclic nucleotide transporter MRP5 (Jedlitschky et al., 2000) or the low $\mathrm{K}_{\mathrm{m}}$ cGMP transporter (Sundkvist et al., 2002). MPP5 mRNA is present in a number of brain areas (McAleer et al., 1999) and has been recently demonstrated to be present in rat brain astrocyte cultures (Ballerini et al., 2002) and in capillary endothelial cells forming the blood-brain-barrier" (Zhang et al., 2000). Thus, administration of PDE5 inhibitors can lead to inhibition of these 
transporters in the brain, and thereby cause increased intracellular cGMP levels. Interestingly, PDE5 has recently been colocalized with the MRP5 transporter in smooth muscle cells from the genitourinary system (Nies et a., 2002). It can be speculated that sildenafil has a dual effect in cells coexpressing PDE5 and MRP5, thus causing increased cGMP levels by inhibiting PDE5 and by preventing export of cGMP.

To conclude, thus far the exact cellular target(s), as mentioned above, which will be influenced after in vivo administration of PDE5 inhibitors still needs to be elucidated. The components affected will strongly be dependent on the final concentration of the inhibitor, which is reached in cells after peripheral administration of the compound. However, the amount of inhibitor in cells is not known at this moment and cannot be estimated with the methods used in this study.

\section{Expression of multiple cGMP-hydrolyzing PDEs in cells}

To learn more about the role of PDEs in brain functioning, it is inevitable that information is needed on the precise cellular localization of the $\mathrm{mRNA}$ and protein of ideally every PDE family. This might even extend to the distribution of all the splice variants known to date. To obtain more insight in the mechanism of how administration of a PDE5 inhibitor can enhance memory, we studied the cellular localization of PDE5 in the brain in greater detail, especially in the hippocampus. So far PDE5 was demonstrated on the cellular level only in the cerebellar Purkinje cells (Kotera et al, 1997; Juilfs et al, 1999; Kotera et al., 2000; Giordano et al., 2001), although some reports indicated a low expression of PDE5 $\mathrm{mRNA}$ in other brain areas (Kotera et al., 1997; Loughney et al., 1998, Kotera et al., 1999). As increased cGMP levels in the hippocampus were associated with increased memory retention, we investigated not only the localization of PDE5 but also the expression of other cGMP-hydrolyzing PDEs. Besides the mapping of PDE5, we focused on PDE2 and PDE9. Of the eleven PDE families known to date, PDE1, PDE2, PDE5, PDE6, PDE9, PDE10 and PDE11 are able to hydrolyze cGMP. Based on reported findings that PDE6 is localized in rods and cones of the netina (Gillespie and Beavo, 1988), PDE10 has been observed only in striatum and olfactory tubercle (Fujishige et al, 1999), and PDEI1 was detected only in pituitary (Fawcett et al., 2000; Yuasa et al, 2000), these three cGMP-hydrolyzing PDE families were excluded from our study. Furthermore, we did not include PDE1 in our study based on our earlier observation that the PDEI inhibitor calmidazolium or vinpocetine were without effect, or only showed a minimal effect on cGMP-accumulation in rat hippocampus (Chapter 3 ).

It was reasoned that PDE2 could be an interesting candidate involved in memory processes due to two reasons. First, it had been reported to be highly expressed in the limbic system (Repaske et al., 1993). Second, our own observations showed that the PDE2 inhibitor EHNA strongly increased cGMP levels in rat hippocampus slices (Chapter 3). Furthermore, PDE9 seemed to be an interesting target enryme as well, since it was reported as 
the PDE with the highest affinity for CGMP of any PDE family known to date (Soderling et al., 1998a) and at the time of the start of this study the localization of this PDE was unknown.

Due to unsuccessful results with antibodies directed against PDE families, it was decided to study PDE2, PDE5 and PDE9 at the MRNA level. For the first time it was demonstrated that besides the high expression of PDE5 in the cerebellum as previously reported (Kotera et al., 1997; Juilfs et al., 1999; Kotera et al., 2000; Giordano et al., 2001), PDE5 mRNA could also be detected in pyramidal and granule cells of the hippocampus as well as some scattered cells in the strata (Chapter 6). Although hybridizations of the cGMP-hydrolyzing PDE mRNAs could not be performed on the same tissue section, our data strongly suggest that pyramidal cells coexpress the mRNAs of PDE2, PDE5 and PDE9 (Chapter 6). The presence of a certain PJE $m R$ RA does not give an immediate indication of the PDE protein expression or $\mathrm{PDE}$ activity. If these results are combined with other localization studies on PDE families in the brain then it must be concluded that a large number of cells including pyramidal cells, express a wide variety of different PDE families.

Since PDE9 has been described having the highest affinity for cGMP of any PDE family cloned to date, it actually seems striking that besides PDE9 expression, other cGMP-hydrolyzing PDEs are expressed in the same cell type. It has been suggested that because of its high affinity for cGMP and its broad distribution, PDE9 might be involved in keeping cGMP at low physiological levels in the cells. However, cGMP levels will not only be determined by the affinity of the PDE type, since the speed by which cGMP can be hydrolyzed is also a factor strongly influencing cGMP concentrations in cells. For instance, comparison of cGMP $K_{m}$ values for PDE2 (15-30 $\left.\mu \mathrm{M}\right)$, PDE5 (1.5 $\mu \mathrm{M})$ or PDE9 (0.07-0.17 $\mu \mathrm{M})$ demonstrates that PDE9 has the highest affinity for cGMP, however the $V_{\max }$ values for cGMP hydrolysis of PDE2 (158 nmol/min/ $/ \mathrm{gg})$, PDE5 (8.9 pmol $/ \mathrm{min} / \mu \mathrm{g})$ or PDE9 (4.9 nmol/min/ $/ \mathrm{g}$ ) reveals that PDE2 can hydrolyze cGMP the fastest (Murashima et al., 1990; Fisher et al., 1998; Rybalkin et al., 2003). However, $K_{m}$ and $V_{\max }$ values are influenced by activity of cellular components. For instance, a decrease in $K_{n}$ value and an increased $V_{\text {max }}$ has been reported recently upon stimulation of PDE5 stimulation (Rybalkin et al., 2003). Furthermore, modification of PDE activity by phosphorylation by PKA and PKG has been described for some PDEs, leading to an activation or inactivation of PDE activity (Macphee et al., 1988; Florio et al., 1994; Corbin et al., 2000). Altogether, cyclic nucleotide levels are determined by the expression pattems and the activity of the PDE families, the latter being influenced by cellular events such as phosphorylation.

\section{Future perspectives}

As discussed before in this chapter, the results indicate that application of" PDE5 inhibitors can improve memory performance in specific tasks (Prickaerts et al., 1997; Baratti and Boccia, 1999; Chapter 2). Also, the data 
point to increased cGMP levels in the hippocampus as a necessary condition for increased performance in memory (Bernabeu et al, 1996; Prickaerts et al., 2002). However, the underlying mechanism of the memory improvement still requires elucidation. As indicated above, the effect might be due to selective PDE5 inhibition, but might as well be caused by a combined effect of inhibition of a number of PDE families, or cyclic nucleotide transporters. The mRNA localization of PDE5 shows that PDE5 inhibition could occur in the hippocampus, but the presence of PDE5 in brain areas such as the cortex suggests that PDE5 inhibitors will influence PDE functioning in other brain areas as well. A future experiment with a radioactive labeled PDE5 inhibitor will give more insight in the brain areas where the inhibitor can induce an effect. As mentioned before, vascular effects of PDE5 inhibitors cannot be excluded, however, it is interesting to note that neither PDE5 mRNA nor PDE5 protein was observed in brain vessel walls (Kotera et al., 2000). In addition, no strong effect on cGMP accumulation in vessel walls was observed after administration of a PDE5 inhibitor to brain slices (Chapter 3).

The answer to the question that specifically PDE5 is involved in object recognition memory and in passive avoidance learning might be obtained with studies using PDE5 gene knock-out mice. More and more results from PDE specific knock-out models are becoming available which give more information about the role of specific PDE families in physiological functions. For instance, PDE4B and PDE4D knock-out mice have been created which demonstrate the critical role of PDE4 isoforms in regulation of cAMP homeostasis (Conti et al., 2003) and their role in various processes such as depression, (Zhang et al., 2002a), fertility (Jin et al., 1999), emesis and anesthesia (Giembycz, 2002; Robichaud et al., 2002). Speculating on PDE5 knock-out mice and their memory performance immediately raises a number of critical notes. First, knocking out PDE5 might lead to compensatory effects of other (cGMP-hydrolyzing) PDEs. Furthermore, it might be speculated that disruption of cyclic nucleotide metabolism during development could have severe effect on brain development, because cGMP and cAMP are involved in axonal growth and guidance, and therefore the formation of inappropriate neuronal connections in PDE5 knock-out mice during development might occur. The in situ hybridization data of cGMP. hydrolyzing PDEs demonstrates that those PDEs are already present in early development (Chapter 6). Therefore, an inducible PDE5 knock-out is more desirable, since in this model developmental disturbances can be excluded more likely than in a complete PDE5 knock-out mouse.

Our findings on the differences in the localization of NO-mediated cGMP synthesis in rat and mouse hippocampus raised the question about the impact of these differences (Chapter 7). Especially striking is the presence of the numerous varicose fibers immunoreactive for cGMP in the rat, whereas in the mouse these fibers are much less pronounced and the strongest cGMP accumulation was observed in astrocytes. However, no differences in the localization of the $\beta 1$ subunit of the cGMP-producing $s G C$ or the mRNAs patterns of PDE2, PDE5 and PDE9 were observed between rat and mouse 
hippocampus. Furthermore, the behavioral data that are so far published for PDE5 inhibitors are derived from rats (Prickaerts et al., 2002) and mice (Baratti and Boccia, 1999) and in both species an improvement in memory performance is induced, though in different tasks. Although the physiological significance of the differences in cGMP localization is not known at this moment, these findings indicate that care should be taken evaluating results of mouse (knock-out) models for the enzymes involved in cGMP signaling and extrapolating these results to other species. Intracranial application of antisense oligodeoxynucleotide probes directed against PDE5, might be an other option in order to obtain more insight in the role of PDE5 during memory formation. These probes are sequences which are complementary (antisense) to the mRNA of interest and by binding to the target mRNA, duplex structures are formed inside the cell and thereby disrupt the protein level transiently (Guzowski, 2002).

In this thesis focus was set on the role of PDE5 in memory, however, it is reasonable to expect the involvement of numerous PDE families in learning and memory processes. Behavioral studies indicate that besides a critical role for cGMP during early memory formation $(<1$ hour), cAMP is involved during later stages ( $\geq 3$ hours) of the memory process. Therefore, inhibition of cAMP-hydrolyzing PDEs at later stages of memory formation seems an attractive candidate to enhance memory as well. In this respect the CAMPhydrolyzing PDE4B3 might be a target, since it has been shown recently that this PDE isoform is modulated during long-term potentiation (LTP) phases and is induced by NMDA activation (Ahmed and Frey, 2003). Furthermore, inhibition of PDE2 has been postulated as a memoryenhancing target (Boess et al., 2003). Moreover, it has been recently reported that $\mathrm{PDE} 1 \mathrm{~B}^{*}$ and $\mathrm{PDE} 1 \%$ mice demonstrated Morris maze spatiallearning deficits (Reed et al., 2002). Further studies will be needed to obtain more insight into the role of the various PDE families in memory formation.

\section{Inhibition of cGMP-hydrolyzing PDEs as a potential target for memory deficits during ageing or disease?}

The memory enhancing effects after administration of PDE5 inhibitors observed in animal models brings up logically the intriguing question: is administration of PDE5 inhibitors a therapeutic possibility for humans in the treatment of cognitive impairments due to ageing or diseases such as Alzheimer's disease?

In rats, ageing is associated with changes in the NMDA-NOS-cGMP signaling pathway (Vallebuona and Raiteri, 1995; Chalimoniuk and Strosznajder, 1998; Fedele and Raiteri, 1999; Fedele et al., 2001; Law et al., 2002; Jesko et al., 2003). Decreased cGMP levels have been reported in aged rat brains Vallebuona and Raiteri, 1995; Chalimoniuk and Strosznajder, 1998; Fedele et al., 2001). In the human brain, a decrease has been reported in the amount of the $\alpha 1$ and $\beta .1$ subunit of $\mathrm{sGC}$ in cortical areas during ageing (Ibarra et al., 2001). A study on the temporal cortex of Alzheimer's 
disease patients has shown that the $V_{\text {mar }}$ walues for basal and $\mathrm{SNP}$ stimulated $\mathrm{BCC}$ activity was reduced by approximately $50 \%$ compared to aged-matched controls (Bonkale et al., 1995). Also the NO producing enzyme, NOS, as demonstrated by NADPH staining is reduced in the hippocampus of patients suffering from Alzheimer's disease, with the greatest loss in the most severely affected cases (Rebeck et al., 1993).

Neurotransmitter release modulated by NO and cGMP has been postulated for a number of neurotransmitters (Prast and Philippu, 2001). In the postulated model of $\mathrm{NO}$ as a retrograde messenger (Chapter 1 , Fig.1), it is hypothesized that increased cGMP levels in glutamatergic neurons leads to an increased release of glutamate. However, in brain slices treated with an NO donor and IBMX, cGMP was maimly present in acetylcholine fibers (De Vente et al., 2001). In contrast, cGMP was only occasionally present in glutamatergic cells, which was to some extent increased after co-incubation of an $\mathrm{NO}$ donor and an $\mathrm{NO}$-independent sGC activator (Chapter 4). In rats, cortical infusion of an $\mathrm{NO}$ inhibitor resulted in a decreased acetylcholine release in the basal forebrain, whereas application of the NO donor SIN-1 increased acetylcholine release (Prast and Philippu, 1992), which suggests that cholinergic neurotransmission is modulated by NO. A relationship between the reduced $\mathrm{sGC}$ activity in brains from Alzheimer's disease patients, which are characterized by a severe deficit in cholinergic neurotransmission, and abnormal cholinergic neurotransmission needs still to be elucidated.

Beta-amyloid peptides, the major component of senile plaques in Alaheimer's disease, have been associated with cGMP production. Application of beta-amyloid caused a decreased NMDA receptor mediated NOS activity in hippocampus and cortex slices (Chalimoniuk and Strosznajder, 1998). In rat cortical and hippocampal astrocyte cell cultures, beta-amyloid caused lowering of cGMP levels due to a decrease in $\mathrm{sGC}$ $m R N A$ and protein expression. In addition it was shown that intracerebral beta-amyloid injections decreased mRNA of the $\beta 1$-subunit of the $\mathrm{SGC}$ (Baltrons et al., 2002). Intra-arterial infusion of beta-amyloid in rats has been demonstrated to decrease blood flow specifically in the cerebral cortex (Suo et al., 1998). In aortic rings, treatment with beta-anyloid decreases vascular relaxation induced by $\mathrm{NO}$, which was reversed by administration of dipyridamole (Paris et al., 1999). Although so far only a few studies have been reported on cGMP signaling in relation to Alzheimer's disease, results point to a severe reduction of both $\mathrm{NO}$-producing and $\mathrm{NO}$-responsive $\mathrm{SGC}$ structures in patients. This would suggest that cGMP levels in the brain are reduced in Alzheimer's patients. From the behavioral studies it can be concluded that reduced cGMP levels are associated with an impaired cognitive performance in specific tasks. Therefore, the investigation of whether increasing cGMP levels by inhibition of cGMP-PDEs leads to an improved cognitive performance in specific tasks in Alzheimer patients, should be seriouslly considered. 
Developments in the field of regulation of PDE gene expression and PDE activity during the past few years strongly suggest that influencing second messenger levels by inhibition of PDEs can lead to beneficial effects in the treatment of a number of diseases. The research on PDEs, still strong in development, has a large potential for drug design. This is especially due to the diversity and complexity in terms of biochemical properties of the PDE superfamily and their specific expression patterns in tissues throughout the body. In addition to the obtained clinical results with PDE5 inhibitors as sildenafil (Viagra(B) or PDE4 inhibitors used as a treatment in chronic obstructive pulmonary disease, other studies indicate potential for PDE inhibitors in other disorders. Results obtained with exisulind (sulindac sulfone) show a preventive effect on tumorigenesis in patients with polyposis of the colon and has been shown to have an antiproliferative effect in a number of tumor cell lines, as well as in animal models of a variety of human cancers (Haanen, 2001). Application of sildenafil promoted functional recovery after stroke (Zhang et al., 2002b). "Treatment of motorneurons in culture with PDE5 inhibitors was neuroprotective and a possible therapeutic intervention in amyotrophic lateral scleroses was suggested (Nakamizo et al., 2003).

It will be an interesting and challenging task to further investigate cyclic nucleotide signaling at the cellular level on the one hand and their implications in various in vivo models on the other hand. It will be fascinating to see in more and more detail how ingenious cellular communication is regulated.

\section{References}

AHMED T, FREY JU. (2003) Expression of the specific type IV phosphodiesterase gene PDEAB3 during different phases of longterm potentiation in single hippocampal slices of rats in vitro. Neuroscience 117:627-638.

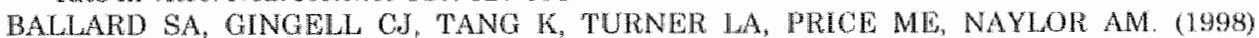
Effects of sildenafil on the relaxation of human corpus cavernosum tissue in vitro and on the activities of cyclic nucleotide phosphodiesterase isozymes of Urol 159:2164-2171.

BALLERINI P, DI IORIO P, CICCARELLI R, NARGI E, DALIMONTE 1 , TRAVIERSA $U$, RATHBONE MP, CACLAGLI E. (2002) Glial cells express multiple ATP binding cassette proteins which are involved in ATP release. Neuroreport 13:1789.1792.

BALTRONS MA, PEDRAZA CE, HENEKA MT, GARCIA A. (2002) Beta-amyloid peptides decrease soluble guanylyl cyclase expression in astroglial cells. Neurobiol Dis 10: 139-149.

BARATTI CM, KKOPF SR. (1996) A nitric oxide synthase inhibitor impars menory storage in mice. Neurobial Learn Mem 65: 197-201.

BARATTI CM, BOCCIA MM. (1999) Effects of sildenafil on long-term retention of an inhibitory avoidance response in mice. Behav Prormacol 10: 731.737 .

BEAVO JA. (1995) Cyclic nucleotide phosphodiesterases: functional implications of multiple isoforms. Physiol Rev 75: 725-748.

BEAVO JA, BRUNTON LL. (2002) Cyclic mucleotide research - still expanding after half a century. Nat Rev Mol Cell Biol 3: 71.0-718.

BERNABEU R, DE STEIN ML, FIN C, IZQUIERDO I, MEDINA, JH. (1995) Role of hippocampal NO in the acquisition and consolidation of inhibitory avoidance learning. Neuroreport $6: 1.498 \times 1500$. 
BERNABEU R, SCHMTL P, FALLACE MP, IZQUTERDO I, MEDINA JH. (1996) Hippocampal cGMP and CAMP are differentially involved in memary processing of inhibitory avoidance lexuning. Neuroreport $7: 585-588$.

BERNABEU R, SCHRODER N, QUEVEDO J, CAMMAROTA M, IZQUIERDO I, MEDINA JH. (1997) Further evidence for the involvement of a hippocampal CGMP/cGMP-dependent protein linase cascade in me mory consolidation. Neuroreport 8:2221-2224.

BLOKLAND A, PRICKAERTS J, HONIG W, DE VENTE J. (1998) State-dependent impairment in object recognition after hippocampal NOS inhibition. Newroreport 9: 42054208.

BOESS FG, HENDRIX M, VAN DER STAAY FU, VAN STAVEREN W, DE VENTE J, SIK A, PRICKAERTS J, BLOKLAND A, KOENIG G (2003) Inhibition of PDE2 a novel mechanism for the treatment of memory disorders. 6th International Conference $\mathrm{AD} / \mathrm{PD}$ 2003, Seville, Spain, May 8-12, 2003, Seville.

BON CL, GARTHWAITE I. (2003) On the role of nitric oxide in hippocampal long-term potentiation. I Neurosei 23: 1941-1948.

BONKALE WL, WINBLAD B, RAVID $R$, COWBURN RF. (1995) Reduced nitric oxide responsive soluble guanylyl cyclase activity in the superior temporal cortex of patients with Alweimer's disease. Newrosci Lett 187: $5 \times 8$.

BURETTE A, ZABEL U, WEINBERG RJ, SCHMIDT HHHW, VALTSCHANOFF J. (2002) Symaptic localization of nitric oxide synthase and soluble guanylyl cyclase in the hippocampus. of Neurosei 22: 8961-8970.

BURNS $\mathbb{F}^{2}$, RODGER IW, PYNE N. (1992) The catalytic subunit of protein kinase A triggers activation of the type $V$ cyclic GMP-specific phosphodiesterase from guinea-pig lung. Biochem of 283: 487-491.

CHALIMONIUK M, STROSZNAEDER JB. (1998) Aging modulates nitric oxide synthesis and cGMP levels in hippocampus and cerebellum. Effects of amyloid beta peptide. Mol Chem. Neuropathol 35: 77-95.

CHAPMAN PF, ATKINS CM, ALLEN MT, HALEY JE, STEINMETZ JE (1992) Inhibition of nitric oxide synthesis impairs two different forms of leaming. Neuroreport $3: 567-570$.

CONTI M, RICHTER W, MEHATS C, LIVERA G, PARK JY, JIN C. (2003) Cyclic AMP-specific PDE4 phosphodiesterases as critical components of cyclic AMP signaling. of Biol Chem 278 : $5493-5496$.

CORBIN JD, FRANCIS SH (1999) Cyclic GMP phosphodiesterase-5: target of sildenafil. J Biot Chem 274: 13729-13732.

CORBIN ID, FRANCIS SH, WEBB DJ. (2002) Phosphodiesterase type 5 as a pharmacologic target in erectile dysfunction. Urology 60: 4-11.

CORBIN JD, TURKO IV, BEASLEY A, FRANCIS SH. (2000) Phosphorylation of phosphodiesterase-5 by cyclic nucleotide-dependent protein kinase alters its catalytic and allosteric cGMP.binding activities. Eur of Biochem 267: $2760-2767$.

DE VENT'U. JARKERINK.VAN ITTERSUM M, AXER H, STEINBUSCH HWM. (2001) Nitricoxide-induced cGMP synthesis in cholinergic neurons in the rat brain. Exp Brain Res 136: 480.491 .

FAWCETT L, BAXENDALE R, STACEY P, MCGROUTHER C, HARROW I, SODERILNG $S$, HETMAN J, BEAVO JA, PHILLIPS SC, (2000) Molecular cloning and chatacterization of a distinct human phosphodiesterase gene family: PDEll 1 A. Proc Natl Acad Sci U S A 97: $3702-3707$.

FEDELE E, RAITERI M. (1999) In vivo studies of the cerebral glutamate receptor/NO/cGMP pathway. Prog Nerurobiol 58: 89-120.

FEDELEE $\mathbb{E}$, MARCHI M, RAITERI M. (2001) In vivo NO/cGMP signalling in the hippocampus. Neurochen Res 26: 1069-1078.

FISHER DA, SMTTH JF, PILLAR JS, ST DENIS SH, CHENG JB. (1998) Ilsolation and characterization of PDE9A, a novel human cGMP-specific phosphodiesterase. I Biol Chem. 273: $15559-15564$.

FLORIO VA, SONNENBURG WK, JOHNSON R, KWAK KS, JENSEN GS, WALSH KA, BEAVO JA. (1994) Phosphorylation of the 61-kDa calmodulin-stimulated cyclic nucleotide phosphodiesterase at serine 120 reduces its affinity for calmodulin. Biochemistry 33: 89488954 
FRANCIS SH, TURKO IV, CORBIN JD. (2001) Cyclic nucleotide phosphodiesterases: relating structure and function. Prog Nucleic Acid Res Mol Biol 65: 1-52.

FUJISHIGE K, KOTERA J, MCHIBATA H, VUASA K TAKEBAYASHI S, OKUMURA K, OMORI $\mathrm{K}$. (1999) Cloning and characterization of a novel human phosphodiesterase that. hydrolyzes both CAMP and CGMP (PDE10A), If Biol Chem 274: 18438-18445.

GARTHWAITE J. (1995) Neural nitric oxide signalling. Thends Neurosci 18:51-52.

GIBSON A. (2001) Phosphodliesterase 5 inhibitors and nitrergic transmission-from zaprinast to sildenafil. Eur of Pharmacol 411: 1-10.

GIEMBYCZ MA. (2002) 4D or not 4D - the emetogenic basis of PDE4 inhilbitors uncovered? Trends Pharmacol Sci $23: 548$.

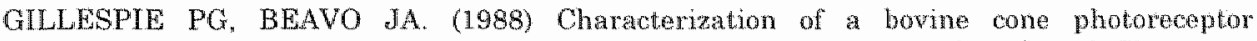
phosphodiesterase purified by cyclic GMP-sepharose chromatography. If Biol Chen 263: $8133-8141$.

GIORDANO D, DE STEFANO ME, CTTRO G, MODICA A, GIORGI M. (2001) Expression of cGMP-bunding cGMP-specific phosphodiesterase (PDE5) in mouse tissues and cell lines using an antibody against the enzyme amino-teminal domain. Biochin Biophys Acta 1539 : $16 \cdot 27$.

GUZOWSKI JF. (2002) Insights into immediate-early gene function in hippocampal memory consolidation using antisense oligonucleotide and fluorescent imaging approaches. Hippoccmpus 12: 86-104.

HAANEN C. (2001) Sulindac and its derivatives: a novel dass of anticancer agents. Curm Opin Investig Drugis 2: 677-683.

HETMAN JM, SODERLING SH, GLAVAS NA, BEAVO JA. (2000a) Cloning and characterization of PDE7B, a CAMP-specific phosphodiesterase. Proc Nall Acad Sci US A 97: $472-476$.

HETMAN JM, ROBAS N, BAXENDALE R, FIDOCK M, PHILLIPS SC, SODERLING SH, BEAVO JA. (2000b) Cloning and characterization of two splice variants of human phosphodiesterase 11A. Proc Natl Acad Sci US A 97: 12891-12895.

HOSLER JS, BUXTON KL, SMITH BH. (2000) Impairment of olfactory discrimination by blockade of GABA and nitric oxide activity in the honey bee antennal lobes. Behov Newrose 114: $514-525$.

IBARRA C, NEDVETSKY PI, GERLACH M, RIEDERER P, SCHMIDT HH. (2001) Regional and age-dependent expression of the nitric oxide receptor, soluble guanylyl cyclase, in the human brain. Broin Res 907: 54-60.

IZQUTERDO LA, VIANNA M, BARROS DM, MELLO E SOUZA T", ARDENGHI P, SAN" ANNA MK, RODHIGUES C, MEDINAM JH, LZQUIERDO I. (2000) Short- and long-tern memory are differentially affected by metabolic inhibitors given into hippocampus and entorhinal contex. Neurobiol Learn Mem 73: 14:1-149.

JEDLITSCHKY G, BURCHELL B, KEPPLER D. (2000) The multidrug resistance protein 5 functions as an ATP-dependent export pump for cyclic mucleotides. \& Biol Chem 275: 30069 30074.

JESKO H. CHALMONIUK M, STROSZNAEDER JB. (2003) Activation of constitutive mitric oxide synthase(s) and absence of inducible isoform in aged rat brain. Neurochem Int 42: $30.5-322$

JIN SL, RICHARD FJ, KUO WP. DERCOLE AJ, CONTI M. (1999) Impared growth and fertility of cAMP-specific phosphodiesterase PDEAD-deficient mice. Proc Natl Acad Soi is A 96: 11998-12003.

JUILFS DM, SODERLING S, BURNS F, BEAVO JA (1999) Cyclic GMP as substrate and regulator of cychic nucleotide phosphodiesterases (PDEs). Rev Physiol Brochem Pharmacol 135: 67-104.

JUILFS DM, FULLE HJ, ZHAO AZ, HOUSLAY MD, GARBERS DL, BEAVO JA. (1997) A subset of olfactory neurons that selectively express cGMP-stimulated phosphodiesterage (PDE2) and guanylyl cyclase-D define anique olfactory signal transduction pathway. Proc Noul Acad Sci U S A 94: $3388-3395$.

KEMENES I, KEMENES G, ANDREW RJ, BENJAMHN PR, O'SHEA M. (2002) Criticat timewindow for NO-cGMP-dependent longterm memory formation after one-trial appetilive conditioning. of Neurosci 22: 1.414-1425. 
KENDRLCK KM, GUEVARA-GULMAN $P_{n}$ ZORRILLA $d$, HINTON MR, BROAD KD, MIMMACK M. OHKURA $\mathrm{S}$. (1997) Formation of alfactory memories mediated by nitric axido. Nature 388: 670-674.

KIM P, SCHINI VA, SUNDT TM, JR., VANHOUTTE PM. (1992) Reduced production of oGMP underlies the loss of endotheliurn-dependent relaxations in the canine basilar artery after gubarachnoid hemorrhage. Circ Res 70: 248-256.

KOTERA J; YANAKA N, FUAISHIGE K, IMAI Y, AKATSUKA $H$, ISHIZUKA $T$, KAWASHIMA $K$, OMORI $K$. (1997) Expression of rat cGMP-binding cGMP-specitic phosphodiesteraste mRNA in Purkinje cell layers during postnatal neuronal development. Eur of Biochem 249: 434-442.

KOTERA I, FUJISHIGE, IMAI Y, KAWAI E, MCHIBATA H, AKATSURA H, YANAKA N, OMORI $K$. (1999) Genomic origin and transcriptional regulation of two variants of cGMP. binding cGMP-specific phosphodiesternses. Eur of Biochem 262: 866-873.

KOPERA J, FUJISHIGE $K$, OMORI K. (2000) Immunohistochemical localization of cGMP. binding CGMP-specific phosphodiesterase (PDE5) in rat tissues. I Histochen Cytochem 48 : 685693.

KRUUSE C, RYBALKIN SD, KHURANA TS, JANSEN-OLESEN 1, OLESEN J, EDVINSSON L. (2001) The role of cGMP hydrolysing phosphodiesterases 1 and 5 in cerebral artery dilatation. Eur ef Pharmacol 420:55-65.

LAW A, O'DONNELL J, GAUTHIER S, QUIRION R. (2002) Neuronal and inducible nitrie oxide synthase expressions and activities in the hippocampi and cortices of young adult. aged cognitively unimpaired, and impaired Long-Evans rats. Neuroscience 112: 267-275.

LOUGHNEY K, HLL TR, FLORIO VA, UHER L, ROSMAN GJ, WOLDA SL, JONES BA, HOWARD ML, MCALLISTER-LUCAS LM, SONNENBURG WK, FRANCIS SH, CORBIN JD, BEAVO JA, FERGUSON K. (1998) Isolation and characterization of cDNAs encoding PDISEA, a human cGMP-binding, cGMP-specific 3:5'-cyclic nucleotide phosphodiesterase. Giene 216: 139-147.

MACPTEE CH, REIFSNYDER DH, MOORE TA, LEREA KM, BEAVO JA. (1988) Phosphorylation results in activation of a CAMP phosphodiesterase in human platelets. $J$ Biol Chem 268: 10353-10358.

MCALEER MA, BREIEN MA, WHITE NL, MATTEEWS N. (1999) pABC11 (also known as MOAT-C and MRP5), a member of the ABC family of proteins, has anion transporter activity but does not confer multidrug resistance when overexpressed in human embryonic Kidney 293 cells. J Biol Chem 274: 23541.23548.

MOGENSEN J, WORTWEIN G, GUSTAFSON B, ERMENS P. (1995) L-nitroarginine reduces hippocampal mediation of place learning in the rat. Neurobiol Leam Mem 64: 17-24.

MONFORT P, MUNOZ MD, KOSENKO E, FEIJPO V. (2002) Long-term potentiation in inippocampus involves sequential activation of soluble guanylate cyclase, cGMP-dependent protein kinase, and cQMP-degrading phosphodiesterase. I Neurosci 22: $10116-10122$.

MURASHIMA S, TANAKA T, HOCKMAN S, MANGANIELLO V. (1990) Characterization of particulate cyclic nucleotide phosphodiesterases from bovine brain: purification of a distinct. cOMP-stimulated isoenzyme. Biochemistry 29:5285-5292.

MYSLIVECEK , HASSMANNOVA J, BARCAL J, SAFANDA J, ZALUD V, (1996) Inhibitory learning and memory in newborn rats influenced by nitric oxide. Newroscience 71: 299-312.

NAKAMIZO T, KAWAMATA J, YOSHIDA K, KAWAI Y, KANKI R, SAWADA H, KIHARA T, YAMASHITA H, SHIBASAKI H, AKAIKE A, SHIMOHAMA S. (2003) Phosphodiesterase inhibitors are neuroprotective to cultured spinal motor neurons. If Neurasci Res 71: 485495.

NEDVETSKY PI, KLEINSCHNITZ C, SCHMIDT HHHW. (2002) Regional distribution of protein and activity of the nitric oxide receptor, soluble guanylyl cyclase, in rat brain suggests multiple mechanisms of regulation. Brain Res 950: 148-154.

NIES AT, SPRING H, THON WF, KEPPLER D, JEDLITSCHKY G. (2002) Immunolocalization of multidrug resistance protein 5 in the human genitourimary system. of Urol 167: 2271. 2275

PARIS D, TOWN T, PARKER TA, TAN J, HUMPHREY J, CRAWFORD F, MULLAN M. (1999) Inhibition of Alzheimer's beta-amyloid induced vasoactivity and proinflammatory response in microglia by a cGMP-dependent mechanism. Exp Neurol 157: 211-221. 
PRAST H, PHILIPPU A. (1992) Nitric owide releases acetylcholine in the basal forebrain. Eur $d$ Pharmacol 216: 139.140.

PRAST H, PHILIPPU A. (2001) Nitric oxide as modulator of neuronal function. Prog Netrobiol 64: $51-68$.

PRICKAERTS J, STEINBUSCH HWM, SMITS JFM, DE VENTE J. (1997) Possible role of nituic oxide-cyclic GMP pathway in object recognition memory: effects of 7 -nitroindazole and zaprinast. Eur of Pharmacol 387: 125-136.

PRICKAERTS J, DE VENTE J, HONIG W, STENBUSCH HWM, BLOKLAND A. (2002) cGMP, but not CAMP, in at hippocampus is involved in early stages of object memory consolidation. Eur of Pharmacol 436: 83-87.

QIANG M, XIE J, WANG H, QLAO J. (1999) Effect of nitric oxide synthesis inhibition on $\mathrm{c}-\mathrm{Fos}$ expression in hippocampus and cerebral cortex following two forms of learning in rats: an immunohistochemistry study. Behav Pharmacol 10: 215-222.

QIANG M, CHEN YC, WANG R, WU FM, QIAO JT. (1997) Nitric wxicle is involved in the formation of learning and memory in rats: studies using passive avoidance response and Morris water maze task. Behaw Pharmacol 8: 18:3-187.

REBECK GW, MARZLOFF K. HYMAN BT. (1993) The pattern of NADPH diaphorase staining, a marker of nitric oxide synthase activity, is altered in the perforant pathway terminal zone in Alzheimer's disease. Neurosci Let. 152: 165-1.68.

REED TM, REPASEE DR, SNYDER GL, GREENGARD P, VORHEES CV. (2002) Phosphodiesterase 1B knock-out mice exhibit exaggerated locomotor hyperactivity and DARPP-32 phosphorylation in response to dopamine agonists and display impaired spatial learning. J Neurosei 22: 5188.5197.

REPASKE DR, CORBIN JG, CONTI M. GOY MF. (1993) A cyclic GMP-stimulated cyclic nucleotide phosphodiesterase gene is highly expressed in the limbic system of the rat brain. Neuroscience 56: 673-686.

ROBICHAUD A, STAMATIOU PB, JIN SL, LACHANCE N, MACDONALD D, LALIBERTE F, LIU S, HUANG Z, CONTI M, CHAN CC. (2002) Deletion of phosphodiesterase 4D in mice shortens alpha(2)-adrenoceptor-mediated anesthesia, a behavioral correlate of emesis. I Clin Invest 110: 1045-1052.

ROTELLA DP. (2002) Phosphodiesterase 5 inhibitors: current status and potential applications. Nat Rev Drug Discow 1: 674-682.

RYBALKIN SD, RYBALKINA IG, SHIMIZU.ALBERGINE M, TANG XB, BEAVO JA, (2003) PDE5 is converted to an activated state upon cGMP binding to the GAF $A$ domain. EMBO J 22: $469-478$.

SAENZ DE TEJADA I, ANGULO J, CUEVAS P, FERNANDEZ A, MONCADA I, ALLONA A, T.LEDO E, KORSCHEN HG, NIEWOHNER U, HANING H, PAGES E. BISCHOFF E. (2001) The phosphodiesterase inhibitory selectivity and the in vitro and in vivo potency of the new PDE5 inbibitor vardenafil. IN J Impot Res 13: 282-290.

SAMAMA B, BOEHM N. (1999) Inhibition of nitric oxide synthase impans early olfactory associative learning in newborn rats. Neurobiol Leam Mem 71: 219-231.

SODERLING SH, BAYUGA SJ, BEAVO JA. (1998a) Identification and characterization of a novel family of cyclic nucleotide phosphodiesterases. of Biol Chem 273: 15553-15558.

SODERLING SH, BAYUGA S., BEAVO JA. (1998b) Cloning and chatacterization of a cAMP. specific cyclic nucleotide phosphodiesterase. Proc Nall Acad Sci U S A 95: 8991-8996.

SODERLING SH. BAYUGA SA, BEAVO JA. (1999) lsolation and characterization of at dual. substrate phosphodiesterase gene family: PDE10A. Proc Nall Acad Sci U A 96: 70717076.

STURTON G, FITZGERALD M. (2002) Phosphodiesterase 4 inhibitors for: the treatment of COPD. Chest 121:192S-1968.

SUNDKVIST E, IAEGER R, SAGER G. (2002) Pharmacological characterization of tho ATP. dependent low $\mathbb{K}(\mathrm{m})$ guanosine $3^{\prime}, 5^{\prime}$-cyclic monophosphate (cGMP) transporter in human erythrocytes. Biochem Pharmacol 63: 945-949.

SUO Z, HUMPHREY \#, KUNDTZ A, SETHI F, PLACZEK A, CRAWFORD F, MULLAN M. (1998) Soluble Alzheimers beta-amyloid constricts the cerebral vasculature in vivo. Neurosci Lett 257: 77-80. 
SUVARNA NU, ODONNELI JM. (2002) Hydrolysis of N-methyl-D-aspartate receptorgtimulated CAMP and GCMP by PDEA and PDE2 phosphodiesterases in primary neuronal cultures of rat cerebral cortex and hippocampus. I Pharmacol Exp Ther 302: 249-256.

VALLEBUONA F, RAITEIRI M. (1995) Age-related changes in the NMDA receptor/nitic oxide/CGMP pathway in the hippocampus and cerebellum of freely moving rats subjected to transcerebral microdialysis. Eur ol Neurose 7: 694-701.

YAMADA $\mathbb{K}$, NODA $Y$, NAKAYAMA S, KOMORI $Y$, SUGHHARA H, HASEGAWA T, NABESHMA T. (1995) Role of nitric oxide in learning and memory and in monoamine metabolism in the rat brain. Bro Pharmacol 115: 852-858.

YUASA K, KOTERA J, FU,ISHIGE K, MICHIBATA H, SASAKI T, OMORI K. (2000) Isolation and characterization of wo novel phosphodiesterase PDE11A variants showing unique structure and tissue.specific expression. of Biol Chem 275: 31469-31479.

ZHANG HT, HUANG Y, JIN SL, ERITH SA, SUVARNA N, CONTI M, ODONNELL WM. (2002a) Antidepressant-like profile and reduced sensitivity to rolipram in mice deficient in the PDEAD phosphodiesterase enzyme. Neuropsychopharmacology $27,587-595$.

ZHANG R, WANG Y, ZHANG $L_{4}$ ZZHANG Z, TSANG W, LU M, CHOPP M (2002b) Sildenafil (Viagra) induces neurogenesis and promotes functional recovery after stroke in rats. Stroke 33: $2675-2680$.

ZHANG S, CHEN J. WANG S. (1998) Spatial learning and memory induce up-regulation of nitric oxide-producing neurons in rat brain. Brain Res 801: 101-106.

ZHANG Y, HAN H, ELMQUIST WF, MLLER DW. (2000) Expression of various multidrug resistance-associated protem (MRP) homologues in brain microvessel endothelial cells. Brain Res 876: 148-153. 


\section{Summary}

The aim of the studies described in this thesis was to investigate nitric oxide (NO)-mediated guanosine 3', $5^{\prime}$-cyclic monophosphate (cGMP) synthesis in the central nervous system (CNS), with respect to its relation to learning and memory. NO-cGMP signaling is found in virtually all regions of the CNS. Five protein families are involved in the regulation of the NO-cGMP signaling cascade. NO synthase (NOS) is responsible for the synthesis of $\mathrm{NO}$, the endogenous activator of the NO-receptive guanylyl cyclase (GC), known as the soluble isoform of this enzyme ( $\mathrm{sGC}$ ). Binding of $\mathrm{NO}$ to $\mathrm{sGC}$ can lead to a hundredfold stimulation of cGMP synthesis. The produced cGMP plays an important role as a second messenger in cells and therefore cGMP levels need to be critically regulated. cGMP concentrations are for a large part regulated by the activity of cGMP-hydrolyzing enzymes, the $3^{\prime}, 5^{\prime}$ cyclic nucleotide phosphodiesterases (PDEs). Nowadays, a total of 11 different PDE families have been identified, consisting of an estimated ninety-five different forms. Other proteins involved in NO-cGMP signaling are the cGMP-dependent protein kinases and the cGMP-regulated ion channels.

The involvement of a number of protein families in NO-cGMP signaling, expressed in various cell types and brain areas, points to the involvement of this cascade in numerous brain processes. In this thesis research was performed on the function of this signaling pathway in learning and memory. This was chosen for the reason that it had been found by our department and other external research groups that inhibition of NO synthesis had an adverse effect on learning and memory in a number of animal tasks, including the object recognition test. In contrast, application of a compound which can inhibit a PDE family of type 5 (PDEs) resulted in an improved performance in the object recognition task. The precise mechanism that occurs after application of a PDE5 inhibitor was unknown at the start of our investigations. Furthermore, it was not clear where PDE inhibitors are effective in the brain. Therefore, the localization of components involved in NO-cGMP signaling were studied in detail. Testing of novel PDE5 inhibitors was one of the approaches used in this research. Special emphasis was given to study the localization of PDE5 in the brain in comparison to other cGMP-hydrolyzing PDE families.

Chapter 1 gives a historical description of the discovery of NO-cGMP signaling and describes the different components involved in this cascade. The cellular targets of cGMP are discussed in detail with special emphasis on the description and biochemical characteristics of the superfamily of PDEs. Furthermore, studies on cGMP signaling in relation to learning and memory models are reviewed. 
In Chapter 2 the effects of the in wivo application of PDE5 inhibitors such as sildenafil and vardenafil on object recognition memory are described in relation to their administration in vitro using hippocampal slices. Both PDE5 inhibitors enhanced retention for object memory, with vardenafil being more potent than sildenafil. In agreement, in vitro analysis of both PDE5 inhibitors confirmed the higher potency of vardenafil. Both compounds induced local cGMP accumulation in neuronal fibers of the hippocampus. It is argued that the observed cGMP accumulation in the in vitro incubated hippocampus slice might be part of the underlying mechanism of memory improvement after in vivo administration of PDE5 inhibitors.

Since scarce information was available about the effects of selective inhibitors of PDE isoforms in the hippocampus, the properties of a number of PDE inhibitors on CGMP and cAMP accumulation in the hippocampus slices are described in greater detail in Chapter 3 . Dose response curves showed a strong cGMP production after incubation of hippocampus slices with the non-selective PDE inhibitor 3-isobutyl-1-methylxanthine (IBMX), the PDE2 inhibitor erythro-9-(2-hydroxy-3-nonyl)adenine (EHNA) and the mixed type inhibitor dipyridamole. Furthermore, it was observed using cGMP-immunocytochemistry, that these inhibitors stimulated cGMP accumulation throughout the hippocampal slices, whereas the PDE5 inhibitor zaprinast induced a more local cGMP production, similar as sildenafil or vardenafil. (Chapter 2). Furthermore, cGMP accumulation in the hippocampus slices was quantified using a classical radioimmunoassay and by semi-quantitative measurements of cGMP-immunofuorescence intensity using an image analysis system. Both methods yielded essential identical results. However, the immunocytochemical approach has the additional advantage that the structures responding to the treatment are visible and can be characterized by double immunocytochemistry using structural and neurochemical markers.

In Chapter 4 we studied $9 \mathrm{GC}$ activation using $\mathrm{NO}$ donors and the novel NO-independent sQC stimulators $\mathrm{YC}-1$ and $\mathrm{BAY}$ 41-2272. The objective was to compare the cellular structures synthesizing cGMP in three different brain areas with NO donors of different classes, varying in the mechanism of NO release. It was observed that although the NO donors differed to some extent in their potency to stimulate cGMP production, the cGMP-responsive cellular structures were similar, i.e. mainly in varicose fibers. In the cortex, cGMP-immunoreactivity was predominantly present in cholinergic fibers after incubation of the slices with an $\mathrm{NO}$ donor or $\mathrm{YC}-1$ or $\mathrm{BAY} 41-2272$ alone. In contrast, co-administration of an $\mathrm{NO}$ donor with $\mathrm{YC}-1$ or $\mathrm{BAY} 41$ 2272 extended cGMP staining to GABAergic and glutamatergic neurons. It was concluded that $\mathrm{SGC}$ in GABAergic and glutamaterigic cells appears to be unresponsive to $\mathrm{NO}$ without the presence of a $\mathrm{NO}$-independent activator of $\mathrm{sGC}$. Another explanation might be that $\mathrm{sGC}$ is desensitized rapidly 
and/or that the rate of CGMP breakdown in these cells greatly exceeds the rate of cGMP synthesis induced by NO only.

In Chapter 5, the rat cGMP-specific PDE type 9 (PDE9) was investigated in closer detail. Structural analysis of the cloned rat PDE9 revealed that this PDE is highly homologous to the mouse and human PDE9 and contains potential domains for regulation by protein kinases, including cGMP- and cAMP-dependent protein kinases. Furthermore, the cellular mRNA distribution patterns of PDE9 were investigated in the brain. It was found that PDE9 is highly expressed mainly in neurons throughout the rat and mouse brain, including strong expression in cerebellum and hippocampus.

Chapter 6 describes a comparison of the mRNA localization patterns of three cGMP-hydrolyzing PDE families, i.e. PDE2, PDE5 and PDE9, during development of the rat brain. PDE9 was the most abundantly expressed PDE throughout the brain, followed by PDE2 and PDE5. The expression patterns of each of the PDE families was maintained during the development of the brain, although in some cell types PDE expression was absent in early stages. For the first time it was demonstrated that PDE5 is expressed in other brain areas besides the cerebellum, as had been described previously, and was present in areas such as cortex and hippocampus. The results indicate that some cell types, such as the hippocampal pyramidal cells and the Purkinje cells in the cerebellum coexpress the mRNAs of all three cGMP-degrading PDE families.

In Chapter 7 a comparison was made between the localization of NOmediated cGMP signaling in the mouse and rat hippocampus. It was found that the localization patterns of cGMP-immunoreactivity differ between the two species. In mouse hippocampus, cGMP staining is predominantly present in astrocytes, whereas cGMP is present mainly in varicose fibers in rat hippocampal slices. To investigate if this difference was due to a differential expression of components of cGMP signaling, the localization of the betal subunit of $\mathrm{sGC}$ and of PDE2, PDE5 and PDE9, three cGMPhydrolyzing PDEs, was studied in rat and mouse hippocampus. It was concluded that although cGMP-staining patterns differ between rat and mouse hippocampus, localization patterns of $\mathrm{s} \mathrm{CC}$ and PDE2, PDE5 and PDF9 mRNAs are similar in both species. These data point to that care should be taken when extrapolating results of experiments of NO-cGMP signaling in different species. 


\section{Final conclusions}

Administration of PDE5 inhibitors to rats leads to an enhanced performance in an object recognition task. To obtain more insight in the mechanism of action of $\mathrm{PDE} 5$ inhibitors, these inhibitors in combination with inhibitors of other PDE families were investigated using in vitro incubation of brain slices. The method of in vitro incubation of slices is an appropriate method to investigate whether a compound of interest can stimulate cyclic nucleotide (cGMP and cAMP) levels in the brain and in which cellular structures. However, it can be concluded that this method does not provide a straightforward answer to the question whether the observed memory improvement after in vivo application of a PDE5 inhibitor is due to an increase in cGMP levels through PDE5 inhibition. This is because an effect on cGMP levels was observed at relative high concentrations of the PDE5 inhibitor. At these high inhibitor concentrations, other proteins such as other members of the PDE family will possibly be inhibited in addition to PDE5. Since the final concentration of a PDE5 inhibitor in the brain, or intracellular is not known after in vivo administration, a direct correlation between the in vitro and in vivo data is difficult. This situation is even more complex as we also have to take into account the expression of multiple members of various PDE families in one cell type, and/or cellular compartment, and the differential regulation of each PDE family by events such as phosphorylation, and regulation by cGMP and/or cAMP. Nevertheless, the observed memory enhancing effect by PDE5 inhibitors holds promise for future therapeutic use as cognition enhancers and, it should therefore be investigated whether these compounds can also improve cognitive performance in humans. 


\section{Samenvatting}

Het doel van de studies beschreven in dit proefschrift was een onderzoek te verrichten aan de stikstof monoxide (NO)-gestimuleerde guanosine 3",5'cyclic monophosphate (cGMP) vorming in de hersenen, in relatie tot leren en geheugen. NO-geinduceerde cGMP productie wordt aangetroffen door het gehele brein. Een vijftal families van eiwitten speelt een belangrijke rol bij de regulatie van het NO-cGMP signaaloverdracht systeem. NO synthase (NOS) zorgt voor de vorming van NO, dat vervolgens het enzym genaamd oplosbaar guanylyl cyclase ( $\mathrm{GGC}$ ) kan activeren tot de vorming van cGMP. Binding van $\mathrm{NO}$ aan het $\mathrm{sGC}$ kan leiden tot een honderdvoudige stimulatie van de cGMP productie. Het gevormde cGMP speelt een bellangrijke rol als een boodschapper molecul in cellen en daarom moeten cGMP niveaus intracellulair sterk gereguleerd worden. cGMP gehalten worden voor een groot gedeelte bepaald door de activiteit van cGMP-afbrekende enzymen, de zogeheten 3,5'-cyclic nucleotide fosfodiesterases (PDEs). Op dit moment zijn elf verschillende PDE families geïdentificeerd, waarbij het totale aantal verschillende vormen binnen deze familie geschat wordt op vijfennegentig. Daarnaast zijn bij de cGMP signaaloverdracht nog andere families betrokken, waaronder de cGMP-afhankelijke proteine kinasen en de cGMP. gereguleerde ionkanalen.

Het feit dat verschillende eiwitfamilies betrokken zijn bij NO-cGMP signaaloverdracht die tot expressie gebracht worden in verschillende celtypen en hersengebieden, wijst erop dat dit signaaloverdracht systeem betrokken is bij een groot aantal hersenfuncties. In dit proefschrift werd onderzoek gedaan naar de rol van NO-cGMP signaalroute in leren en geheugen. De reden hiervoor was dat eerdere studies door de vakgroep en externe onderzoeksgroepen hadden aangetoond dat remming van de NO vorming een negatief effect heeft op leren en geheugen taken in een aantal diersoorten. In tegenstelling, toediening van een stof die het type 5 van de PDE familie (PDE5) kan remmen, een PDE5 remmer, resulteerde in een verbetering van de prestatie in een geheugentaak bij ratten, namelijk in de object herkenningstaak. Het werkingsmechanisme dat optreedt na toediening van een PDE5 remmer was onbekend tijdens de start van het in dit proefschrift beschreven onderzoeksproject. Ook was het onduidelijk waar PDE remmers in de hersenen hun effect uitoefenen. Daarom werd de lokalisatie van componenten betrokken bij NO-cGMP signaaloverdracht nader bestudeerd. Hiervoor werd ondermeer gebruik gemaakt van het testen van nieuw ontwikkelde PDE5 remmers. Speciale aandacht werd gegeven aan het bestuderen van de lokalisatie van PDE5 in combinatie met verscheidene andere cGMP-afbrekende PDE families. 
Hoofdstuk 1 geeft een historische beschrijving van de ontdekking van NOcGMP signaaloverdracht en geeft de verschillende componenten weer die hierbij betrokken zijn. De verschillende cellulaire doelwitten die beinvloed worden door CGMP worden bediscussieerd waarbij speciale aandacht wordt geschonken aan de beschrijving van de kenmerken van verschillende PDE families. Daarnaast wordt een uiteenzetting gegeven van verschillende studies met leer- en geheugenmodellen die effecten beschrijven met stoffen die op cGMP aignaaloverdracht ingrijpen.

In Hoofdstuk 2 worden de resultaten weergegeven van de effecten in de object herkenningstaak na toediening van de PDE5 remmers sildenafil en vardenafil. Deze resultaten werden vergeleken met de effecten die deze PDE5 remmers induceren in plakken van de hippocampus, een hersenstructuur die een belangrijke rol speelt bij geheugenvorming. Beide PDE5 remmers bevorderden de prestatie in de geheugentaak, waarbij vardenafil potenter was dan sildenafil. Beide stoffen stimuleerden lokaal cGMP productie in neuronale vezels van de hippocampus, en ook hier was vardenafil potenter dan sildenafil. Er wordt beredeneerd dat de waargenomen cGMP verhoging in de hippocampus het onderliggende mechanisme kan zijn van de geheugenverbetering na toediening van de PDE5 remmer aan ratten.

Aangezien weinig informatie aanwezig was over de effecten van selectieve PDE remmers in de hippocampus, werden in Hoofdstuk 3 de eigenschappen van een aantal verschillende remmers bestudeerd met betrekking tot het bevorderen van de cGMP en cAMP productie. Concentratie afhankelijke effecten werden gemeten waarbij toediening van de niet-selectieve PDE remmer 3-isobutyl-1-methylxanthine (IBMX), de PDE2 remmer erythro-9-(2-hydroxy-3-nonyl)adenine (EHNA) en dipyridamole, remmer van een aantal PDE families, de sterkste effecten lieten zien. Daamaast werd vastgesteld dat deze remmers een sterke cGMP productie bewerkstelligen over de gehele hippocampus coupe. In tegenstelling, het effect van toediening van de PDE5 remmer zaprinast was lokaal en vergelijkbaar met het patroon gevonden na toediening van sildenafil of vardenafil (Hoofdstuk 2). Daarnaast werd het gevormde cGMP gemeten met behulp van twee methoden. In hippocampus plakken werden cGMP niveaus bepaald met een radioimmunoassay en via het meten van het cGMP-fluorescentie signaal met behulp van een beeldbewerkingsysteem. Met beide methoden werden vergelijkbare resultaten verkregen; echter met behulp van cGMP-immunocytochemie kunnen in coupes ook de celstructuren zichtbaar worden gemaakt die op de behandeling reageren.

Hoofdstuk 4 beschrijft een onderzoek naar de eigenschappen van een aantal activatoren van het cGMP-producerende enzym sGC. NO donoren, stoffen die NO afsplitsen, werden onderzocht als ook twee nieuwe NOonafhankelijke sGC stimulators, YC-1 en BAY 41-2272. Het doel was om een vergelijking te maken tussen de structuren die cGMP maken na toediening 
van NO donoren. De gebruikte NO donoren maken deel uit van verschillende klassen en verschillen in het mechanisme van NO afsplitsing. Gevonden werd dat, alhoewel de NO donoren verschillen in de stimulatie van cGMP vorming, de celstructuren, met name neuronale vezels, die cGMP produceren hetzelfde zijn. In de hersenschors (cortex) was cGMP met name aanwezig in cholinerge vezels nadat een behandeling gegeven was met een NO donor alleen of na enkelvoudig toedienen van .YC-1 of BAY 41-2272. In tegenstelling, toediening van een $\mathrm{NO}$ donor in combinatie met $\mathrm{YC}-1$ of $\mathrm{BAY}$ 41-2272 resulteerde in een uitbreiding van cGMP in GABAerge en glutamaterge neuronen. Een mogelijke verklaring is dat het $\mathrm{SGC}$ in GABAerge en glutamaterge niet reageert op NO zonder de aanwezigheid van een $\mathrm{NO}$-onafhankelijke sGC activator. Het kan echter ook zijn dat sGC in deze cellen snel ongevoelig is (gedesensitiseeerd) en/of dat de snelheid van cGMP afbraak hoger is dan de cGMP productie.

In Hoofdstuk 5 werd een onderzoek verricht an het cGMP-specifieke PDE type 9 (PDE9). Structuur analyse van het gekloneerde ratten PDE9 toont aan dat dit eiwit sterk lijkt op de muizen en humane vorm. Daarnaast bevat de structuur potentiële gebieden voor de regulatie van de PDE activiteit middels phosphorylering, door onder andere cGMP- en cAMP-afhankelijke proteïne kinasen. Verder werd de lokalisatie van het mRNA onderzocht in de hersenen. PDE9 bleek sterk tot expressie te komen in het gehele brein, waaronder hersengebieden als het cerebellum (kleine hersenen) en de hippocampus. Deze expressie bleek met name waargenomen te worden in neuronen.

Hoofdstuk 6 geeft een vergelijking weer van de lokalisatie patronen van het mRNA van drie PDE families die cGMP afbreken, te weten PDE2, PDE5 en PDE9. Deze patronen werden bestudeerd tijdens de ontwikkeling van de hersenen. Uit de resultaten is gebleken dat PDE9 het sterkst tot expressie komt in het brein, gevolgd door PDE2 en PDE5. De patronen van elk van de PDE families bleken gehandhaafd te worchen tijdens de hersenontwikkeling, alhoewel in sommige celtypen de expressie afwezig was in jonge ontwikkelingsstadia. In eerdere literatuur werd beschreven dat PDE5 in de hersenen alleen voorkomt in het cerebellum. In deze studie kon voor het eerst op celniveau aangetoond worden dat PDE5 ook aamwezig is in andere hersengebieden dan het cerebellum, namelijk onder meer in de hersenschors (cortex) en hippocampus. Verder wijzen de resultaten erop dat sommige celtypen, zoals piramide cellen in de hippocampus of Purkinje cellen in het cerebellum meerdere cGMP-afbrekende PDE families bezitten.

In Hoofdstuk 7 wordt een vergelijking gemaakt tussen de lokalisatie van NO-gestimuleerde cGMP vorming in de hippocampus van de muis en rat. Er werd gevonden dat de cGMP-aankleuringspatronen verschillen tussen beide diersoorten. In de hippocampus van de muis is cGMP kleuring met name aanwezig in astrocyten, terwijl in de rat cGMP met name gevonden wordt in neuronale vezels. Om te onderzoeken of deze verschillen te wijten zijn aan 
en verschil in expressie van componenten van cGMP signaaloverdracht route werd de lokalisatie van de betal subeenheid van het $8 \mathrm{GC}$ en van drie cGMPafbrekende enzymei. PDE2, PDE5 en PDE9, onderzocht in de hippocampus van de rat en muis. Geconcludeerd werd dat alhoewel cGMP aankleuring verschilt tussen ratten en muizen hippocampus, de lokalisatie patronen van de beta1 subunit $\operatorname{van} \mathrm{SGC}$ op eiwitniveau en de mRNA patronen van PDE2, PDE5 en PDE9 gelijk zijn. De resultaten wijzen exop dat bij de extrapolatie van experimenten betreffende het NO-cGMP signaaloverdracht species verschillen in beschouwing genomen dienen te worden.

\section{Eind conclusies}

Toediening van PDE5 remmers leidt tot een verbetering van het geheugen in een ratten object herkenningstaak. Om meer inzicht te krijgen in de effecten wan PDE5 remmers werden deze remmers getest op hersenplakken en vergeleken met gevonden effecten na behandeling met remmers die selectief zijn voor een aantal verschillende PDE families. De methode van behandeling van hersenplakken met substanties is een valide methode om te onderzoeken of een stof in staat is om cyclische mucleotiden (cGMP en cAMP) niveaus te beinvloeden. Echter, gebleken is dat deze methode geen eenduidig antwoord kan geven op de vraag of het geheugenverbeterend effect na toediening van PDE5 remmers aan ratten, bewerkstelligd wordt door een verhoging van cGMP via remming van het enzym PDE5. Dit komt doordat een meetbaar effect op cGMP niveaus in hersenplakken slechts bij relatief hoge concentraties van de PDE5 remmer gevonden worden. Bij hoge concentraties van de remmers zullen naast PDE5 ook andere eiwitten in cellen, waaronder andere PDE families, geremd worden. Het is echter niet bekend wat de uiteindelijke concentratie van een PDE5 remmer in de hersenen of in cellen is maclat deze stof is toegediend aan ratten. Dit maakt dat een direct verband tussen enerzijds het toedienen van een PDE5 remmer aan ratten en anderzijds het toedienen van de remmer aan hersenplakken onduidelijk is. Het feit dat daarnaast in cellen/celcompartimenten meendere vormen van PDE families aanwezig zijn, warvan de activiteit op verschillende wijzen geregeld kan worden, makt de situatie nog complexer en dient in beschouwing genomen te worden bij de interpretatie van experimenten met PDE remmers. Desondanks, het wargenomen geheugenverbeterend effect na toediening van PDE5 remmers biedt mogelijkheden voor toekomstige ontwikkeling van cognitieverbeteraars en daarom zal onderzocht moeten worden of deze stoffen ook het geheugen kumnen verbeteren bij mensen. 


\section{Publications}

Van Staveren, W.C.G., Steinbusch, H.W.M., Markerink-van Ittersum, M., Repaske, D.R., Goy, M.F., Kotera, J., Omori, K, Beavo, J.A. and De Vente, J. mRNA expression patterns of the cGMP-hydrolyzing phosphodiesterases types 2, 5 and 9 during development of the rat brain. The Journal of Comparative Neurology 467 (4): 566-580 (2003)

Van Staveren, W.C.G., Glick, J., Markerink-van I.ttersum, M., Shimizu, M., Beavo, J.A., Steinbusch, H.W.M. and De Vente, J. Cloning and localization of the cGMP-specific phosphodiesterase type 9 in the rat brain. Journal of Neurocytology 31 (8/9): $729-741$ (2003)

Prickaerts, J., Van Staveren, W.C.G., Sik, A., Markerink-van Ittersum, M., Niewohner, U., Van der Staay, F.J., Blokland, A. and De Vente, J. Effects of two selective phosphodiesterase type 5 inhibitors, sildenafil and vardenafil, on object recognition memory and hippocampal cyclic GMP levels in the rat. Neuroscience 113 (2): 351-361 (2002)

Van Staveren, W.C.G., Markerink-van Ittersum, M., Steinbusch, H.W.M. and De Vente, J. The effects of phosphodiesterase inhibition on cyclic GMP and cyclic AMP accumulation in the hippocampus of the rat. Brain Research 888 (2): 275-286 (2001)

Jeuken, J.W.M., Nelen, M.R., Vermeer, H., Van Staveren, W.C.G., Kremer, H., Van Overbeeke, J.J. and Boerman, R.H. PTEN mutation analysis in two genetic subtypes of high-grade oligodendroglial tumors. PTEN is only occasionally mutated in one of the two genetic subtypes. Cancer Genetics and Cytogenetics 119 (1): 42-47 (2000)

Nelen, M.R., Van Staveren, W.C.G., Peeters, E.A.J., Hassel ,M.B., Gorlin, R.J., Hamm, H., Lindboe, C.F., Fryns, J.P., Sijmons, R.H., Woods, D.G., Mariman, E.C.M., Padberg, G.W. and Kremer, H. Germline mutations in the PTEN/MMAC1 gene in patients with Cowden disease. Human Molecular Genetics 6 (8): 1383-1387 (1997) 


\section{Publications in progress}

Van Staveren, W.C.G., Steinbusch, H.W.M., Markerink-van Ittersum, M., Behrends, S. and De Vente, J. Species differences in the localization of cGMP-producing and $\mathrm{NO}$-responsive elements in the mouse and rat hippocampus using cGMP-immunocytochemistry. European Journal of Neuroscience (submitted)

Van Staveren, W.C.G., Steinbusch, H.W.M., Markerink-van Ittersum, M., Behrends, S. and De Vente, J. Comparison of NO-dependent and NOindependent stimulation of soluble guanylyl cyclase in rat forebrain slices: a micropharmacological study. Neuropharmacology (submitted)

Boess, F.G., Hendrix, M., Van der Staay, F.J., Erb, C., Schreiber, R., Van Staveren, W., De Vente, J., Prickaerts, J., Blokland, A. and Koenig, G. Inhibition of phosphodiesterase 2 increases neuronal cGMP, synaptic plasticity and memory performance. The Journal of Neuroscience (submitted)

Van Staveren, W.C.G. and Markerink-van Ittersum, M. Localization of the cGMP-hydrolyzing phosphodiesterase type 9 (PDE9) in the rat brain by a non-radioactive in situ hybridization. Invited author for a book chapter in Phosphodiesterase Methods and Protocols, Humana Press Inc. (submitted) 


\section{Curriculum vitae}

Wilma van Staveren was born on January $10^{\text {th }} 1974$ and grew up in Veulen (Limburg). After her Atheneum-beta graduation at the Boschveldcollege in Venray, she started in 1992 her Biology studies at the Katholieke Universiteit Nijmegen with graduation subjects in Cellular Amimal Physiology, Pathology and an additional training period at the Department of Neurology at the Academic Hospital St. Radboud in Nijmegen. After her graduation, she worked as a Ph.D. student on the project described in this thesis at the Department of Psychiatry and Neuropsychology (Institute Brain \& Behaviour) at the Maastricht University. For her research project, she had the opportunity to visit the Department of Pharmacology at the University of Washington (Seattle) with a grant awarded by the Netherlands Organisation for Scientific Research (NWO). Furthermore, she participated in a EURON (European Graduate School of Neuroscience) exchange program, with an awarded Marie Curie fellowship, to perform research at the Institute of Interdisciplinary Research (IRIBHM) at the Free University of Brussels.

Wilma van Staveren werd geboren op 10 januari 1974 in Venray en groeide op in Veulen (Limburg). Na het behalen van haar eindexamen Atheneumbeta aan het Boschveldcollege in Venray, begon zij in 1992 met de studie Biologie aan de Katholieke Universiteit Nijmegen met als afstudeervakken Cellulaire Dierfysiologie, Pathologie en een extra stage op de afdeling Neurologie op het Academisch Ziekenhuis St. Radboud in Nijmegen. Na het doctoraal examen was zij werkzaam als assistent in opleiding (AIO) aan de Universiteit Maastricht bij de vakgroep Psychiatrie en Neuropsychologie (Instituut Hersenen \& Gedrag). In deze periode werd het onderzoek verricht dat beschreven staat in dit proefschrift. Met behulp van een toegekende beurs van de Nederlandse Organisatie voor Wetenschappelijk Onderzoek (NWO), kreeg ze de gelegenheid om voor haar onderzoeksproject op werkbezoek te gaan bij de vakgroep Farmacologie aan de University of Washington (Seattle). Verder was haar een Marie-Curie beurs toegekend binnen EURON (European Graduate School of Neuroseience) om onderzoek te kunnen verrichten op het IRIBHM (Institute of Interdisciplinary Research) instituut aan de Vrije Universiteit Brussel. 


\section{Dankwoord (Acknowledgments)}

Hierbij dan gekomen aan het einde van het proefschrift. De AIO periode is voor mij een tijd geweest waarin ik de kans gekregen heb om mezelf wetenschappelijk en persoonlijk verder te ontwikkelen. Verschillende personen zijn hiervoor belangrijk geweest. Daarom wil ik hier graag van de gelegenheid gebruik maken om iedereen te bedanken, die op welke manier dan ook hieraan een bijdrage heeft geleverd.

Een promotie onderzoek begint natuurlijk met een AIO aanstelling. Prof. dr. H.W.M. Steinbusch, promotor. Beste Harry, bedankt voor het vertrouwen dat je mij gegeven hebt om dit project te laten uitwerken. De onderzoeksvrijheid die je me gaf heeft geresulteerd in het ontwikkelen van mijn creativiteit en doorzettingsvermogen. Ik heb van jou geleerd dat (neurale) netwerken belangrijk zijn. Verder wil ik je bedanken voor de mogelijkheden die ik heb gekregen om deel te nemen aan cursussen en congressen in binnen- en buitenland.

Dr. J. de Vente, copromotor. Beste Jan, ik wil je bedanken voor alle gesprekken die we gehad hebben over artikelen, cGMP, PDEs, antilichamen en de wetenschap. De gevoerde discussies hebben uiteindelijk geleid tot dit proefschrift. Bedankt dat je deur altijd openstond en dat je mij met je positieve blik gestimuleerd hebt om dit proefschrift te voltooien. Verder vond ik het een leuke ervaring om met jouw congressen te bezoeken. En inderdaad, promoveren is net topsport.

Marjanne Markerink-van Ittersum. Beste Marjanne, waar moet ik beginnen? Misschien omvat dit het beste: echt bedankt voor alles, van het uitvoeren van wetenschappelijke experimenten tot de vele gesprekken, etentjes, het verven van plinten en al die andere dingen. Je warmhartigheid heeft mede gezorgd dat ik snel gewend was aan het wonen en werken in Maastricht. Je bent voor mij een grote steun geweest tijdens mijn AIO tijd en ik vind het heel fijn dat je mijn paranimf wilde zijn.

Verder wil ik Jos Prickaerts en Arjan Blokland bedanken voor de inspirerende wetenschappelijke discussies over gedrag, PDEs, morfologie en biochemie. Daarnaast ben ik jullie dankbaar voor de mogelijkheid die jullie me hebben gegeven om ervaring op te doen met de farmaceutische industrie. Franz-dosef van der Staay and colleagues, thank you for the nice collaboration and the interest you have shown for my research project.

Hellen Steinbusch, bedankt voor je vele adviezen op morfologisch gebied en ook voor de gezellige talky-talkies. Wiel Honig, jou wil ik bedanken voor al 
je geboden computer hulp. Maurice Stassen en Barbie Machiels, bedankt voor de gegeven thulp bij de moleculair-biologische experimenten.

Kamergenote en namgenote Wilma van de Berg. Beste Wilma, ik vond het een heel leerzame ervaring om tegelijkertijd met jou een promotieonderzoek te kunnen beginnen. Ik wil je bedanken voor de gesprekken die we gevoerd hebben en ook voor de gezellige tijd die we op de salsa lessen gehad hebben. Ook wil ik Daniëlle Tisserand, waarmee ik nog een tijd de werkplek heb gedeeld, nog speciaal bedanken voor de goede gesprekken en de gezelligheid.

Michel Aquarius, Marjo van de Waarenburg en Fabienne Ronden, bedankt dat jullie mijn onderzoek weer een stapje vooruit geholpen hebben. Ik. hoop dat jullie veel geleerd hebben tijdens jullie tijd op het: lab en dat ik jullie enthousiast heb kunnen maken voor het doen van onderzoek.

De hele vakgroep P\&N, alle studenten en buitenlandse gasten die en tijdens mijn AIO tijd op de afdeling aanwezig waren. Tedereen bedankt voor de gezelligheid gedurende de dagjes-uit, borrels, feestjes, film en de (cup-asoup) lunches.

A special word of thanks to Prof. Joe Beavo, Jenmifer Glick, Masami Shimizu and all the others of the Department of Pharmacology in Seattle. Thank you very much for the opportunity you have given me for staying in a laboratory which has so much experience in the field of PDEs. For me, it was a really inspiring environment and I still look back on the fruitful discussions, which have had a positive impact on my thesis. Dear Jennifer and Dave, I especially want to express my gratitude for your generous gesture of letting me stay at your home and introducing me to the neal American way of life.

Els en Chantal, ik vind het erg leuk dat ik jullie tijdens mijn beginperiode van mijn aanstelling heb leren kennen. Jk ben blij dat we nog steeds de tijd kumen vinden om elkaar regelmatig te zien.

Lieve familie, pa, ma en Marianne. Bedankt voor jullie steun en het vertrouwen dat jullie in mij hebben. Ik vind het nog steeds fantastisch dat jullie me zijn komen opzoeken in Seattle. Matianne, ik vind het echt geweldig dat je mijn paranimf wilde zijn.

Cher Didier, un grand merci pour tout. I am very grateful that I had the opportunity to meet you on a EURON course. "Thank you so much for your understanding and the support you have always given me. Thanks for making my life special. 